
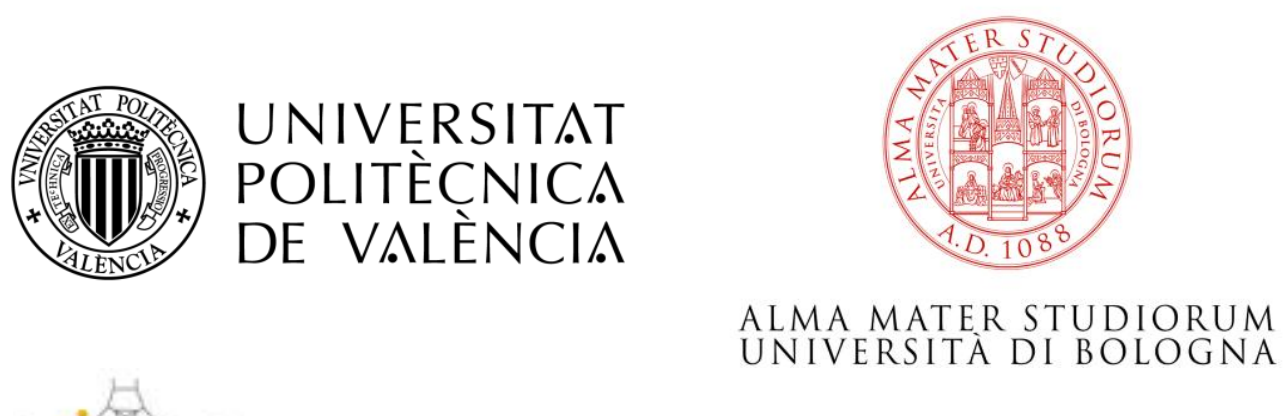

ALMA MATER STUDIORUM UNIVERSITÁ DI BOLOGNA
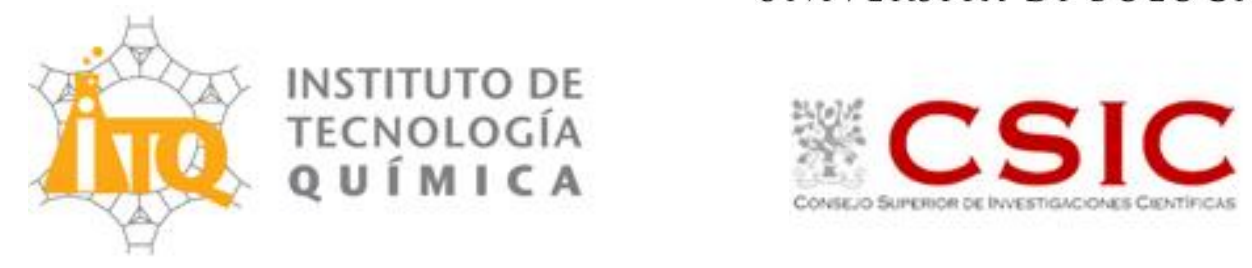

\title{
Glycerol oxidehydration to acrylic acid on complex mixed-metal oxides
}

CO-SUPERVISED Ph.D. THESIS

\author{
Presented by: \\ Alessandro Chieregato
}

\begin{abstract}
Directors:
Prof. Dr. José M. López Nieto (ITQ-UPV-CSIC)

Prof. Dr. Fabrizio Cavani (UNIBO)
\end{abstract}

Tutor:

Prof. Dr. Sara Iborra Chornet (ITQ-UPV)

VALENCIA, 05/03/2015 
The degree of civitization of any epoch, people, or group of peoples, is measured by ability to utilize energy for human advancement or people needs Human Origins, G. G. MacCurdy, 1924 


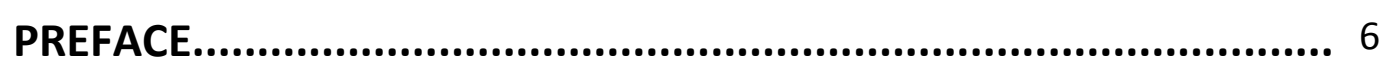

1 INTRODUCTION.......................................................................... 9

1.1 From oil to renewables................................................................... 9

1.2 Green and sustainable chemistry .............................................. 11

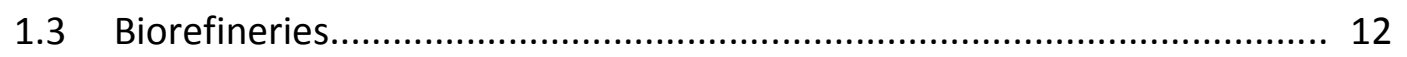

1.4 Cellulosic biomass to fuels.............................................................. 13

1.4.1 Biomass gasification.................................................... 13

1.4.2 Biomass hydrolysis....................................................... 14

1.4.3 Bio-oil............................................................................ 14

1.4.3.1 Bio-oil from fast pyrolysis........................................ 15

1.4.3.2 Bio-oil from liquefaction.......................................... 15

1.5 Vegetable oils and animal fats to fuels............................................. 16

1.6 Platform chemicals for biorefineries............................................... 17

1.7 Glycerochemistry...................................................................... 19

1.7.1 Production of acrolein and acrylic acid from glycerol..................... 20

1.7.2 Life Cycle Assessment (LCA) for the production of acrolein from glycerol......................................................................................... 23

1.8 Vanadium substituted HTBs: complex mixed-oxides for glycerol oxidehydration to acrylic acid....................................................... 24

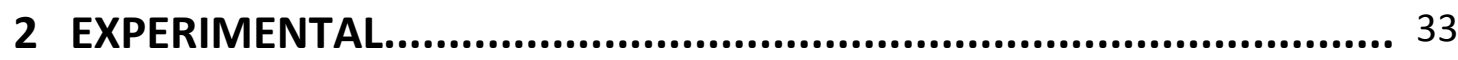

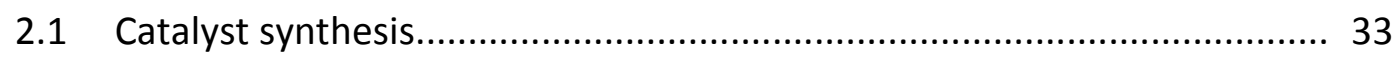

2.1.1 Hydrothermal synthesis of HTBs................................................ 33

2.1.2 lon-exchange and Incipient wetness impregnation...................... 34

2.1.3 Hydrothermal synthesis of modified AIPO-5.............................. 36

2.1.4 Slurry synthesis of a $\mathrm{M}_{5} \mathrm{O}_{14}$-like oxide........................................ 37

2.2 Catalyst characterization................................................................... 37

2.2.1 Surface area and textural properties....................................... 37

2.2.2 Scanning electron microscopy (SEM)....................................... 39

2.2.3 Transmission electron microscopy (TEM).................................... 40

2.2.4 Powder X-ray Diffraction (Powder-XRD)................................... 41

2.2.5 Fourier transform infrared spectroscopy (FTIR)......................... 42

2.2.6 X-ray absorption spectroscopy (XAS)......................................... 43

2.2.7 Pulse chemisorption and temperature-programmed desorption of ammonia............................................................................................ 44

2.2.8 FTIR of adsorbed carbon monoxide or ammonia........................... 45

2.2.9 Raman spectroscopy............................................................. 46

2.2.10 X-ray photoelectron spectroscopy (XPS) ............................... 47 
2.3 Catalytic testing .......................................................................... 49

3 RESULTS AND DISCUSSION................................................. 53

3.1 Introduction of Niobium in V-substituted HTBs................................ 53

3.1.1 Physicochemical properties of the oxides.................................. 53

3.1.2 Lab-scale reactor tests.......................................................... 58

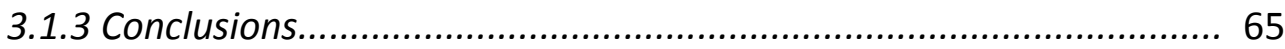

3.2 $\mathrm{Nb}$ - and V-substituted HTBs: the influence of reaction conditions on catalytic performance in glycerol oxidehydration................................. 67

3.2.1 Physicochemical properties of the oxides.................................... 67

3.2.2 Lab-scale reactor tests..................................................... 73

3.2.3 Conclusions............................................................................ 84

3.2.4 Notes on reaction conditions and process safety....................... 85

3.3 Introduction of Molybdenum in V-substituted HTBs............................ 87

3.3.1 Physicochemical properties of the oxides.................................. 87

3.3.2 Lab-scale reactor tests.......................................................... 93

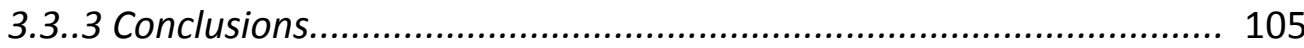

3.4 The importance of acid-redox properties and structure-reactivity correlations in one-pot glycerol oxidehydration.................................... 106

3.4.1 Physicochemical properties of the oxides................................... 107

3.4.2 Lab-scale reactor tests...................................................... 113

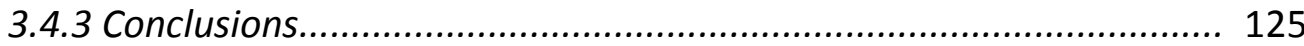

3.5 X-ray Absorption Spectroscopy (XAS) with synchrotron radiation as a tool to better comprehend the complex structure of substituted-HTBs... 127 3.5.1 From reagents to HTBs................................................................ 128

3.5.2 Vanadium coordination in HTBs............................................ 131

4 OVERALL CONCLUSIONS........................................................ 134

5 PUBLICATIONS.................................................................. 136

5.1 Publications related to the research project presented in this $\mathrm{PhD}$ thesis............................................................................................ 136

5.2 Publications related to other projects............................................ 136

6 BIBLIOGRAPHY................................................................. 137

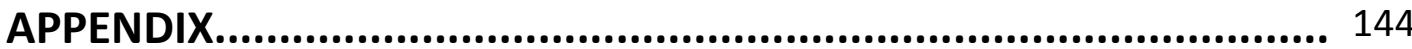

(i) Summary in English........................................................... 144

(ii) Summary in Spanish............................................................... 145

(iii) Summary in Valencian........................................................... 146

Acknowledgements........................................................ 147 


\section{Preface}

This $\mathrm{PhD}$ thesis relates to the synthesis, characterization and catalytic testing of mixed-metal oxides for the conversion of glycerol into acrylic acid as a one-pot reaction. The project is based on a co-supervised collaboration between Università di Bologna, ALMA MATER STUDIORUM (Italy) and Instituto de Tecnología Química, Universitat Politècnica de València ITQ-UPV-CSIC (Spain). The thesis work was carried out from January 2012 to December 2014. 20 months were spent in Bologna and 16 months in Valencia.

After the publication of a first study on Vanadium-substituted Hexagonal-Tungsten-Bronzes (HTBs) by the group of research [1], the investigation on glycerol oxidehydration has continued and the results obtained are reported in this thesis. The main objectives have been those of improving the catalytic performance and gaining further insights at the molecular level. Deeper characterizations of the titled complex mixed oxides was carried out also by means of X-ray Absorption Spectroscopy (XAS) using synchrotron radiation and high resolution transmission electron microscopy (HR-TEM). Attention was focused on the introduction of Niobium or Molybdenum in V-substituted HTBs. Furthermore, a systematic study on the influence of redox and acid properties was performed by modifying V-substituted HTBs with potassium. Other multifunctional oxides were also studied and compared to HTBs.

As it will be further discussed in the following sections, HTBs have been studied and applied for decades in various fields of material science. However, in spite of their great potential, very limited attention was given to their application in catalysis. Results reported herein might represent a contribution for their wider application in catalysis, particularly for the conversion of renewable polyoxygenated compounds.

Going more into details, the main objectives of this Ph.D. thesis, i.e. the synthesis, characterization and catalytic testing of mixed-metal oxides for the conversion of glycerol into 
acrylic acid as a one-pot reaction, have been carried out following different approaches. As far as the synthesis is concerned, hydrothermal preparation was used as a novel and more controllable method to introduce niobium or molybdenum in the W-V HTBs, so as to improve respectively the acid or the redox properties of the catalysts. Compared to the ceramic method (see next sections), the hydrothermal synthesis allows making mixed-oxide with morphology and crystalline phases in a much quicker, milder and controllable way. Moreover, the final surface area of the oxides obtained is consistently higher, hence favoring the catalytic phenomenon. Finally, vanadium-modified Al-P-Co-oxides were also prepared by hydrothermal synthesis and used as reference materials along with some commercial samples, both for characterization and catalytic testing purposes.

Due to the complexity of the materials prepared, an in depth physicochemical characterization was performed using state-of-the-art techniques. Fresh and spent catalysts were analyzed by spectroscopic methods such as Raman, FTIR, XPS and XAS to gain insights on the oxidation state, coordination and surface content of the elements, so as to correlate these features to the catalytic performance and in turn design new catalysts with tailor-made properties. FTIR studies with probe molecules (e.g. ammonia and carbon monoxide) were used to study the catalyst surface properties and $\mathrm{H}_{2}$-TPR tests were used to analyze the redox properties of the mixedoxides prepared. Surface area analyses performed by $\mathrm{N}_{2}$-adsorption were also combined with microscopy characterization using (HR-)SEM and (HR-)TEM to determine the morphology and the long-range order of the crystals.

Finally, catalytic tests were performed in the gas-phase in lab-scale fixed-bed reactors operating at atmospheric pressure and temperature variable between $250^{\circ} \mathrm{C}$ and $410^{\circ} \mathrm{C}$. The products obtained were qualified and quantified by on-line and off-line GC, GC-MS and MS-ESI. The 
influence of the partial pressures of reactants on the products distribution was studied into details as well as the catalysts productivity.

The combination of the physicochemical characterization and the catalytic tests allowed improving the knowledge and the catalytic performance on the one-pot transformation of glycerol into acrylic acid on single catalysts. Structure-reactivity correlations were also gained comparing the substituted-HTBs to other multifunctional systems containing vanadium as the redox element. 


\section{Introduction}

\subsection{From oil to renewables}

Life is unconditionally dependent from energy. In 1944, the Nobel laureate physicist Erwin Schrödinger used thermodynamic as a tool to explain this relationship [2]: "[...] a living organism continually increases its entropy -or, as you may say, produces positive entropy- and thus tends to approach the dangerous state of maximum entropy, which is of death. It can only keep aloof from it, i.e. alive, by continually drawing from its environment negative entropy, [...] freeing itself from all the entropy it cannot help producing while alive".

In the last hundred years or so, the human race has got the greatest ever available source of energy (i.e. negative entropy) thanks to the availability of massive amounts of petroleum. This has made clearly apparent the existing correlation between energy and life; indeed, such energy has been transformed into food, fuels, fertilizer, drugs and an enormous quantity of other goods that have made it possible for (part of) the human race to reach a general status of wellness that had never been observed before in the human history. For instance, the average life expectancy in Europe moved from 50 years in 1900 to 80 years in 2008 [3] and the world population moved from 1.6 billion in 1900 [4] to more than 7 billion today.

However, hand in hand with the oil depletion and related environmental issues, pivotal questions have been raised on the sustainability of our modern lifestyle and future availability of resources. Although "degrowth theories" and "degrowth movements" are attracting increasing attention worldwide [5], it is hard to predict if the model of capitalism so far ruling our society is going to be replaced soon (particularly in case the current financial and economic crisis reached an endpoint). Indeed, in the aim of assuring the long-term existence of this economic model, since the 1970s oil crisis both governments and private corporations have started to look for alternative sources of 
energy; particularly, due to both the developing mandatory environmental policies and strategic differentiation of the energy-source portfolio. In this context and with alternate fortune, the biorefinery [6], green chemistry and sustainability concepts have been developed $[7,8]$ (however, even if not explicitly referred to as so, the same general philosophy can be located much earlier in the history of science).

Before going into details of these subjects, some important but more general points on the future of the chemical and the fuel industry have to be underlined. In spite of the great environmental issues and fossil sources exhaustion, as well as the conspicuous worldwide investments in the renewable sector, energy outlooks for the next 20-40 years seem to firmly assert that conventional sources (mainly coal, gas and oil) will still represent more than the $60-70 \%$ energy source of the fuel sector [9-11]; in 2035 renewable resources are forecasted to represent only $<7 \%$ of the total fuel division. Because of the strict relationship between the fuels and the chemical industry (only ca. $5 \%$ of the total petroleum goes to chemical products and trends are not expected to change in biorefineries [12]) it appears quite difficult to predict a surpass of renewable building blocks to the fossil ones in the chemical industry. At least in the next 20 years. A main player in directing such tendencies might be the availability of natural gas at a cheap price. With the increasing oil price and the availability of new technologies (e.g. horizontal drilling and hydraulic fracturing), it is now possible to extract natural gas from shale formations previously unexploited [13]. Generally speaking, the latter option is considered as a major negative impact to the development of bio-based chemicals; however, different viewpoints have been recently proposed [14] and a lack of conventional petrochemical feedstocks in the "shale gas scenario" is actually proposed as a new opportunity for bio-based chemicals.

Overall, in the current unstable political, economical and energetic worldwide situation any outlooks is quite likely to be unreliable in the medium-long term. Instead, what is assuredly true is 
the non-sustainability of fossil resources, as well as the derived environmental issues. Hence, maybe not in the next 20 years or so, but for sure the next generations will have to face these problems and the current technological and scientific development is pivotal to pave the way for a vaster utilization of renewable resources as feedstocks.

\subsection{Green and Sustainable Chemistry}

The concept of Green Chemistry was introduced in the early 1990s in the USA, and it has reached its today's relevance with the introduction in 1998 of the twelve principles of Green Chemistry [8]. In the USA and UK "green chemistry" has become synonymous with chemical industrial processes that avoid (toxic) by-products as much as possible: the greening of industry [7]. However, the underlying meaning of the terms green chemistry and sustainable chemistry is different. Sustainable chemistry is the maintenance and continuation of an ecological-sound development, whereas green chemistry focuses on the design, manufacture, and use of chemicals and chemical processes that have little or no pollution potential or environmental risk and are both economically and technologically feasible. In Europe, apart from in the UK, the term sustainable chemistry is now preferred over green chemistry, but this practice is extending worldwide [7].

Overall, the concept of sustainability as "meeting the needs of the present generation without compromising the needs of future generations to meet their own needs" [15] is mandatory. Indeed, without this goal in mind, whatever the energy source is, if we exploit resources at a higher rate than their ability of formation, the next generations (and likely ourselves, too) will have to pay a high price in terms of quality of life. Energy efficiency and responsible utilization of (renewable) resources have to be the cornerstones of a new perspective of doing business. 


\section{$\underline{1.3 \text { Biorefineries }}$}

The biorefinery concept as we know it today was defined in the 1990s [6] and it is currently considered as " the sustainable processing of biomass into a spectrum of marketable products (food, feed, materials, chemicals) and energy (fuels, power, heat)" [16]. In contrast to the oilrefinery, the bio-refinery consists not only of chemical processes but also fermentations. The choice of one or the other technology is related to economic and engineering considerations. The term (industrial) biomass means any organic matter that is available on a renewable or recurring basis, including dedicated energy crops and trees, agricultural food and feed crop residues, aquatic plants, wood and wood residues, animal wastes, and other waste materials usable for industrial purposes (energy, fuels, chemicals, materials) and include wastes and co-wastes of food and feed processing [6]. Specifically, it is possible to classify the biomass in three different generations [17]:

- $1^{\text {st }}$ generation, based on standard crops;

- $\quad 2^{\text {nd }}$ generation, based on residues, agro-industrial residues and non-edible crops;

- $3^{\text {rd }}$ generation, based on algae.

The first generation raised important ethic issues mainly due to the competition with food production [18], but it has been crucial for developing the current status of biorefineries. The second generation, although largely limits the latter problem, it still moves concerns over competing land use or required land use changes. Hence, the third generation seems to be the most sustainable option since it avoids strain on world food markets, water shortages and destruction of the world's forests [19]. Nonetheless, both for economic and technological reasons, to date hardly any production of algae is carried out at hundreds ton capacity, as it would be required for industrial scale synthesis of fuels and chemicals [20, 21]. For these reasons, a great 
deal of attention has being paid to first and second generation biomass; with particular focus on (i) cellulosic biomass and (ii) vegetable oils and animal fats.

\subsection{Cellulosic biomass to fuels}

As far as cellulosic biomass is concerned, the main input of the biorefineries using this raw material would be a mixture of more or less complex polysaccharides and lignin. Indeed, by means of new biomass pre-treatment technologies as well as direct- and genetic-manipulations of the plants, it is now possible to produce lignin feedstocks "easy" to depolymerise with favourable properties for recovery and downstream conversion [22]. Lignocellulosic material can be transformed into liquid fuels by three different primary routes [23]:

- syngas production by gasification;

- hydrolysis of biomass to produce sugar monomer units;

- bio-oil production by (fast)pyrolysis or liquefaction.

\subsubsection{Biomass gasification}

Gasification is an old technological process (already used in 1940s) in which solid or liquid carbonaceous materials (e.g. biomass) react with oxygen, and/or steam at temperature $>700^{\circ} \mathrm{C}$ to produce syngas $\left(\mathrm{CO}+\mathrm{H}_{2}\right)$. A complex combination of reactions in the solid, liquid, and gas phases occurs during biomass gasification, including pyrolysis, partial oxidation, and steam gasification [23]. Syngas is then used in a number of conventional processes, e.g. water gas shift, FischerTropsch, methanol synthesis etc. to produce fuels and chemicals. 


\subsubsection{Biomass hydrolysis}

This process consists in cellulose depolymerisation into sugar polymers, finally into $C_{5}$ and $C_{6}$ sugar monomers. It can be carried out by fermentations or chemical processes with strong inorganic acids more or less diluted (from $2 \%$ to $30 \%$ ), under ambient temperature and pressure, or up to $200^{\circ} \mathrm{C}$ and 30 bar $[23,24]$. Another pivotal variable is the biomass pretreatment since it determines the accessibility of the cellulosic material to acids or microorganisms, which allowed obtaining sugars yield up to $90 \%$ of the theoretical one [24]. Once sugars are obtained, a number of intermediates can be produced with the final aim of producing bio-fuels and bio-chemicals. For instance, ethanol can be produced by fermentation processes and used directly as a fuel; moreover, Hydroxy Methyl Furfural (HMF) can be synthesized by dehydration of all types of C6 carbohydrates [25] and it can be further converted into $C_{9}-C_{12}$ alkanes [26]. HMF can also be converted into levulinic acid (LA) which is converted to $C_{9}$ ketons used as fuels [26]. In turn, LA can be dehydrated and hydrogenated to $\curlyvee$-valerolactone (GVL) which can be upgraded to liquid alkenes [27]. However, in spite of the great number of papers reported, the overall production of bio-fuels and bulk-chemicals from biomass hydrolysis is currently generally indicated as leading to low yields and high production costs $[25,26]$.

\subsubsection{Bio-oil}

Bio-oils chemistry is strongly dependent on a great number of variables, as the raw-materials used, process technologies, etc. Generally speaking, they are characterized by more than 400 compounds, relatively little sulphur and nitrogen and high oxygen content (ca. 40\%); the components are monofunctional, like phenol and acetic acid, and multifunctional, like hydroxyacetaldehyde and guaiacol. Char and residual alkali metals (e.g., $\mathrm{Na}, \mathrm{K}$ ) are also present $[23,28]$. 


\subsubsection{Bio-oil from Fast Pyrolysis}

Fast pyrolysis is used as an independent process or as a pre-treatment for gasification. To produce bio-oil, the biomass feedstock is heated (at ca. $500^{\circ} \mathrm{C}$ ) in the absence of air, forming a gaseous product, which then condenses [23]. The produced pyrolysis bio-oil can either be directly combusted in a gas turbine to generate electricity or to be fed to a high temperature (1000$1600^{\circ} \mathrm{C}$ ) gasifier for efficient conversion to syngas and hydrogen [29].

\subsubsection{Bio-oil from liquefaction}

Cellulosic biomass liquefaction consists in the direct conversion of complete plants into liquid fuels, without the gasification step [30]. After mechanical treatments to reduce the plants into small particles, the obtained biomass is immersed in a solvent, slurried and heated in a temperature range $250-450^{\circ} \mathrm{C}$ and pressures up to 250 bars; in doing so the biomass (cellulose, hemicellulose, and lignin) is depolymerised to produce smaller molecules. At the same time, by means of reducing gas (e.g. pure $\mathrm{H}_{2}$ or syngas) and hydrogenating catalysts, the oxygen-to-carbon ratio of the biomass is reduced and eliminated as water and $\mathrm{CO}_{x}$; moreover, the hydrogen-tocarbon ratio is increased. Therefore, the general stoichiometry characterizing dry wood biomass, i.e. $\mathrm{CH}_{1.4} \mathrm{O}_{0.7}$, is transformed towards the general " $\mathrm{CH}_{2}$ " stoichiometry defining conventional fuels [30]. The overall process can be summarized with the formula: $\mathrm{CH}_{1.4} \mathrm{O}_{0.7}+\mathrm{H}_{2}(+\mathrm{CO}) \rightarrow \mathrm{CH}_{2}+\mathrm{H}_{2} \mathrm{O}+$ $\mathrm{CO}_{\mathrm{x}}$. Another option is to perform the liquefaction process without reducing gas; the bio-oil obtained is therefore separated from light gas and heavy residues, and finally treated with reducing gas and dehydrogenation catalysts.

The scientific and industrial interest in biomass liquefaction has been so far definitely less relevant compared to gasification and pyrolysis, as demonstrated by the number of citations per year reported in Figure 1.4.1. Indeed, in a 2008 review [30] it was affirmed that "direct liquefaction of 
biomass [...] is far away from a technical and economical feasibility. The core problem is the presence of large amounts of oxygen to be removed before a useful fuel conforming to standards will result". However, looking at the citations' trend from 2005 and considering that more than 50 patents have been published between 2010 and 2013, it seems likely that biomass liquefaction is going to gain a significant attention. For instance, Shell Oil Company has recently patented, and in the minority published in the open literature, numerous contributions were it is reported bio-oil C-yield up to $93 \%$, e.g. [31, 32], therefore superior to the bio-oil yield from fast pyrolysis $(70-80 \%)$ [33].

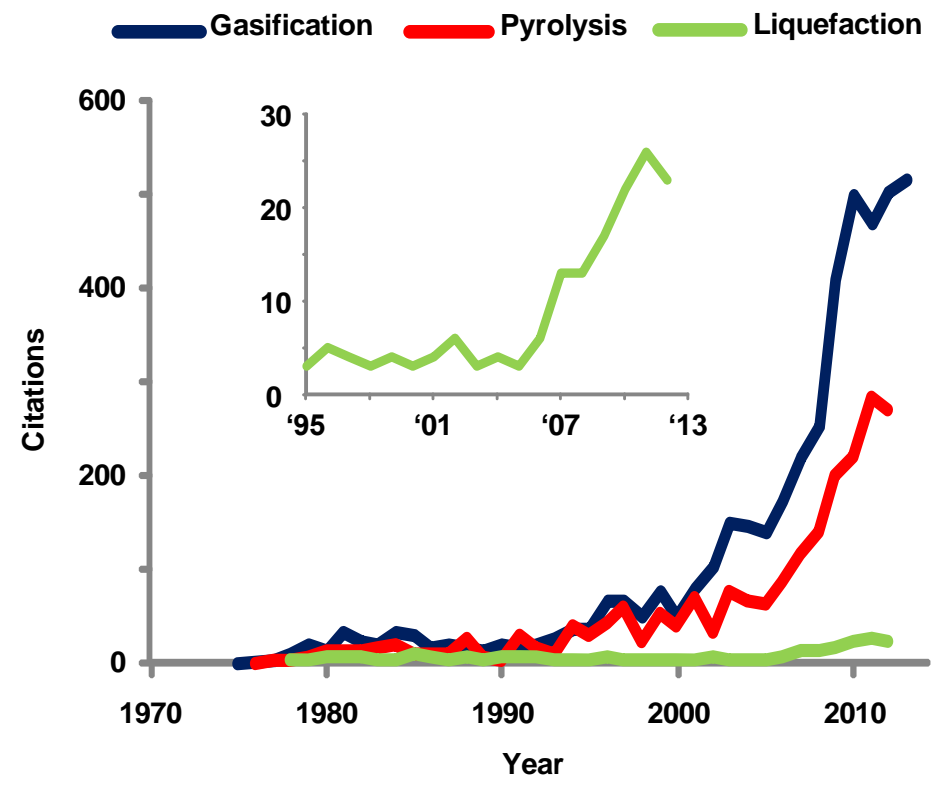

Figure 1.4.1. Number of citations per year as given by Scifinder ${ }^{\circledast}$ search engine for "Biomass $X "$, where $X$ can be gassification, pyrolysis or liquefaction. Insight: zoom on biomass liquefaction trend.

\subsection{Vegetable oils and animal fats to fuel}

Triglycerides are the natural constituents of vegetable oils and animal fats. Vegetable oils could theoretically be used directly as fuels but they are well known to lead to important problems to cars' engines. Although various techniques have been developed to more efficiently utilize oils and fats, the transesterification process and the hydrogenation one are the most widely applied 
[34]. The former leads to the commercial product known as biodiesel, whereas the latter leads to green diesel (also called renewable diesel). Biodiesel is a well known product which invention is dated back to 1938 [35] and its world market is expected to reach 37 billion gallons (ca. 140 billion liters) by 2016 [36]; the aim of transesterification is the removal of glycerin from natural triglycerides since the polyol has low calorific power and damages the engines. Hence, triglyceride are most commonly transesterified with methanol and a mineral homogeneous catalyst (such as $\mathrm{NaOH}$ ), producing Fatty Acid Methyl Esters (FAMEs) and glycerol. However, homogeneous catalysis cause challenging separation problems that have been trying to overcome by new heterogeneous catalysts [37], even if most of the latter still show unsatisfactory catalytic performance compared to homogeneous bases.

Green diesel is a much newer product; for its production are used the same raw-materials of biodiesel (natural triglycerides) which are catalytically hydrogenated to paraffins and propane [34]. The paraffins obtained are exactly equivalent to the ones derived by oil-distillation, hence completely compatible with current engines. On one hand, green diesel production is a cleaner process than the biodiesel one, since it requires less purification steps; on the other hand it needs more complex apparatus and of bigger volumes. Nonetheless, the latter are already available technologies currently used in conventional oil-refineries, so the capital expenditure (CAPEX) is minimized; for these reasons, the main players in the green diesel market are well-known oil companies as ENI, UOP and Neste Oil [34].

\subsection{Platform chemicals for biorefineries}

As previously mentioned, the manufacture of chemicals is strictly bounded to fuels production, since it mostly uses the (valuable) by-products of the latter as feedstocks. Looking at bio-fuels production (reported in the previous sections) it is possible to predict the possible intermediates 
and by-products that could be used as platform chemicals in the medium/long-term future. A general overview on the topic has been recently published by R. A. Sheldon [15] and further information can be found in a 2007 review by A. Corma et al. [38]. Further details on routes from bio-oil to chemicals and fuels were published elsewhere $[33,39]$. Since in this thesis it is not possible to develop the topic into further details, the overall discussion will be limited to the schematic representations reported in figure 1.6.1 and 1.6.2. Nevertheless, for the obvious affinity to the topic of this thesis, the chemistry of (bio-)glycerol, i.e. the so called glycerochemistry, will be addresses in a dedicated section with focus on glycerol dehydration and oxidehydration to acrolein and acrylic acid.

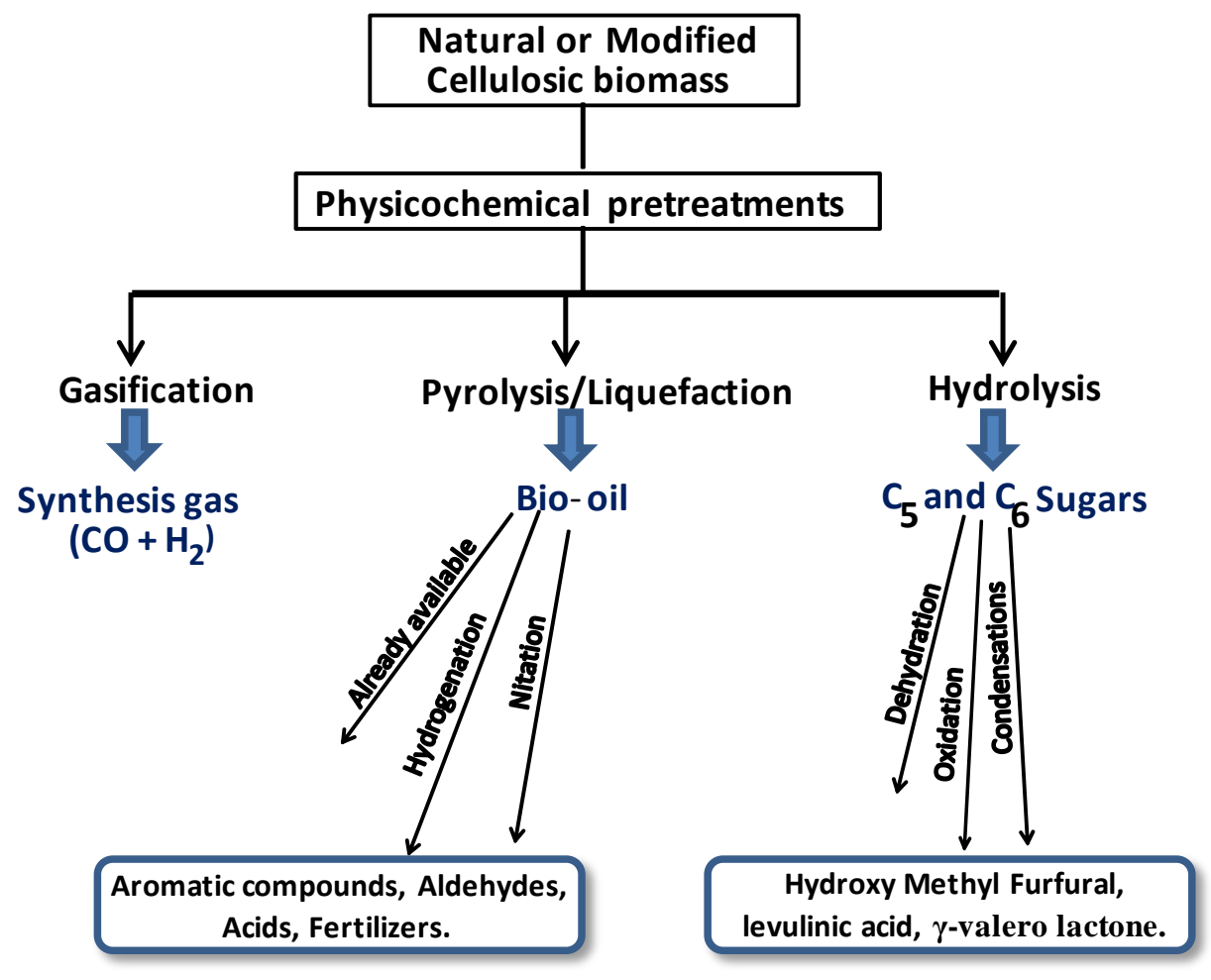

Figure 1.6.1 Platform chemicals from cellulosic biomass. 


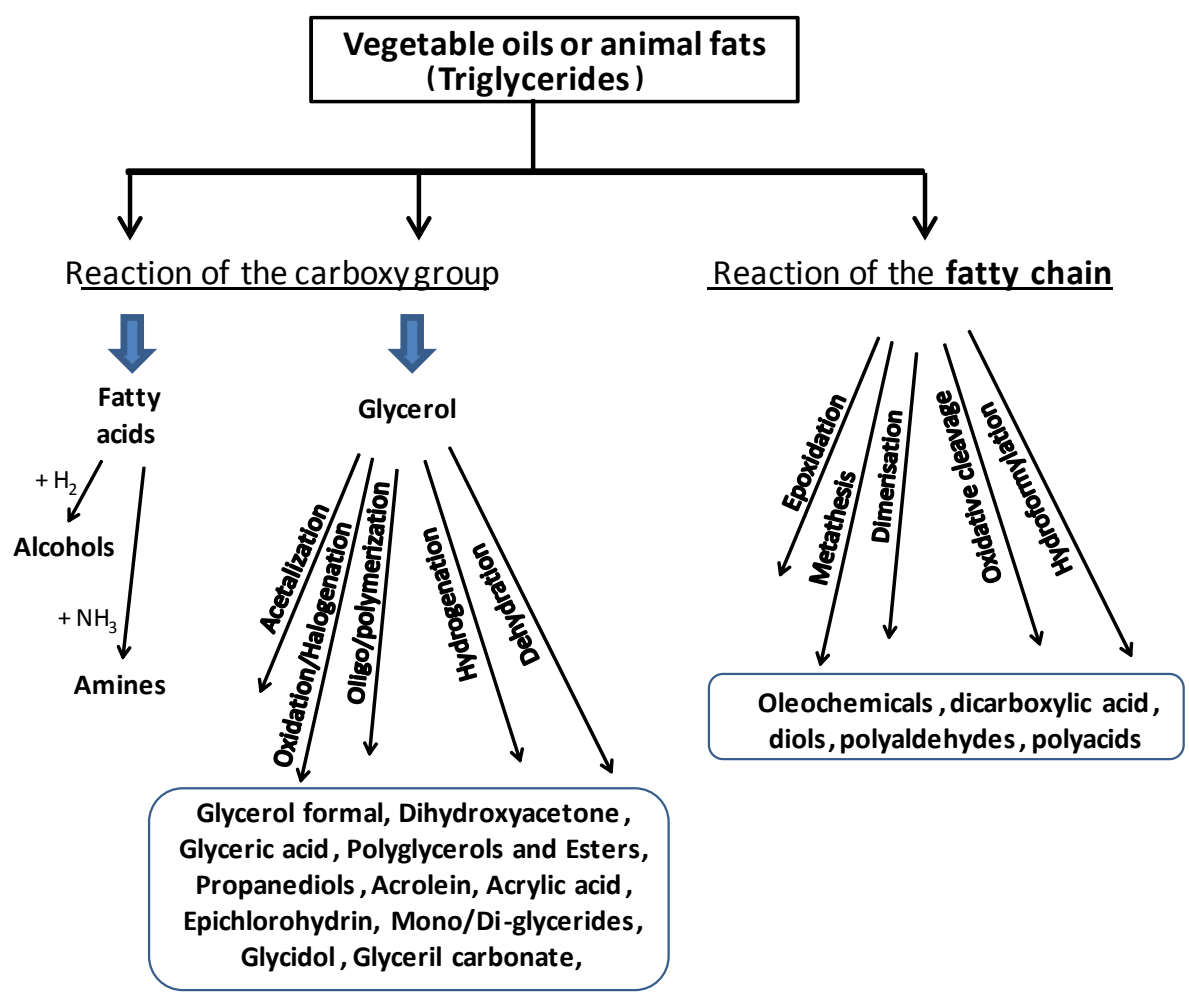

Figure 1.6.2 Platform chemicals from triglycerides.

\subsection{Glycerochemistry}

Among the chemical intermediates producible from triglycerides, glycerol has doubtless a leading position, due to its massive production from biodiesel synthesis and its peculiar chemistry. Particularly, production of bulk chemicals could represent a real solution to the glycerol surplus issue. For instance, glycerol transformation into epichlorohydrin have assumed great interest in the last decade and the processes has been commercialized by Solvay (the so-called Epicerol ${ }^{\circledR}$ process) [40]. Indeed, the process has economic and environmental advantages compared to the petrochemical synthesis from propylene (e.g. less chlorinated by-products and avoidance of the use of chlorine) [15] that have boosted its commercialization process. Other products that have attracted significant attention are propylene glycols (PG) (1,2 and 1,3) [41] and acrolein for producing acrylic acid and DL-methionine [42-44]. In 2010, the production of 1,2-PG was commercialized by Synergy Chemicals with a production capacity of $30 \mathrm{kt} /$ year [43], whereas the 
acrolein process hasn't still been commercialized. However, the industrial attention is great and the French chemical company Arkema seems to be on the way to industrial production [45-47]. Other processes such as direct glycerol oxidation have found considerable interest in literature for the production of fine chemicals and some of them have been commercialized [48].

\subsubsection{Production of acrolein and acrylic acid from glycerol}

Amongst the various options for glycerol upgrading, the dehydration process to acrolein is one of the most debated in literature since this aldehyde is the intermediate molecule for the production of important chemicals such as DL-methionine and acrylic acid [42-44, 49]. As far as acrylic acid is concerned, it can be synthesized from glycerol thorough a two-step process where glycerol is first dehydrated into acrolein and successively oxidized into acrylic acid; this option would need the utilization of two reactors, the first loaded with an acid catalyst and the second loaded with a redox one. In order to reduce the CAPEX needed for a "multi-reactor approach", two options have been proposed in literature: (i) the location of the two catalysts in a single reactor or (ii) the design of a multifunctional catalyst able to carry out both the dehydration and the oxidation step. The first approach is generally mentioned to lead to higher yields into acrylic acid [42] even if, being forced to use the same temperature for both catalytic beds, important drawbacks in the catalytic performance are implied. Otherwise, the use of more complicated technologies to overcome this issue (e.g. inter-stage heat exchange) could severely affect the economic feasibility of the process and its competitiveness to the current propylene-based one. The second option would significantly simplify the reactor design and theoretically allow increasing the overall catalytic performance, since it was demonstrated that proximity of acid and redox sites plays an important role in the oxidehydration process [50]. On the other hand, the multifunctional catalyst 
approach is very demanding from the catalyst design perspective, and so far few materials have shown remarkable acrylic acid yields.

In the following chapters many insights (catalysts features, reaction mechanism, optimal reaction conditions, etc.) concerning the acrolein and acrylic acid production from glycerol will be developed. However, some remarkable consideration on the process scale-up feasibility can be already addressed. The various reviews on glycerol dehydration to acrolein that have been published in the last years $[36,42-44]$ share some common conclusions on the main issues that impede its commercialization:

- Glycerol price volatility (both crude and refined) makes it difficult to perform accurate economic evaluations on the process' feasibility; roughly, 300 US\$/ton is considered the glycerol price needed for a breakthrough from propylene to glycerol [51]. However, current quotation of refined glycerol lies between 900-1000 US\$/ton.

- Crude glycerol can be purchased for a much cheaper price, around 150 US\$/ton; however its impurities do not allow direct processes for its transformation. Development of cost-effective purification techniques is pivotal for lowering the polyol's work-up price. - Liquid-phase catalysis still shows unsatisfactory performance and difficult conditions for process scale-up. Gas-phase catalysis looks more promising, with acrolein yield $>90 \%$ at total glycerol conversion [52].

- The main problems related to gas-phase synthesis is the fast deactivation of the catalyst due to cocking and deposition of high-boiling compounds.

Nevertheless, comparing the prices of reactants and products involved in the few commercialized production from glycerol (epichlorohydrin and 1,2-PG) to the acrolein and acrylic acid process, it is possible to draw some (partially) alternative conclusions. In order to do so, and because of the 
different molecular weight of the chemicals involved, a convenient way of comparison is to calculate prices per mol of molecular species (Table 1.1).

\begin{tabular}{|c|c|c|c|}
\hline Chemical species & Primary data price & Price $(\mathrm{ct} € / \mathrm{mol})^{\mathrm{a}}$ & Ref. \\
\hline Crude Glycerol & 150 US\$/ton & 1 & [42] \\
\hline Refined Glycerol & $900-1000 € /$ ton & 8-9 & [42] \\
\hline Propylene & 1200 US\$/ton & 7 & [42] \\
\hline Acrylic Acid $^{b}$ & 1.1-1.5 US\$/lb & $14-19$ & [53] \\
\hline Epichlorohydrin & 1.0 US\$/lb & 16 & [54] \\
\hline $\begin{array}{c}\text { 1,2-Propylene } \\
\text { Glycol }\end{array}$ & $1200 € /$ ton & 9 & [53] \\
\hline
\end{tabular}

First of all, it is worth noting that propylene price is very close to the one of refined glycerol, although the former is still more convenient. However, what is really remarkable is the similar price of acrylic acid and epichlorohydrin as well as the lower price of 1,2-propylen glycol (1,2-PG), which is basically the one of refined glycerol. These observations open important questions on the reason why acrylic acid (hence, acrolein) production hasn't still been scaled-up. Indeed, the aforementioned issues on glycerol price volatility and uncompetitiveness to propylene price must affect the other two processes as well, and the products' prices are not substantially different. Nevertheless, the 1,2-PG and Epichlorohydrin processes have been commercialized, whereas this is not the case for acrolein and acrylic acid. Therefore, it seems that the real problem affecting the acrolein and acrylic acid industrial production from glycerol is actually ascribable to issues either in the acrylic acid market and/or, most likely, at a technological level. Particularly once compared to the propylene process. Consequently, further research is mandatory in the aim of pursuing the process commercialization. 


\subsubsection{Life Cycle Assessment (LCA) for the production of acrolein from glycerol}

We have recently reported in literature a LCA study for the transformation of glycerol to acrolein, i.e. the intermediate step for the production of acrylic acid [55]. Considering the source of glycerol, we have compared two real-case industrial scenarios: (i) vegetable oil (from rapeseed) transesterification for biodiesel synthesis and (ii) fat hydrolysis. The latter process is now considered to be the second major source of glycerol and, due to the synthesis of fatty acids, its industrial importance makes it a secure reserve process for glycerol production. Overall, some interesting conclusions have been drawn:

- The major benefits in terms of environment and human health of the overall bioacrolein production chain come from the substitution of conventional diesel with biodiesel (-9.4 $\mathrm{Kg}$ of $\mathrm{CO}_{2}$ equivalent);

- Transesterification of vegetable oil is less sustainable than animal fat hydrogenolysis, largely due to land occupation and terrestrial eco-toxicity during the crop cultivation phase (due to release of pesticide in soil and exploitation of arable land); although, animal breeding and tallow production are energy intensive stages, too;

- Regarding the fossil fuel depletion, a contribution as high as $53 \%$ is due to the cultivation phase, whereas the glycerol dehydration process contributes only for $7 \%$;

- Compared to the conventional propylene based scenario and contrary to common beliefs, fossil fuel depletion and climate change are greatly affected by glycerol purification, finally making the impact of acrolein from partial oxidation of propylene lower than the two bio-based scenario.

Therefore, it emerges that the development of a fully integrated bio-refinery (i.e. both for fuels and chemicals) is the only option to effectively reduce the overall environmental impact. Indeed, 
not only the raw materials for the chemical industry have to derive from renewable resources, but also the whole compartment of utilities and energy sources. Moreover, the utilization of third generation biomass as well as selected cultivation growing in marginal land that do not require consumption of pesticides have an enormous potential to consistently reduce the impact of human activities on the environment.

\subsection{Vanadium substituted HTBs: complex mixed-oxides for glycerol oxidehydration to acrylic acid}

As previously mentioned, the multifunctional catalyst approach is very demanding from the catalyst design standpoint, since only fine tuning of acid and redox properties of the material allows obtaining noteworthy yields into the acid monomer. Indeed, few multifunctional materials have been so far demonstrated as effective catalysts for the direct transformation of glycerol into acrylic acid, i.e. $\mathrm{FeVO}_{4} / \mathrm{Fe}_{2} \mathrm{O}_{3}$ [50], Mo-V-O, Mo-V-Te-Nb-O, W-V-(Nb)-O [1, 56-60] and Vimpregnated zeolites [61]. At present, the complex mixed-oxides related to the hexagonal tungsten bronzes (HTBs) family, i.e. W-V-(Nb)-(Mo)-O, have shown the best catalytic performance in the glycerol oxidehydration process on single catalysts.

HTBs are non-stoichiometric oxides which are closely related to the Perovskites family. They can be represented with the general formula $\mathrm{A}_{n} \mathrm{BO}_{x}$, where $A$ is a cation (e.g. $\mathrm{Li}, \mathrm{Na}$, Ca, etc.), $B$ is tungsten and/or another transition-metal and " $x$ " is less than, but close to, 3 . The structure of $\mathrm{HTBs}$ is made up of corner-sharing $\mathrm{BO}_{6}$ octahedra which position themselves in the threedimensional space to form three-sided and six-sided channels that give rise to tunnels running along the c direction [62]. A-cations of large size (e.g. $\mathrm{Cs}^{+}$) can be found only within hexagonal channels with a maximum theoretical stoichiometry $\mathrm{n}=0.33$; instead, smaller cations (e.g. $\mathrm{Na}^{+}$) 
may also be located in three-sided channels, with a maximum total occupancy when $n=1$ [63]. A general representation is provided in Figure 1.8.1.

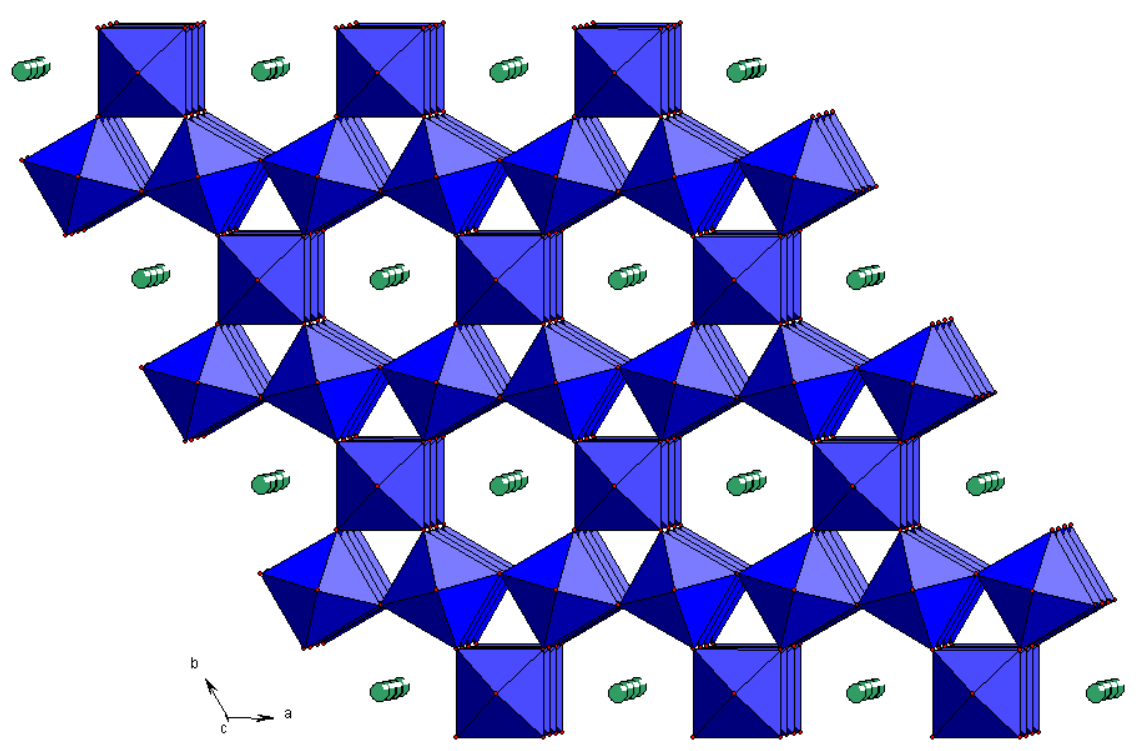

Figure 1.8.1. General representation of the HTB structure.

Due to their electronic structure and the possibility of altering it through both the insertion of Acations and the partial substitution of tungsten, HTBs have found a wide range of applications in electrochromic devices, humidity sensors, solid fuel cells, and ion-sensitive electrodes [64, 65]. However, in spite of their long history in material science, the use of HTBs as catalysts is a major novelty.

Their potential for such applications is related first of all to the HTBs' acidity; when comparing a monoclinic $\mathrm{WO}_{3}\left(\mathrm{~m}-\mathrm{WO}_{3}\right)$ and a tungsten-oxide with hexagonal HTB structure $\left(\mathrm{h}-\mathrm{WO}_{\mathrm{x}}\right)$, the gap is apparent: the former has a total acidity of around $20 \mu \mathrm{molNH} / \mathrm{g}$, whereas the latter exceeds 130 $\mu \mathrm{molNH} / \mathrm{g}$ [1]; the strength of the acid sites is also different, as illustrated in figure 1.8.2. These features make them interesting for those catalytic processes where a medium-to-strong acidity is needed; indeed, so far HTBs have been mainly used as catalysts for glycerol dehydration and 
oxidehydration. Hexagonal tungsten oxide is a good candidate for acrolein synthesis, since it shows acrolein yield as high as $70 \%$ at total glycerol conversion [1].

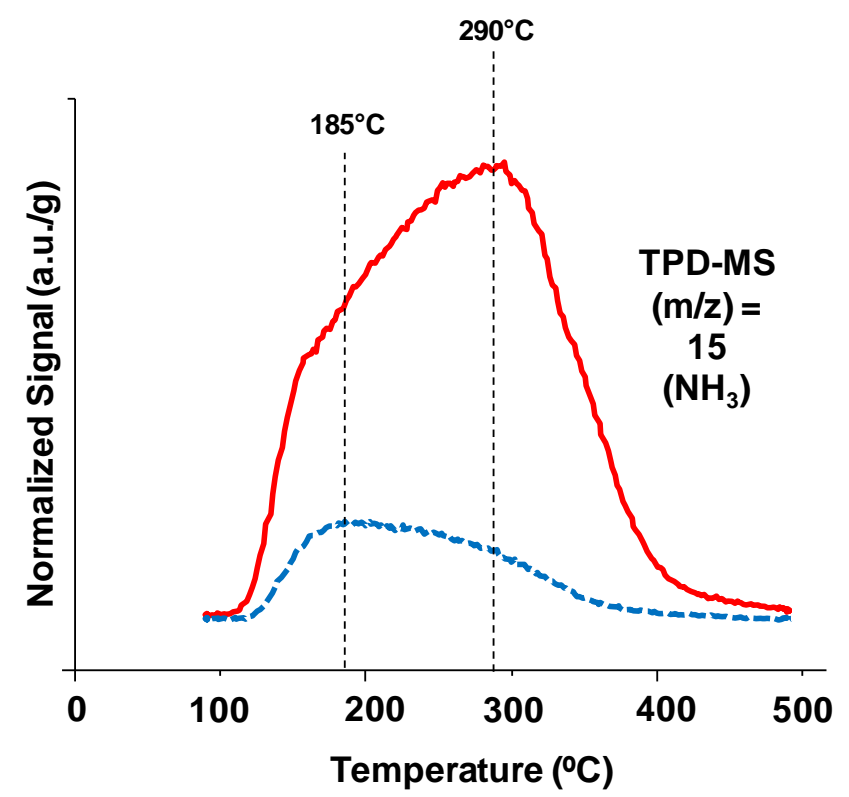

Figure 1.8.2 Comparison of $\mathrm{NH}_{3}-\mathrm{TPD}$ for $\mathrm{h}-\mathrm{WO}_{\mathrm{x}}$ (red, continuous line) and $\mathrm{m}-\mathrm{WO}_{3}$ (blue, dashed line).

However, the interest in HTBs as catalysts is actually much greater than in their use as simple acid oxides. It has been demonstrated that tungsten atoms belonging to the hexagonal framework can be (partially) replaced by other elements such as vanadium, molybdenum, and niobium [66-69]. Therefore, by varying the atomic ratio of the above-mentioned metals, an acid $\mathrm{h}-\mathrm{WO}_{\mathrm{x}}$ is transformed, in the end, into a multifunctional catalyst: tungsten (and niobium) atoms provide the acid sites, whereas vanadium (and molybdenum) atoms provide the redox features (vide infra).

While the potential for using HTBs as multifunctional catalysts is evident, both the preparation methods and the difficult physical-chemical characterization are most likely responsible for their tardy application in catalysis. The traditional preparation of these mixed oxides is based on the ceramic method, which involves mixing and grinding powders of constituent oxides, carbonate, 
and other compounds and their consequent heating at a high temperature and for a very long time. However, this "hard" method generally leads to a poor control of structure, stoichiometry, and phasic purity; moreover, of particular importance for applications in catalysis, the surface area of the obtained oxides is generally very low (i.e. $<5 \mathrm{~m}^{2} / \mathrm{g}$ ). Only starting from the 1980 s have these issues been partially overcome with new "soft" chemical methods (chimie douce) that have paved the way for the synthesis of metastable compounds with high phase purity and significant surface area [66, 70]; however, up to the present time, rational design (rather than serendipity) is still a great challenge even for soft methods such as the most common hydrothermal synthesis [71], making the preparation of substituted HTBs (i.e. metastable phases) not so straightforward in the end.

The other big challenge for the development of HTBs as catalysts is their physical-chemical characterization. Indeed, some of the most common techniques used in the field of catalysis either provide rather poor information or leave room for ambiguous interpretation. X-ray diffraction is a paradigmatic example of this; HTBs (and related phases) often form crystals of little order and poor quality. Moreover, they involve a high absorption of the X-ray radiation, while the contribution of oxygen atoms to the observed intensities is weak if compared to heavy atoms ( $B$ atoms) [63]. Therefore the results obtained give an approximate position of oxygen atoms and are frequently affected by the presence of an amorphous phase (due to the poor long-range order of crystals), thus making it impossible to draw some univocal conclusions on the real nature of the oxide phase. In this respect, high-resolution electron microscopy (mainly HR-TEM) has been pivotal; imaging studies allow characterizing the intimate nature of even poorly crystallized samples, while highlighting the contemporary presence of different crystal phases and on-going changes $[63,72,73]$. 
As previously discussed, the great interest in hexagonal tungsten bronzes (HTBs) for catalytic application is mainly related to the possibility of creating multifunctional oxides. In order to do so, tungsten-atoms belonging to the oxide lattice can be partially substituted with different transition metals; given the well-known properties of vanadium in oxidation catalysis, the insertion of the latter element is an interesting option. In literature, the substitution of vanadium in the HTB structure has been reported on in recent decades, synthesized both through solid-state and precipitation methods $[66,67,74]$. In both cases, exhaustive characterizations were carried out so as to assess the physical-chemical features of the $\mathrm{W}-\mathrm{V}$ oxides obtained; as far as their structure is concerned, XRD patterns clearly indicated that the V-containing oxides are isostructural with $\mathrm{h}$ $W_{\mathrm{x}}$. In particular, the slight decrease in the cell parameters was attributed to the replacement of large $\mathrm{W}$-atoms by vanadium. The preservation of the hexagonal phase was also unambiguously determined by HR-TEM/SAED. More recently, hexagonal oxides with tungsten and vanadium ( $\mathrm{h}$ $\left.W_{V O}\right)$ were also synthesized by hydrothermal synthesis, with $\mathrm{V}$-content in the range $0<[\mathrm{V} /(\mathrm{W}+\mathrm{V})]<0.24[1]$. When comparing the amount of vanadium on the surface layers of these samples -from XPS analysis- to its quantity in the bulk -from EDX characterization- (figure 1.8.3), an almost constant vanadium surface concentration was reported regardless of its bulk content, thus strongly suggesting the substitution of lattice-W-atoms by vanadium even for the $h-W_{V} O_{x}$ oxides prepared by hydrothermal method.

The acid properties of $\mathrm{h}-\mathrm{WVO}_{\mathrm{x}}$ oxides (and $\mathrm{h}-\mathrm{WO}_{\mathrm{x}}$ ) may be ascribed to (i) $\mathrm{H}^{+}$cations located in hexagonal-channels and to (ii) $\mathrm{M}-\mathrm{OH}$ moieties $(\mathrm{M}=\mathrm{W}, \mathrm{V})$ present on the oxide surface. Evidence for the existence of extra-framework protons was clearly provided by TG-analysis [66, 74]; indeed, water loss between around $100^{\circ} \mathrm{C}$ and $500^{\circ} \mathrm{C}$ exceeded the amount of crystallization water which was stable in the hydrated form at room temperature (molar ratio $\mathrm{H}_{2} \mathrm{O} /(\mathrm{W}+\mathrm{V})=0.33$ ). Therefore it 
was assumed that some of the hydrogen ions in the channels and oxygen atoms from the oxide combined together to form the additional water detected.

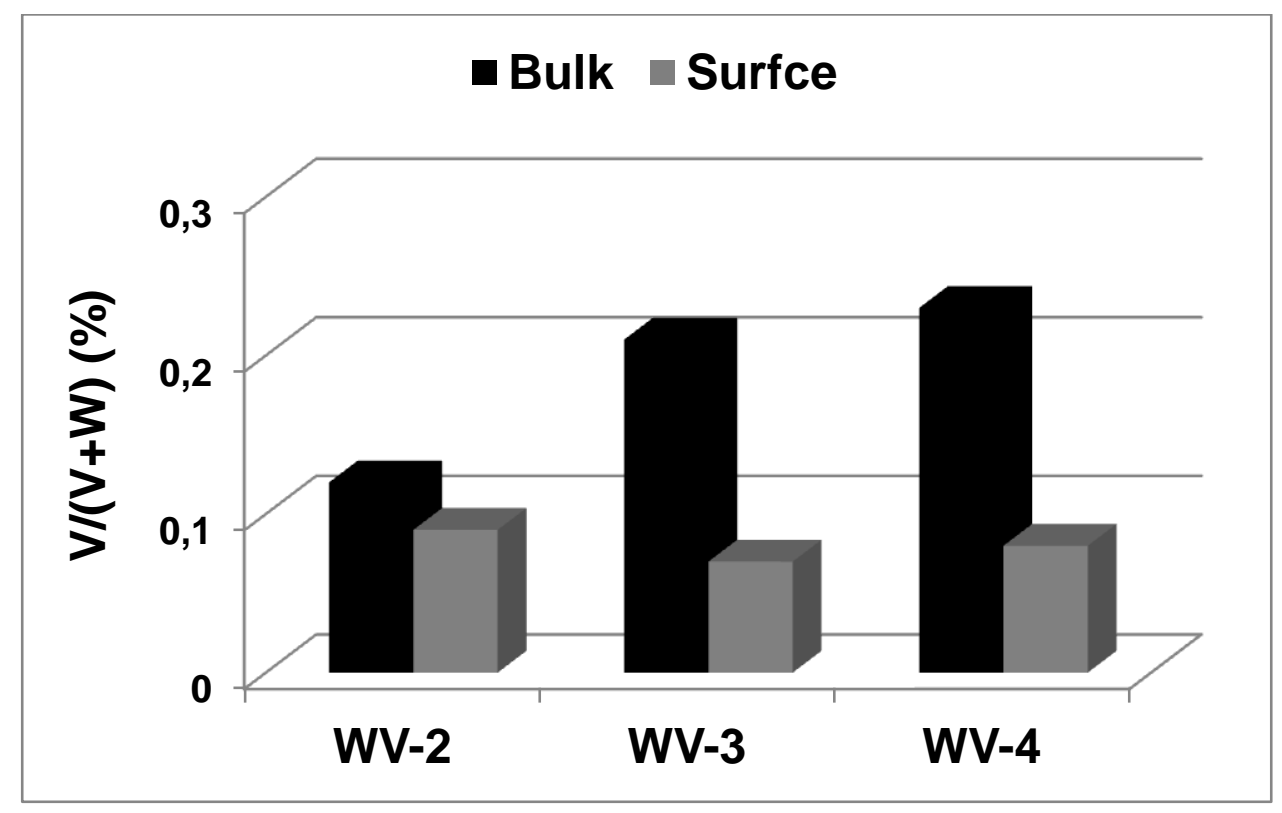

Figure 1.8.3. Bulk and surface content of vanadium in different V-substituted HTBs [1].

It is worth mentioning that the difference between the acid properties of $\mathrm{h}-\mathrm{WOx}$ and $\mathrm{m}-\mathrm{WO}_{3}$ previously discussed must be mainly attributed to $\mathrm{H}^{+}$ions in the hexagonal channels, which, clearly, are not present in the monoclinic phase. Indeed, W-OH groups (i.e. Brpnsted acid sites) may be present in both cases, and actually should be stronger for the fully oxidized $\mathrm{m}-\mathrm{WO}_{3}$, where only $\mathrm{W}^{6+}$ ions are present (vs. the mixed valence state $+5 /+6$ of tungsten in $h-W O x$ : see below). Lastly, when samples were treated at temperatures higher than $500^{\circ} \mathrm{C}$, all the protons present in the structure were removed and a thermodynamically stable monoclinic-tungsten/vanadium oxide $\left(m-\mathrm{WVO}_{\mathrm{x}}\right)$ formed.

Overall, the mentioned temperature ranges for phase-transformation (from $\mathrm{h}-\mathrm{WVO}_{\mathrm{x}}$ to $\mathrm{m}-\mathrm{WVO} \mathrm{O}_{\mathrm{x}}$ ) are significantly different if compared to values reported in ref. [1]; in the last case $\mathrm{h}-\mathrm{WVO}_{\mathrm{x}}$ phases were reported to be stable up to $600^{\circ} \mathrm{C}$ and for a relatively long heat treatment time ( $2 \mathrm{~h}$ isotherm). The gap observed may be attributable to the distinct compositions obtained; indeed, 
the atomic ratio obtained by the precipitation method was $V /(W+V)=0.27$, whereas by hydrothermal synthesis it was not possible to exceed the atomic ratio 0.24 , even for the highest amount of vanadium added in the parent gel (up to $V /(W+V)=0.33$ ). However, such a difference for the stability of the $\mathrm{h}-\mathrm{WVO}_{\mathrm{x}}$ phase seems to be too important to be simply attributed to the slight difference in composition. More likely, an important role is played by contaminants such as $\mathrm{Na}^{+}$ions, which are always present when typical lab-glassware is used and also as impurities in starting materials (W-and V-salts). In fact, in one case, particular precautions were taken to avoid these contaminations $[66,74]$, whereas a more common synthetic procedure was used for the hydrothermal synthesis [1]. Sodium ions, as well as many other cations, are indeed well known to strongly affect the stabilization of the crystal phases in the $\mathrm{W} /(\mathrm{V}) / \mathrm{O}$ system [63]. If, on the one hand, the contamination of the hexagonal-phase may be a significant issue for the application of $\mathrm{h}-\mathrm{WO}_{\mathrm{x}}$ (and substituted analogues) in electrochromic devices and other applications in physics, from the standpoint of catalysis this contamination may actually represent a great opportunity. Indeed, since traces of A-cations can significantly thermally stabilize the hexagonal phase without major effects on its peculiar acid properties, the latter features may also be preserved under insitu conditions of gas-phase chemical processes. This is in contrast, for example, with the degradation phenomena ascribed to Mo/V/P-Keggins [75], therefore offering promising expectations for industrial applications of these materials. However, pure $\mathrm{h}-\mathrm{WO}_{\mathrm{x}}$ is actually much less stable than the substituted oxides. The sample made up of only $\mathrm{WO}_{6}$ octahedra prepared by hydrothermal treatment decomposed at a temperature as low as $450^{\circ} \mathrm{C}$; this temperature corresponds to the complete loss of ammonium-ions present as A-cations. Therefore, the insertion of different B-atoms into the hexagonal lattice may also have a beneficial effect on thermal stability. As it will be explained into details in the results and discussion section, the same phenomenon was also observed for HTBs where both niobium and vanadium were introduced 
into the lattice. Indeed, even after rather long time-on-stream tests (approximately $100 \mathrm{~h}$ ) for glycerol oxidehydration, no significant change was reported for the crystal structure. These observations may be related to the oxidation state of transition elements. Indeed, pure $\mathrm{h}-\mathrm{WO}_{\mathrm{x}}$ is made up by both $\mathrm{W}^{6+}$ and $\mathrm{W}^{5+}$ ions, the overall neutral charge of the oxide being preserved by both A-cations and oxygen vacancies. High temperature (and the presence of oxygen) can promote structural changes in the metastable hexagonal phase towards stable $\mathrm{m}-\mathrm{WO}_{3}$, with all $\mathrm{W}$-atoms as $\mathrm{W}^{6+}$. The introduction of elements of low and stable valence state (e.g. $\left.\mathrm{Nb}^{5+}\right)$ may thus preserve the HTB structure even at high temperatures and for fully-oxidized tungsten atoms (e.g. $\mathrm{h}-\mathrm{A}_{\mathrm{n}}^{+} \mathrm{W}^{6+}{ }_{1-\mathrm{y}} \mathrm{Nb}^{5+}{ }_{\mathrm{y}} \mathrm{O}_{\mathrm{x}}$ ). A similar phenomenon may be hypothesized for $\mathrm{h}-\mathrm{WVO}_{\mathrm{x}}$ samples (without $\mathrm{Nb}$ ), since $\mathrm{V}^{4+/ 5+}$ ions make the hexagonal phase stable up to $600^{\circ} \mathrm{C}$. However, as it will be further discussed, the easily changeable oxidation state of vanadium under reaction conditions might play a role in the stability of the phase and in the catalytic behavior.

The Brpnsted acid sites present in HTBs, both in hexagonal channels and surface $\mathrm{M}-\mathrm{OH}$ moieties, may be considered to be active sites for glycerol dehydration to acrolein. Extensive studies on the influence of Brфnsted and Lewis acid sites on glycerol dehydration have been carried out in recent years, and to date it has been clearly demonstrated that Brpnsted acid sites are selective and active in performing the double dehydration to acrolein $[76,77]$. Lewis acid sites lead mainly to a partial dehydration of glycerol into 1-hydroxyacetone and 3-hydroxypropanal, the latter being the precursors for the formation of other by-products (i.e. formaldehyde, acetaldehyde, vinyl-alcohol, 1,2-propanediol, acetone, etc.) and oligomers (see Results and Discussion section and [60]). The low selectivity into the mentioned by-products, shown by $\mathrm{h}-\mathrm{WO}_{\mathrm{x}}$ [1] compared to other acid catalysts [42-44], is good evidence that Bronsted acid sites are predominant in HTBs. In the results and discussion section, for W-Mo-V samples with HTB-structure it will also be reported a study on the presence of Brpnsted and Lewis acid sites. 
All in all, limiting the discussion of the catalytic performance of substituted-HTBs to the presence of (Brpnsted) acid sites and vanadium ions would give only a partial view of the topic. One of the first attempts reported in the open literature to perform the glycerol oxidehydration process on a single multifunctional catalyst was performed on VPO catalysts [78]. Different VPO-crystalline phases were used, but the only major change was related to acrolein yields (from $24 \%$ to $66 \%$ ), basically highlighting the different acid properties of vanadium-phosphorous oxides. Indeed, in spite of the various oxygen partial pressures used, the acrylic acid yield always was between $0 \%$ and $8 \%$ (vs. acrylic acid yields > 50\% for substituted HTBs, see results and discussion section). Considering the well known presence of acid sites (Brpnsted and Lewis) and vanadium-ions in multiple oxidation states in VPO phases, it is of great interest to stress the low selectivities observed in the partial oxidation product (as well as $\mathrm{CO}_{\mathrm{x}}$ ). Therefore, given the important similarities in the general features of $\mathrm{h}-\mathrm{WVO}_{\mathrm{x}}$ and VPO-catalysts, the significant difference observed deserve more attention. Hence, we carried out further studies on a commercial VPP (see chapter 3.4). 


\section{Experimental}

\subsection{Catalysts synthesis}

\subsubsection{Hydrothermal synthesis of HTBs}

Most of the catalysts reported in this thesis belong to the family of Hexagonal Tungsten Bronzes (HTBs) and were synthesized through the hydrothermal method. This methodology usually refers to any heterogeneous reaction in the presence of aqueous solvents under high pressure and temperature conditions (i.e. supercritical or near-supercritical conditions) to dissolve and recrystallize materials that are relatively insoluble under ordinary conditions. Indeed, under such states, reactants otherwise difficult to dissolve go into solution as complexes allowing chemical transport reactions [79].

From the catalysts preparation view-point, the hydrothermal synthesis consists in preparing an aqueous solution (or gel) from the corresponding salts of selected transition-metals. The solution (or gel) is transferred to a teflon-lined stainless steel autoclave, fitted with two valves that allow purging it with a flow of nitrogen, so as to create an inert atmosphere -if required- and finally a wanted pressure. The autoclave is heated-up to a desired temperature and for a selected period of time. Finally the autoclave is cooled-down, degassed and the solid obtained is filtered and washed to remove the mother-liquor. The cleaned solid is dried and used for further treatments. Both bi-component and tri-component HTB-like catalysts were prepared, that is $\mathrm{W}-\mathrm{V}, \mathrm{W}-\mathrm{Nb}, \mathrm{W}$ Mo, W-V-Nb and W-Mo-V. The initial solutions/gels were prepared from the salts of the selected metals, i.e. ammonium metatungstate hydrate ( $\geq 85 \mathrm{wt} \% \mathrm{WO}_{3}$ basis, Sigma-Aldrich), vanadium (IV) oxide sulfate hydrate ( $\geq 99.99 \%$, Sigma-Aldrich), niobium oxalate (monooxalate adduct, $A B C R$ ) and ammonium heptamolybdate (GR for analysis, MERCK). 
In a typical preparation, the tungsten solution is warmed-up to $80^{\circ} \mathrm{C}$ and stirred for 10 minutes. For bi-component catalysts, the solution of the second element is added dropwise to the one of tungsten. For tri-component catalysts the same procedure is followed but the order of addition of the second and the third components might be pivotal for a reproducible synthesis. Indeed, if the addition of an element causes the formation of a gel, the following element added might not be properly dispersed and/or the metal-complexes forming in solution might be of a different nature. Therefore, for three-component systems, vanadium is always the first element to be added to tungsten since it forms a stable and transparent-greenish solution. Once all the wanted elements are added, the obtained solution is left mixing at $80^{\circ} \mathrm{C}$ for 10 minutes. Hence, the solution/gel is loaded in a Teflon-lined stainless-steel autoclaves and heated at $175^{\circ} \mathrm{C}$ for $48 \mathrm{~h}$. The solid obtained is filtered off with approximately $120 \mathrm{ml}$ of distilled water per gram of tungsten salt used in the initial solution. The filtered solid is washed and dried at $100^{\circ} \mathrm{C}$ for $16 \mathrm{~h}$. Finally, the solids are heattreated at $600^{\circ} \mathrm{C}$ during $2 \mathrm{~h}$ under $\mathrm{N}_{2}$.

\subsection{2 lon-exchange and Incipient wetness impregnation}

A vanadium-substituted HTB was used as reference bi-functional material (acid and redox) to perform a systematic analysis of the influence of acid properties on glycerol oxidehydration (see chapter 2.7). In order to do so, a W-V catalyst prepared according to the hydrothermal procedure described above (WV-3 in ref. [1]) was doped with potassium-ions. This procedure was carried out with two different methods, (i) ion-exchange and (ii) incipient wetness impregnation. Moreover, to investigate the structure-reactivity correlations in glycerol oxidehydration, a V-exchanged catalyst was also prepared by ion-exchange.

The first method was already reported in literature using analogous materials; indeed, HTBs prepared by hydrothermal methods were proved to be effective materials to carry out ion- 
exchange reactions with various cations [80]. It was demonstrated that the cations present within the channels of the HTB framework can be exchanged with other cations. In order to do so, the not heat-treated W-V sample, in the following called "WV-precursor" (i.e. the solid obtained after the hydrothermal treatment, washed and dried), was left stirring for 4 hours at room temperature in a solution containing the cation to exchange. By doing so, the new cation substitutes the ammonium-ions already present in the WV precursor. Specifically, so as to exchange ammonium for potassium ions, the WV-precursor was stirred in a solution of $\mathrm{KHCO}_{3}$; the operation was carried out, respectively, with different solutions, the gap of their concentration being calculated considering the maximum amount of potassium which is theoretically possible to insert into the HTB structure, according to the approximate stoichiometry $\mathrm{K} / \mathrm{W}=0.3$ [63]. Catalysts prepared according to this procedure where named as "K-n", where " $n$ " indicates the molar concentration of the $\mathrm{KHCO}_{3}$ solution used to perform the synthesis.

To exchange ammonium for vanadium ions, a tungsten oxide -without vanadium- with HTB structure, prepared by the formerly reported hydrothermal synthesis but not heat-treated, was stirred in a solution of $\mathrm{VOSO}_{4}$. The amount of vanadium dissolved was calculated so as to obtain an oxide with theoretical composition equal to the $\mathrm{W}-\mathrm{V}$ sample used as reference $(\mathrm{V} / \mathrm{K}=0.21)$. The catalyst prepared according to this procedure is named as $\mathrm{V} / \mathrm{WO}_{\mathrm{x}}$.

After the ion-exchange process, the solid was filtered and washed (ca. $120 \mathrm{~mL}$ of water per gram of catalyst) to remove the excess of ions that might have been adsorbed on the surface of the catalyst rather than incorporated within the channels of the material. Once dried, the solid was heat-treated in nitrogen at $600^{\circ} \mathrm{C}$, except for V/WOx, who was heat-treated at $450^{\circ} \mathrm{C}$-see discussion in chapter 3.4-.

The second method used for preparing K-containing catalysts, i.e. impregnation of the WV precursor with potassium, was carried out through a conventional wet-impregnation procedure 
using a solution of $\mathrm{KHCO}_{3}$. The solid was left stirring in the solution for 5 minutes and the water was following removed by rotavapor. The total amount of potassium impregnated was calculated so as to obtain an overall atomic composition (calculated by EDX analysis) similar to the selected catalyst prepared by ion-exchange (i.e. K-0.1), in order to make easier their comparison. Once dried, the solid was heat-treated in nitrogen at $600^{\circ} \mathrm{C}$. The catalyst prepared according to this procedure is named as K-Imp.

For a batter overview on the influence of the preparation method on K-containing catalysts, a WV-K HTB was prepared by the conventional hydrothermal method, adding the alkaline metal directly in the synthesis gel.

\subsubsection{Hydrothermal synthesis of modified AIPO-5}

VCoAIPO-5 sample was synthesized by hydrothermal method [81] using triethylamine as a template. Aluminum hydroxide (Catapal A, Sasol) was added to an $85 \%$ solution of phosphoric acid (Aldrich) in water, and the mixture was stirred until a homogeneous solution was obtained. Triethylamine was added to this mixture under continuous stirring. Then an aqueous solution of cobalt (II) acetate was incorporated to the synthesis gel. In the materials with vanadium, this was added as a $\mathrm{V}_{2} \mathrm{O}_{5} /$ triethylamine solution. The final reaction mixture was stirred until achieving a homogeneous gel. The gel was introduced in Teflon-lined stainless steel autoclaves and heated at $200^{\circ} \mathrm{C}$ for 16 hours. After crystallization, the sample was centrifuged at $10,000 \mathrm{rpm}$, washed with deionised water and dried overnight at $100^{\circ} \mathrm{C}$.

Vanadium oxide supported on VCoAIPO (sample name V/VCoAIPO) was prepared by wetness impregnation of the sample V-CoAIPO with an aqueous solution of ammonium metavanadate. After the impregnation, water was removed by rotavapor and the oxide was dried overnight at $100^{\circ} \mathrm{C}$. Dried materials were calcined in air for 6 hours at $550^{\circ} \mathrm{C}$. 


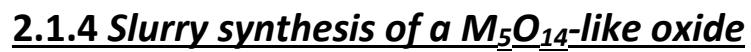

A molybdenum-vanadium-tungsten oxide (Mo-V-(W)-O) with the $\mathrm{Mo}_{5} \mathrm{O}_{14}$ structure was prepared by slurry synthesis. This oxide is a well-known catalyst used at industrial level to make the oxidation of acrolein into acrylic acid [82]. A solution containing the desired amount of the metals salts was prepared and stirred at $80^{\circ} \mathrm{C}$ for 10 minutes. The salts used were ammonium metavanadate (Sigma Aldrich, 99.99\% trace metals basis), ammonium metatungstate hydrate ( $\geq 85$ wt $\% \mathrm{WO}_{3}$ basis, Sigma-Aldrich), and ammonium heptamolybdate (GR for analysis, MERCK). Sodium oxalate was also added to favor the reduction of the elements so as to form the $\mathrm{M}_{5} \mathrm{O}_{14}$ structure. Water was removed by evaporation in a rotavapor (at $50^{\circ} \mathrm{C}$ ). The solid was dried at $100^{\circ} \mathrm{C}$ overnight and then calcined in air at $350^{\circ} \mathrm{C}$. Lastly, the solid was heat-treated in $\mathrm{N}_{2}$ at $500^{\circ} \mathrm{C}$ for $2 \mathrm{~h}$.

\subsection{Catalyst characterization}

Generally speaking, the information reported below was mainly obtained from the reference [83] and personal laboratory experience. Moreover, in some cases additional details are reported from various references, respectively mentioned in the text.

A general overview on each technique is given, providing more stress on the practical aspects needed to carry out the experiments and interpret the data obtained, rather than on the theoretical aspects. Further details can be found in the mentioned references and bibliography there reported.

\subsubsection{Surface area and textural properties}

Analyses of all samples were performed using nitrogen adsorption on a Micromeritics ASAP 2000 porosimeter. Samples (approx. $200 \mathrm{mg}$ ) were degassed under vacuum at $120^{\circ} \mathrm{C}$ for $2 \mathrm{~h}$ prior to analysis using physisorbed $\mathrm{N}_{2}$ at $77 \mathrm{~K}$. 
The surface areas of all samples were calculated using the Brunauer-Emmet-Teller (BET) isotherm. This is a derivation of the Langmuir isotherm, which can be used to calculate the surface areas of solids based on a model of adsorption that employs several assumptions, involving both the adsorbate and adsorbent, and which can be described by the BET equation [84].

$$
\frac{P}{\mu\left(P_{0}-P\right)}=\frac{1}{\mu_{m} c}+\frac{(c-1)}{\mu_{m} c} \frac{P}{P_{0}}
$$

Equation 2.1. BET equation

where $P=$ equilibrium pressure, $P_{0}=$ saturation pressure, $c=$ BET constant, $\mu=$ quantity of absorbed gas and $\mu_{m}=$ quantity of monolayer absorbed gas. Surface areas were calculated over a pressure range of $P / P_{0}=0.05-0.25$, where a linear relationship is maintained; indeed, beyond relative pressures of ca. 0.25 capillary condensation of the adsorbate (nitrogen) can occur in mesopores, leading to a sharp rise in nitrogen adsorption as the pores saturate. Analyses were performed over a large $P / P$ range, in order to probe both the mesoporous and microporous regimes -if any-.

External surface area (i.e. mesopore + macropore) of selected samples was evaluated by the t-plot method, i.e. the plot of the statistic thickness " $t$ " vs. the adsorbed volume of $N_{2}$ $[85,86]$. The " $t$ " value is taken into consideration since it is assumed that an adsorbent is never covered with an adsorbed film of uniform thickness, but with a characteristic density profile. Overall, the t-plot method assumes that in a certain isotherm region, the micropres are already filled-up, whereas the adsorption in larger pores occurs according 
to some simple equation, characteristic for a large class of solids. Particularly, in our case the " $t$ " value was evaluated according to Harkins-Jura equation [87], which is for nitrogen:

$$
t=\left\{\frac{13.99}{\left[0.034-\log \left(\frac{P}{P_{0}}\right)\right]}\right\}^{0.5}
$$

Equation 2.2. Harkins-Jura equation for nitrogen adsorption.

However, it must be stressed that these equations, although largely accepted for routine calculations, are affected by intrinsic approximation due to the theoretical models used; hence, deeper analysis of $\mathrm{N}_{2}$-adsorption data plots might be needed for more accurate evaluations [88].

\subsubsection{Scanning electron microscopy (SEM)}

Scanning electron microscopy (SEM) micrographs were collected in a JEOL 6300 microscope operating at $20 \mathrm{kV}$. The quantitative EDX analysis was performed using an Oxford LINK ISIS System with the SEMQUANT program, which introduces the ZAF correction. EDX analysis was performed five times per sample at $20 \mathrm{kV}$, with a sample collection time of $100 \mathrm{~s}$.

In scanning electron microscopy (SEM) a beam of electrons is generated by an electron gun situated at the top of the microscope. The beam passes through a series of condenser lenses and scanning coils, which focus and direct the beam onto the sample surface. On reaching the sample, the primary electrons lose energy through a variety of interactions, generating high energy backscattered electrons, secondary electrons through inelastic scattering and X-ray radiation. The generated X-rays can also be analyzed with the energy dispersive X-ray (EDX) system attached to the SEM instrument. 


\subsubsection{Transmission electron microscopy (TEM)}

High resolution transmission electron microscopy (HR-TEM) and selected area electron diffraction (SAED) were carried out on a JEOL JEM3000F electron microscope (point resolution of $0.17 \mathrm{~nm}$ ). Crystal by crystal XEDS microanalysis was performed by using the same microscope equipped with an X-ray microanalysis ISIS 300 (Oxford Instruments) with a detector model LINK "Pentafet" (resolution $135 \mathrm{eV}$ ). Samples for TEM were ultrasonically dispersed in $\mathrm{n}$-butanol and transferred to carbon coated copper grids.

TEM uses transmitted and diffracted electrons, in a sense similar to an optical microscope, if one replaces optical lenses for electromagnetic ones. Indeed, bright field images are formed when a beam of electrons, generated by an electron gun at the top of the instrument, is directed at the sample after passing through one or more condenser lenses. The transmitted, undeviated beam is focused and magnified by the objective lens and an image is formed on a phosphorescent screen. Digital images are generated by a charged-coupled device. The theoretical principle of XEDS micro-analysis is exactly the same of EDX coupled with SEM.

SAED is a crystallographic experimental technique that can be performed inside a transmission electron microscope (TEM). In a TEM, a thin crystalline specimen is subjected to a parallel beam of high-energy electrons. As TEM specimens are typically 100 nm thick, and the electrons typically have an energy of 100-400 KeV, the electrons pass through the sample easily. In this case, electrons are treated as wave-like, rather than particle-like. Because the wavelength of highenergy electrons is a few thousandths of a nanometer and the spacing between atoms in a solid is about a hundred times larger, the atoms act as a diffraction grating to the electrons, which are diffracted. That is, some fraction of them will be scattered to particular angles, determined by the crystal structure of the sample, while others continue to pass through the sample without deflection. As a result, the image on the screen of the TEM will be a series of spots - the selected 
area diffraction pattern, SADP, each spot corresponding to a satisfied diffraction condition of the sample's crystal structure.

\subsubsection{Powder X-ray Diffraction}

Powder X-ray diffraction (XRD) was used to identify the crystalline phases present in the catalysts. An Enraf Nonius FR590 sealed tube diffractometer, with a monochromatic CuK $\alpha 1$ source operated at $40 \mathrm{kV}$ and $30 \mathrm{~mA}$ was used. Samples were scanned over a $2 \theta$ range of $5-90^{\circ}$ with a $0.02^{\circ}$ step size and a scan speed of $0.04 \mathrm{~s} / \mathrm{step}$.

The X-ray source directs photons towards a homogeneous (finely ground powder) solid sample. Although the powdered samples are polycrystalline in nature and therefore, over the bulk of the material, consist of randomly-oriented crystal domains, there will nevertheless be a degree of short-range order within these individual domains. Constructive interference can occur between incident X-rays when these are diffracted from adjacent crystal Bragg planes within these domains, as long as the planes are aligned at the correct angle. The spacing between the crystal planes, $d$, is different for each polycrystalline solid and will therefore give rise to a specific diffraction pattern, according to Bragg's Law.

$$
n \lambda=2 d \sin \theta
$$

Equation 2.3: Bragg's Law

where $\mathrm{n}=$ order of interference (integer), $\lambda=$ incident wavelength, $\mathrm{d}=$ lattice spacing and $\theta=$ diffraction angle. The generated diffraction pattern can therefore be used to identify the material being analyzed. 


\subsubsection{Fourier transform infrared spectroscopy (FTIR)}

Infrared spectra were recorded at room temperature in the $300-3900 \mathrm{~cm}^{-1}$ region with a Nicolet $205 \times B$ spectrophotometer, equipped with a Data Station, at a spectral resolution of $1 \mathrm{~cm}^{-1}$ and accumulations of 128 scans. Pellets were prepared with catalysts and $\mathrm{KBr}$.

Infrared spectroscopy can be considered as the first important modern spectroscopic technique that has found general acceptance in catalysis. The most common application of infrared spectroscopy in catalysis is to identify adsorbed species and to study the way in which these species are chemisorbed on the surface of the catalyst (see below), as well as identifying phases that are present in the catalyst.

The infrared region between 4000 and $200 \mathrm{~cm}^{-1}$ can be roughly divided into five regions:

- The X-H stretch region (4000-2500 $\left.\mathrm{cm}^{-1}\right)$, where strong contributions from $\mathrm{OH}, \mathrm{NH}, \mathrm{CH}$ and SH stretch vibrations are observed,

- The triple bond region $\left(2500-2000 \mathrm{~cm}^{-1}\right)$, where contributions from gas phase CO (2143 $\left.\mathrm{cm}^{-1}\right)$ and linearly adsorbed CO $\left(2000-2200 \mathrm{~cm}^{-1}\right)$ are seen.

- The double bond region (2000-1500 $\left.\mathrm{cm}^{-1}\right)$, where in catalytic studies bridgebonded CO, as well as carbonyl groups in adsorbed molecules (around $1700 \mathrm{~cm}^{-1}$ ), absorb.

- The fingerprint region (1500-500 $\left.\mathrm{cm}^{-1}\right)$, where all single bonds between carbon and elements such as nitrogen, oxygen, sulfur and halogens absorb

- The $\mathrm{M}-\mathrm{X}$ or metal-adsorbate region (around $200-450 \mathrm{~cm}^{-1}$ ), where the metal-carbon, metal-oxygen and metal-nitrogen stretch frequencies in the spectra of adsorbed species are observed.

The first three regions are clearly meaningful particularly for studying the adsorption of molecules on the (oxide-)catalysts' surfaces, whereas the last two are fundamental to identify both the 
presence of a specific crystal structure and specific metal-oxygen bonds that constitute the overall catalyst framework.

\subsubsection{X-ray absorption spectroscopy (XAS)}

Vanadium K-edge X-ray absorption spectroscopy (XAS) measurements were performed at the Spanish beamline located at the synchrotron in Grenoble, using a Si $\left(\begin{array}{lll}1 & 1 & 0\end{array}\right)$ monochromator. The monochromator was calibrated by setting the first inflection point at the k-edge spectrum of a standard metallic vanadium foil at $5465 \mathrm{eV}$. The measurements were performed in transmission mode using ion chambers filled with Ar/N2 as detectors. Typically, $50 \mathrm{mg}$ of catalyst powder were pressed in a stainless steel sample holder in order to obtain self-supported discs of samples with appropriated transmission properties. Analyses of the XANES data were performed with the Athena software. A factor of $k 3$ was used for obtaining the Fourier Transforms (FT) of the EXAFS region of the spectra.

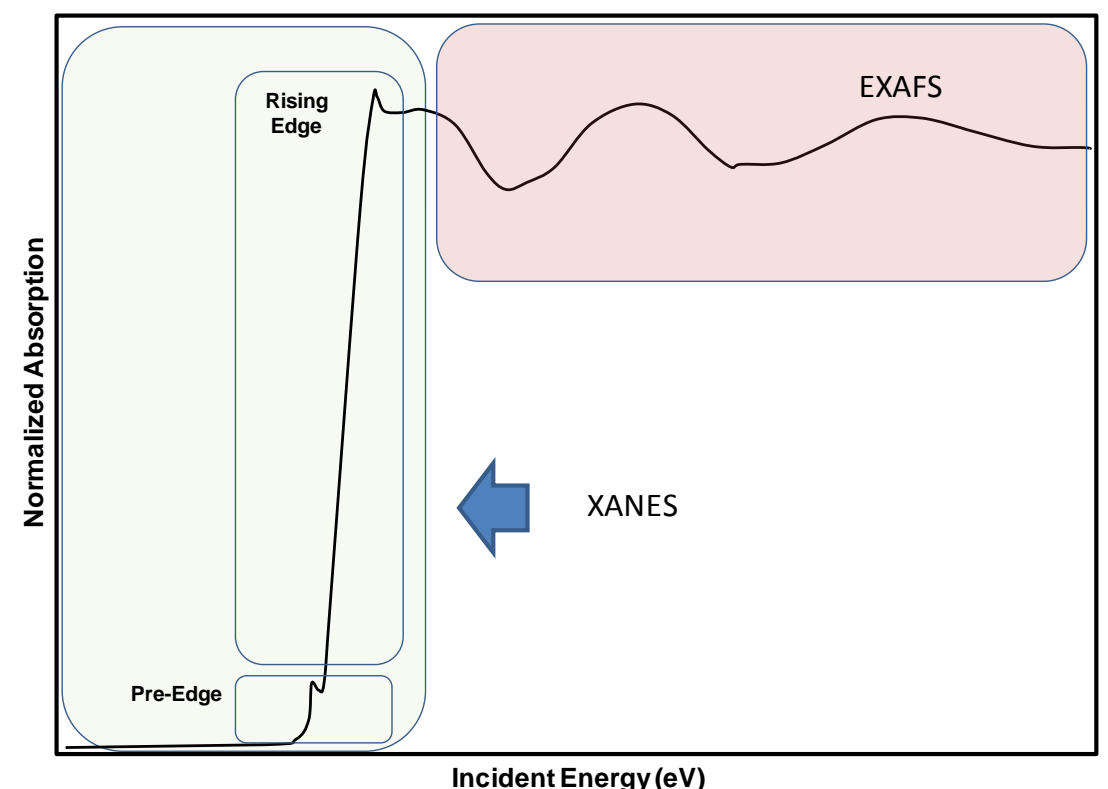

Figure 2.1.1 Example XAS spectrum showing the three major data regions. 
X-ray absorption spectroscopy (XAS) is a non-destructive technique which employs monochromatic X-rays, typically from a synchrotron radiation source, to obtain bulk structural information about a solid. The X-ray absorption spectrum of an hypothetical isolated atom would show only edges corresponding to the binding energy of all electrons in the atom core levels, but no further structure. If, however, the atom is bound in a lattice, the absorption is modulated due to its local coordination, and fine structure arises. X-ray absorption near edge spectroscopy (XANES) focuses on the shape of the absorption edge -see figure 2.1.1-, and is highly sensitive for the valence state of the atom and its bonding geometry. Extended X-ray absorption fine structure (EXAFS) deals with the interference effects visible in the absorption spectrum beyond the edge, and provides detailed information on the distance, number, and type of neighbors of the absorbing atom. However, the correct interpretation of the EXAFS region requires utilization of mathematical modeling and highly technical knowledge in the field that make this technique of more difficult access compared to XANES.

\subsubsection{Pulse chemisorption and temperature-programmed desorption of ammonia}

The experiments of chemisorption and subsequent temperature programmed desorption of ammonia ( $\mathrm{NH}_{3}$-TPD) were carried out on a TPD/2900 apparatus from Micromeritics. The samples (ca. $0.3 \mathrm{~g}$ ) were pre-treated in an $\operatorname{Ar}$ stream at 450 으 for $1 \mathrm{~h}$. Ammonia was chemisorbed by pulses at $100^{\circ} \mathrm{C}$ until equilibrium was reached. Then, the sample was fluxed with a He stream for 15 minutes, prior to increase the temperature up to $500^{\circ} \mathrm{C}$ in a helium stream of $100 \mathrm{ml} \mathrm{min}$-1 and using a heating rate of $10^{\circ} \mathrm{C} \mathrm{min}-1$. The $\mathrm{NH}_{3}$ desorption was monitored with a thermal conductivity detector (TCD) and a mass-spectrometer.

TPD of ammonia is a widely used method for characterization of site densities in solid acids due to the simplicity of the technique (however, quite time-consuming); it provides information on the 
surface concentration of acid sites and the relative distribution of their strength. However one must bear in mind that ammonia often overestimates the quantity of acid sites since its small molecular size allows ammonia to penetrate into all pores of the solid whereas larger molecules (e.g. glycerol and acrolein) only have access to large micropores and mesopores. Also, ammonia is a very basic molecule which is capable of titrating weak acid sites which may not contribute to the activity of catalysts. The strongly polar adsorbed ammonia is also capable of adsorbing additional ammonia from the gas phase.

\subsubsection{FTIR of adsorbed carbon monoxide or ammonia}

IR spectra of adsorbed $\mathrm{CO}$ and $\mathrm{NH}_{3}$ were collected with a Nexus 8700 FTIR spectrometer using a DTGS detector and acquiring at $4 \mathrm{~cm}^{-1}$. An IR cell allowing in situ treatments in controlled atmospheres and working in the temperature range $-176^{\circ} \mathrm{C}$ to $500^{\circ} \mathrm{C}$ has been used. The samples, prior to $\mathrm{CO}$ and $\mathrm{NH}_{3}$ adsorption experiments, were treated at $200^{\circ} \mathrm{C}$ in vacuum $\left(10^{-5} \mathrm{mbar}\right)$ for 1.5 h. IR spectra of $\mathrm{CO}$ adsorption were recorded at $-176^{\circ} \mathrm{C}$ using $\mathrm{CO}$ doses from $0.4-4 \mathrm{mbar}$. In the case of $\mathrm{NH}_{3}$ adsorption experiments $20 \mathrm{mbar} \mathrm{NH}_{3}$ were adsorbed at $25^{\circ} \mathrm{C}$ and then desorbed at increasing temperatures $\left(25^{\circ} \mathrm{C}, 100^{\circ} \mathrm{C}\right.$ and $\left.200^{\circ} \mathrm{C}\right)$.

The nature of the acid sites present on the catalysts prepared can be investigated by means of infrared spectroscopy using $\mathrm{NH}_{3}$ as the probe molecules. Indeed, ammonia chemisorbed on Brpnsted acid sites or Lewis acid sites presents different modes of vibration that, generally speaking, allow to discern the respective presence, abundance and strength of the two different acid sites [89]; particularly when the FTIR experiment is coupled with TPD analysis.

FTIR of adsorbed CO has been extensively used in the literature since it is highly sensitive to the electron-acceptor properties of the metal ion. Indeed in transition metal oxides the electrophilic properties of the metal ion depends not only to their coordination but also to the nature and the 
coordination state of the ligands. Accordingly, IR spectroscopy of CO can be performed in order to analyze the surface nature of substituted-HTBs. In fact, $\mathrm{W}^{6+}$ and $\mathrm{V}^{5+}$ do not form stable complexes with $\mathrm{CO}$ even at low temperature because of their high coordination saturation [9092], while $W^{n+}(n<6)$ and $V^{n+}(n<5)$ form stable CO carbonyl complexes [90, 93]. The $v(C O)$ frequency as well as the stability of the carbonyl complex is highly depended on the electrophilic properties of the metal ion, i.e coordination and oxidation state.

Overall, basically for the same reasons previously discussed for $\mathrm{NH}_{3}-\mathrm{TPD}$, adsorption of both ammonia and carbon monoxide cannot give a univocal picture of the real nature of the catalyst's surface. Therefore, results have to be carefully analyzed and compared to other figures obtained through various characterization methods.

\subsubsection{Raman spectroscopy}

Raman spectra were obtained with an "in via" Renishaw spectrometer, equipped with an Olympus microscope. The exciting wavelength was $514 \mathrm{~nm}$ from a Renishaw HPNIR laser with a power of approximately $15 \mathrm{~mW}$ on the sample. The dehydration of catalysts (under $20 \mathrm{~mL} \mathrm{~min}{ }^{-1}$ argon flow at $150^{\circ} \mathrm{C}$ ) was carried out by using a home-designed microreactor for in situ Raman spectroscopy measurement.

Raman analyses are typically carried out illuminating a sample with a laser beam. Electromagnetic radiation from the illuminated spot is collected with a lens and sent to a monochromator. Elastic scattered radiation at the wavelength corresponding to the laser line (Rayleigh scattering) is filtered out, while the rest of the collected light is dispersed onto a detector.

In infrared spectroscopy a molecule absorbs photons with the same frequency as its vibrations. In contrast, Raman spectroscopy is based on the inelastic scattering of photons, which lose energy by exciting vibrations in the sample. As in infrared spectroscopy, not all vibrations are observable. 
A vibration is Raman active if it changes the polarizability of the molecule. This requires in general that the molecule changes its shape. For example, the vibration of a hypothetical spherical molecule between the extremes of a disk-shaped and a cigar-shaped ellipsoid would be Raman active. Since the selection rule for infrared spectroscopy needs that a dipole moment changes during the vibration, some stretch vibrations of for example $\mathrm{H}_{2}\left(4160.2 \mathrm{~cm}^{-1}\right), \mathrm{N}_{2}\left(2330.7 \mathrm{~cm}^{-1}\right)$ and $\mathrm{O}_{2}\left(1554.7 \mathrm{~cm}^{-1}\right)$ are observed in Raman spectroscopy but not in infrared. Hence, the two techniques complement each other, in particular for highly symmetrical molecules.

A disadvantage of the technique is the small cross sections for Raman scattering, which makes the intensity of the inelastic scattered light signal very low, particularly compared to the elastic scattered light (Rayleigh band). This issue can be overcome coupling the use of intense radiation sources, e.g. lasers, with high-resolution monochromators. Finally, fluorescence of the sample, giving rise to spectral backgrounds, may seriously limit the detectability of weak signals.

\subsubsection{X-ray photoelectron spectroscopy (XPS)}

X-ray photoelectron spectroscopy (XPS) measurements were performed on a SPECS spectrometer equipped with a Phoibos 150 MCD-9 detector using a monochromatic Al K-alpha (1486.6 eV) X-ray source. Spectra were recorded using analyzer pass energy of $50 \mathrm{~V}$, an X-ray power of $200 \mathrm{~W}$, and an operating pressure of $10^{-9} \mathrm{mbar}$. Spectra treatment was performed using the CASA software. Binding energies (BE) were referenced to C1s at $284.5 \mathrm{eV}$.

X-ray photoelectron spectroscopy (XPS) is an analytical technique that characterizes the surface of a material, providing information about the surface elemental composition and chemical environment of the sample being probed. XPS operates firing monochromatic X-rays onto the sample surface. The X-ray photons excite and consequently eject core level electrons from the atoms in the sample. The binding energy of these electrons $-E_{b}$ - is the energy required to promote 
an electron from a given electronic level to the Fermi level and it is characteristic of the elements in the solid being investigated; this is what gives rise to the discrete peaks in an XP spectrum. The binding energy can be calculated by measuring the kinetic energy of the emitted electrons according to the following equation:

$$
E_{b}=h v-E_{k}-\Phi
$$

Equation 2.4: The binding energy

where $E_{b}=$ the binding energy of the emitted electron, $h v=$ the incident X-ray photon energy, $E_{K}$ $=$ the kinetic energy of the emitted electron and $\Phi=$ the spectrometer work function.

When photoemission occurs from non-s orbitals, the peaks in the XP spectrum appear as doublets. These doublets arise from the coupling between an electron's orbital angular momentum, with characteristic quantum number $I$, and its spin momentum, with characteristic quantum number $s$, which can take either of the values $\pm 1 / 2$. These can be summed to give the total angular momentum, possessing the quantum number $j$, which can take two values when $/$ is $>0$, i.e. in $p, d$ and $f$ orbitals. The full width at half maximum (FWHM) and line-shape are the same for both of the peaks. Characteristic binding energies and doublet peak separations of different elements can be readily found on the National Institute of Standards and Technology (NIST) XPS database [94].

Atoms of the same element in a solid, in dissimilar chemical environments, can give rise to inner orbital peaks with significantly different binding energies. These so-called 'chemical shifts' can be due to initial and final state effects. Initial state effects relate to the charge on the atom being probed. An electron in a more electron-deficient environment, in an atom with high oxidation state for instance, would possess a higher binding energy than one located in an electron-rich system, in a more reduced atom. Higher energy orbitals are more sensitive to these binding energy shifts, therefore better resolution of different chemical environments can be achieved by 
analyzing the outer shells, although this is not always possible due to overlapping peaks or low signal intensities. Final state effects occur after photoemission and can include any combination of core hole screening, orbital relaxation and polarization. Absolute binding energies can sometimes be difficult to interpret directly due to these final state effects, as well as electrostatic charging effects in the material being analyzed. This charging can be particularly problematic in an insulating solid. Although the instrument charge neutralizer can alleviate this effect, some slight shifts in energy can still occur. Typically, internal charge correction to the adventitious $C$ is peak is performed but this can be inaccurate and can vary depending on the type and amount of carbon present on the sample.

\subsection{Catalytic testing}

The glycerol (oxi)dehydration and the acrolein oxidation tests were carried out in a bench-scale reactor for heterogeneous gas-phase catalytic experiments; the simplified P\&I-scheme is reported in figure 2.3.1.

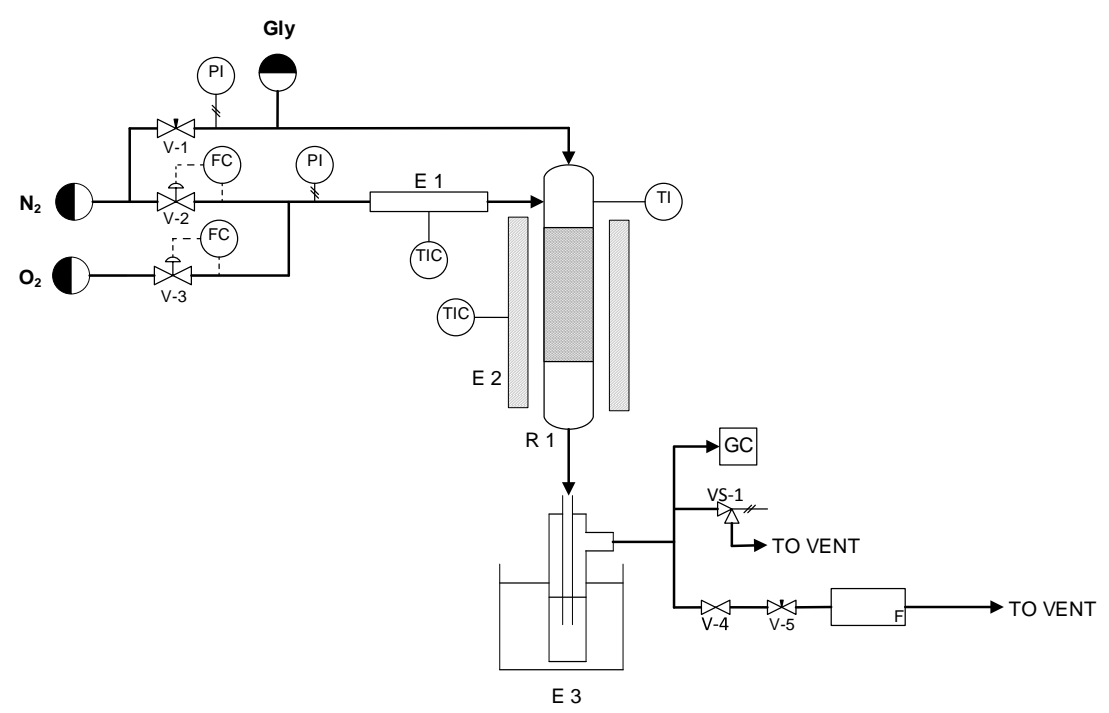

Figure 2.3.1. P\&I-scheme of the bench-scale reactor. 
The liquid feed (indicated in short as Gly) is injected by means of a programmable infusion pump. A nitrogen gas stream, regulated by $V-1$, is used as a carrier gas to help the solution reaching the reactor. For safety reasons (see paragraph 3.2.4) and to avoid side reactions in the gas phase, the final mixture is introduced directly into the reactor (R-1), through a 1/16" pipe, ca. $1 \mathrm{~cm}$ above the catalytic bed. The small diameter of the pipe, as well as the reactor temperature and the small quantity of reactants used, guarantee a fast and complete evaporation of the liquid phase. Two pressure indicators $(\mathrm{PI})$ are use to monitor the relative pressure in the hole plant.

Oxygen and a second stream of nitrogen, before entering the reactor, are pre-heated by heating tapes (E1); their respective flows are controlled by two mass flow controllers (FC). The reactor consists in a quartz tube with an internal diameter of ca. $0.5 "$, operating at atmospheric pressure and heated by a vertical tube furnaces. The temperature of reaction is measured by means of an axial thermocouple placed inside the catalytic bed. The effluent stream is bubbled through two inseries abatement devices (E-3), which are filled with water (but in some cases anhydrous acetone were used, for the identification of compounds which are less soluble in water) and maintained at a temperature of $0-2^{\circ} \mathrm{C}$; a third refrigerated condenser is left empty. After this abatement, the gaseous stream, still containing nitrogen, oxygen and carbon oxides, is fed to an automatic sampling system for gas-chromatography (GC-TCD) analysis. The water solution containing the unconverted glycerol and reaction products is analyzed by gas-chromatography (GC).

In a typical experiment, from $0.2 \mathrm{~g}$ to $0.50 \mathrm{~g}$ of catalyst are loaded either in the form of granules, with a diameter ranging from 0.25 to $0.60 \mathrm{~mm}$, or in the form of powder; the overall gas inlet flow rate varied from $25 \mathrm{~mL} / \mathrm{min}$ up to $60 \mathrm{~mL} / \mathrm{min}$ (measured at room T). All the contact time values reported in the next sections are calculated at room temperature. In experiments made with variation of contact time, the amount of catalyst loaded was varied, whereas the flow was kept constant. If not different specified, the inlet feed composition was: 2 mol\% glycerol, 4 mol\% 
oxygen, 40 mol\% water, and 54 mol\% helium. Overall reaction conditions are illustrated in each figure or table.

Gas chromatographic analyses were carried out using a Hewlett-Packard 5890 instrument equipped with a FID detector. A semi-capillary wide-bore OV 351 (polyethylenglycol treated with terephthalic acid) column was used for the separation of condensed compounds; oven temperature was set from $40^{\circ} \mathrm{C}$ to $190^{\circ} \mathrm{C}$ (heating rate $10^{\circ} / \mathrm{min}$, isothermal step at $190^{\circ} \mathrm{C}, 3 \mathrm{~min}$ ), then from $190^{\circ} \mathrm{C}$ to $225^{\circ} \mathrm{C}$ (heating rate $30^{\circ} / \mathrm{min}$, final isothermal step at $225^{\circ} \mathrm{C}, 30 \mathrm{~min}$ ). Two wide-bore columns were used for the separation of incondensable products: a Molsieve 5A for oxygen and $\mathrm{CO}$, and a Silica Plot for $\mathrm{CO}_{2}$ (oven temperature $80^{\circ} \mathrm{C}$ ). Compounds were identified by means of both GC-MS and injection of pure reference standards for the comparison of retention times in the GC columns. Depending on catalyst and reaction condition used, unknown compounds were also eluted in the GC column; it was attributed to these compounds the same response factor of the corresponding known compound with the closest retention time. Cyclic ethers were also sometimes produced; however, because it was not possible to perfectly resolve each peak corresponding to cyclic ethers with the chromatographic setup used, both the cyclic ethers and heaviest compounds not eluted from the GC column (left as residues on both the catalyst surface and reactor walls) were quantified as the remainder of the total carbon balance and labeled as "heavy compounds". Minor identified products and unknown compounds (except for ketals) have been grouped together under the heading "Others". For the sake of completeness and clarity, only few exceptions to this nomenclature have been reported in this thesis. Where needed, the various chemical species involved are specified both in the text and figures' caption.

Catalytic tests for methanol conversion were carried out in a fixed bed reactor operating at atmospheric pressure in the $250-400^{\circ} \mathrm{C}$ temperature region. The overall set-up being similar to the one reported in figure 2.3.1. The catalyst weight was either $0.10 \mathrm{~g}$ or $0.20 \mathrm{~g}$, and the feed 
consisted in a methanol/oxygen/nitrogen mixture with a molar ratio of 6/13/81 (total flow of 100 $\left.\mathrm{mL} \mathrm{min}^{-1}\right)$. The analysis of reactants and products was carried out by means of on-line gaschromatography, using two different chromatographic columns: (i) Molecular sieve 5A (3 m length) and (ii) RT-U-bond (30 m, 0.53 i.d.). 


\section{Results and discussion}

\subsection{Introduction of Niobium in V-substituted HTBs}

Niobium is a well known element for improving the acid properties of mixed-oxide catalysts and it was demonstrated to be effective in enhancing the selectivity to acrolein from glycerol $[43,44]$. Therefore, the idea at the bases of the research was to introduce niobium in the W-V HTBs previously studied so as to improve the glycerol dehydration step and hence the overall selectivity to acrylic acid. Indeed, the possibility of substituting tungsten atoms for niobium in the HTBs lattice, was already proved in the ' 80 s by means of solid state preparations [95]. Moreover, milder and more controllable hydrothermal methods would be more desirable from an industrial perspective.

\subsubsection{Physicochemical properties of the oxides}

Table 3.1.1 compiles the samples prepared, and summarizes their main characteristics. Different samples based on hexagonal- $\mathrm{WO}_{\mathrm{x}}$ were synthesized: (i) bi-component systems made of mixed oxides of either $\mathrm{W}-\mathrm{V}$ or $\mathrm{W}-\mathrm{Nb}$, and (ii) tri-component systems of $\mathrm{W}, \mathrm{Nb}$ and $\mathrm{V}$. Provided the results obtained on $\mathrm{W}-\mathrm{V}$ catalysts [1], the $\mathrm{W} / \mathrm{V}$ ratio was maintained also in tri-component systems. The acronyms used for W-V catalysts, refer to samples studied in [1].

Figure 3.1.1 (left) shows the XRD patterns of samples heat treated at $600^{\circ} \mathrm{C}$ in $\mathrm{N}_{2}$, except in the case of pure $\mathrm{WO}_{\mathrm{x}}$ (hexagonal) sample which was heat-treated at $450^{\circ} \mathrm{C}$, which otherwise decomposes (see paragraph 1.8). All samples present the hexagonal tungsten bronze (HTB) crystal structure (JCPDS: 85-2460), although smaller changes in the intensity of some of the diffraction lines might be related to changes in their morphologies [96]. Indeed, SEM images showed changes in morphology depending on catalysts' composition. 


\begin{tabular}{|c|c|c|c|c|c|}
\hline \multirow[t]{2}{*}{ Sample } & \multicolumn{2}{|c|}{$\begin{array}{c}\mathrm{V} /(\mathrm{W}+\mathrm{V}+\mathrm{Nb}) ; \mathrm{Nb} /(\mathrm{W}+\mathrm{V}+\mathrm{Nb}) \\
\text { atomic ratios }\end{array}$} & \multirow{2}{*}{$\begin{array}{c}\text { Surface area } \\
\left(\mathrm{m}^{2} \mathrm{~g}^{-1}\right)\end{array}$} & \multicolumn{2}{|c|}{ TPD } \\
\hline & In synthesis gel & $\begin{array}{l}\text { Heat-treated } \\
\text { samples }{ }^{\text {a) }}\end{array}$ & & $\mu \mathrm{mol}_{\mathrm{NH}} \mathrm{g}^{-1}$ & $\mu \mathrm{mol}_{\mathrm{NH3}} \mathrm{m}^{-2}$ \\
\hline$W O_{x}(h)$ & $0.0 ; 0.0$ & $0.0 ; 0.0$ & 30.6 & 135 & 4.4 \\
\hline WV-2 & $0.17 ; 0.0$ & $0.12 ; 0.0$ & 19.0 & 72 & 3.8 \\
\hline WV-3 & $0.30 ; 0.0$ & $0.21 ; 0.0$ & 20.6 & 76 & 3.7 \\
\hline WNb & $0.0 ; 0.20$ & $0.0 ; 0.25$ & 28.3 & 121 & 4.3 \\
\hline WVNb-1 & $0.20 ; 0.15$ & $0.13 ; 0.13$ & 57.3 & 192 & 3.4 \\
\hline WVNb-2 & $0.20 ; 0.34$ & $0.11 ; 0.20$ & 59.6 & 211 & 3.5 \\
\hline WVNb-3 & $0.40 ; 0.15$ & $0.18 ; 0.16$ & 45.6 & 178 & 3.9 \\
\hline
\end{tabular}

Figure 3.1.1 (right) shows also the IR spectra of catalysts. The IR spectrum of Nb-free catalyst shows a broad band centered at $802 \mathrm{~cm}^{-1}$ (spectrum a), but the maximum shifts to $828 \mathrm{~cm}^{-1}$ in Nbcontaining catalysts (spectra b-d), which are in good agreement to V- [1] and Nb-containing [97] tungsten oxide with HTB crystal structure. It has been reported that hexagonal-tungsten oxide structure is characterized by the presence of a broad band at $817 \mathrm{~cm}^{-1}$ [98], as shown in $\mathrm{WO}_{\mathrm{x}}$ sample (spectrum e). Moreover, the band in the $800-830 \mathrm{~cm}^{-1}$ range can be assigned to $\mathrm{O}-\mathrm{W}-\mathrm{O}$ stretching modes, while the band in the $700-550 \mathrm{~cm}^{-1}$ can be assigned to $\mathrm{W}-\mathrm{O}-\mathrm{X}(\mathrm{X}=\mathrm{W}, \mathrm{V}$ or $\mathrm{Nb})$ stretching modes [99]. 

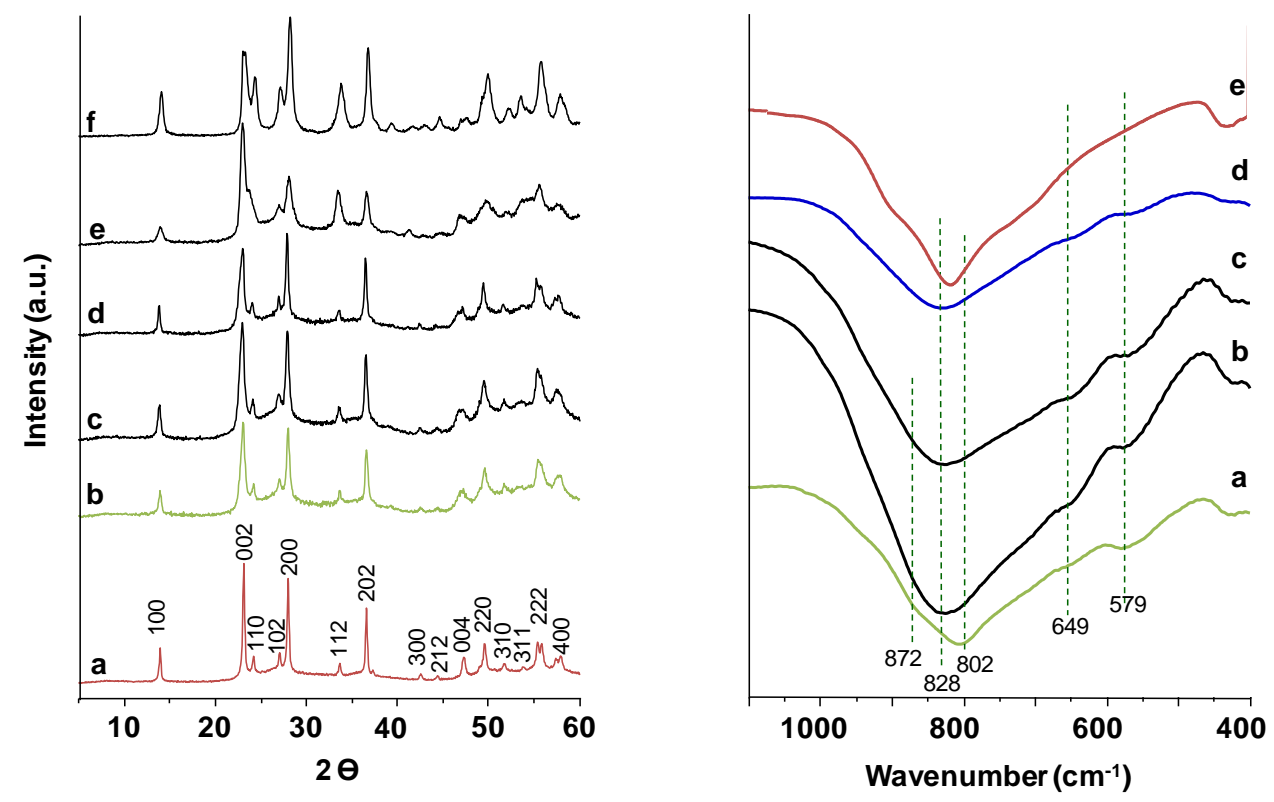

Figure 3.1.1. Left) XRD patterns of catalysts: $W O_{x}(a), W V-3(b), W V N b-1$ (c), WVNb-2 (d), WVNb-3 (e), WNb (f). Right) FTIR spectra of catalysts: WV-3 (a), WVNb-1 (b), WVNb-2 (c), WNb (d), $W O_{x}(e)$.

The acid characteristics of catalysts have been investigated by means of TPD of adsorbed ammonia as well as by infrared spectroscopy using $\mathrm{NH}_{3}$ and $\mathrm{CO}$ as the probe molecules. The $\mathrm{NH}_{3}-$ TPD profiles of V-and/or Nb-containing catalysts are shown in Figure 3.1.2 (left) and summarized in Table 3.1.1. Nb-free $\mathrm{W}-\mathrm{V}$ samples show a density of acid sites (expressed as $\mu \mathrm{mol}_{\mathrm{NH}} / \mathrm{g}$ ) lower than $\mathrm{Nb}$-containing samples. This way, $\mathrm{W}-\mathrm{V}-\mathrm{Nb}$ catalysts have a higher amount of acid sites when considering the number of acid sites per unit weight (i.e. $178-211 \mu \mathrm{mol}_{\mathrm{NH} 3} \mathrm{~g}^{-1}$ ) with respect to $\mathrm{WO}_{\mathrm{x}}$ or $\mathrm{WNb}$. However, they show a relatively lower number of acid sites when considering the catalyst surface area (ca. 3.4-3.9 $\mathrm{mol}_{\mathrm{NH} 3} \mathrm{~m}^{-2}$.

IR spectra of adsorbed $\mathrm{NH}_{3}$ after desorption at 100 and $200^{\circ} \mathrm{C}$ show the presence of both Brpnsted acid sites (IR band at $1410 \mathrm{~cm}^{-1}$ ) and Lewis acid sites $\left(1273\right.$ and $\left.1231 \mathrm{~cm}^{-1}\right)$ in all samples (Fig. 3.1.2, right) $[100,101]$. Both $V$-containing samples, i.e. WVNb-2 and $W V-3$, show a higher

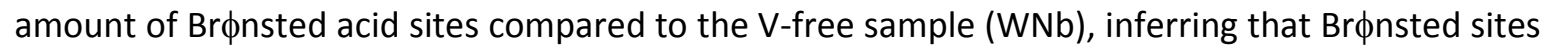
are related to the presence of $\mathrm{V}^{4+}-\mathrm{O}-\mathrm{W}^{6+}$ and/or $\mathrm{W}^{5+}-\mathrm{O}-\mathrm{W}^{6+}$ pairs in these samples. 

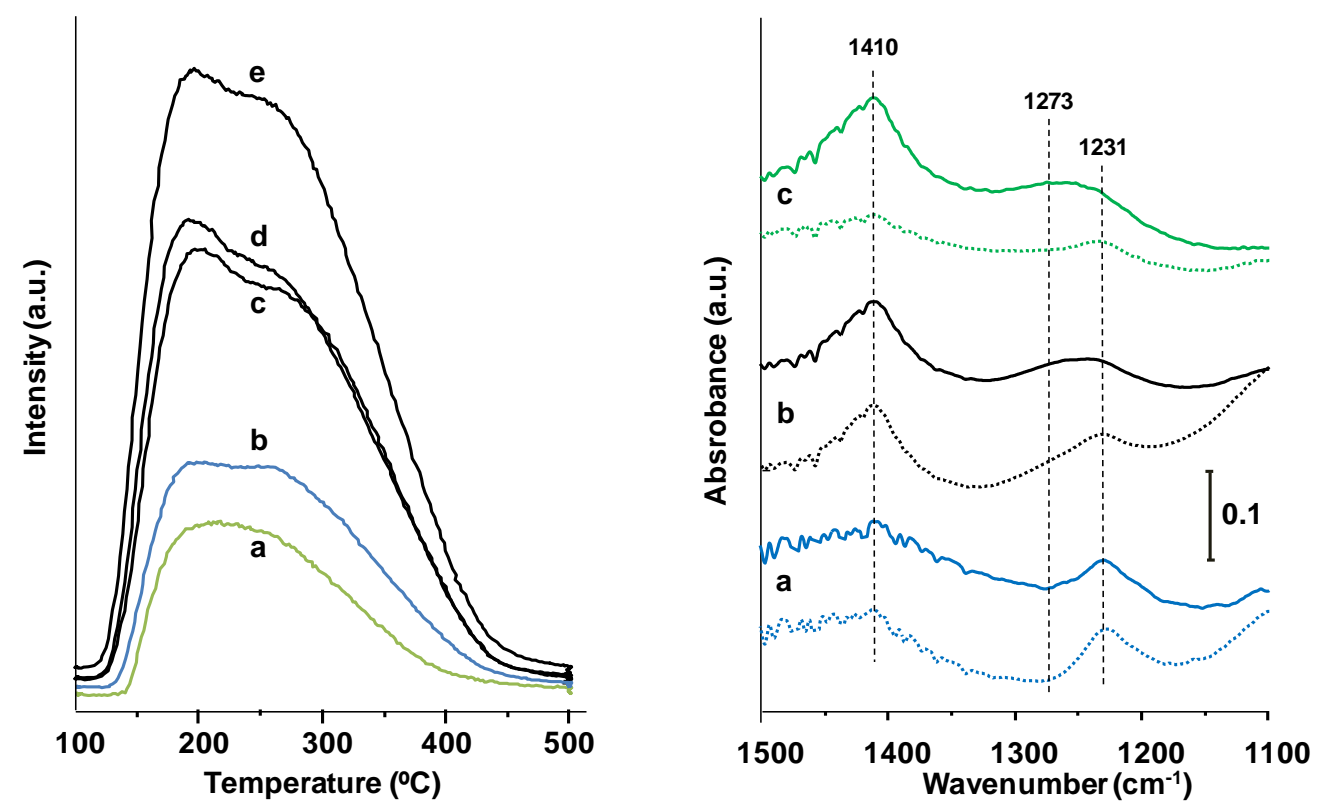

Figure 3.1.2. Left) TPD of adsorbed ammonia of: (a) WV; (b) WNb; WVNb-3 (c); (d) WVNb-1; (e) WVNb-2. Right) FTIR spectra of adsorbed ammonia: (a) WNb; (b) WVNb-2; (c) WV-3. After desorption at 100 으 (solid line) or $200 \circ \mathrm{C}$ (dashed line).

Moreover, for both V-containing samples two different types of Lewis acid sites can be observed (IR bands at 1273 and $1231 \mathrm{~cm}^{-1}$ ) showing different strength, as observed from the different behavior after desorption at 100 and $200^{\circ} \mathrm{C}$. On the other hand, in $\mathrm{Nb}$-containing samples (WNb and WVNb-2), the acid strength of both Brpnsted and Lewis sites is greater than in WV-3, whereas this is not the case for WV-3.

IR of CO adsorption as probe molecule has been extensively used in the literature since it is highly sensitive to the electron-acceptor properties of the metal ion. Figure 3.1.3, shows the IR spectra of adsorbed CO on the most representative catalysts. Only one IR band at $2195 \mathrm{~cm}^{-1}$ is observed on the $\mathrm{WO}_{\mathrm{x}}$ sample, which can be unambiguously associated to $\mathrm{W}^{5+}$ ions. This band is less intense for WV-3 and WVNb-1; it is possible to conclude that the quantity of $\mathrm{W}^{5+}$ species in the last two samples is lower than in $\mathrm{WO}_{\mathrm{x}}$, highlighting the stabilizing role for HTBs of transition metals with 
oxidation state lower than $6+$ (see chapter 1.8). However, other IR bands at 2180, 2168 and 2131 $\mathrm{cm}^{-1}$ are observed in WV-3 and WVNb-1.

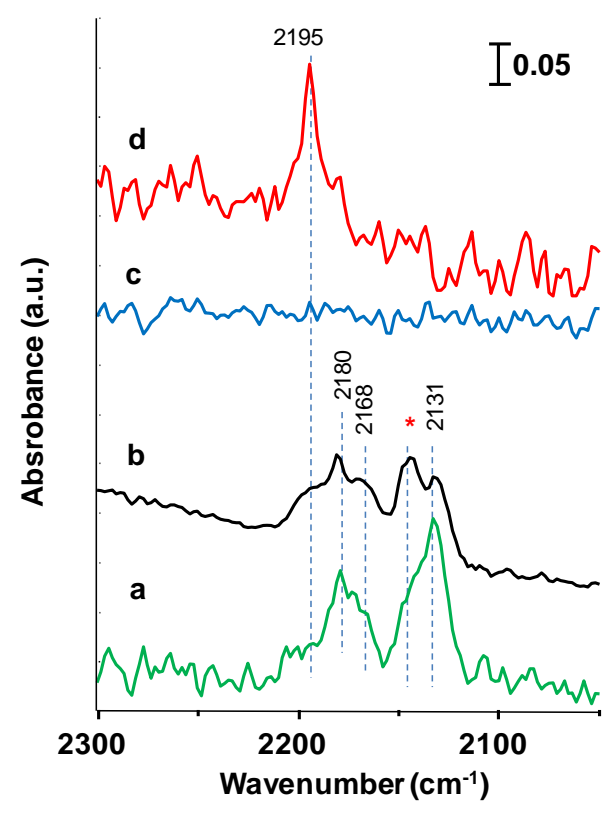

Figure 3.1.3. FTIR spectra of adsorbed CO on: WV-3 (a); WVNb-1 (b); WNb (c); and $\mathrm{WO}_{\mathrm{x}}(\mathrm{d})$. The band with $\left({ }^{*}\right)$ corresponds to physisorbed CO.

According to the XPS results of W-V mixed oxides [1], in which a low contribution of surface $\mathrm{W}^{5+}$ versus $\mathrm{V}^{4+}$ species is observed, the new bands observed in WVNb-1 catalyst can tentatively be associated to the interaction of $\mathrm{CO}$ with $\mathrm{V}^{4+}$ and/or $\mathrm{W}^{5+}$ ions in different environments (framework positions, ion exchange positions or extra framework oxidic species) [102]. However, further experiments are required in order to better evaluate the local environment of the transition metals involved and to evaluate the mechanism in the incorporation of $\mathrm{V}$ - and $\mathrm{Nb}$ species in the framework of this type of materials. More insights will be indeed provided in the next chapter as well as in chapters 3.3 and 3.5 by means of TEM and XAS analysis.

On the other hand, for WNb no IR bands are observed, meaning that $\mathrm{W}^{5+}$ species are not present in this catalyst; however, this sample shows a higher thermal stability than pure $\mathrm{WO}_{\mathrm{x}}$ since the 
bronze structure of $\mathrm{WNb}$ catalysts is stable during the heat-treatment up to $600^{\circ} \mathrm{C}$, hence making it possible to conclude that $\mathrm{Nb}^{5+}$ ions are incorporated in the hexagonal framework.

The main conclusions inferred from the characterization of samples are:

- W-V-Nb mixed oxides with the HTB structure can be prepared hydrothermally. The incorporation of $\mathrm{Nb}^{5+}$ leads to a lower concentration of surface $\mathrm{W}^{5+}$ sites, thus making possible to form an HTB with fully oxidized (or almost) tungsten atom.

- The presence of $\mathrm{Nb}$ in tri-component systems (W-V-Nb-O) leads to a remarkable increase of surface area compared to both $\mathrm{W}-\mathrm{Nb}-\mathrm{O}$ and $\mathrm{W}-\mathrm{V}-\mathrm{O}$ samples. However, surface area values close to $\mathrm{W}-\mathrm{V}-\mathrm{Nb}-\mathrm{O}$ were also obtained for $\mathrm{W}-\mathrm{Nb}$ oxides prepared by hydrothermal methods [103], suggesting that the postsynthesis treatments (e.g. grinding) and/or synthetic procedure (e.g. pH, directing agents etc.) are pivotal in governing the final surface area value.

- The amount of surface acid sites in $\mathrm{W}-\mathrm{V}-\mathrm{Nb}$ samples is relatively higher than that in $\mathrm{W}-\mathrm{V}, \mathrm{W}-\mathrm{Nb}$ or $\mathrm{W}$ - bronzes, but the surface density of acid sites is similar for $\mathrm{W}$ $\mathrm{V}$ and $\mathrm{W}-\mathrm{V}-\mathrm{Nb}$, and lower than that of $\mathrm{W}-\mathrm{Nb}$ and $\mathrm{W}$ - bronzes. On the other hand, the fraction of stronger sites is greater in Nb-containing samples.

\subsubsection{Lab-scale reactor tests}

In figure 3.1.4 are summarized some representative results obtained on the best performing acid catalysts, i.e. $W O_{x}$ and $W N b$, as well as bi-functional acid-redox catalysts, i.e. WV-2, WV-3 and WVNb-1. Data concerning catalysts $W V-2$ and $W O_{x}$ are reported from [1]. 

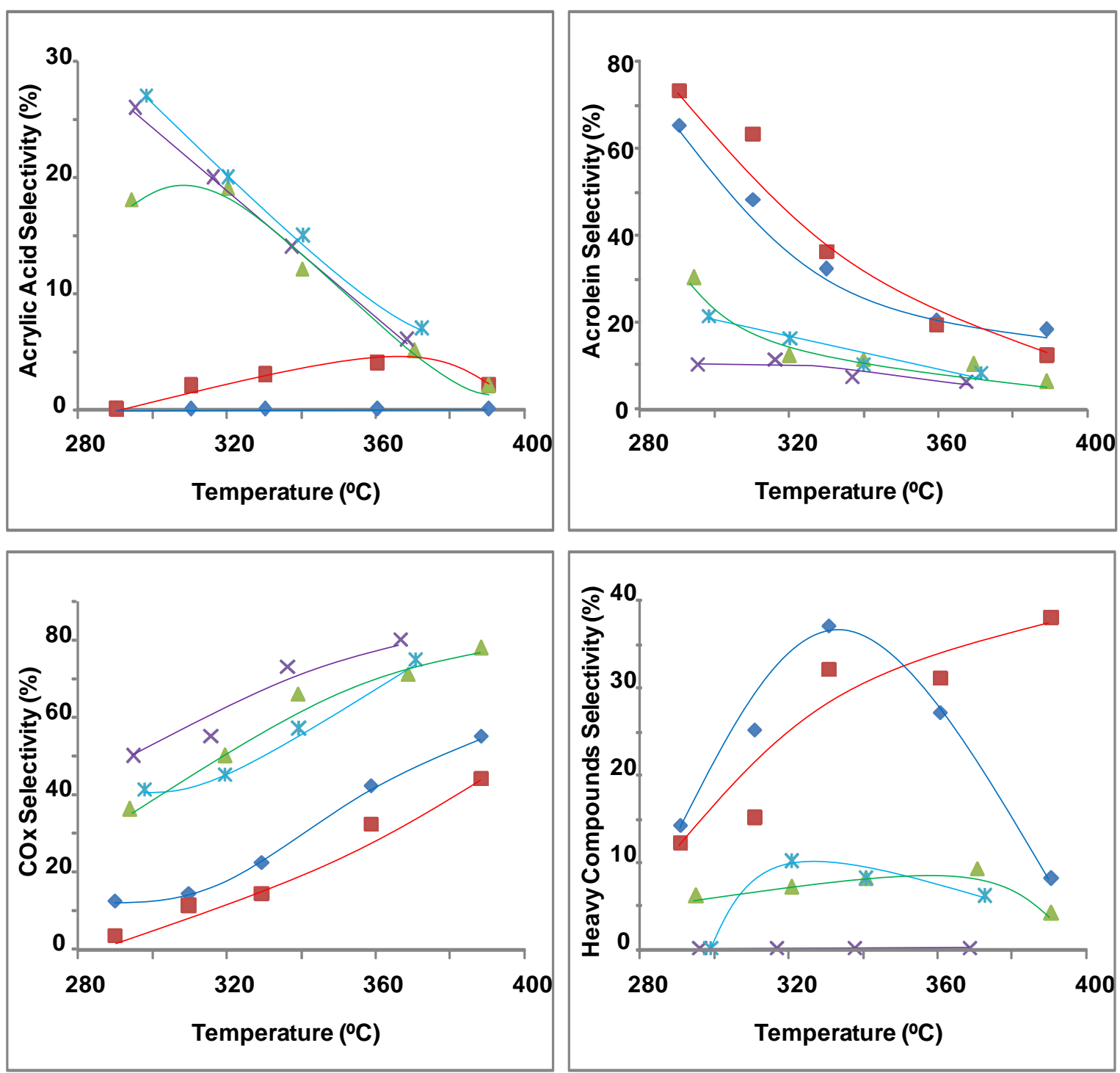

Figure 3.1.4. Catalytic behavior of $\mathrm{WO}_{\mathrm{x}}(\diamond), \mathrm{WNb}(\square), \mathrm{WV}-2(\Delta), \mathrm{WV}-3(\mathrm{X})$ and WVNb-1 $(*)$ in glycerol oxidehydration tests as a function of temperature. Feed composition: 2 mol\% glycerol, 4 mol\% oxygen, 40 mol\% water, and 54 mol\% helium. Contact time $0.38 \mathrm{~s}$ (Calculated at room temperature).

For all the catalysts, the conversion of glycerol was always complete over the range of temperature examined, with the only exception of WV-2 which showed a glycerol conversion between $95 \%$ and $98 \%$ in the temperature range $290^{\circ} \mathrm{C}$ to $320^{\circ} \mathrm{C}$. This is typically observed with most catalysts used for glycerol dehydration or oxidehydration reported in the literature; further comments are reported below. 
The catalytic performance of WV-3 was similar to that of WV-2, (see Table 3.1.2), but the maximum selectivity to acrylic acid was higher, $26 \%$ for WV-3 vs $18 \%$ for WV-2. The selectivity to acrolein was close to $10 \%$ in the $\mathrm{T}$ range $270-320^{\circ} \mathrm{C}$, but then decreased when the temperature was further increased. Major by-products were $\mathrm{CO}, \mathrm{CO}_{2}$, acetaldehyde and acetic acid. Other byproducts formed were: allylic alcohol, acetone, propionaldehyde, propionic acid, and hydroxyacetone; these are the generally observed by-products forming in low amounts (i.e. $<7 \%$ ) and for this reason not shown in the plot. Finally, the selectivity to "heavy compounds" (i.e., compounds that were not eluted in the GC column, and were indirectly determined by means of the $\mathrm{C}$ balance) became nil for temperatures higher than $310^{\circ} \mathrm{C}$. The selectivity to acrylic acid declined when the temperature was raised, with a concomitant increase of selectivity to CO.

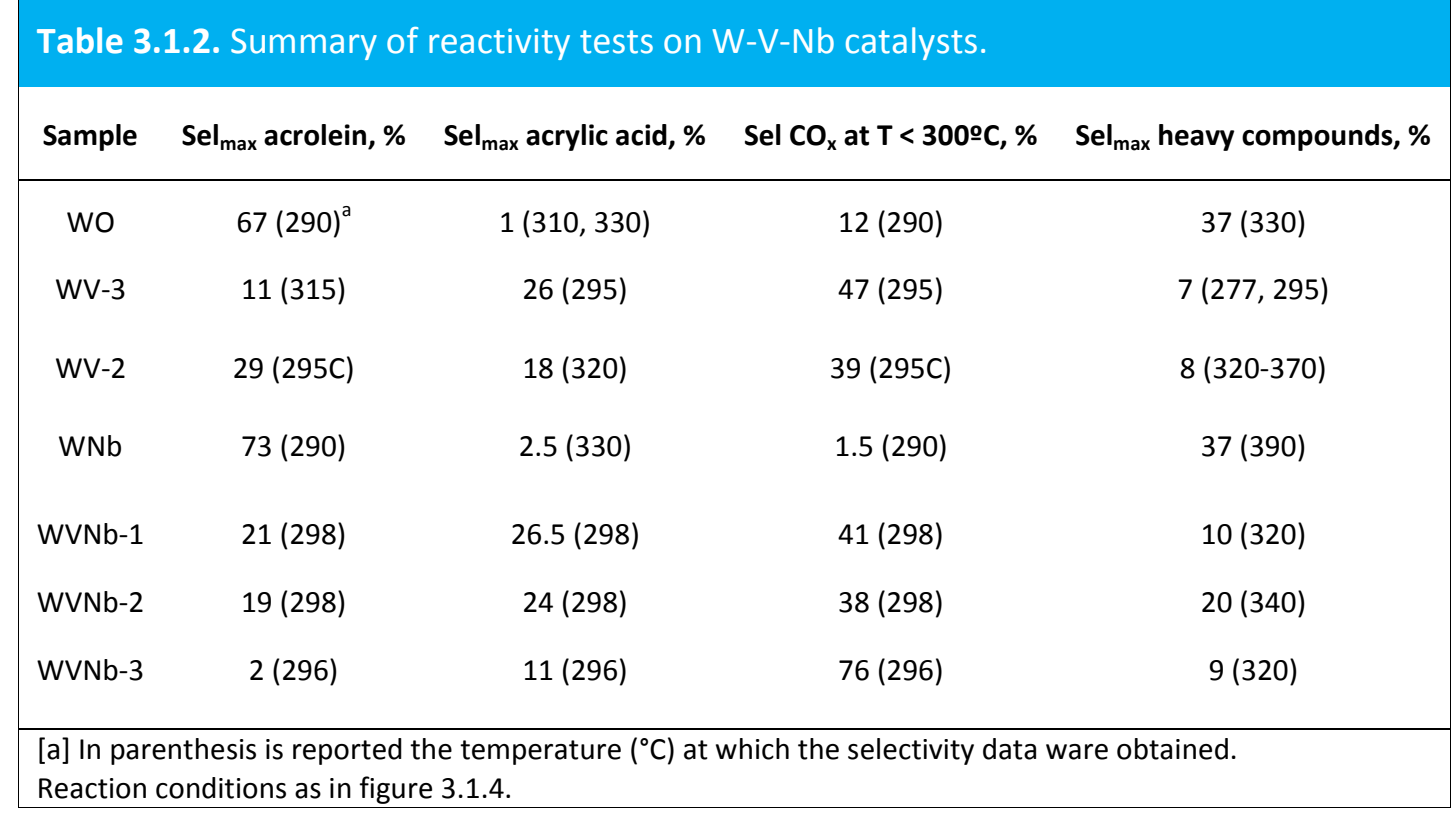

WNb catalyst showed some important differences with respect to the $\mathrm{WO}_{\mathrm{x}}$. In fact, the trend of the selectivity to acrolein in function of temperature was similar for the two catalysts, but the selectivity to acrolein at low temperature was greater with WNb $\left(73 \%\right.$ at $290^{\circ} \mathrm{C}$ and $64 \%$ at $310^{\circ} \mathrm{C}$ ) than with $\mathrm{WO}_{\mathrm{x}}\left(65 \%\right.$ at $290^{\circ} \mathrm{C}$ and $49 \%$ at $\left.310^{\circ} \mathrm{C}\right)$. Another difference between the two 
samples is the selectivity to heavy compounds; indeed, with $W_{x}$, they first increased (in concomitance with the decrease of selectivity to acrolein), reached a maximum value at $330^{\circ} \mathrm{C}$, and finally decreased when the temperature was further raised, with a strong increase of selectivity to $\mathrm{CO}_{\mathrm{x}}$. With $\mathrm{WNb}$, instead, the raise of $\mathrm{CO}$ selectivity at temperatures higher than $330^{\circ} \mathrm{C}$ was less relevant than with $\mathrm{WO}_{\mathrm{x}}$, and the selectivity to heavy compounds in this temperature range was ca $30-35 \%$. Differences of catalytic behavior between $\mathrm{WO}_{\mathrm{x}}$ and $\mathrm{WNb}$ can be attributed to both the presence of $\mathrm{Nb}^{5+}$ sites, probably responsible for the greater fraction of stronger acid sites (Figure 3.1.2), and to the lower surface concentration of $\mathrm{W}^{5+}$ sites, as inferred from CO-adsorption experiments (Figure 3.1.3).

It is of interest to compare WVNb-1 to WV-3. At low temperature, the overall selectivity to acrolein + acrylic acid was greater with WVNb-1 than with WV-3 $\left(47.5 \%\right.$ at $298^{\circ} \mathrm{C}$ for WVNb-1, $33 \%$ with WV-3); this difference was mainly due to the greater selectivity to acrolein obtained with the former catalyst. Moreover, when the temperature was raised with the WVNb-1 catalyst, the selectivity to both acrolein and acrylic acid declined; at the same time, the selectivity to $\mathrm{CO}_{\mathrm{x}}$ increased, and that to heavy compounds first increased (selectivity $10 \%$ at $320^{\circ} \mathrm{C}$ ), and then decreased. With WV-3, instead, the selectivity to acrylic acid also declined (with a corresponding higher selectivity to $\left(\mathrm{O}_{x}\right)$, but that to acrolein changed only at a minor extent, and there was no formation of heavy compounds at all.

Table 3.1.2 compares the catalytic behavior of WVNb-1, WVNb-2 and WVNb-3; the table compiles the values of maximum selectivity to acrolein and acrylic acid (both obtained at temperatures lower than $320^{\circ} \mathrm{C}$ ), the selectivity to $\mathrm{CO}+\mathrm{CO}_{2}$ at low temperature, and the maximum selectivity to heavy compounds. It is shown that the increase of $\mathrm{Nb}$ content (sample WVNb-2) led to a worse catalytic behavior at low temperature, with a slightly lower selectivity to acrolein and acrylic acid and a higher selectivity to heavy compounds. This indicates that a low amount of $\mathrm{Nb}$ favors the 
formation of acrolein (and of acrylic acid) at low temperature, but when the amount of $\mathrm{Nb}$ exceeds a defined value, it definitely enhances the formation of heavy compounds even at low temperatures. Finally, in the case of sample WVNb-3, containing a greater amount of $\mathrm{V}$ than in WVNb-1 and WVNb-2, yields to both acrolein and acrylic acid were remarkably lower compared to the other tri-component catalysts. In this case, this difference was mainly due to the greater formation of $\mathrm{CO}_{x}$.

Accordingly, the presence of $\mathrm{Nb}$ had a positive effect on the selectivity to acrolein at low temperature, with both the WNb and $\mathrm{W}-\mathrm{V}-\mathrm{Nb}$ catalysts; however, at temperatures higher than $310^{\circ} \mathrm{C}$ it promoted the formation of heavy compounds. The best composition for the tricomponent system falls in a very narrow range of atomic ratios between elements. Additional experiments were also carried out in function of contact time (Figure 3.1.5), with WVNb-1 at $290^{\circ} \mathrm{C}$, so as to pursuing both a clearer picture of the reaction scheme and eventually find the optimum reaction conditions for improving the selectivity to the desired monomers.

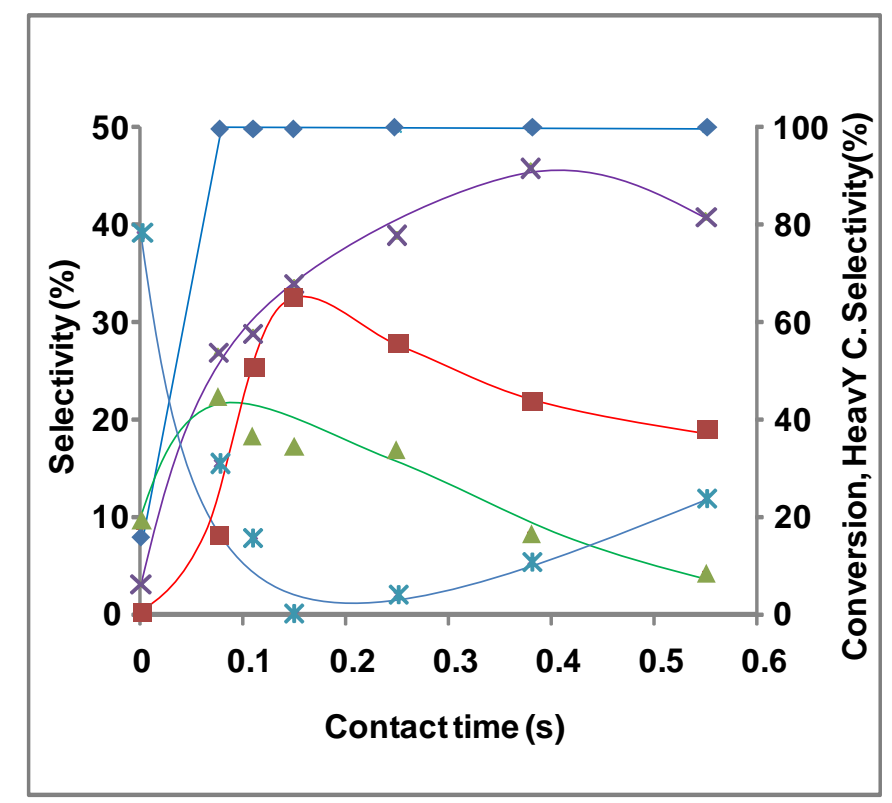

Figure 3.1.5. WVNb-1. Catalytic performance as a function of contact time. Temperature: $290^{\circ} \mathrm{C}$. Feed composition: 2 mol\% glycerol, 4 mol\% oxygen, 40 mol\% water, and 54 mol\% helium. Symbols: Acrylic Acid ( $\square$ ), Acrolein ( $\Delta$ ), COx $(X)$,Heavy compounds (*), Glycerol Conversion $(\diamond)$. 
As far as the reaction mechanism is concerned, it is possible to notice that when no catalyst was present (contact time zero), the glycerol conversion was close to $9 \%$ and there was formation of acrolein. Hence a minor contribution by homogeneous reactivity in the gas phase has to be taken into account. Moreover, there is a very high formation of heavy compounds, consisting of both glycerol oligomers and ketals obtained by reaction between glycerol and acrolein (the nature of heavy compounds was determined by means of ESI-MS). However, it must be stressed that selectivity values at such low glycerol conversion are affected by a significantly higher experimental error compared to data obtained at higher conversions.

The presence of the catalyst (contact time $<0.1 \mathrm{~s}$ and higher) led to total glycerol conversion, and to a remarkable decrease of the selectivity to heavy compounds. However, the overall yield to the latter compounds was greater than that obtained with no catalyst at all, meaning that the catalyst also contributed to their formation. The products formed in the greater amount were acrolein (selectivity $22 \%$ ) and $\mathrm{CO}_{x}$; acrylic acid selectivity was $8 \%$.

In the 0.08 -to- $0.20 \mathrm{sec}$ contact time range, the selectivity to heavy compounds decreased considerably, whereas a rapid decline of selectivity to acrolein led to a corresponding increase of the selectivity to acrylic acid, a proof for the consecutive oxidation of the aldehyde into the acid. The maximum yield to acrylic acid, obtained at 0.15 s contact time, was $33 \%$.

Contact times higher than 0.20 s led to a progressive decline of selectivity to acrylic acid, acetaldehyde, and acrolein. Conversely, selectivity to $\mathrm{CO}_{\mathrm{x}}$ and acetic acid increased, a clear indication of the presence of consecutive reactions of oxidative degradation or decomposition. An unexpected phenomenon was the increase of selectivity to heavy compounds (mainly of oligomers of acrolein). This might indicate that (total) oxidation and oligomerization are competitive parallel reactions whose contribution depends on the acid and redox sites relative distribution and contact time. 
Finally a time-on-stream test was carried out under the optimal conditions for WVNb-1, that is $290^{\circ} \mathrm{C}$ and $0.15 \mathrm{~s}$ contact time (Figure 3.1 .6 ). It must be stressed that, generally speaking, catalyst's life tests have to be performed at conversion $<100 \%$. Indeed, incomplete conversion guarantees that the whole catalytic bed participates to the reaction under the conditions used. Total conversion might mask a partial use of the catalyst and forge the time-on-stream tests, leading to stable long lasting overall catalytic performance, even if the catalytic bed is actually undergoing deactivation.

In the case of the catalytic test reported in figure 3.1.6, the glycerol conversion was always complete, therefore potentially leading to the problems just mentioned. However, if different reaction conditions were used to lower the glycerol conversion, the catalytic performance would have been significantly affected, particularly due to the formation of heavy compounds. Indeed, it has been demonstrated above that their selectivity strongly increases when glycerol is present, (unconverted) in the gas phase, due to the formation of ketals through condensation of aldehydes with glycerol, as well as glycerol oligomerization (see chapter 3.2). Therefore, reaction conditions different from the optimal ones, would have led to a faster deactivation of the catalyst, not representative of the real time-on-stream performance under the optimized conditions.

Overall, taking into consideration the very low amount of catalyst used (ca. $0.3 \mathrm{~g}$ ) and the relatively long time-on-stream test (ca. 100h), the partial utilization of the catalytic bed is definitely unlikely, as also proved by the contact time tests in figure 3.1.5. 


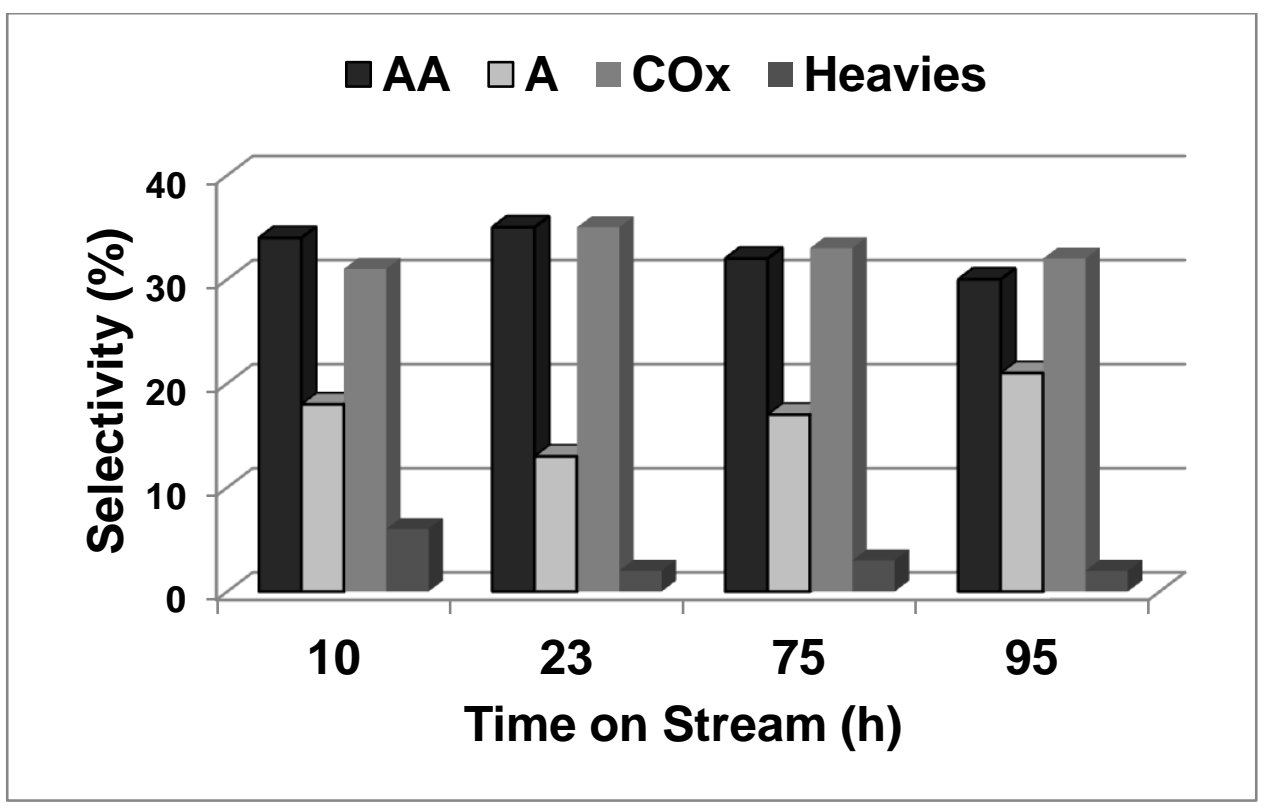

Figure 3.1.6. Catalyst WVNb-1. Time on stream test. Contact time $0.15 \mathrm{~s}, 290^{\circ} \mathrm{C}$. Feed composition: 2 mol\% glycerol, 4 mol\% oxygen, 40 mol\% water, and 54 mol\% helium.

Along ca. 100 hours reaction time, only a slight decline of selectivity to acrylic acid was observed, from $34 \%$ to $30.5 \%$; at the same time, acrolein selectivity increased from $17 \%$ to $21 \%$; therefore, the overall selectivity to acrolein and acrylic acid remained stable around $51 \%$. A similar behavior was also observed in the case of sample WV-3 [1]; however, in that case the fall of selectivity was much more important than with the WVNb-1 catalyst. The decline of selectivity to acrylic acid for WV-3 was attributed to a progressive oxidation of $\mathrm{V}^{4+}$ in the bronze; therefore, the more stable behavior here observed can be tentatively attributed to a stabilization of the reduced state of $V$ in the bronze, favored by the incorporation of $\mathrm{Nb}$. Further comments on this matter is reported in the next chapter.

\subsubsection{Conclusions}

Tri-component $\mathrm{W}$-V-Nb mixed oxides with the hexagonal tungsten bronze structure can be prepared hydrothermally and thermal treatment at $600^{\circ} \mathrm{C}$ in nitrogen atmosphere. These mixedoxides possess both acid and redox features, which are needed for the one-pot oxidehydration of 
glycerol into acrylic acid, via intermediate formation of acrolein. The incorporation of $\mathrm{Nb}^{5+}$ leads to a lower surface density of acid sites compared to both $W O_{x}$ and the bi-component $\mathrm{W}-\mathrm{V}$ systems, but to a greater fraction of stronger sites. The catalyst WVNb-1 gave $34 \%$ yield to acrylic acid (with overall selectivity to acrylic acid and acrolein of $51 \%$ ), at $290^{\circ} \mathrm{C}$. The selectivity to acrolein and acrylic acid was greatly affected by the reaction conditions used. 


\section{$3.2 \mathrm{Nb}$ and $\mathrm{V}$-substituted HTBs: the influence of reaction conditions on}

catalytic performance in glycerol oxidehydration

In order to fully investigate the catalyst activity of the best-performing tri-component sample (WVNb-1) further studies were performed on the catalyst's behavior under different reaction conditions. This study allowed reaching unprecedented values of acrylic acid yield and productivity. Moreover, methanol oxidation was used as a probe reaction to assess the surface acid-redox properties $[104,105]$ and to compare WVNb-1 with a bi-component W-V catalyst with analogous composition, i.e. WV-2. The results obtained make it possible to draw important general conclusions on the relation between the reaction conditions and catalyst features.

Finally, so as to support the conclusions depicted on substituted-HTB structures, the same reactions were carried out on a $\mathrm{MoV}(\mathrm{W})$ oxide with $\mathrm{Mo}_{5} \mathrm{O}_{14}$-type bronze structure, a typical catalyst for acrolein oxidation into acrylic acid. In order to obtain a complete picture of the catalysts' behavior, the acrolein oxidation reaction was also studied on both $\mathrm{HTBs}$ and $\mathrm{Mo}_{5} \mathrm{O}_{14^{-}}$ type bronzes.

\subsubsection{Physicochemical properties of the oxides}

The surface area of the solids synthesized decreased as follows: WVNb-1 > WV-2 > MoV(W) (Table 3.2.1); the difference in surface area can be attributed to both the different structures and the amount of niobium introduced in the material as already noticed in part one and as reported in literature [106, 107]. On the other hand, the chemical composition of these materials (determined by EDX analysis), revealed a homogeneous distribution of the elements in all cases. 


\begin{tabular}{|c|c|c|c|c|c|c|c|}
\hline \multirow{2}{*}{ Sample } & \multirow{2}{*}{$\begin{array}{c}\text { Surface } \\
\text { area } \\
\left(\mathrm{m}^{2} \mathrm{~g}^{-1}\right)\end{array}$} & \multicolumn{2}{|c|}{ TPD-NH } & \multicolumn{2}{|c|}{$\mathrm{H}_{2}-\mathrm{TPR}^{\mathrm{a}}$} & \multirow{2}{*}{$\begin{array}{l}\text { Crystalline } \\
\text { phase }\end{array}$} & \multirow{2}{*}{$\begin{array}{c}\text { Catalyst } \\
\text { composition }^{c}\end{array}$} \\
\hline & & $\mu \mathrm{mol}_{\mathrm{NH} 3} \mathrm{~g}^{-1}$ & $\mu \mathrm{mol}_{\mathrm{NH} 3} \mathrm{~m}^{-2}$ & Peak 1 & Peak 2 & & \\
\hline WV-2 & 19.0 & 72 & 3.8 & 0.59 & 2.09 & HTB & $W V_{0.12}$ \\
\hline WVNb-1 & 57.3 & 192 & 3.4 & n.c. ${ }^{b}$ & 3.99 & HTB & $W V_{0.13} N_{0.13}$ \\
\hline $\operatorname{MoV}(\mathrm{W})$ & 6.3 & 21 & 3.5 & 0.08 & 2.91 & $\mathrm{Mo}_{5} \mathrm{O}_{14}$ & $\mathrm{Mo}_{0.68} \mathrm{~V}_{0.23} \mathrm{~W}_{0.09}$ \\
\hline
\end{tabular}

[a] $\mathrm{H}_{2}$-TPR results: $\mathrm{H}_{2}$-uptake (in $\mathrm{mmolH}_{2} \mathrm{~g}$-1) in the $450-550 \circ \mathrm{C}$ (peak 1) and $550-750^{\circ} \mathrm{C}$ (peak 2) temperature region. [b] The $\mathrm{H}_{2}$-uptake have been not calculated since only a shoulder is observed at 590 으 for the first reduction peak. [c] Data calculated by means of SEM-EDX analysis.

Powder XRD analysis of heat-treated materials is presented in Figure 3.2.1. Diffraction maxima match with those of a basic hexagonal tungsten bronze, HTB structure (JCPDS: 85-2460) for WV-2 and WVNb-1 catalysts, even if, for the latter catalyst, a consistent amount of amorphous phase is present (ca. $60 \%$, calculated by means of the Rietveld method).

$\operatorname{MoV}(\mathrm{W})$ presents diffraction maxima and intensities very similar to those oxides presenting a $\mathrm{Mo}_{5} \mathrm{O}_{14}$-type structure, i.e. $\mathrm{Mo}_{5} \mathrm{O}_{14}$ oxide (JCPDS: 12-0517) or $\mathrm{Nb}_{0.09} \mathrm{Mo}_{0.91} \mathrm{O}_{2.8}$ (JCPDS: 27-1310), having a tetragonal lattice cell. However, the presence of $\mathrm{MoO}_{3}$ (JCPDS: 5-508), as minority, cannot be completely excluded.

Figure 3.2.2 (A) shows the IR spectra of catalysts. The IR spectrum of WV-2 and WVNb-1 are very similar presenting a broad band at ca. $802 \mathrm{~cm}^{-1}$ (spectrum a) or $828 \mathrm{~cm}^{-1}$ (spectrum b), respectively, which can be assigned to $\mathrm{O}-\mathrm{W}-\mathrm{O}$ stretching modes in tungsten oxide with $\mathrm{HTB}$ crystal structure [1]. Moreover, the broad band in the $700-550 \mathrm{~cm}^{-1}$ range can be assigned to W$\mathrm{O}-\mathrm{X}(\mathrm{X}=\mathrm{W}, \mathrm{V}$ or $\mathrm{Nb})$ moieties [108]. 


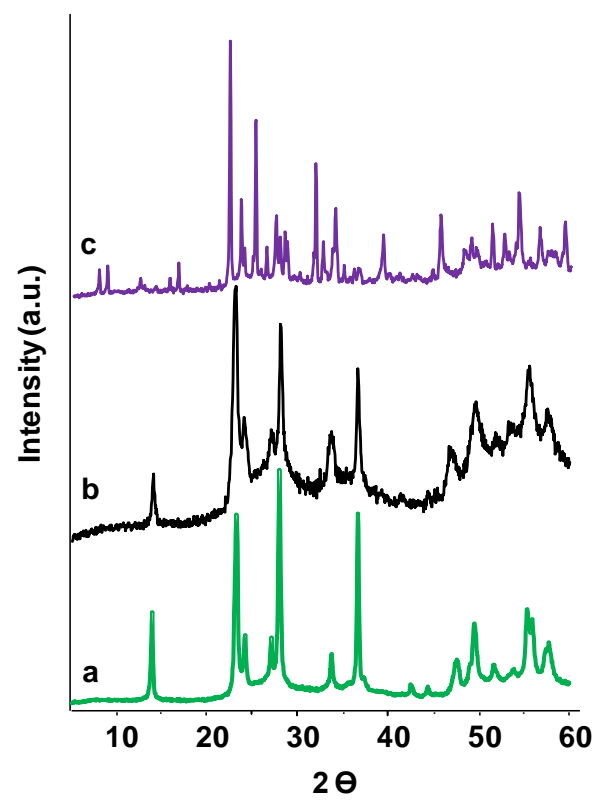

Figure 3.2.1. XRD of the fresh catalysts: (a) WV-2, (b) WVNb-1, (c) MoV(W).

A different IR spectrum is observed in the case of Mo-V-(W) (Fig. 3.2.2 (A), spectrum c). Thus, three intense bands are observed at 905,859 and $792 \mathrm{~cm}^{-1}$, which have also been reported in a Fe-doped Mo/V/W [109] and Ta-containing $\mathrm{Mo}_{5} \mathrm{O}_{14}$ [110], both presenting $\mathrm{M}_{5} \mathrm{O}_{14}$-type bronze structure. However, this spectrum is different from that previously reported for Mo and W-based bronze with a tetragonal tungsten bronze, TTB, structure [107]. On the other hand, the presence of a shoulder at $995 \mathrm{~cm}^{-1}$ (as well as low intense bands at 870 and $583 \mathrm{~cm}^{-1}$ ) suggests the minor presence of $\mathrm{MoO}_{3}[111]$.

Raman spectra of fresh catalysts are presented in Figure 3.2.2 (B). The Raman spectra of WV-2 and WVNb-1 show three broad bands at 970,800 and $692 \mathrm{~cm}^{-1}$, similar to those previously reported for W-based HTB materials. However, in the case of sample MoV(W) (spectra c1 and c2), heterogeneous material is observed as concluded from the different spectra achieved for this sample. The band at ca. $845 \mathrm{~cm}^{-1}$ is related to $\mathrm{Mo}-\mathrm{O}$ bond in $\mathrm{Mo}_{5} \mathrm{O}_{14}$ [112]. Moreover, and in addition to $\mathrm{Mo}_{5} \mathrm{O}_{14}$-type crystals, the Raman bands at 673,822 , and $999 \mathrm{~cm}^{-1}$ are typical of $\mathrm{MoO}_{3}$ crystallites (Fig. 3.2.2 (B), spectrum c2) [113]. 

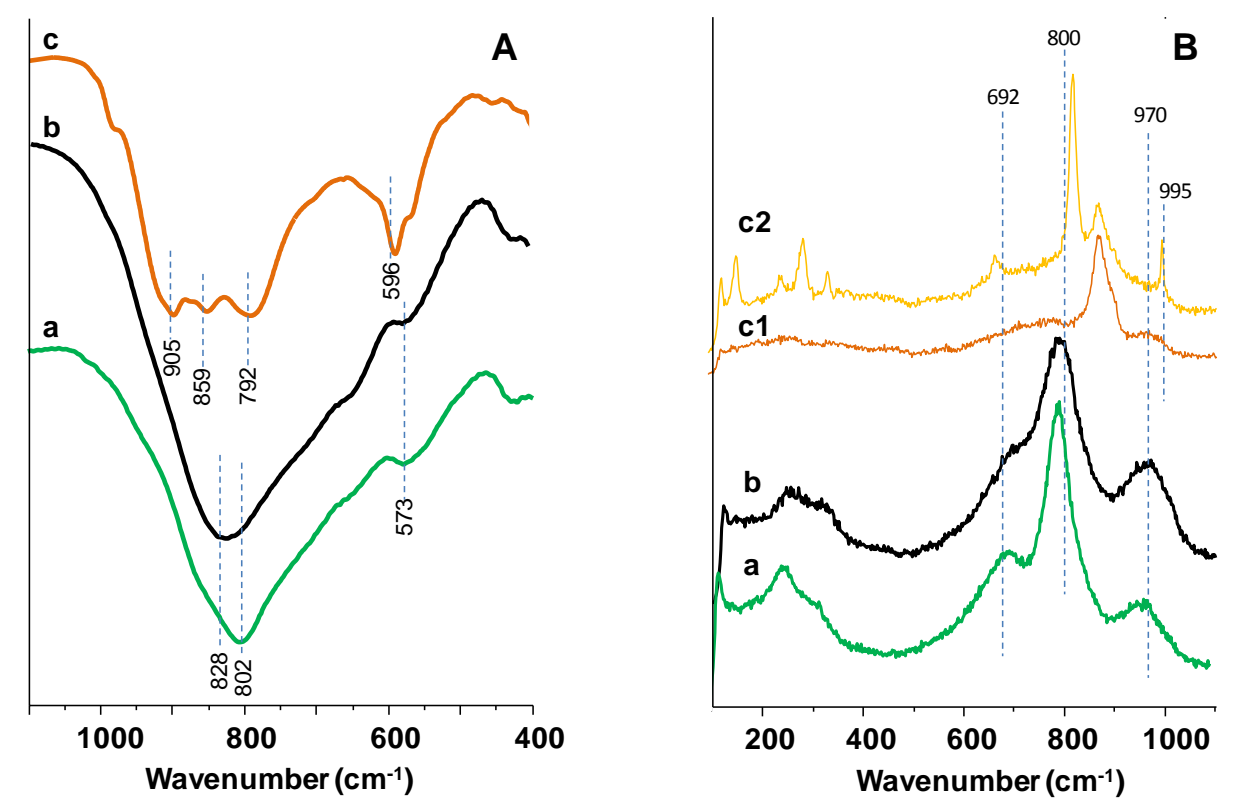

Figure 3.2.2. FTIR spectra (A) and Raman spectra (B) of fresh catalysts: a) WV-2, b) W-V-Nb, c) Mo-V-(W).

The acid characteristics of catalysts have been investigated by means of TPD of adsorbed ammonia. The $\mathrm{NH}_{3}$-TPD profiles of catalysts are shown in Fig. 3.2.3,B and summarized in Table 3.2.1. All samples show desorption peaks at approximately $200-220^{\circ} \mathrm{C}$ and ca. $350^{\circ} \mathrm{C}$, indicating the presence of both medium and strong acid sites.

On the other hand, from the $\mathrm{NH}_{3}$-desorption profile, in $\mathrm{MoV}(\mathrm{W})$ catalyst it is clear the almost complete lack of strong acid sites (with desorption temperature $>250^{\circ} \mathrm{C}$ ) in comparison to both WV-2 and WVNb-1 samples. Moreover, when considering the number of acid sites per unit weight, WVNb-1 catalyst shows an amount of sites (i.e., $192 \mu \mathrm{mol}_{\mathrm{NH} 3} \mathrm{~g}^{-1}$ ) higher than in WV-2 or $\mathrm{MoV}(\mathrm{W})$ catalysts. However, when considering the surface area of catalysts, the three samples show a similar density of acid sites, although it decreases as follows: WV-2 $>$ MoV $(W)>W V N b-1$. Figure 3.2.3 (A) shows the $\mathrm{H}_{2}$-TPR profiles of catalysts. A small peak is observed for all samples in the $500-600^{\circ} \mathrm{C}$ temperature range, which should correspond to the reduction of $\mathrm{V}$-atoms, as previously discussed. In addition to this, a peak at high temperature, which shifts depending on 
the catalyst composition, is also observed. This second peak can be related to the reduction of the rest of elements.
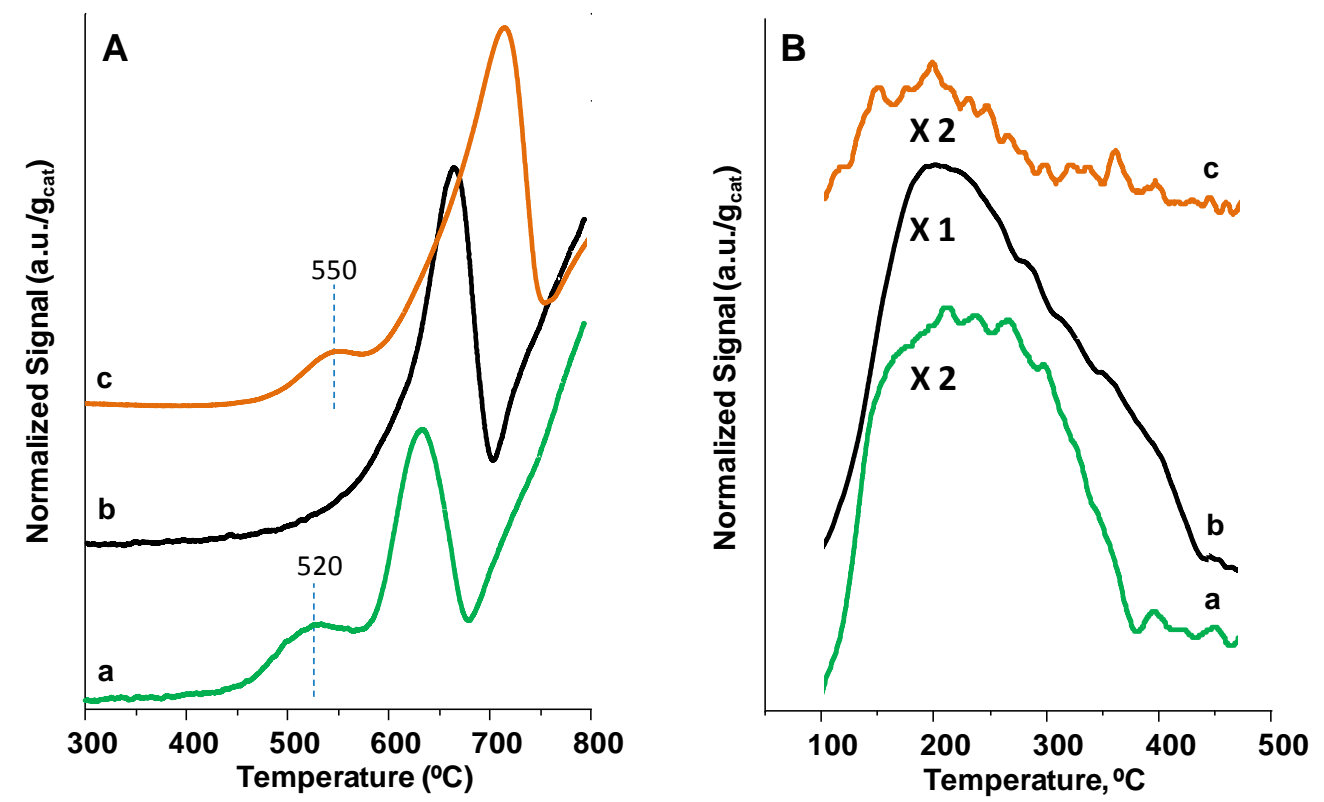

Figure 3.2.3. $\mathrm{H}_{2}-\mathrm{TPR}$ patterns $(\mathrm{A})$ and TPD- $\mathrm{NH}_{3}$ patterns (B) of catalysts: $\mathrm{a}$ ) $\left.\left.\mathrm{WV}-2, \mathrm{~b}\right) \mathrm{WVNb}-1, \mathrm{c}\right) \mathrm{MoV}(\mathrm{W})$.

The valence state of constituent elements was studied by XPS. The effect of $V$ loading on the $V$ valence state in $\mathrm{W}$-V based catalysts was discussed previously [1] and in the previous section. The XPS results are summarized in Table 3.2.2, while Fig. 3.2.4 shows the V2p and W4f bands. The $\mathrm{V} / \mathrm{W}$ ratio on the surface of WV-2 and WVNb-1 (ca. 0.1 and 0.06 ) is lower than that observed in bulk catalysts (ca. 0.12 in both samples, Table 3.2.1). On the other hand, the W/Mo ratio on the surface of $\operatorname{MoV}(\mathrm{W})$ (ca. 0.15 ) is similar to that observed in the bulk of catalyst (ca. 0.13 , Table 3.2.1). However, differences in the oxidation state of each element are observed depending on the catalyst composition. Thus, $\mathrm{V}^{4+}(\mathrm{BE}=516.3 \mathrm{eV})$ and $\mathrm{V}^{5+}(\mathrm{BE}=517.2 \mathrm{eV})$ are mainly observed in the catalysts, both in fresh and spent ones, except for WV-2 fresh sample in which the presence of $\mathrm{V}^{4+}$ is mainly shown. Moreover, the $\mathrm{V}^{4+} / \mathrm{V}^{5+}$ ratio on the catalyst surface is higher in Mo-V-(W) catalyst. Overall, it is remarkable the consistent change of the V-oxidation state in W-V compared 
to $\mathrm{W}-\mathrm{V}-\mathrm{Nb}$ (fresh vs. spent samples, respectively). It is clear that niobium plays a pivotal role in stabilizing the oxidation state of vanadium and it might be one of the main reasons that make $\mathrm{W}$ V-Nb a more stable catalysts than W-V -vide infra-.

\section{Table 3.2.2. XPS results of fresh and used catalysts}

\begin{tabular}{|c|c|c|c|c|c|c|c|c|}
\hline \multirow[t]{2}{*}{ Sample } & \multirow{2}{*}{$\frac{w 4 f 7 / 2^{a}}{w^{6+}}$} & \multicolumn{3}{|c|}{$V 2 p 3 / 2^{b}$} & \multirow{2}{*}{$\frac{\mathrm{Nb} 3 \mathrm{~d} 5 / 2^{\mathrm{b}}}{\mathrm{Nb}^{5+}}$} & \multicolumn{2}{|c|}{$\operatorname{Mo3d} 5 / 2^{b}$} & \multirow{2}{*}{$\begin{array}{c}\mathrm{W}: \mathrm{V}: \mathrm{O}: \mathrm{Nb}: \mathrm{Mo} \\
\text { Surface atomic ratio }\end{array}$} \\
\hline & & $\mathrm{v}^{3+}$ & $\mathrm{v}^{4+}$ & $\mathrm{v}^{5+}$ & & $\mathrm{Mo}^{5+}$ & $\mathrm{Mo}^{6+}$ & \\
\hline $\begin{array}{l}\text { W-V } \\
\text { (fresh) }\end{array}$ & $35.5(1.6)$ & $\begin{array}{c}515.5 \\
(7 \%)\end{array}$ & $\begin{array}{l}516.7 \\
(93 \%)\end{array}$ & -- & -- & -- & & 28.4: 2.7: 68.9: $0: 0$ \\
\hline $\begin{array}{c}\text { W-V } \\
\text { (spent) }\end{array}$ & $35.6(1.4)$ & & $\begin{array}{l}516.2 \\
(20 \%)\end{array}$ & $\begin{array}{l}517.3 \\
(80 \%)\end{array}$ & -- & -- & & 29.8: 2.9: 67.2: $0: 0$ \\
\hline $\begin{array}{l}\text { W-V-Nb } \\
\text { (fresh) }\end{array}$ & $36.1(1.6)$ & & $\begin{array}{l}516.4 \\
(21 \%)\end{array}$ & $\begin{array}{l}517.4 \\
(79 \%)\end{array}$ & $\begin{array}{c}207.5 \\
(100 \%)\end{array}$ & -- & & 27.3: $1.7: 66.3: 4.5: 0$ \\
\hline $\begin{array}{l}\text { W-V-Nb } \\
\text { (spent) }\end{array}$ & $36.0(1.6)$ & & $\begin{array}{c}516.5 \\
(24.3 \%)\end{array}$ & $\begin{array}{c}517.5 \\
(75.7 \%)\end{array}$ & $\begin{array}{c}207.5 \\
(100 \%)\end{array}$ & -- & & 25.4: 2.1: $67.7: 4.8: 0$ \\
\hline $\begin{array}{c}\text { Mo-V- } \\
\text { (W) } \\
\text { (fresh) }\end{array}$ & $35.2(1.6)$ & & $\begin{array}{c}516.6 \\
(43.4 \%)\end{array}$ & $\begin{array}{c}517.6 \\
(56.6 \%)\end{array}$ & & & $\begin{array}{c}233.1 \\
(100 \%)\end{array}$ & 3.9: 4.4: 65.8: $0: 25.8$ \\
\hline
\end{tabular}

In the case of tungsten, $\mathrm{W}^{6+}$ atoms (in the $35.6-36.2 \mathrm{eV}$ range) are observed in the three catalysts; although, different binding energies were registered, probably as a consequence of different W atoms environment. $\mathrm{Nb}^{5+}(\mathrm{BE}=206.6 \mathrm{eV}$, in $\mathrm{W}-\mathrm{V}-\mathrm{Nb})$ and $\mathrm{Mo}^{6+}(\mathrm{BE}=232.5 \mathrm{eV}$, in $\mathrm{MoV}(\mathrm{W})$ sample $)$ are the only species observed for these elements. The presence of $\mathrm{Nb}^{5+}$ in $\mathrm{WVNb}-1$ seems to stabilize $\mathrm{V}^{5+}$ ions in the fresh sample, which instead is the minor species in the $\mathrm{Nb}$-free catalyst (i.e., in $\mathrm{W}-\mathrm{V}$ ). Moreover, no change in the $\mathrm{V}^{4+} / \mathrm{V}^{5+}$ ratio of $\mathrm{WVNb}-1$ was observed in the spent catalyst. On the other hand, the presence of $\mathrm{V}$ species stabilizes both $\mathrm{Mo}^{6+}$ and $\mathrm{W}^{6+}$ in $\mathrm{MoV}(\mathrm{W})$. 

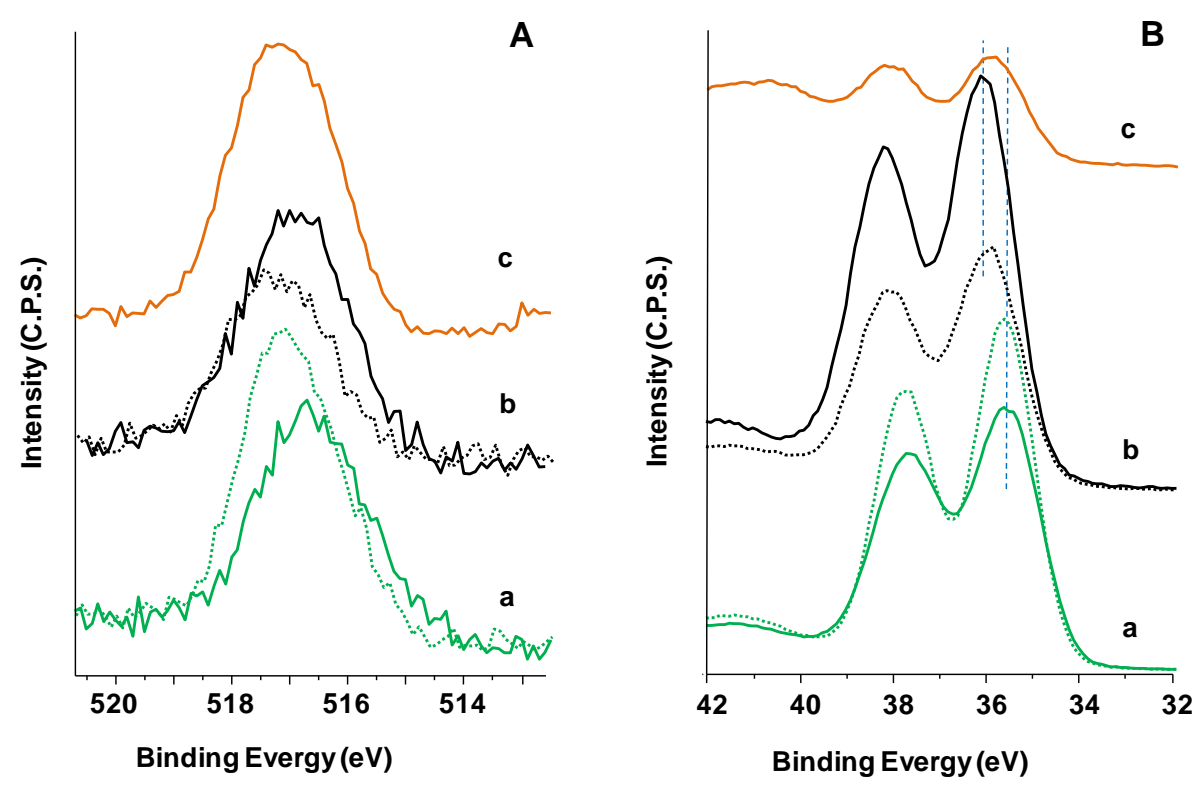

Figure 3.2.4. X-ray photoelectron spectra of $A)$ V2P and B) W4f transitions in fresh (continue line) and spent (dashed lines) catalysts: (a) W-V, (b) W-V-Nb, (c) Mo-V-(W)

\subsubsection{Lab-scale reactor tests}

In order to examine the catalytic activity of WVNb-1, the inlet feed composition was changed; for each oxygen-to-glycerol ratio value, the catalytic performance was analyzed in the temperature range $260-410^{\circ} \mathrm{C}$. Specifically, Figure 3.2 .5 (Left) shows the catalytic results obtained at $265^{\circ} \mathrm{C}$, where the maximum acrylic acid yield was registered (however, analogous trends were obtained for the other temperatures examined). In this experiment both the glycerol molar content in feed (6\%) and the water content (40\%) were kept constant; oxygen and inert gas ( $\mathrm{He}$ ) molar contents were changed so as to satisfy both the desired feed composition and the pursued residence time. The latter was always set constant to $0.15 \mathrm{~s}$. 

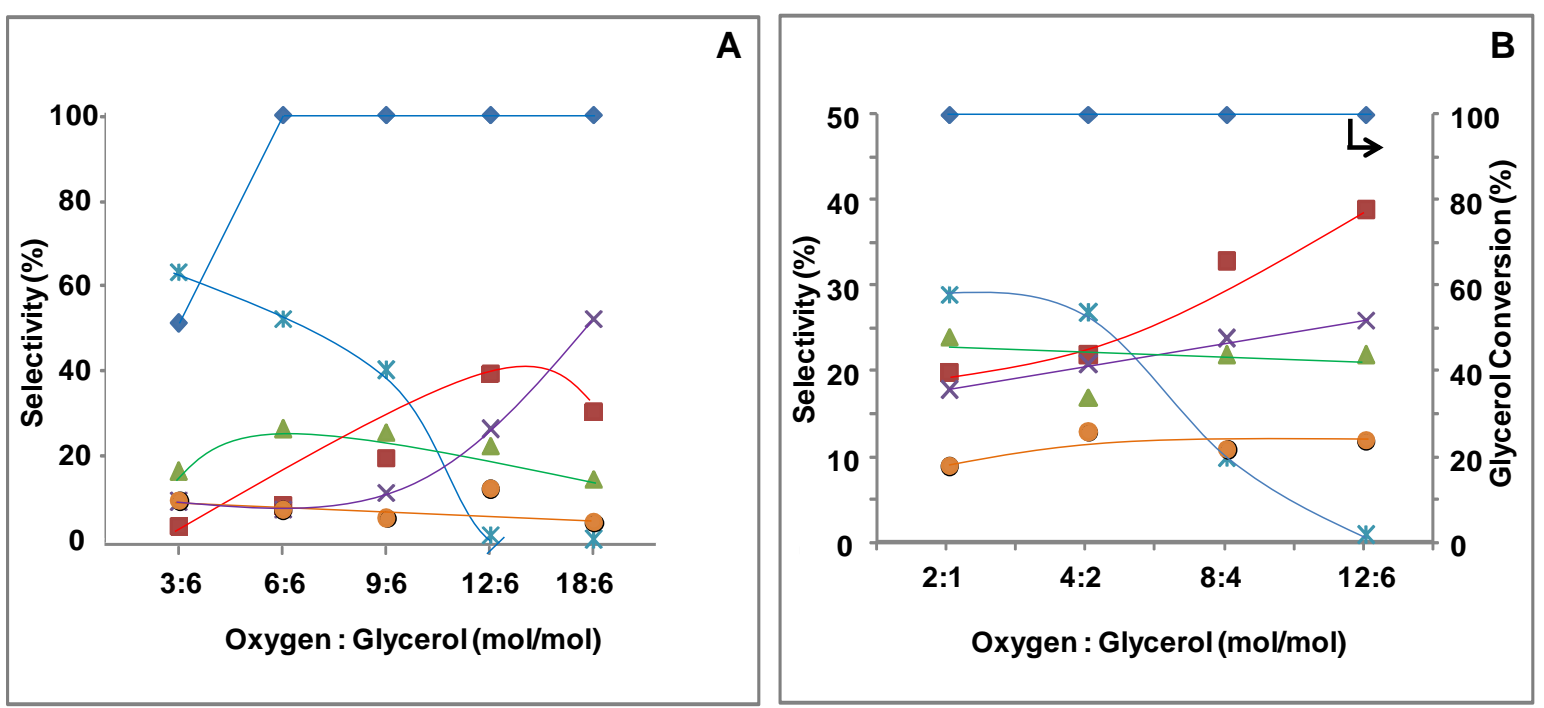

Figure 3.2.5. Glycerol oxidehydration on W-V-Nb catalyst. A): Variable oxygen-to-glycerol ratio; B) Constant Oxygen-toGlycerol molar ratio (equal to 2). Symbols: Acrylic Acid ( $\square$ ), Acrolein ( $\Delta$ ), COx (X), Heavy compounds (*), Others ( $($ ) Glycerol Conversion $(\diamond)$. Others: mainly acetaldehyde and acetic acid (in minor amounts, < 4\%: allylic alcohol, acetone, propionaldehyde, propionic acid and hydroxyacetone). Reaction conditions: temperature $265^{\circ} \mathrm{C}, 0.3 \mathrm{~g}$ of catalyst, contact time $0.15 \mathrm{~s}$, time factor $0.0039 \mathrm{~g}_{\text {cat }}$ min $\mathrm{mL}^{-1}$. Feed composition (molar \%): Oxygen and glycerol as reported in the plots, water $40 \%$, helium up to $100 \%$. Reaction time: $90 \mathrm{~min}$.

When a stoichiometric amount of oxygen and glycerol was fed (molar ratio 3:6), the glycerol conversion was close to $50 \%$ and very low selectivity to both acrolein and acrylic acid were registered. On the other hand, selectivity into heavy compounds was very high. When increasing the amount of oxygen, the heavy compound selectivity dropped in favor of selectivity to other products; the acrylic acid selectivity trend showed a peak (39\%) with the oxygen-to-glycerol molar ratio $12: 6$, finally decreasing in favor of carbon oxides with the molar ratio 18:6. Figure 3.2 .5 (right) shows the catalytic test when the oxygen-to-glycerol molar ratio was kept constantly equal to 2 (which proved to be the best ratio in the variable oxygen-to-glycerol test), but the inlet molar fraction of reactants was proportionally decreased compared to the 12:6 oxygen-to-glycerol ratio. In spite of the constant optimal ratio between the reactants, heavy compound selectivity increased mainly with lower selectivity to acrylic acid, when the molar fraction of reactants was decreased. This result was the opposite of what might be expected based on the fact that higher 
reactant loading should facilitate the condensation reaction leading to heavy compounds. This indicates that the most important parameter affecting catalytic behavior is the oxygen partial pressure; higher oxygen contents enhance the oxidation of the intermediately formed acrolein into acrylic acid, thus limiting the undesired formation of acrolein condensation into by-products. When, instead, lower oxygen molar fractions are used, irrespectively of glycerol partial pressure (i.e., at both low and high glycerol partial pressure), the kinetically preferred reaction involves the transformation of acrolein into by-products (Scheme 3.2.1). This strongly suggests that (i) the rate-determining step in the redox mechanism of acrolein transformation into acrylic acid is the oxidation of the reduced $\mathrm{V}$ sites into $\mathrm{V}^{5+}$, the latter being the species involved in the aldehyde oxidation; and (ii) the surface concentration of the oxidizing species is thus affected by oxygen partial pressure.

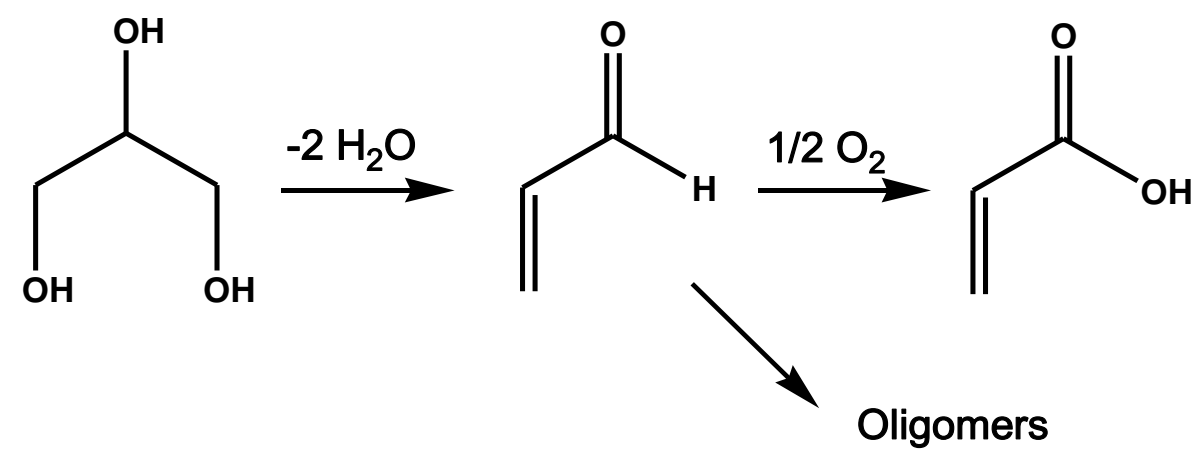

Scheme 3.2.1. Competitive reactions in the transformation of the intermediately formed acrolein.

On the other hand, if the partial pressure of oxygen is too high, the selectivity to acrylic acid decreases, with a concomitant increase in carbon oxides. These findings make it possible to draw an important conclusion: i.e., in order to minimize the undesired competitive reaction of heavier compounds formation - likely catalyzed by the same acid sites which are also required for the glycerol dehydration step - the crucial factor is the development of a steady-state showing a controlled amount of oxidizing sites on the catalyst surface. 
Generally speaking, it is important to underline that the reported variations of both acrolein and acrylic acid selectivities might be affected by other unrevealed phenomena masked by the total glycerol conversion; on the other hand, even though conversion is complete, consecutive reactions still are affected by contact time and therefore selectivity is also affected.

Figure 3.2.6 compares the productivity into acrolein + acrylic acid for the $\mathrm{W}-\mathrm{V}$ catalyst [1] and for the $\mathrm{W}$ - $\mathrm{V}-\mathrm{Nb}$ catalyst under non-optimized reaction conditions (see Chapter 2.4), with the productivity achieved under the conditions shown in this chapter, and with results reported in the literature as well.

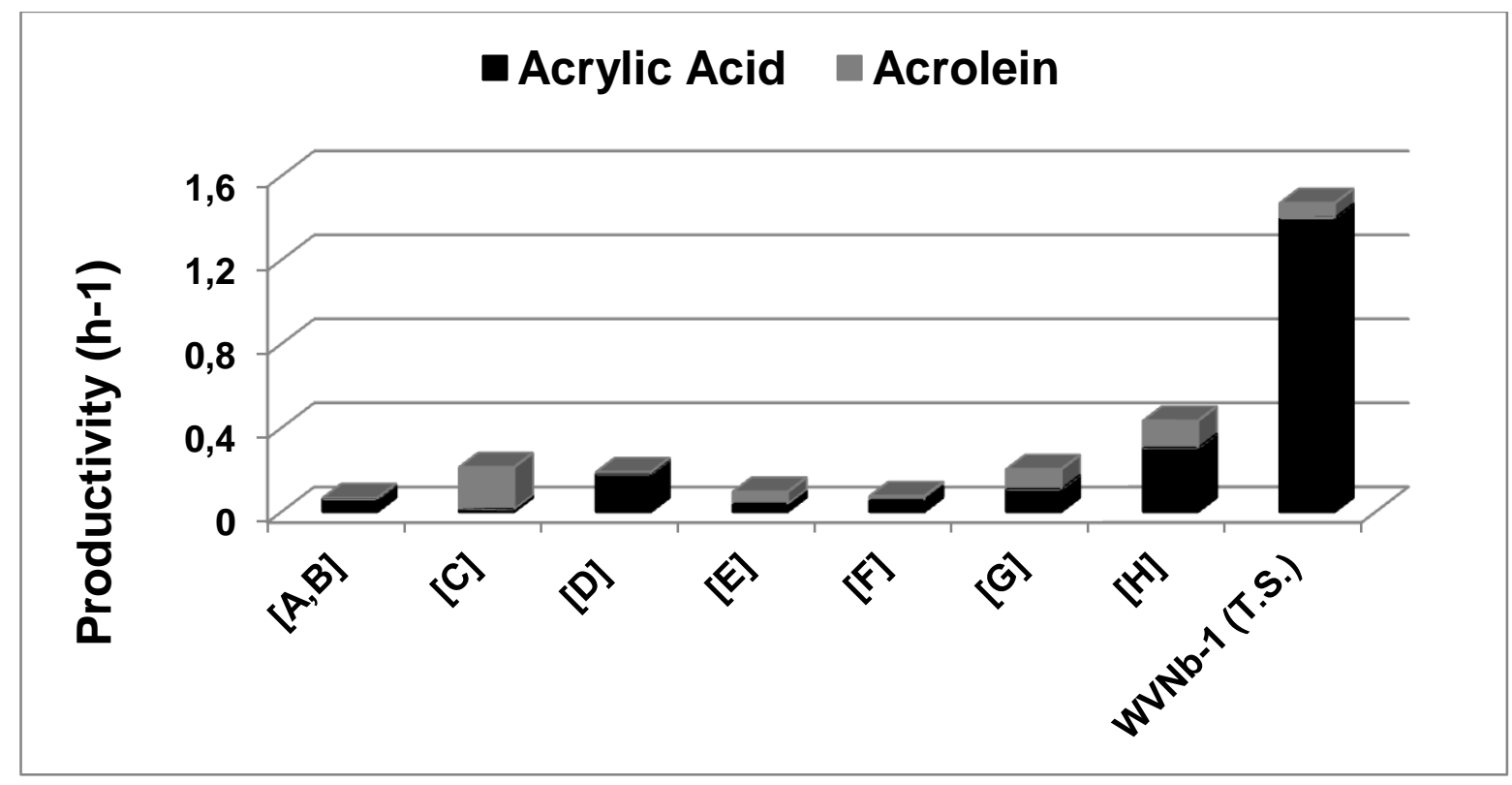

Figure 3.2.6. Comparison of acrylic acid ( $\square$ ) and acrolein ( $\square$ ) productivities reported in the literature for glycerol oxidehydration reaction (references in brackets), with the best performance obtained with W-V-Nb catalyst in the timeon-stream test (W-V-Nb T.S.) reported in this study (acrylic acid yield 50.5\%, acrolein yield 3.3\%, total glycerol conversion, Figure 3.2.7). Explanation A) J.L. Dubois et al, Eur. Patent 1874720, 2006, assigned to Arkema France; B) J.L. Dubois, WO Patent, 2007/090991; WO Patent, 2008/007002, assigned to Arkema France; C) F. Wang et al., J. Catal. 268 (2009) 260-267; D) F. Wang et al., J.-F. Devaux, W. Ueda, Catal. Today 157(2010) 351-358; E) J. Xu et al, ChemSusChem 3 (2010) 1383-1389; F) M.D. Soriano et al., Green Chem. 13 (2011) 2954-2962; G) A. Witsuthammakul et al, Appl. Catal. A 413-414 (2012) 109-116; H) Figure ; I) C.F.M. Pestana et al, J. Braz. Chem.Soc. 24 (2013) 100-105.

The productivity achieved over WVNb-1 catalyst appeared to be much higher than that previously reported, and also much better than that reported for other catalytic systems and for the two- 
catalyst in-series reactor configuration, which is the alternative approach proposed in literature. Indeed, the best value achieved, of approximately $1.6 \mathrm{~h}^{-1}$, is quite significant for industrial processes aimed at the synthesis of bulk chemicals or intermediates. Overall, some of the catalysts reported in literature, such as the M1-phase catalyst in reference "D" (Fig. 3.2.6), might also have similar productivities to $\mathrm{W}-\mathrm{V}-\mathrm{Nb}$, if tested under optimized reaction conditions; however, no further results have so far been published.

Figure 3.2.7 shows the catalytic behavior of WVNb-1 as a function of the time-on-stream (ToS), when using experimental conditions that made it possible to obtain the best acrylic acid yield (feed molar ratio $\mathrm{O}_{2} / \mathrm{Gly} / \mathrm{H}_{2} \mathrm{O} / \mathrm{He}=12 / 6 / 40 / 40$, temperature $265^{\circ} \mathrm{C}$, residence time $0.15 \mathrm{~s}$ ). The yields shown in figure 3.2.5 obtained after around $90 \mathrm{~min} \mathrm{ToS}$, and fit the trends shown here well; on the other hand, after ca $5 \mathrm{~h}$ ToS an inverse trend for acrolein and acrylic acid selectivities was registered.

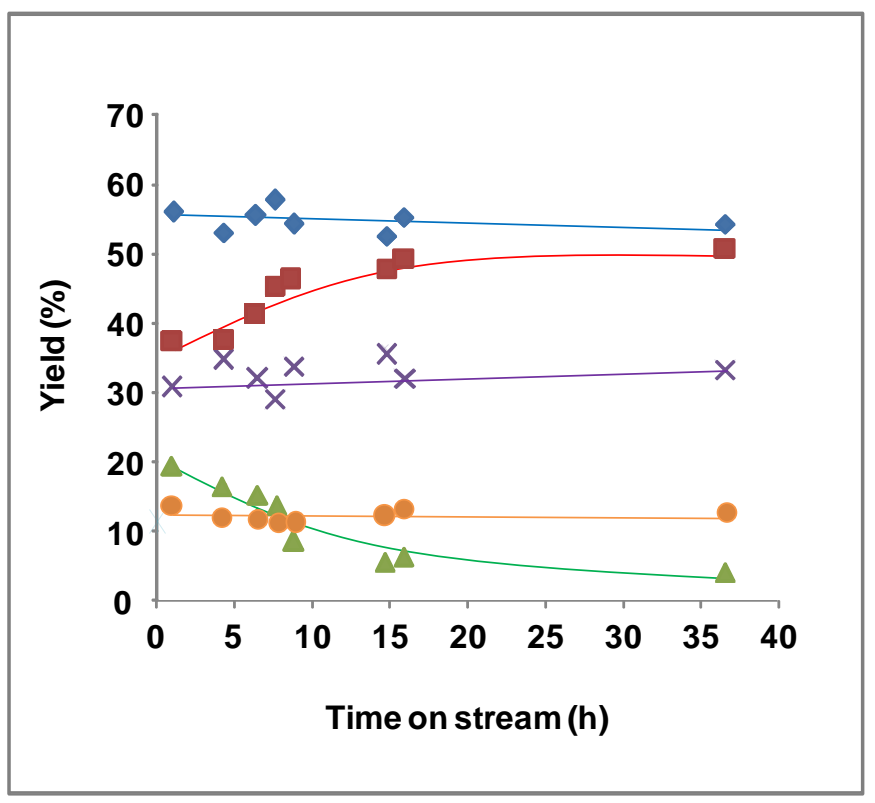

Figure 3.2.7. Glycerol oxidehydration on WVNb-1. Time-on-stream test. Glycerol conversion always complete. Symbols: Acrylic Acid $(\square)$, Acrolein $(\Delta)$, COx $(X)$, Others $(\bullet)$, A+AA $(\diamond)$. Others: mainly acetaldehyde and acetic acid (in minor amounts, < 4\%: allylic alcohol, acetone, propionaldehyde, propionic acid and hydroxyacetone). Negligible formation of heavy compounds was registered. Reaction conditions: $0.3 \mathrm{~g}$ of catalyst, contact time $0.15 \mathrm{~s}$, time factor $0.0039 \mathrm{~g}_{\text {cat }} \mathrm{min}$ $\mathrm{mL}^{-1}$. Feed composition (molar \%): glycerol $6 \%$, oxygen $12 \%$, water $40 \%$, helium $42 \%$. 
Indeed, until around $20 \mathrm{~h}$ ToS, the consecutive selective oxidation of acrolein to acrylic acid was clearly facilitated, since the acrolein selectivity decreased in favor of acrylic acid. At around $37 \mathrm{~h}$ ToS, the highest $50.5 \%$ acrylic acid yield was registered. It should be stressed that a clear kinetic relationship between acrolein and acrylic acid exists; indeed, the sum of yields to both compounds was always close to $54-55 \%$, even if the relative quantity of the two was consistently different during the time of the experiment.

The XRD and FTIR analysis on the spent WVNb-1 sample indicates that at the end of the lifetime experiment the catalyst structure was not changed (Figure 3.2.8).
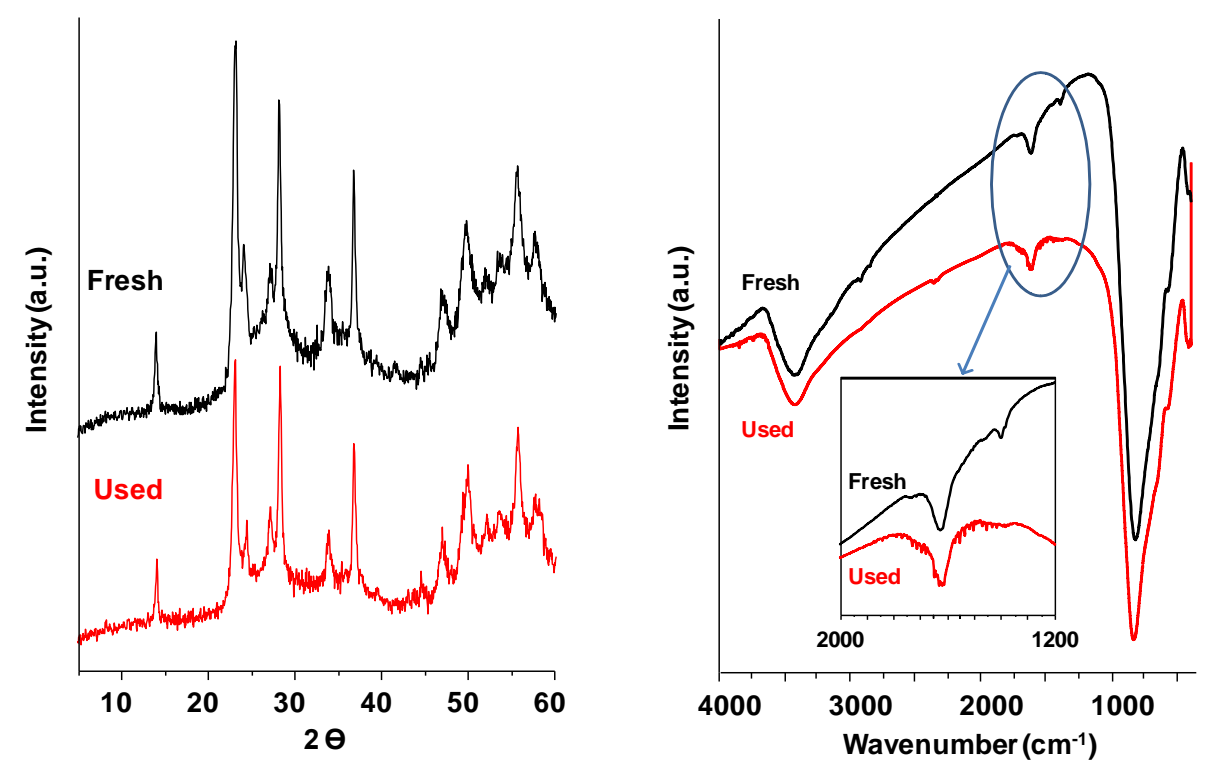

Figure 3.2.8. XRD patterns (Left) and FTIR spectra (Right) of fresh and used WVNb-1 catalyst.

In order to elucidate the phenomenon registered, the acid and redox properties of the spent catalyst were analyzed by means of methanol transformation in oxidative conditions, and compared to those of the fresh catalyst. Under the same reaction conditions used in fig. 3.2.9, at low methanol conversion ( $28 \%$ ca.) the ratio between dimethylether (DME) and formaldehyde ( $\mathrm{HCHO}$ ) yields halved from 2.4 (for the fresh catalyst) to 1.2 (for the catalyst after $37 \mathrm{~h}$ of reaction time). This finding is an important evidence that stronger acid sites were neutralized during the 
lifetime test, most likely due to coking and/or strong adsorption of intermediates or heavy compounds, as highlighted by FTIR spectra of spent catalyst reported in fig. 3.2.8. However, small modifications (due to the presence of different crystalline or amorphous surface structures) during
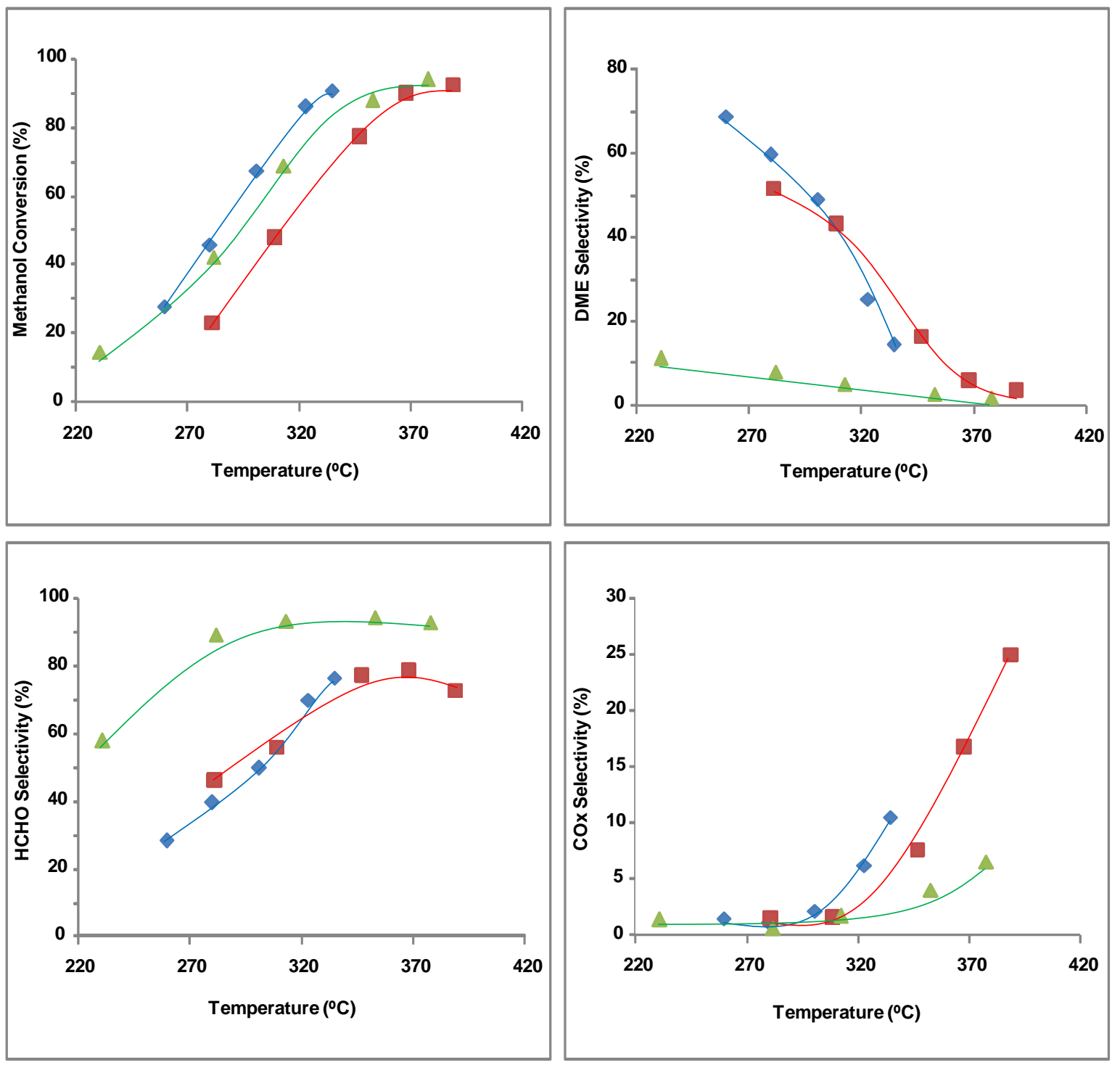

Figure 3.2.9. Oxidative transformation of methanol on catalysts WVNb1 $(\diamond), W V-2(\square)$ and $\operatorname{MoV}(W)(\Delta)$. Reaction conditions for WVNb-1 and WV-2: $0.1 \mathrm{~g}$ of catalyst, contact time $0.06 \mathrm{~s}$, time factor $1^{*} 10^{-3} \mathrm{~g}_{\text {cat }} \mathrm{min} \mathrm{mL}^{-1}$. Feed composition (molar \%): methanol 6\%, oxygen 13\%, nitrogen $81 \%$. Reaction conditions for MoV(W): $0.2 \mathrm{~g}$ of catalyst, contact time $0.12 \mathrm{~s}$, time factor $2 * 10^{-3} \mathrm{~g}_{\text {cat }} \operatorname{min~} \mathrm{mL}^{-1}$. Feed composition (molar \%): methanol 6\%, oxygen $13 \%$, nitrogen $81 \%$. 
the 5-to-20 $\mathrm{h}$ tos cannot be completely ruled out. The formation of more active amorphous structures is well known to occur on our Mo-V-(W) catalysts - which are similar to those typically used to selectively oxidize acrolein into acrylic acid [114-116] - and it is not possible to rule out the possibility that a similar phenomenon may occur on WVNb-1. Figure 3.2 .9 show the results obtained when methanol was made to react in the presence of oxygen on $\mathrm{W}-\mathrm{V}-\mathrm{Nb}$ and $\mathrm{W}-\mathrm{V}$ catalysts. As a general trend, at low temperatures the formation of DME was faster than its oxidation into $\mathrm{HCHO}$ (higher $\mathrm{DME} / \mathrm{HCHO}$ ratio); when the temperature was increased, the DME/HCHO ratio decreased.

High temperatures led to both decomposition and total oxidation, thus increasing the overall carbon oxide selectivity, mainly carbon monoxide, through $\mathrm{HCHO}$ decomposition. Minor amounts of dimethoxymethane and methylformiate also formed.

When comparing the catalytic behavior of WV-2 and WVNb-1, it is possible to see that with the latter sample there was a much higher selectivity to DME, in accordance with its higher acid strength. With the increase in temperature, the reaction of methanol oxidehydrogenation to $\mathrm{HCHO}$ kinetically prevailed over the etherification reaction; lastly, at high methanol conversion (90\%), $\mathrm{HCHO}$ selectivity was almost identical for the two catalysts. Moreover, it is interesting to note that different temperatures were needed to achieve similar conversions: for the WVNb-1 catalyst, $90 \%$ methanol conversion appeared at $330-335^{\circ} \mathrm{C}$, whereas for the $\mathrm{WV}-2$ catalyst the same conversion was achieved at $380^{\circ} \mathrm{C}$. This difference is attributable to a higher specific surface area of the $\mathrm{Nb}$-containing sample, which is one of the main features of this catalyst compared to the WV-2; moreover, the faster reaction of methanol etherification may also contribute to the higher activity registered. CO selectivity also was slightly different for the two catalysts, respectively $10 \%$ for $W V N b-1$ and $16 \%$ for $W V-2$ (at the same methanol conversion of $90 \%$ ). Whereas, the lack of strong acid sites in $\mathrm{Mo}_{5} \mathrm{O}_{14}$-type bronze, $\mathrm{MoV}(\mathrm{W})$, is also evident from the 
catalytic behavior shown in methanol oxidation (Fig. 3.2.9); indeed, the acid-catalyzed route to DME was very low. On the other hand, this system proved to be very selective in the oxidation of methanol to $\mathrm{HCHO}$ : a maximum aldehyde selectivity equal to $93 \%$ was registered at $87 \%$ methanol conversion (at $350^{\circ} \mathrm{C}$ ). At low temperatures, we also observed the formation of dimethoxymethane (not reported in figure 3.2.9), which may derive from the acetalization of $\mathrm{HCHO}$ with the unconverted methanol. On the other hand, because of the low specific surface area of this catalyst, in order to obtain methanol conversions close to those obtained by both WV2 and WVNb-1 catalysts, higher contact time (0.12 s) was needed, as compared to that used with the latter systems (0.06 s).

The differences observed between the catalysts, particularly between the HTBs and MoV(W), well explain the catalytic behavior obtained for glycerol oxidehydration (Figure 3.2.10).

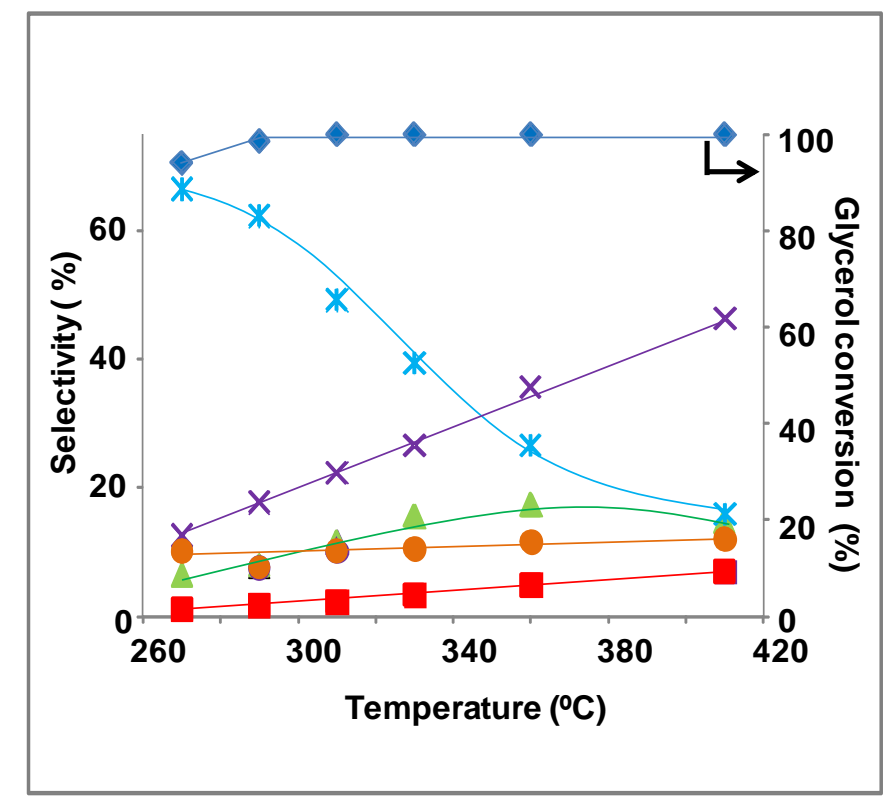

Figure 3.2.10. Glycerol oxidehydration on Mo-V-(W) catalyst. Symbols: Acrylic Acid ( $\square)$, Acrolein ( $\Delta$ ), COx (X), Heavy compounds $(*)$, Others $(\bullet)$, Glycerol Conversion $(\diamond)$. Others (decreasing order of selectivity): acetaldehyde, acetic acid, allylic alcohol, propionaldehyde, acetone, hydroxyacetone, unknown compounds. Reaction conditions: $0.3 \mathrm{~g}$ of catalyst, contact time $0.15 \mathrm{~s}$, time factor $0.0039 \mathrm{~g}_{\text {cat }}$ min $\mathrm{mL}^{-1}$. Feed composition (molar \%): $2 \%$ glycerol, $4 \%$ oxygen, $40 \%$ water, $54 \%$ helium.

Indeed, when glycerol was made react on this catalyst, very high selectivity to heavier compounds was registered, since the catalyst does not have the acid properties needed to quickly and 
selectively dehydrate glycerol into acrolein. The intermediately formed acrolein may react in a similar way with glycerol to form other cyclic ethers, as shown in Scheme 3.2.2; indeed, the formation of these ethers was confirmed by means of ESI-MS analysis of the reaction mixture. When the temperature was raised, the ketal selectivity decreased mainly in favor of COx and acrolein formation; on the other hand, the acrylic acid selectivity remained low, even if the catalyst is specifically designed for acrolein oxidation into acrylic acid. When acrolein was fed in analogous conditions (residence time $0.15 \mathrm{~s}$, temperature $360^{\circ} \mathrm{C}$ ), selectivity to acrylic acid was close to $70 \%$ at $20 \%$ acrolein conversion. This was apparently due to both the low selectivity to acrolein and the specific residence time used (optimal for glycerol dehydration on WVNb-1), which is too low to convert acrolein into acrylic acid on $\mathrm{MoV}(\mathrm{W})$ with $\mathrm{Mo}_{5} \mathrm{O}_{14}$-type structure [112].

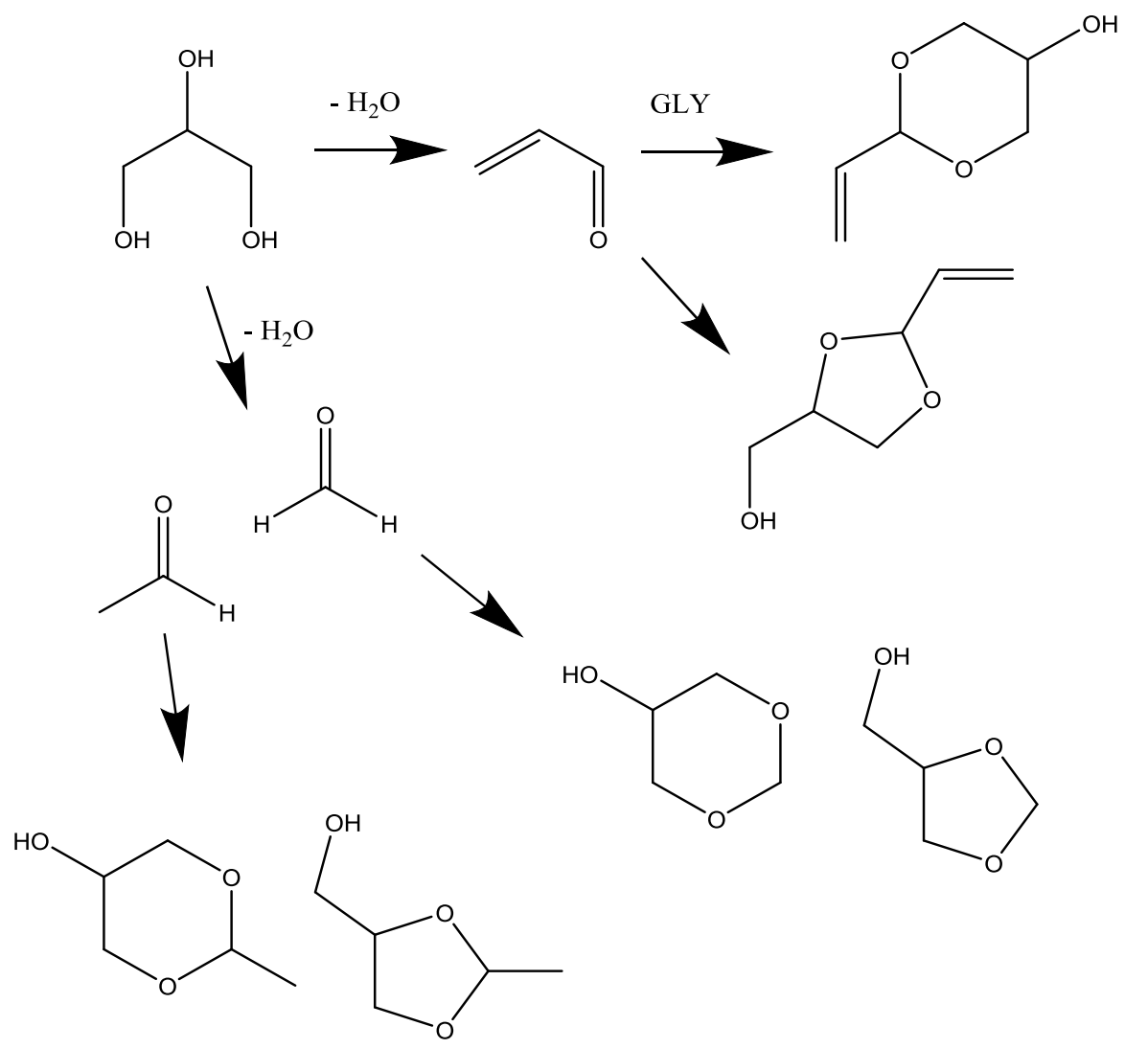

Scheme 3.2.2. Ketals formation pathways as by-products of the glycerol oxidehydration reaction. 
Finally, acrolein was made react on the WVNb-1 and WV-2 (Figure 3.2.11) so as to better understand the redox ability to selectively oxidize the aldehyde produced as intermediate along the glycerol oxidehydration process. Under the same working conditions (the optimal ones for WVNb-1), the two catalysts showed important differences: the WV-2 sample exhibited both a lower acrolein conversion than WVNb-1 (which may be explained by taking into account both the higher specific surface area of this latter sample) and a lower selectivity into acrylic acid, with higher selectivity to heavy compounds. Therefore, it may be suggested that the improved acid features of this latter sample may help the desorption of acrylic acid, thus limiting its combustion. On the other hand, the low selectivity to acrolein oligomers suggests that the aldehyde oxidation into acrylic acid is much faster than the side acid-catalyzed reactions, which may also be related to the high concentration of $V$ sites. The latter, in turn, is greatly affected by oxygen partial pressure (see above), but a role of $\mathrm{Nb}$ ions in facilitating the re-oxidation of reduced $\mathrm{V}$ sites may not be ruled out. Finally, it is of interest to underline that the productivity of acrylic acid from acrolein is much higher for WVNb-1 than for $\operatorname{MoV}(\mathrm{W})$, making this mixed-oxide catalyst quite interesting for the latter reaction, as well.

Overall, it seems evident that the better catalytic performance for glycerol oxidehydration of WVNb-1 has to be assigned to its optimal equilibrium between acid and redox properties which allows reaching a steady state were glycerol is fast dehydrated into acrolein and the latter intermediate is efficiently transformed into the acid monomer. 


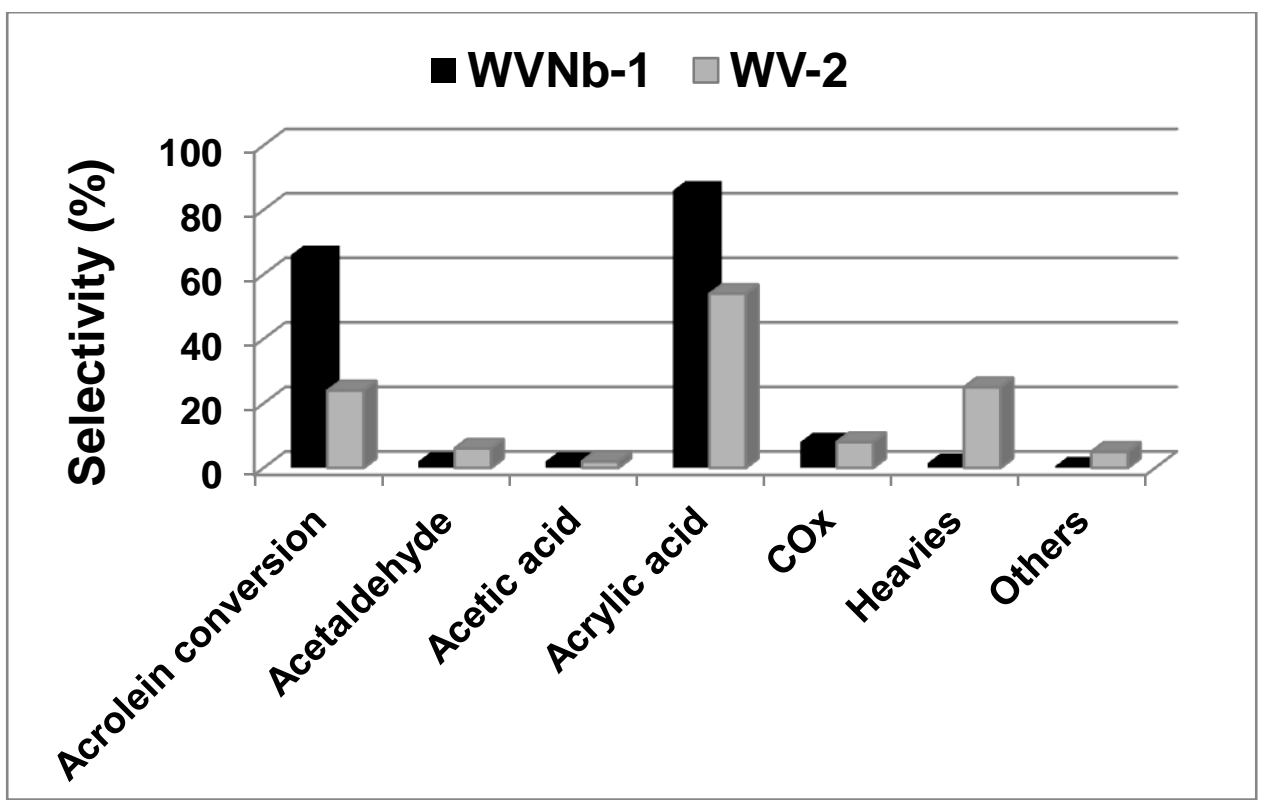

Figure 3.2.11. Acrolein conversion and selectivity to products on $\mathrm{W}-\mathrm{V}-\mathrm{Nb}(\square)$ and $\mathrm{W}-\mathrm{V}(\square)$ catalysts. Reaction conditions: $0.3 \mathrm{~g}$ of catalyst, contact time $0.15 \mathrm{~s}$, time factor $0.0039 \mathrm{~g}_{\text {cat }} \mathrm{min} \mathrm{mL}^{-1}$. Feed composition (molar \%): $2 \%$ acrolein, $4 \%$ oxygen, $40 \%$ water, $54 \%$ helium.

\subsubsection{Conclusions}

The studies carried out on both $\mathrm{HTBs}$ and $\mathrm{Mo}_{5} \mathrm{O}_{14}$-type oxides allow drawing important conclusions on the relation between reaction conditions and catalyst features needed by multifunctional oxides for one-pot oxidehydration starting from glycerol. The consecutive oxidation step must be fast, compared to the dehydration step, in order to avoid the formation of heavy compounds generated by both ketal formation and oligomerization reactions that take place from the intermediately formed unsaturated aldehyde. For this reason, the latter being achieved by using oxygen partial pressures well above that needed for the stoichiometric oxidehydration of glycerol into acrylic acid, strongly oxidizing conditions are necessary with the best-performing WVNb-1 catalyst. The latter is characterized by high surface area and high concentration of stronger acid sites, properties which on the one hand are important for an efficient dehydration of glycerol into acrolein, but on the other hand might lead to the formation of undesired by-products. Under selected reaction conditions, an outstanding productivity to acrolein + acrylic acid close to $1.6 \mathrm{~h}^{-1}$ with a yield to acrylic acid as high as $50.5 \%$ were achieved. 


\subsubsection{Notes on reaction conditions and process safety}

Before concluding this chapter, a final note must be added about the reaction conditions used to reach the improved catalytic performance of the HTBs, that is high partial pressure of oxygen. Generally speaking, in oxidation processes particular attention has to be paid to the flammability of the gas mixtures present all along the process, i.e. not only in the reactor but also up-stream and down-stream. So as to avoid explosions, oxidants (e.g. oxygen, chlorine etc.) and combustive agents (e.g. organic compounds, ammonia etc.) in the gas phase must be present in relative molar ratios that guarantee their non-flammability. In order to avoid this problem, it is mandatory to work outside the explosion limits. The latter vary according to the nature of the chemical species involved as well as the presence of diluting inert gases (e.g. nitrogen, water etc.). A very important safety parameter is the Minimum Oxygen Concentration (MOC) since it represents the limiting concentration of oxygen below which combustion is not possible, independently of the concentration of fuel [117]. Although, because of the limited availability of data concerning the specific gaseous mixture of interest, it is good practice to consider the MOC close to 7-8\%; indeed, with few exceptions -e.g. acetylene, which MOC is $6.2 \%$ - a great number of organic compounds have a MOC varying between $10 \%$ (e.g. ethylene) and $12 \%$ (e.g. propylene). For instance, ethanol's MOC is $10.5 \%$ and the one of gasoline ca. $11 \%$ [118].

In the experiments for glycerol oxydehydration reported above and in the following chapters, the best catalytic performance was actually registered for oxygen-to-glycerol molar ratio 12:6. Therefore, it might be that under such reaction conditions, the gaseous mixture fed to the reactor is within the explosion limits or very close to it. So as to avoid safety problems, the lab-scale plant was designed to limit as much as possible the presence of gaseous stream potentially flammable. Particularly, glycerol was mixed with oxygen only in close proximity of the catalytic bed, ca. $1 \mathrm{~cm}$ above it: this allows a good mixing of reagents but it limits the risk of potentially explosive 
gaseous mixtures to a very restricted area of the reactor. Indeed, after the catalytic bed, taking into consideration an oxygen conversion between $50 \%$ and $90 \%$ (i.e. typical values obtained in the catalytic tests performed) the oxygen concentration is well above the MOC, guaranteeing the process safety. Another precaution is the usage of a glass reactor, which greatly limits the possible formation of sparks that might act as ignition sources (glycerol flash point $193^{\circ} \mathrm{C}$, autoignition temperature $400^{\circ} \mathrm{C}$ ). Moreover, in case of explosion, the fast increment of the gas' volume -finally translated into a sudden increment of pressure- would be limited by over pressure valves present in the lab-scale plant and connected to a vent. Finally, in case of failure of these safety systems, the small amount of organic fed (between 1 and $2 \mathrm{ml} / \mathrm{h}$ of glycerol solution with composition varying between 20 and 40 wt\%) intrinsically guarantees the lab safety.

Nevertheless, more complicated would be the scale-up of these reaction conditions at an industrial scale. First of all, a complete study on flammability ranges specific for the gaseous mixtures fed and potentially formed all along the plant should be carried out. In case that the gaseous mixtures didn't respect the flammability limits, it would be important to study alternative reaction conditions, maybe close to the optimum but not within the flammability ranges. In case the catalytic performance varied significantly under "safe working conditions" and if required by an economic study, some industrial technologies allow to work within the explosion limits. For instance, with fluidized bed reactor it is possible to work in the latter conditions although keeping the process safety [117]. Indeed, the solid particles of the catalyst interrupt the propagation of radical species in the gas phase which would lead to explosions. 


\subsection{Introduction of Molybdenum in V-substituted HTBs}

This section deals with a new class of catalysts related to the HTB phase. The aim of this research is to insert molybdenum in the HTB W-V catalyst framework. Indeed, molybdenum is well known in oxidation catalysis (e.g. it is the main component of industrial catalysts for acrolein oxidation) and its redox properties were thought to potentially lead to an improvement in the oxidation-step of acrolein into acrylic acid; hence, to the overall selectivity of acrylic acid from glycerol.

The best performing catalyst made it possible to reach yields into the acid monomer up to $51 \%$, as well as stable oxidizing properties on a wide range of temperature. Also, interesting changes were observed in the oxides' structures; the W-Mo-V catalysts here presented are revealed to be complex oxides constituted by a hexagonal- $\mathrm{WO}_{\mathrm{x}}$ type phase or a pseudo-crystalline phase. It is also demonstrated that the combination of the three elements is essential in order to optimize the oxidation step from acrolein to acrylic acid.

\subsubsection{Physicochemical properties of the oxides}

In order to study the influence of tungsten, molybdenum and vanadium on both the catalytic performance and the materials structure, bi-component and tri-component catalysts were synthesized, respectively as W-Mo-V and W-Mo oxides. Figure 3.3.1 shows the XRD patterns of catalysts heat-treated at $600^{\circ} \mathrm{C}$ and $800^{\circ} \mathrm{C}$ in nitrogen; for the tri-component systems with low molybdenum contents (samples WMoV-1 and WMoV-2, patterns a and b) X-ray diffraction maxima can be assigned to a hexagonal tungsten bronze (HTB) type phase. 


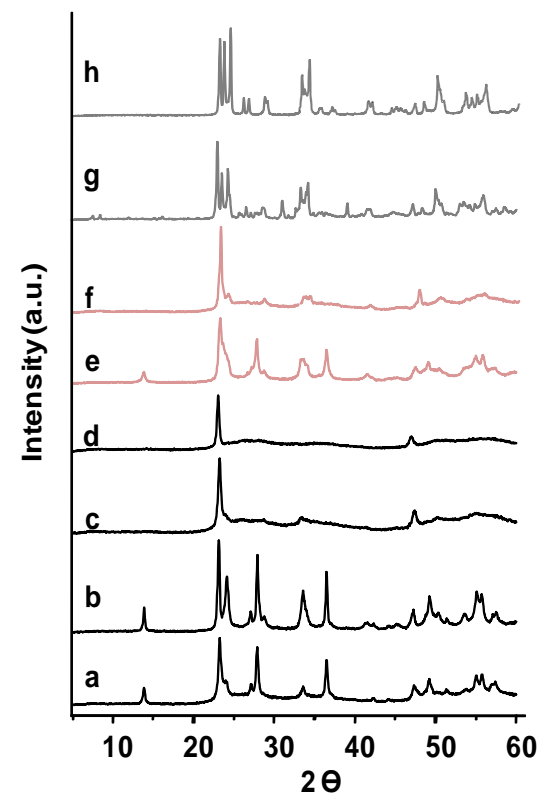

Figure 3.3.1. XRD-patterns of heat-treated oxides at $600^{\circ} \mathrm{C}$. Two samples were also heat-treated in nitrogen at $800^{\circ} \mathrm{C}$. Explanation: Catalyst precursors heat-treated at $600^{\circ} \mathrm{C}$ : a.WMoV-1, b.WMoV-2, c.WMoV-3, d.WMoV-4, e.WMo-1, f.WMo-2; g.WMoV-3[800], h.WMo-2[800].

Interestingly, crystallinity is considerably improved for the sample containing higher vanadium amount (WMoV-2), giving emphasis to the conclusion formerly drawn that highlights how vanadium has a stabilizing effect on the HTB structure [1]. By keeping the $W / V$ ratio and increasing the molybdenum amount (i.e. WMoV-3 and WMoV-4), diffraction patterns are dominated by two diffraction maxima at around $22^{\circ}$ and $46^{\circ} 2 \theta$. In addition, broad diffraction maxima appear at $2 \theta \approx 27^{\circ}, 32^{\circ}, 50^{\circ}$ and $55^{\circ}$ (Figure 3.3.1, patterns $c$ and d). These two peaks at $2 \theta$ equals to $22^{\circ}$ and $46^{\circ}$ can be attributed to the $\left(\begin{array}{lll}0 & 0 & 1\end{array}\right)$ and $\left(\begin{array}{lll}0 & 0 & 2\end{array}\right)$ planes of a bronze type frame, suggesting that these materials have a layer-type crystal structure. Indeed, these diffraction maxima can correspond to the $\left(\begin{array}{lll}1 & 0 & 0\end{array}\right)$ and $\left(\begin{array}{lll}2 & 0 & 0\end{array}\right)$ d-spacing of any structure based on the corner sharing octahedral $\mathrm{ReO}_{3}$-like framework with a basic cell parameter of about $3.8 \AA$.

Provided the ill-defined identity of the present crystal phases, the samples were further investigated by electron diffraction and high resolution electron microscopy. In agreement with XRD data, the tri-component samples WMoV-1 and WMoV-2 are constituted by crystals of the 
hexagonal phase, although bigger crystallites are observed in sample WMoV-2 (average size > 100 $\mathrm{nm}$ vs. $50-100 \mathrm{~nm}$ for WMoV-1)). For high Mo content, the HTB phase is not stabilized (WMoV-3 and WMoV-4) and samples are formed by smaller crystallites, i.e. 10-50 nm. Figure 3.3.2,a shows a typical electron diffraction ring pattern for the WMoV-3 sample. Figure 3.3.2,b shows the high resolution image of a group of crystals in which lattice fringes are observed at d-spacing of about 3.8 Å. Image contrasts illustrates very well the ill-defined periodicity along the perpendicular direction and disordered packing of structural planes is observed.

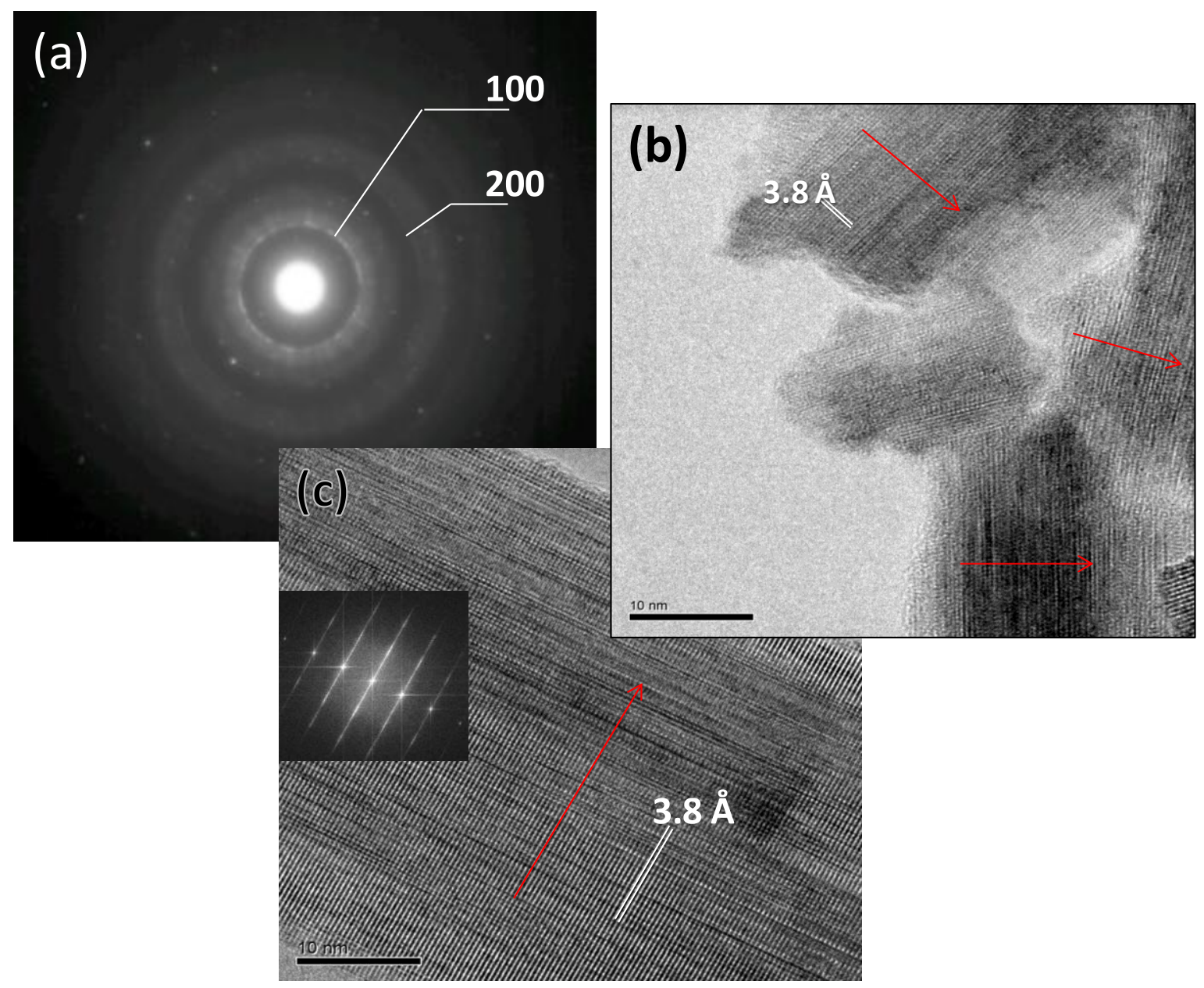

Figure 3.3.2. (a) Electron diffraction ring pattern for the WMoV-3 sample. Rings are diffuse and ill defined except for $(100)(\approx 3.8 \AA ̊$ ). (b) High resolution image showing a bunch of crystals of the WMoV-3 sample. Lattice fringes at $3.8 \AA$ can be observed. The red arrows indicate the direction along which disordered stacking is observed. (c) High resolution image of a rod-like crystal of WMo-2. Lattice planes spaced at $\sim 3.8 \AA$ can be observed as well as disordered contrast along the perpendicular direction. The corresponding Fourier Transform has been included as inset. 
This low resolved structural arrangement is consistent with the previous interpretation of the corresponding XRD pattern. In the absence of vanadium, XRD patterns show strong similarity with those of samples containing vanadium, the $\mathrm{W} / \mathrm{Mo}$ ratio playing a pivotal role in stabilizing the HTB-type phase. Figure 3.3.2 (c) shows a rod-like crystal of the WMo-2 sample. Lattice planes equally spaced at $\sim 3.8 \AA$ can be observed as well as disordered contrast along the perpendicular direction and the image contrast is very similar to that on figure 3.3.2 (b) although the average crystal size is above $100 \mathrm{~nm}$. In order to facilitate the formation of well crystallized phases and as a help in the elucidation of the nature of these materials, the same catalysts precursors were heat treated in nitrogen at $800^{\circ} \mathrm{C}$-see paragraph 2.3.1-.

XRD patterns of samples heat-treated at $800^{\circ} \mathrm{C}$, i.e. WMoV-3[800] and WMo-2[800], are also shown in Figure 3.3.1 (patterns $g$ and $h$, respectively). Both patterns reveal the formation of a monoclinic $\mathrm{WO}_{3}$-type phase. In addition, a certain amount of $\mathrm{Mo}_{5} \mathrm{O}_{14}$-type phase is also visible in the sample containing vanadium (pattern h). The WMoV-3[800] sample is formed by a $\mathrm{m}-\mathrm{WO}_{3}$ type phase as major component. The electron microscopy study, see figure figure 3.3.3 (a) shows that the well grown crystals of $\mathrm{m}-\mathrm{WO}_{3}$ type phase do not contain vanadium, the average atomic composition being $\mathrm{W}_{0.7} \mathrm{Mo}_{0.3} \mathrm{O}_{3}$. Interestingly, vanadium is segregated into the $\mathrm{Mo}_{5} \mathrm{O}_{14}$-type phase crystals which constitute the minor component of the sample and their atomic average composition is $\left(\mathrm{W}_{0.64} \mathrm{Mo}_{0.3} \mathrm{~V}_{0.03}\right)_{5} \mathrm{O}_{14}$ (figure 3.3.3 (b).

All the above results are consistent with the idea that catalysts heat-treated at $600^{\circ} \mathrm{C}$ are constituted by a matrix built up by corner sharing $\mathrm{MO}_{6}$ octahedra and distributed in orderly stacked crystal planes $(\mathrm{d} \sim 3.8 \AA \AA$ ). Inside the planes, further structural reconstruction is needed to achieve a particular structural type, as demonstrated by the ill-defined diffraction maxima as well as the disordered contrast observed in the high resolution images. 

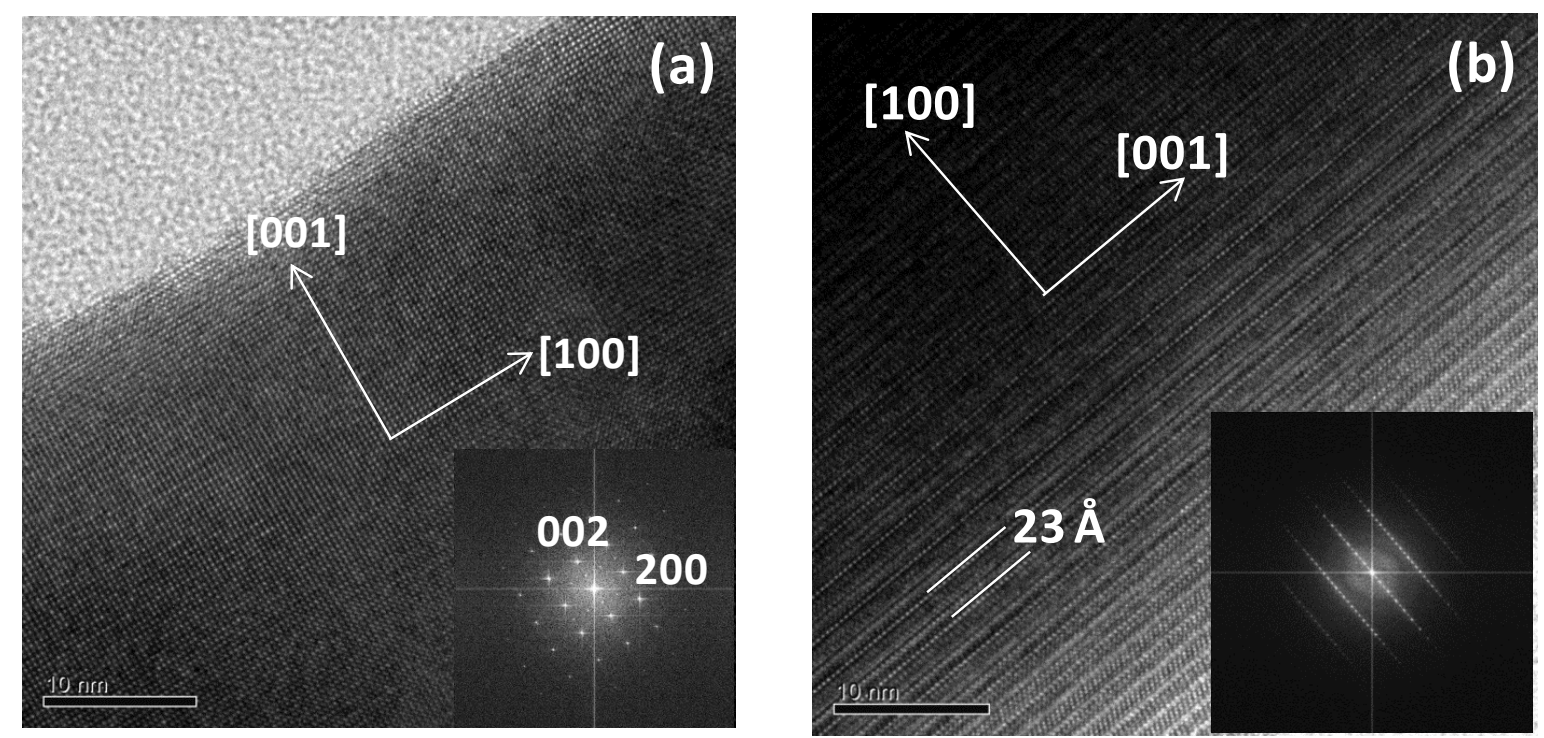

Figure 3.3.3. (a) High Resolution Image of a m-WO3 type crystal contained in the WMoV-3[800] sample. (b) High resolution image of a $\mathrm{M}_{5} \mathrm{O}_{14}$-type crystal contained in the WMoV-3[800] sample. The corresponding Fourier Transforms have included as insets.

FTIR spectra were recorded for both W-Mo and W-Mo-V catalysts; for comparison, the FTIR spectrum of WV-2 has also been reported in Figure 3.3.4, spectrum g. All the bands observed can be assigned to vibrational modes of HTB-like structures (see discussion reported in previous chapters). Therefore, strong similarity between spectra is consistent with the above structural description, whether in the HTB- or pseudo-crystalline structure. The specific surface area for all the catalysts is shown in Table 3.3.1; comparison between samples with the HTB-type structure (WMoV-1 and WMoV-2) reveal that catalyst with the higher vanadium content presents the lower BET surface area as a consequence of its higher crystallinity and bigger average crystal size.

When comparing with samples containing the pseudocrystalline phase, the higher molybdenum content allows obtaining a significant increment of specific surface area (WMoV-1 vs. WMoV-3 or WMoV-2 vs. WMoV-4) the effect being more relevant when vanadium content is higher.

When comparing with samples containing the pseudocrystalline phase, the higher molybdenum content allows obtaining a significant increment of specific surface area (WMoV-1 vs. WMoV-3 or WMoV-2 vs. WMoV-4) the effect being more relevant when vanadium content is higher. 


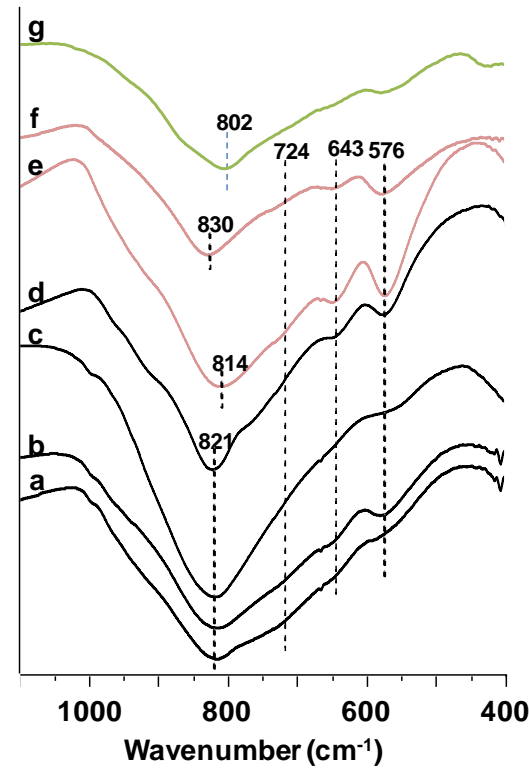

Figure 3.3.4. FTIR spectra of: a.WMoV-1, b.WMoV-2, c.WMoV-3, d.WMoV-4, e.WMo-1, f.WMo-2; g.WV-2;

A similar comparison can be done when characterizing the acid sites (Table 3.3.1); the addition of molybdenum leads to a remarkable decrease in acidity (see WMo-1 and WMo-2), both on mass and surface area basis; however, an important increase in Brфnsted acidity is observed. Similar trend is displayed for HTB-like samples (WMo-1, WMoV-1 and WVMo-2); indeed, introduction of vanadium leads to a general decrease of the total acidity (more pronounced on mass-bases) but it increases the Brфnsted-to-Lewis acid sites ratio.

\section{Table 3.3.1. Main physical-chemical features of the selected catalysts}

\begin{tabular}{|c|c|c|c|c|c|c|}
\hline \multirow[t]{2}{*}{ Sample } & \multicolumn{2}{|c|}{ Catalysts composition $\mathrm{W} / \mathrm{Mo} / \mathrm{V}^{\mathrm{a}}$} & \multirow{2}{*}{$\frac{S_{B E T}}{\left(m^{2} g^{-1}\right)}$} & \multicolumn{2}{|c|}{ TPD } & \multirow[t]{2}{*}{$B / L^{c}$} \\
\hline & (in gel) & (in catalysts) $^{\text {b }}$ & & $\mu \mathrm{mol}_{\mathrm{NH} 3} \mathrm{~g}^{-1}$ & $\mu \mathrm{mol}_{\mathrm{NH} 3} \mathrm{~m}^{-2}$ & \\
\hline WMo-1 & $1 / 0.2$ & $1 / 0.19 / 0$ & 26 & 150.9 & 5.8 & 13 \\
\hline WMo-2 & $1 / 0.6$ & $1 / 0.52 / 0$ & 13 & 47.9 & 3.7 & 18 \\
\hline WMoV-1 & $1 / 0.3 / 0.1$ & $1 / 0.22 / 0.06$ & 30 & 91.1 & 3.0 & 22 \\
\hline WMoV-2 & $1 / 0.2 / 0.2$ & $1 / 0.28 / 0.17$ & 12 & 34.8 & 2.9 & 28 \\
\hline WMoV-3 & $1 / 0.5 / 0.1$ & $1 / 0.45 / 0.04$ & 38 & 129.0 & 3.4 & 18 \\
\hline WMoV-4 & $1 / 0.5 / 0.2$ & $1 / 0.86 / 0.14$ & 22 & 114.3 & 5.2 & 20 \\
\hline
\end{tabular}

[a] Atomic ratios; referred to W equal to unity; [b] Experimental data obtain by SEM-EDS analysis. [c] Ratio between the areas of ammonia peaks relative to its adsorption (at $25^{\circ} \mathrm{C}$ ) on Brönsted $(\mathrm{B})$ or Lewis $(\mathrm{L})$ acid sites. 
On the other hand, the introduction of molybdenum in higher amounts, leading to pseudocrystalline structures (WMo-2, WMoV-3 and WMoV-4), brings about an increase in total acidity, but it depresses the presence of Brpnsted-type acid sites. These trends make it evident that the introduction of redox elements (i.e. vanadium and molybdenum) in the $\mathrm{WO}_{\mathrm{x}}$ framework plays also a role on the nature of acid sites. Overall, it is important to point out that all the mixed-oxides studied have a predominant Brpnsted acid character, therefore emphasizing the role played by these acid sites in the glycerol dehydration step [76, 77].

\subsubsection{Lab-scale reactor tests}

The catalytic behavior of each sample was studied in the temperature range $270-410^{\circ} \mathrm{C}$ and at different residence times. It should be mentioned that for all the catalysts and all the reaction conditions explored, glycerol conversion was always complete, as already pointed out for both W$\mathrm{V}$ and $\mathrm{W}-\mathrm{V}-\mathrm{Nb}$ catalysts. Moreover, as far as the nature of these compounds is concerned, the same kind of compounds were detected for the catalysts here studied both at low contact time and/or low reaction temperature.

In figure 3.3.5 and 3.3.6 are reported the most representative catalytic results obtained in the oxidehydration of glycerol performed on bi-component W-Mo and tri-component W-Mo-V catalysts, when it was used a feed with molar ratio Oxygen/Glycerol/Water/Nitrogen=4/2/40/54. Generally speaking, both bi-component catalysts showed always complete glycerol conversion and remarkable acrolein yield; however, only low yields in partial oxidation products (mainly acrylic and acetic acid) were obtained along with high yields in both heavy compounds and COx. 

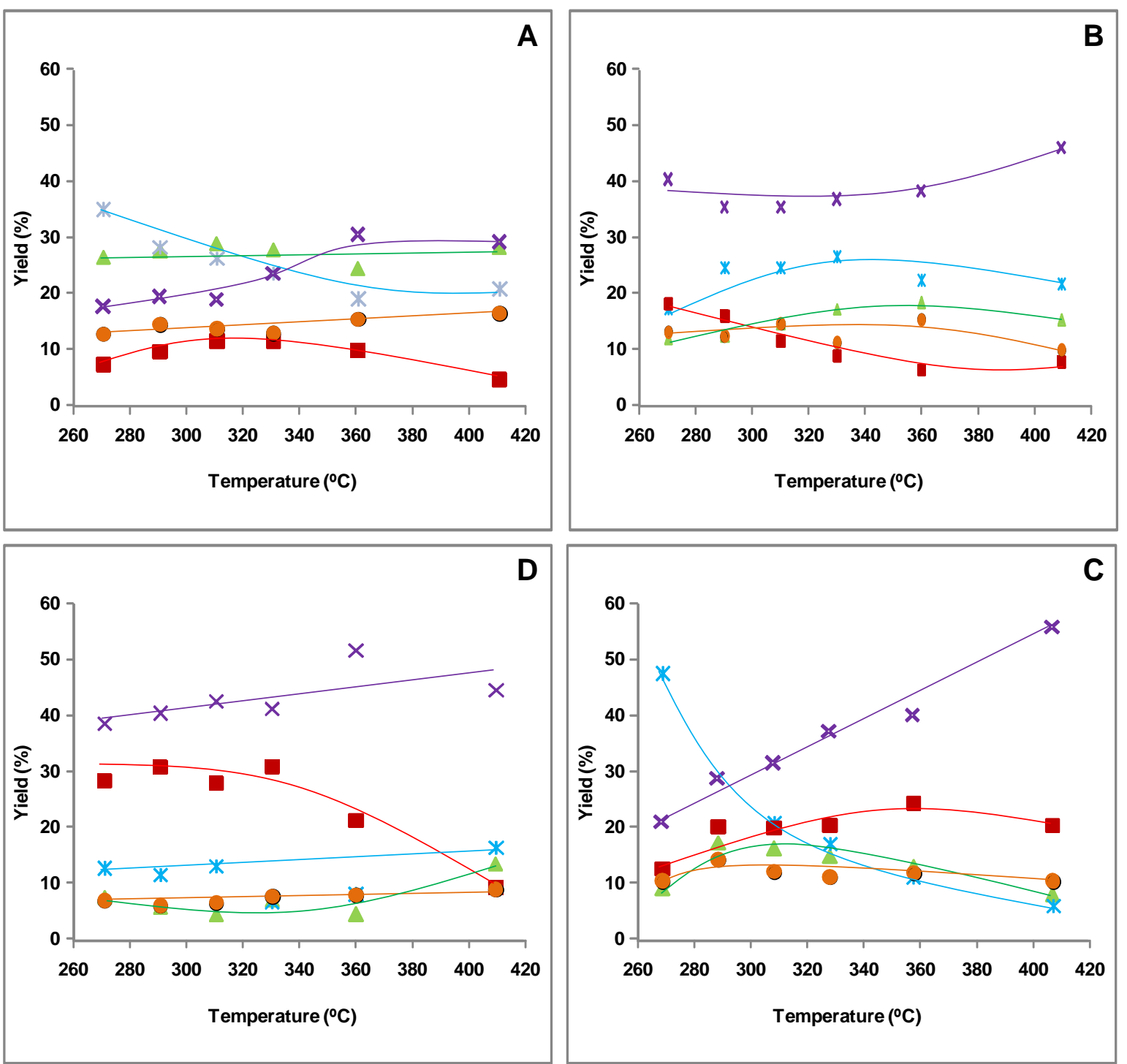

Figure 3.3.5. Glycerol oxidehydration on W-Mo-(V) catalysts. Contact time $0.4 \mathrm{~s}$. A) WMo-2, B) WMoV-1, C) WMoV-4, D) WMoV-3. Symbols: Acrylic Acid $(\square)$, Acrolein $(\Delta), \mathrm{CO}_{x}(X)$, Heavy compounds $(*)$, Others $(\bullet)$. Glycerol conversion always complete. Feed molar ratio Oxygen/Glycerol/Water/Nitrogen=4/2/40/54.

At contact time $0.4 \mathrm{~s}$ and $330^{\circ} \mathrm{C}$, WMo-2 (which showed a better catalytic performance than WMo1) allowed obtaining $12 \%$ acrylic acid selectivity plus $28 \%$ acrolein (Figure 3.3 .5 ); the highest heavy compounds selectivity (35\%) was reached at $270^{\circ} \mathrm{C}$, thus decreasing in favor of carbon oxides at higher temperature. Taking into consideration the high formation of heavy compounds on WMo-1 and WMo-2, molybdenum alone is clearly unable to fast oxidize acrolein (as underlined by the high ratio between acrolein and acrylic acid), even for high molybdenum loadings in the catalyst, 
the parallel reactions taking place from the aldehyde and leading to heavy compounds are favored.
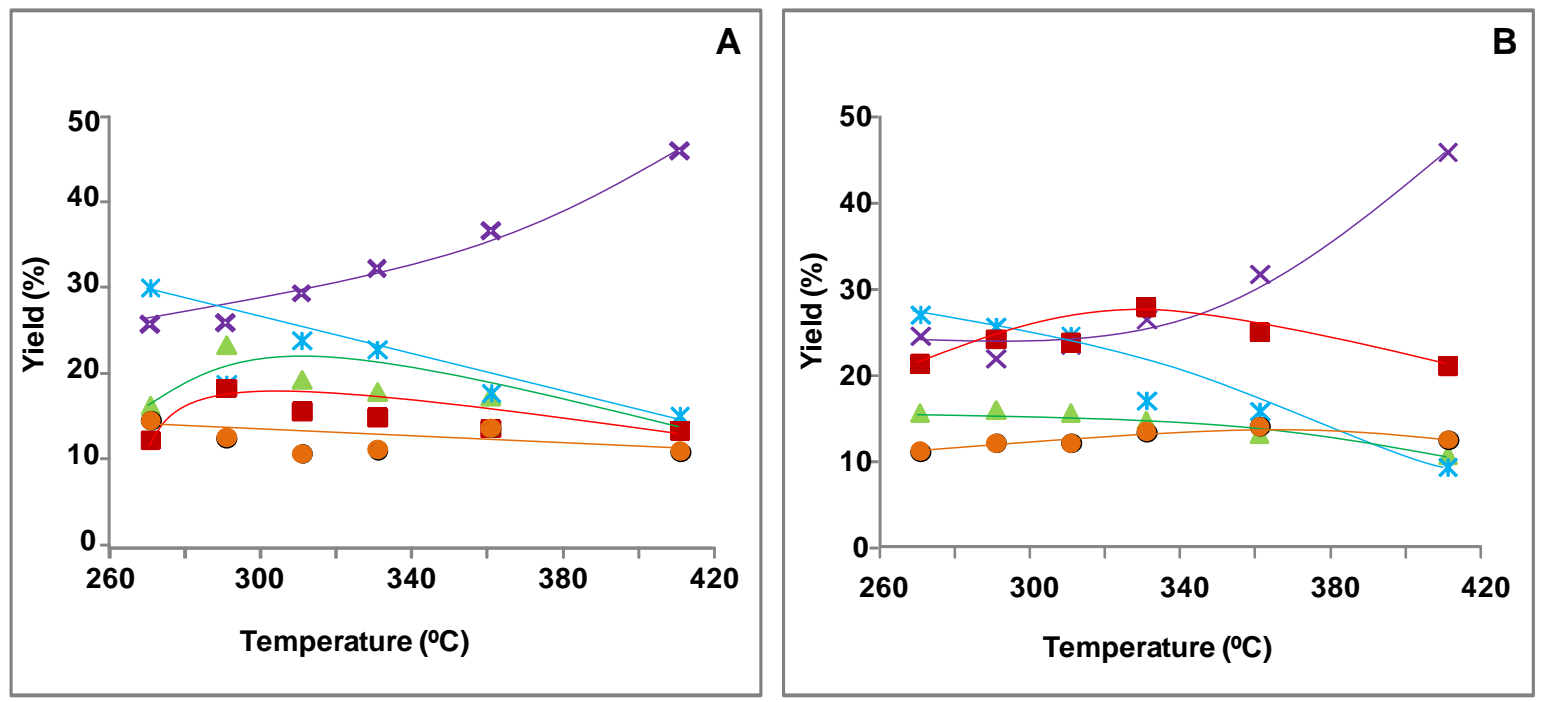

Figure 3.3.6. Glycerol oxidehydration on W-Mo-(V) catalysts. Contact time $0.15 \mathrm{~s}$. A) WMoV-3, B) WMoV-4. Symbols: Acrylic Acid $(\square)$, Acrolein $(\Delta), \mathrm{CO}_{x}(X)$, Heavy compounds $(*)$, Others $(\bullet)$. Glycerol conversion always complete. Feed molar ratio Oxygen/Glycerol/Water/Nitrogen=4/2/40/54.

A remarkable improvement in the oxidation of acrolein to acrylic acid is observed for the tricomponent samples W-Mo-V-O. The incorporation of vanadium in the catalysts, even at low concentration (e.g. WMoV-1), leads to a remarkable difference in the catalytic performance (Fig.

\subsection{5).}

Indeed, at low temperature, acrylic acid yield increased almost three times (from $7 \%$ to $18 \%$ ) and its maximum shifted from $330^{\circ} \mathrm{C}$ to $270^{\circ} \mathrm{C}$, pointing out the superior redox properties of vanadium in comparison to molybdenum; on the other hand, increasing the temperature, total combustion was favored.

WMoV-3 is the catalyst that gave the highest acrylic acid yield at the lowest temperature ( $31 \%$ at $290^{\circ} \mathrm{C}$, tau $\left.0.4 \mathrm{~s}\right)$. The heavy compounds yield set between $7 \%$ and $12 \%$ and the COx varied between $40 \%$ and $50 \%$ yield; at temperature higher than $330^{\circ} \mathrm{C}$, acrylic acid yield decreased, partially in favor of carbon oxides but to some extent also in favor of acrolein and heavy 
compounds, suggesting that at higher temperature the oxygen introduced in the feed is not enough to oxidize acrolein. All in all, a remarkable note for the catalytic performance of WMoV-3 is that acrylic acid yield is almost identical on a wide range of temperature (from $270^{\circ} \mathrm{C}$ to $330^{\circ} \mathrm{C}$ ); comparing this catalyst with the ones already reported in literature for the same reaction (videsupra) and with $\mathrm{W}-\mathrm{V}$ oxides, it is evident that this behavior represents an important leap forward for the design of catalysts more suitable for industrial scale-up, since in oxidation catalysis the precise control of temperature all along the catalytic bed represents a very challenging task at industrial scale. Thus, combination of molybdenum and vanadium leads to a better control of the oxidative properties of the catalysts, smoothing the oxidizing strength of vanadium. In regard to acrylic acid selectivity as a function of temperature, a similar trend to WMoV-3 was registered for WMoV-4, but at a lower contact time (0.15 s) (Figure 3.3.6); indeed, from $270^{\circ} \mathrm{C}$ to $410^{\circ} \mathrm{C}$ acrylic acid yield varied of only few percentage points, from $22 \%$ to $28 \%$. Comparing WMoV-3 (contact time $0.4 \mathrm{~s}$ ) and WMoV-4 (contact time $0.15 \mathrm{~s}$ ), at low temperature carbon oxides yield was much lower in the latter case but there was no gain in acrylic acid yield since the difference is basically accounted in higher formation of heavy compounds; however, comparing WMoV-3 and WMoV-4 tested at contact time $0.15 \mathrm{~s}$, it can be seen that the latter sample leads to higher yields into acrylic acid and lower yields to COx. Nevertheless, comparing WMoV-3 and WMoV-4 tested at contact time $0.4 \mathrm{~s}$, higher acrylic acid yields were obtained in the former case as long as lower yields into acrolein, and much lower yields into heavy compounds, finally corresponding to higher yield into COx.

Therefore, higher loadings of vanadium improve the oxidation process but lead to total oxidation products at higher temperature and residence time; on the other hand, high amounts of molybdenum depress the acrolein oxidation, favoring the parallel reactions leading to heavy 
compounds. Overall, dehydrating properties of W-oxide and redox properties of Mo/V-oxide must be carefully balanced in order to maximize the yields into acrylic acid.

Because of the wide range of physical-chemical properties of the complex oxide catalysts here reported, we calculated both productivity for acrylic acid (AA) and acrolein (A) (Table 3.3.2); indeed, productivity calculations can point out the main differences regarding the active phases, therefore making it possible to relate the catalytic performance and the catalysts' nature. Comparing samples WMoV-1 and WMoV-2, both having an HTB structure, it is possible to figure out the role of vanadium in the catalysts; indeed, on a similar base of molybdenum, the sample richer in vanadium (WMoV-2) improves productivity not only for the partial oxidation product, but also for acrolein. This evidence points out once again the role of vanadium in the acrolein oxidation, but it also reflects that a fast oxidation step is mandatory so as to limit the parallel reaction leading to heavy compounds.

Table 3.3.2. Structure-reactivity correlations for W-Mo-(V) catalysts.

\begin{tabular}{|c|c|c|c|c|c|c|c|}
\hline \multirow[t]{2}{*}{ Sample } & \multirow[t]{2}{*}{ Structure $^{a}$} & \multicolumn{2}{|c|}{$\begin{array}{l}\text { Max. AA sel. } \\
\left(\mathrm{T} \leq 330^{\circ} \mathrm{C}\right)^{\mathrm{b}}\end{array}$} & \multicolumn{2}{|c|}{$\begin{array}{c}\text { Productivity } \\
\left(\mathrm{g}_{\text {product }} \mathrm{h}^{-1} \mathrm{~g}_{\mathrm{CT}}{ }^{-1}\right)^{\mathrm{c}}\end{array}$} & \multicolumn{2}{|c|}{$\begin{array}{c}\text { Productivity } \\
\left(\mathrm{g}_{\text {product }} \mathrm{h}^{-1} \mathrm{~m}_{\mathrm{CT}}{ }^{-2}\right)^{*} 10^{2}\end{array}$} \\
\hline & & $\tau=0.15 \mathrm{~s}$ & $\tau=0.4 \mathrm{~s}$ & AA & A & AA & A \\
\hline WMo-1 & HTB & n.d. & $5(330)$ & 0.008 & 0.021 & 0.032 & 0.080 \\
\hline WMo-2 & Ps-C & $5(330)$ & $12(330)$ & 0.040 & 0.11 & 0.31 & 0.86 \\
\hline WMoV-1 & HTB & 14 (310) & 16 (290) & 0.055 & 0.048 & 0.18 & 0.16 \\
\hline WMoV-2 & HTB & $14(330)$ & 21 (330) & 0.059 & 0.070 & 0.49 & 0.58 \\
\hline WMoV-3 & Ps-C & $17(290)$ & 31 (290) & 0.12 & 0.023 & 0.31 & 0.060 \\
\hline WMoV-4 & Ps-C & $28(330)$ & 20 (330) & 0.066 & 0.053 & 0.30 & 0.24 \\
\hline
\end{tabular}

All the values reported were obtained with feed molar ratio oxygen/glycerol/water/nitrogen $=4 / 2 / 40 / 54$. Glycerol conversion was always complete. Explanation: AA, acrylic acid; A, acrolein. [a] Overall crystalline structure of the sample. HTB: hexagonal tungsten bronze; Ps-C: pseudo-crystalline. [b] Maximum acrylic acid selectivity obtained at temperature lower than $330^{\circ} \mathrm{C}$, respectively at contact time $0.15 \mathrm{~s}$ and $0.4 \mathrm{~s}$. In parenthesis is reported the temperature at which the maximum yield was observed. [c] Productivity calculated as gAA or A h-1 gCT-1 (i.e. h-1). Reaction conditions: feed $290^{\circ} \mathrm{C}$, contact time $0.4 \mathrm{~s}$. [d] Productivity calculated as gAA or A h-1 mCT-2. For graphical reasons these values are multiplied by 102 . Reaction conditions: feed $290^{\circ} \mathrm{C}$, contact time $0.4 \mathrm{~s}$. 
Molybdenum is also crucial in the oxidation process; indeed, moving from WMoV-1 to WMoV-3 (having similar amount of vanadium but higher content of molybdenum) the acrylic acid productivity is improved. However, when the amount of molybdenum is higher (WMoV-4 vs. WMoV-2) the Brpnsted to Lewis acid sites ratio decreases and leads also to a variation in the elements distribution which depress the overall oxidehydration process, as highlighted by the abrupt overall productivity drop $(A A+A)$ per meter square of catalysts; on the other hand, acrylic acid productivity on molar bases increases from 0.059 to $0.066 \mathrm{~h}^{-1}$ due to the increased surface area (from 12 to $22 \mathrm{~m}^{2} / \mathrm{g}$ ). From productivity trends calculated on mass and surface area basis, the role of the crystal structure can also be outlined. First of all, for tri-component catalysts, it can be pointed out that AA productivity (on mass- and surface area-bases) has its maximum located in different position, i.e. WMoV-3 and WMoV-2, respectively. This means that the best catalyst, in terms of activity per specific surface area, is WMoV-2; however, because of its low area, the productivity remains scarce. Therefore, it can be deduced that the pseudo-crystalline structure plays an important role in determining the catalysts productivity per gram of catalyst; indeed, it has been demonstrated that the highest surface area is obtained for low vanadium- and high molybdenum-content, which is the condition where the pseudo-crystalline structure forms. On the other hand, it seems that it is the relative distribution of the elements what has the major impact in the catalytic performance: productivity trends are clearly a function of the oxide composition, whether in the HTB or in the pseudo-crystalline phase.

For bi-component (W-Mo) catalysts, it must be mentioned that acrylic acid productivity is relatively high due to the low surface area; however, acrylic acid productivity per gram of catalyst is low. Moreover, the high overall acrolein productivity underlines the insufficient redox properties of $\mathrm{V}$-free catalysts, since acrolein remains mainly unconverted. 
Finally, so as to gain a wider picture on the role of tungsten, it is of interest to compare our results with the ones recently published by L. Shen et al. [56]. The authors performed the glycerol oxidehydration reaction on Mo/V oxides (without tungsten), prepared by slurry synthesis; the catalysts being composed of $\mathrm{Mo}_{6} \mathrm{~V}_{9} \mathrm{O}_{40^{-}}$and $\mathrm{MoO}_{3}$-phases and presenting relatively low surface area (10-12 $\left.\mathrm{m}^{2} \mathrm{~g}^{-1}\right)$. When glycerol was made react on these oxides, low carbon balances were obtained due to poor acid properties of the catalysts (both as total acidity and most likely as Brфnsted-to-Lewis acid sites ratio), as long as a wide range of C3 and C2 products.

Therefore, the above mentioned evidences on W-Mo- and W-Mo-V-catalysts make clear that: (i) to perform selectively the glycerol dehydration step into acrolein a high amount of Brpnsted acid sites are needed, highlighting the fundamental role of tungsten, (ii) the specific productivity of the catalysts is governed by the relative amount of the elements and their spatial distribution, whether the oxide framework is composed of an HTB- or pseudo-crystalline-structure, (iii) the pseudo-crystalline structure has a role only in determining the catalyst productivity, due to its influence on surface area.

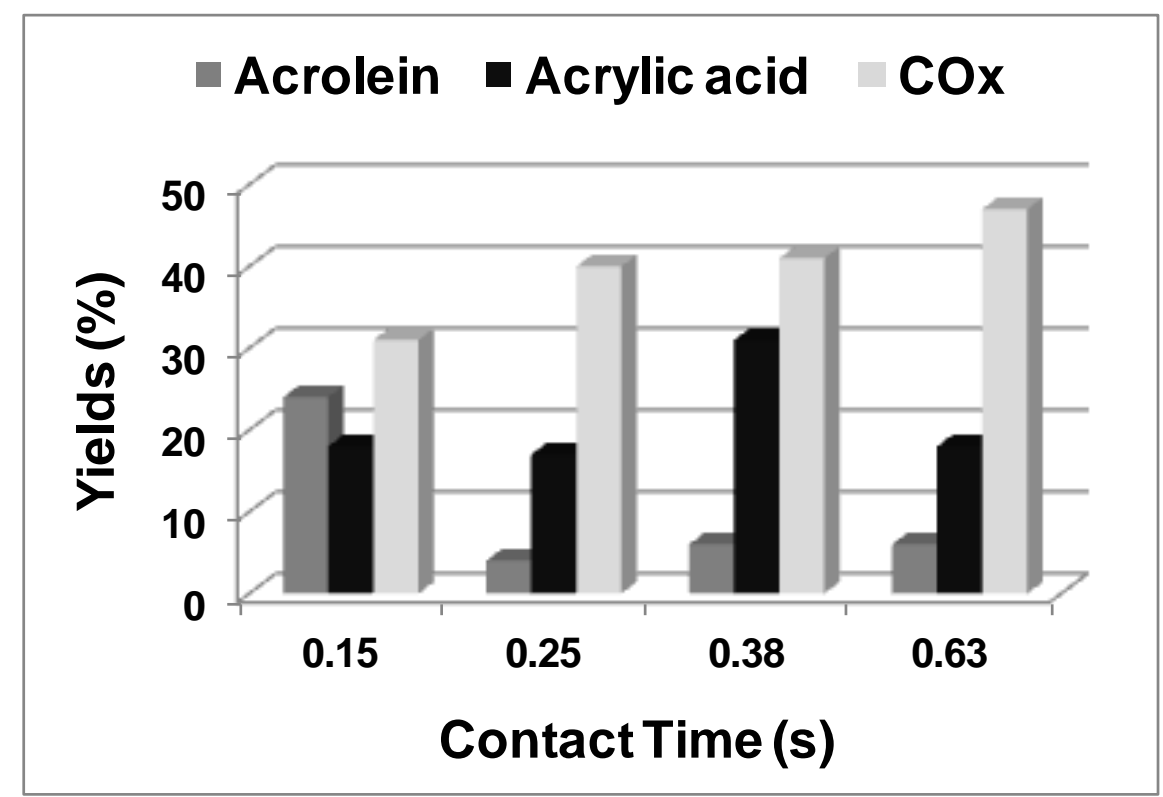

Figure 3.3.7. WMoV-3. Study on the influence of contact time. Feed molar ratio Oxygen/Glycerol/Water/Nitrogen $=4 / 2 / 40 / 54$. Temperature $290^{\circ} \mathrm{C}$. 
Since WMoV-3 allowed obtaining the highest acrylic acid yields at the lowest temperature (the latter parameter being desirable at industrial scale), its catalytic performance was studied as a function of inlet feed composition. These catalytic tests were carried out at contact time close to $0.4 \mathrm{~s}$ since at this value is located the best balance between the partial oxidation of acrolein into acrylic acid and its total combustion into carbon oxides (therefore, as a consequence, the acrylic acid yield maximum) (Figure 3.3.7). Moreover, $290^{\circ} \mathrm{C}$ was chosen as temperature for the catalytic test since it represents an intermediate value in the range of temperature where WMoV-3 showed the acrylic acid yield plateau (Fig. 3.3.5).
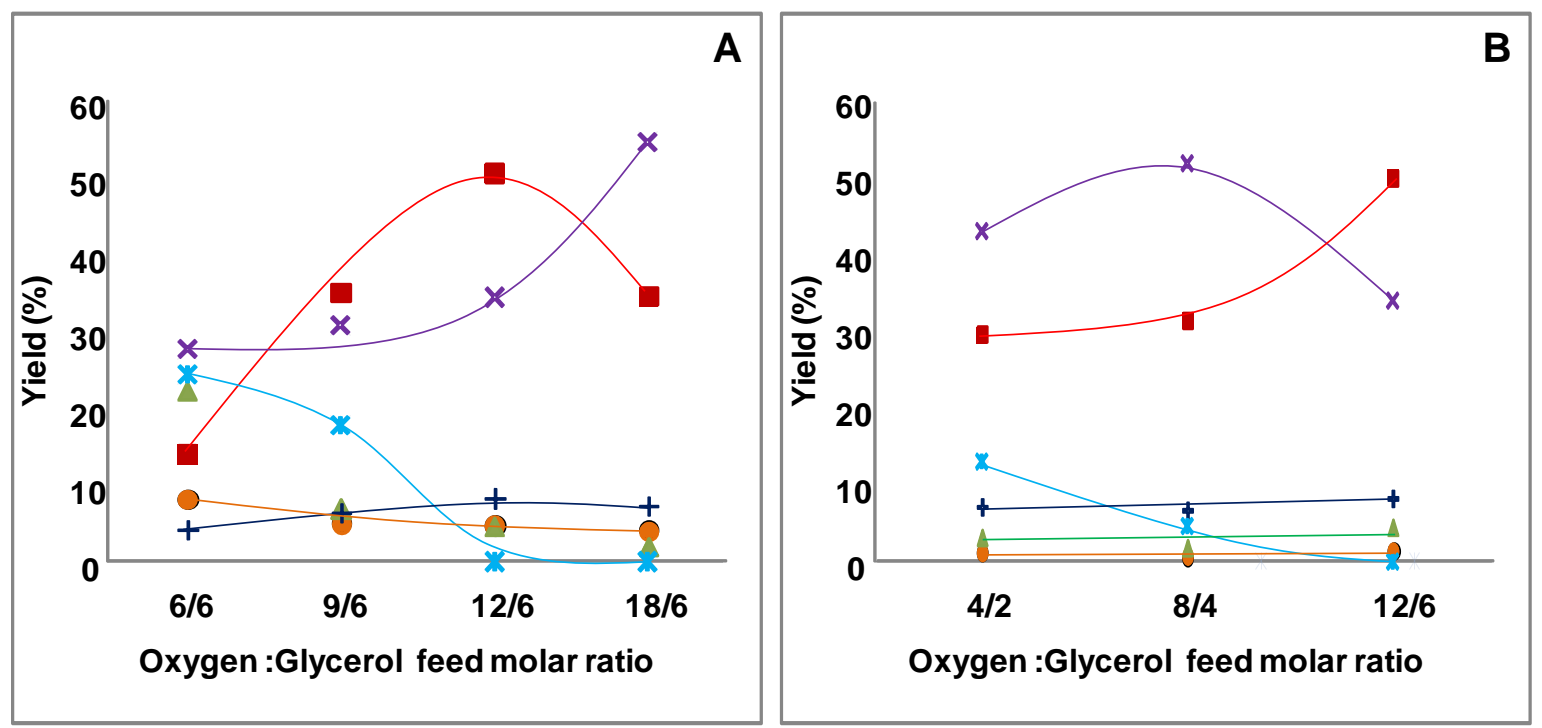

Figure 3.3.8. Glycerol oxidehydration on WMoV-1. A): Variable oxygen-to-glycerol ratio; B) Constant Oxygen-to-Glycerol molar ratio (equal to 2). Symbols: Acrylic Acid ( $\square$ ), Acrolein( $\Delta$ ), $\mathrm{CO}_{x}(\mathrm{X})$, Heavy compounds (*), Acetic acid (+), Others (•). Glycerol conversion always complete. Others: mainly acetaldehyde (in minor amounts, < 4\%: allylic alcohol, acetone, propionaldehyde, propionic acid and hydroxyacetone). Reaction conditions: temperature $290^{\circ} \mathrm{C}, 0.3 \mathrm{~g}$ of catalyst, contact time $0.4 \mathrm{~s}$. Feed composition (molar \%): Oxygen and glycerol as reported in the plots, water $40 \%$, nitrogen up to 100\%. Reaction time: $90 \mathrm{~min}$.

In figure 3.3.8 are presented the catalytic results obtained for WMoV-3 as a function of feed molar ratio. For experiment with oxygen-to-glycerol ratio 6:6, heavy compounds yield reached values as high as $24 \%$ and acrolein yield was close to $23 \%$; on the other hand acrylic acid only 
reached yield close to $14 \%$ together with $28 \%$ COx yield. Increasing the partial pressure of oxygen, the acrylic acid yield augmented at a higher rate than COx, since heavy compounds loss was accounted more into acrylic acid than carbon oxides; acrylic acid yield reached a maximum equal to $51 \%$ at oxygen to glycerol ratio of $12: 6$, finally decreasing in favor of carbon oxides when the oxygen to glycerol ratio reached the value 18:6. A similar trend to the one reported for acrolein and acrylic acid was shown by acetaldehyde and acetic acid, the latter achieving $8 \%$ yield at oxygen-to-glycerol ratio $12: 6$; the acrylic acid maximum obtained is similar to the one obtained with WVNb-1 mixed oxide in the same reaction conditions, but the latter being achieved after ca. 37 hours of time on stream (see figure 3.2.5). Very similar catalytic behavior was also observed when the oxygen to glycerol molar ratio was set constant (equal to 2) (Figure 3.3.8 (B)), since heavy compounds yield decreased mainly in favor of acrylic acid than cOx. Therefore, it is confirmed that high partial pressures of oxygen play the fundamental role of accelerating the catalyst re-oxidation process, the latter being depressed by the high reducing power of glycerol and/or its strong adsorption on the catalyst's surface. Indeed, when acrolein was made react on WMoV-3 in the same reaction conditions (Fig. 3.1.5) a different behavior was registered since increasing the partial pressure of both oxygen and glycerol -but keeping constant their ratio- the acrylic acid selectivity decreased constantly in favor of carbon oxides. 


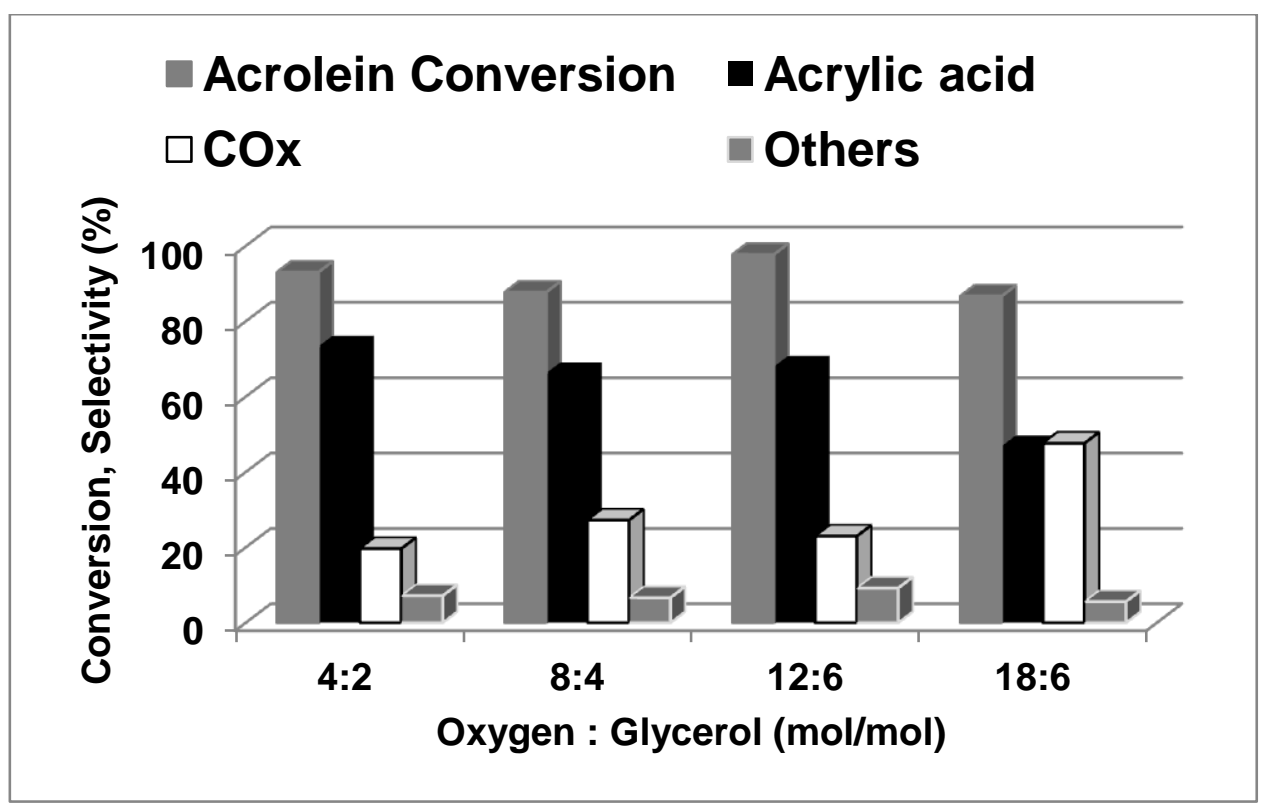

Figure 3.3.9. Acrolein oxidation on WMoV-1 at different oxygen-to-glycerol molar ratios. Others: mainly acetaldehyde and acetic acid. Reaction conditions: temperature $290^{\circ} \mathrm{C}, 0.3 \mathrm{~g}$ of catalyst, contact time $0.4 \mathrm{~s}$. Feed composition (molar \%): Oxygen and glycerol as reported in the plots, water 40\%, nitrogen up to 100\%. Reaction time: $90 \mathrm{~min}$.

Finally, increasing the oxygen partial pressure (oxygen-to-glycerol molar ratio of 18:6), it is evident that total oxidation of acrolein to $\mathrm{CO}_{x}$ is favored. All in all, comparing the latter trends with the ones obtained for glycerol and the different $\mathrm{CO}_{x}$ selectivities got in the two experiments, it seems that glycerol reduces the catalyst's surface because of its direct transformation into carbon oxides (scheme 3.3.1).

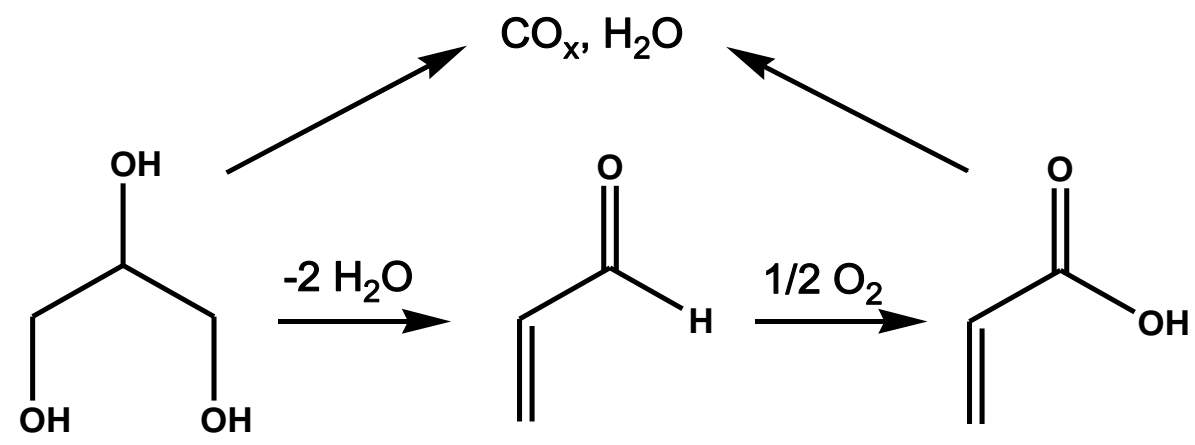

Scheme 3.3.1. The scheme highlights the direct combustion of glycerol and total oxidation of acrolein. 
Finally, the catalytic behavior of WMoV-3 was studied as a function of the time on stream -ToS(figure 3.3.10), using the same reaction conditions where the maximum acrylic acid yield was registered. Along 70 hours ToS glycerol conversion was always complete, the sum of acrolein and acrylic acid being constant with an average value around $53 \%$ and an initial $51 \%$ acrylic acid yield; on the other hand, after 90 minutes ToS (that is the time we normally used to study the catalysts behavior -see experimental section-), acrylic acid yield slowly started to decrease in favor of the aldehyde.

Overall, after ca. $28 \mathrm{~h}$ ToS both products yield reached a stable average value of $42 \%$ (acrylic acid) and $12 \%$ (acrolein); the latter values being stable for at least the following 40 hours. Comparing the XRD spectra of fresh and spent sample -after $69 \mathrm{~h}$ ToS- (figure 3.3.11) it is possible to see that a new diffraction peak appears at ca. 2620 degrees, the latter being most likely related to partial transformation of the pseudo-crystalline structure into monoclinic- $\mathrm{WO}_{3}$. Moreover, when comparing Raman spectra of fresh and spent catalysts (Fig. 3.3.11) it is revealed the presence of carbonaceous deposits on the catalyst surface. Both phenomena could thus be ascribed as responsible for the changes in product distribution during ToS test. So as to assess the relative importance of the two phenomena, an attempt of regeneration was carried out feeding a mixture of oxygen and nitrogen (molar ratio $5: 95$ ) at $350^{\circ} \mathrm{C}$ for 2 hours, contact time $0.4 \mathrm{~s}$. As demonstrated by Raman spectra of regenerated catalyst (figure 3.3.11) the carbon deposits were effectively removed by the oxidation treatment; on the other hand, once the regenerated catalyst was used to continue the ToS test, acrylic acid selectivity improvement was minimum (plus 2-3\%). Therefore the change of the crystalline phase is clearly the key-factor governing the catalyst deactivation. Comparing the variation observed for the crystal structure of the W-Mo-V catalyst to $\mathrm{W}-\mathrm{V}-\mathrm{Nb}$ oxide previously studied, it is evident the stabilizing role played by niobium; indeed, $\mathrm{Nb}-$ containing catalyst preserved the structure after an analogous ToS test. 


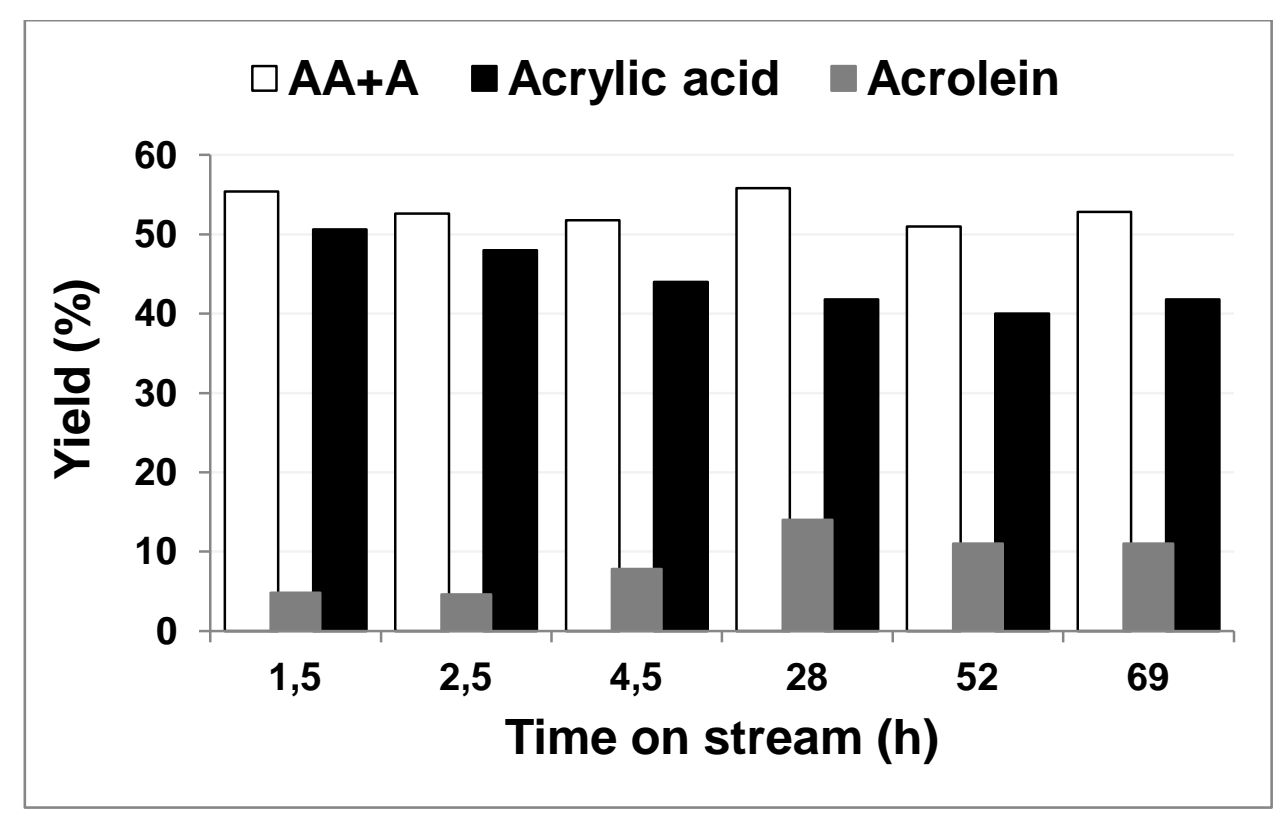

Figure 3.3.10. Glycerol oxidehydration on WMoV-3. Time-on-stream test. Glycerol conversion always complete. Others: mainly acetaldehyde and acetic acid (in minor amounts, < 4\%: allylic alcohol, acetone, propionaldehyde, propionic acid and hydroxyacetone). Negligible formation of heavy compounds was registered. Reaction conditions: contact time $0.4 \mathrm{~s}$, $290^{\circ} \mathrm{C}$. Feed composition (molar \%): glycerol $6 \%$, oxygen $12 \%$, water $40 \%$, helium $42 \%$.
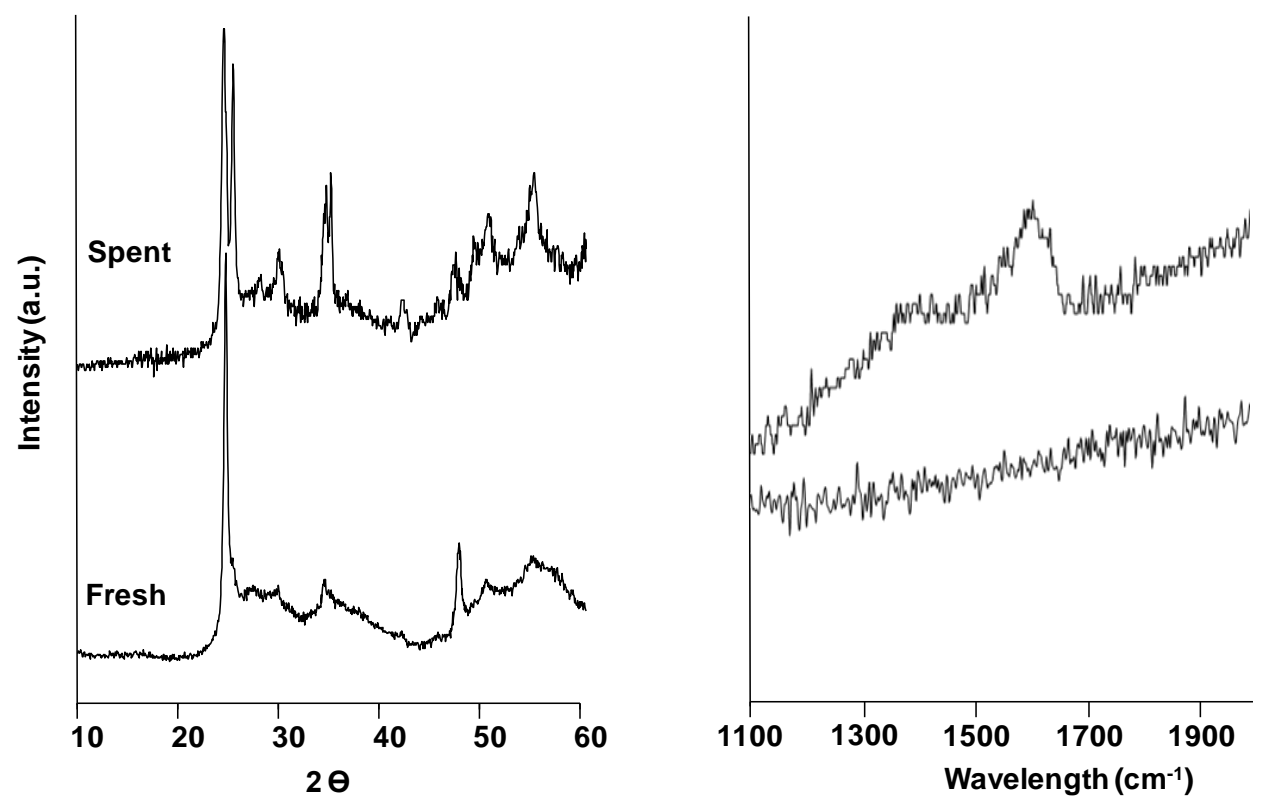

Figure 3.3.11. Comparison between XRD pattern (left) and Raman spectra (right) of Fresh and Spent WMoV-3. 


\subsubsection{Conclusions}

The physical-chemical properties and the catalytic performance of W-Mo-(V) oxides make it clear the main role of each element in the oxide frame: tungsten dehydrates glycerol to acrolein, vanadium oxidizes acrolein into acrylic acid and molybdenum moderates the strong oxidizing properties of vanadium. The atomic ratio of the elements is pivotal for tuning redox and acid properties, but it also plays a role both in the size of the crystals and their long-range distribution, finally influencing the catalysts' productivity. High oxygen feed molar ratios help the catalyst reoxidation step and allowed obtaining acrylic acid yield as high as $51 \%$ on the WMoV-3 catalyst. Acrolein oxidation tests evidence that direct oxidation of glycerol and acrolein also take place. Time on stream test (ca. 70h) on WMoV-3 reveals a stable overall yield for acrolein and acrylic acid. Under reaction conditions, evolution of the crystal phase leads to a slight inversion in the yields of the two consecutive products along the first $5 \mathrm{~h}$ ToS. However, a stable catalytic behavior was observed for more than 40 hours ToS. 


\subsection{The importance of acid-redox properties and structure-reactivity correlations in one-pot glycerol oxidehydration}

Revising the results reported in the previous chapters as well as the ones present in the literature, there is some important lack of information about various insights concerning glycerol oxidehydration at the molecular level. Considerable attention has been focused in finding the best performing catalysts for glycerol oxidehydration to acrylic acid, but the more intimate aspects of the reaction have not been studied into details.

First of all, the studies carried out on the various mixed-oxides discussed previously, have clearly highlighted that both acid and redox properties have to be carefully tuned in order to keep an optimal control on the glycerol oxidehydration reaction. Moreover, it was demonstrated that the same acid sites needed to dehydrate glycerol into acrolein can also catalyze undesired secondary reactions which lead to numerous by-products such as ketals and oligomers. However, so far it has not been reported any systematic study which aims to understand if it is possible to both efficiently dehydrate glycerol into acrolein and also hamper the by-products formation. For instance, a selective poisoning of the strongest acid sites could depress the formation of byproducts while the medium-to-strong acid sites could be preserved to dehydrate glycerol into acrolein. With this idea in mind, a systematic study was carried out by poisoning the acid sites of a vanadium-substituted HTB (WV-3) with potassium. The different preparation methods used as well as reactivity tests and physicochemical characterizations not only shed light on the influence of acid and redox properties on by-products formation but also provide some interesting insights on the structural nature of the substituted-HTBs.

Additionally, revising the literature it can be evinced that some peculiar phenomenon must be behind the different results obtained for the glycerol one-pot oxidehydration on multifunctional catalysts. Mixed-oxides with selective acid properties for the dehydration of the polyol to 
acrolein, showed substantially different selectivity to acrylic acid despite the same redox element, i.e. vanadium, was present. This was the case of vanadium-substituted HTBs, vanadiumcontaining zeolites [61] and Vanadium-Phosphorus-Oxides (VPOs) [78]. Indeed, looking at these results, catalysts related to the Perovskites family seems to be the only mixed-oxides capable of efficiently carrying out the whole glycerol oxidehydration to acrylic acid, with selectivities greater than $50 \%$ at total glycerol conversion. The other systems showed significantly lower selectivities: (i) maximum AA selectivity for $\mathrm{V}-\mathrm{BEA}, 25 \%$ at $75 \%$ glycerol conversion and (ii) maximum $\mathrm{AA}$ selectivity for VPO, $8 \%$ at total glycerol conversion. So as to better examine these peculiar results, selected mixed oxides where used as reference materials: (i) W-V-oxides with HTB structure, (ii) Vcontaining Al-P-(Co)-oxides, (iii) commercial Vanadyl Pyrophosphate -VPP- (DuPont, calcined [119]) and (iv) a V-exchanged hexagonal-tungsten oxide. The results obtained clearly highlight that an important structure-reactivity correlation exists and governs the redox features of vanadium along the oxidation step.

\subsubsection{Physicochemical properties of the oxides}

WV-3 and WV-2 catalysts were described in the previous chapters and in [1], but they are also reported in this chapter as reference materials; for an easier comparison, the main features of these catalyst are also discussed in table 3.4.1 and in the following figures. Generally speaking, all the K-containing catalysts present a lower BET area than WV-3, which indicates that K-ions block the channels running along the c-direction of HTBs and/or form additional species on the catalyst surface that have low specific surface area. The VPP catalyst used is an industrial sample commercialized by DuPont, whose properties were extensively studied and reported in literature $[119,120]$; particularly, we used the calcined oxide. This sample is made by micrometric spheres with a core of VPP-phase (ca. $150 \mu \mathrm{m}$ ) and surrounded by a layer of porous silica (ca. $2 \mu \mathrm{m}$ ) to 
improve its attrition resistance in fluidized bed reactors, where this material was meant to be used for the production of maleic anhydride.

\begin{tabular}{|c|c|c|c|c|c|c|c|c|c|c|}
\hline \multirow[t]{2}{*}{ Sample } & \multicolumn{6}{|c|}{ Atomic ratios $^{\mathrm{a}}$} & \multirow{2}{*}{$\begin{array}{c}\text { BET } \\
\text { area }\end{array}$} & \multirow{2}{*}{$\begin{array}{c}\begin{array}{c}\text { External } \\
\text { area }^{\mathrm{b}}\end{array} \\
\mathrm{m}^{2} \mathrm{~g}^{-1}\end{array}$} & \multicolumn{2}{|c|}{ TPD-NH ${ }_{3}$} \\
\hline & w & v & K & $\begin{array}{c}\text { Al or } \\
\text { (Si) }\end{array}$ & $\mathbf{P}$ & Co & & & $\mu \mathrm{mol} \mathrm{g}{ }^{-1}$ & $\mu \mathrm{mol} \mathrm{m} \mathrm{m}^{-2}$ \\
\hline WV-2 & 1 & 0.12 & - & - & - & - & 19 & 17 & 72 & 3.8 \\
\hline WV-3 & 1 & 0.21 & - & - & - & - & 21 & 18 & 76 & 3.7 \\
\hline K-0.5 & 1 & 0.21 & 0.21 & - & - & - & 12 & 9.4 & 25 & 2.2 \\
\hline K-0.1 & 1 & 0.21 & 0.11 & - & - & - & 16 & 14 & 36 & 2.3 \\
\hline K-Imp & 1 & 0.21 & 0.09 & - & - & - & 17 & 14 & 42 & 2.5 \\
\hline K-Syn & 1 & 0.16 & 0.10 & - & - & - & 11 & 8.4 & 21 & 1.9 \\
\hline VPP & - & 0.37 & - & (0.19) & 0.44 & - & 41 & 40 & 90 & 2.2 \\
\hline $\mathrm{V} / \mathrm{WO}_{\mathrm{x}}$ & 1 & 0.15 & - & - & - & - & 25 & 20 & 113 & 4.5 \\
\hline Co-AIPO & - & - & - & 0.46 & 0.52 & 0.022 & 263 & 26 & 241 & 0.91 \\
\hline V-CoAIPO & - & 0.0046 & - & 0.46 & 0.53 & 0.031 & 298 & 32 & 331 & 1.1 \\
\hline V/V-Co-AIPO & - & 0.0079 & - & 0.49 & 0.51 & 0.019 & 192 & 27 & 249 & 1.3 \\
\hline
\end{tabular}

This catalyst presents a relatively high surface area $\left(41 \mathrm{~m}^{2} / \mathrm{g}\right)$ and it is largely mesoporous, with an average pore diameter of $198 \AA$. V/WO has a lower area than pure h-WOx (25 vs $31 \mathrm{~m}^{2} / \mathrm{g}$ ) which indicates that the vanadium exchanged acts as potassium and blocks the channels in HTBs. Modified-AIPO catalysts present a relevant surface area, although their external area is significantly smaller, since most of the contribution to the total surface area comes from micropores (e.g. V-CoAIPO has a t-plot micropore volume of ca. $0.13 \mathrm{~cm}^{3} / g$ and average BJH pore diameter of ca. $50 \AA$ A). A comprehensive discussion on modified-AlPO materials can be found elsewhere [121].

In figure 3.4.1 are presented the XRD patterns of the catalysts prepared. Modified-AIPO catalysts (trace g-i) present the characteristic diffraction peaks of zeolite-like materials with AFI structure, 
which confirm the correct preparation of AIPO-5 catalysts. Both for CoAIPO and V-CoAIPO no changes are observed in the diffraction peaks, confirming the insertion of cobalt and vanadium in the oxide framework as tetrahedral units [81]. However, when an additional amount of vanadium was added to the V-CoAIPO catalyst by wet impregnation (sample V/V-CoAIPO, trace i), extraframework vanadium species formed as $\mathrm{V}_{2} \mathrm{O}_{5}$, which are responsible for the additional diffraction peaks observed in the latter sample. The XRD pattern of the VPP catalyst (trace I) shows the presence of the characteristic phase $(\mathrm{VO})_{2} \mathrm{P}_{2} \mathrm{O}_{7}$; the lack of additional peaks confirm that no other V-P-O phases constitute this catalyst [119].
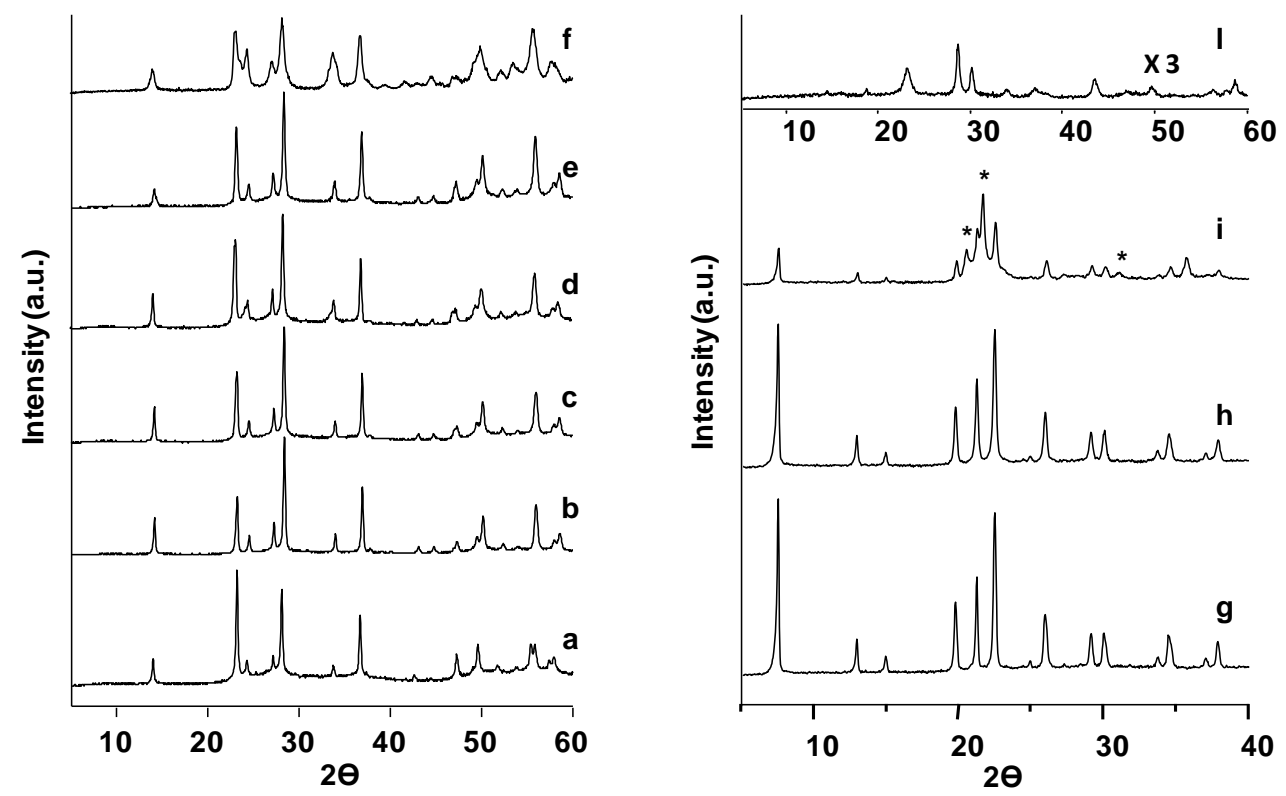

Figure 3.4.1. XRD patterns of catalysts. a) WV-3; b) K-0.5; c) K-0.1; d) K-Imp; e) K-Syn; f) V/WO $\mathrm{W}_{\mathrm{x}}$ g) Co-APO; h) V- CoAPO; i) V/V-Co-APO ( $*$ indicates $\mathrm{V}_{2} \mathrm{O}_{5}$ diffraction peaks), I) VPP.

All the HTB-like materials (traces a-f) present the diffraction peaks of a hexagonal tungsten oxide (JCPDS: 33-1387), with only minor changes in crystallinity. Hence, both the ion-exchange and impregnation processes do not affect the HTB-structure. However, a slight decrease in crystallinity is observed for the sample where potassium was introduced in the synthesis gel (K-Syn, trace e). Sample $\mathrm{V} / \mathrm{WO}_{\mathrm{x}}$ has the poorer crystallinity among all the HTB-like catalysts (trace f); however, this 
oxide was heat-treated at $450^{\circ} \mathrm{C}$, whereas the other ones up to $600^{\circ} \mathrm{C}$. When $\mathrm{V} / \mathrm{WO}_{\mathrm{x}}$ was treated at temperatures above $450^{\circ} \mathrm{C}$, the HTB structure decomposed into a monoclinic-W-V-O. The same behavior was observed for pure hexagonal tungsten oxide (indicated as WV-0 in [1]) since above $450^{\circ} \mathrm{C}$ it decomposed into $\mathrm{m}-\mathrm{WO}_{3}$. Hence, this is a remarkable evidence that $\mathrm{V}$-ions introduced by ion-exchange do not enter the hexagonal framework, but rather stay either in the channels or on the surface of the material; the latter option should play a minor role since the catalyst was washed with abundant distilled water after the ion-exchange procedure.

As far as catalysts prepared by ion-exchange with potassium are concerned, the V/W ratio is preserved if compared to WV-3, which allows discarding leaching phenomena during the preparation, as it was also visible from the color of filtered mother liquors, i.e. colorless. The increased concentration of $\mathrm{KHCO}_{3}$ in the solution used to carry out the exchange process -see chapter 2.1.2-, increased the quantity of potassium in the catalyst (see K-0.1 vs. K-0.5). However, the theoretical atomic ratio $\mathrm{K} / \mathrm{W}=0.3$ [63] was never obtained, most likely due to ion-diffusion problems in the needle-like crystals that characterize ammonium-HTBs, as illustrated in figure

\subsection{2 for WV-3.}

In figure 3.4.3 and table 3.4.1 are reported the results obtained by ammonia-TPD experiments. TPD-MS analysis are currently in preparation for the VPP catalyst; however the total acidity value reported in table 3.4.1 highlights that VPP has relevant acid properties as also reported in the literature by other authors [78]. Potassium-containing catalysts (traces a-d in figure 3.4.3) compared to WV-3 sample (trace e) present lower acidity. From desorption profiles it is also possible to visualize that the strongest acid sites (ammonia desorption range $250-450^{\circ} \mathrm{C}$ ) are the most affected by the introduction of potassium. Therefore, it is confirmed that the addition of potassium can selectively poison the strongest acid sites. Instead, $\mathrm{V} / \mathrm{WO}_{\mathrm{x}}$ maintains a significant 
amount of the overall acid sites (both strong and weak) that characterize the parent $\mathrm{h}-\mathrm{WO}_{\mathrm{x}}(113$ vs. $\left.135 \mu \mathrm{mol}_{\mathrm{NH} 3} / \mathrm{g}_{\mathrm{cat}}\right)$-see WV-0 in [1]-.

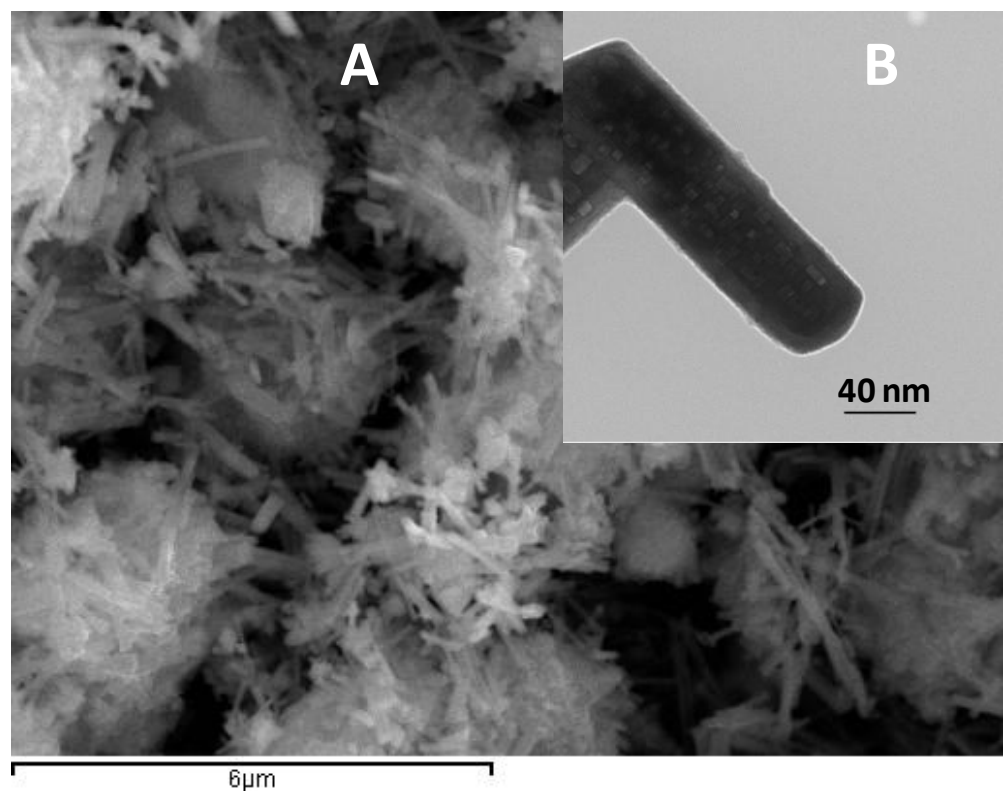

Figure 3.4.2. A) SEM image of $W V-3$. It highlights the needle-like morphology of $\left(\mathrm{NH}_{4}^{+}\right)-\mathrm{W}-\mathrm{V}$ catalysts prepared by hydrothermal method. B) TEM image of a needle that compose WV-3. The presence of cavities on the crystals' surface of heat-treated samples (the geometrically defined brighter areas on the crystal in B) was discussed in a recent publication [122].
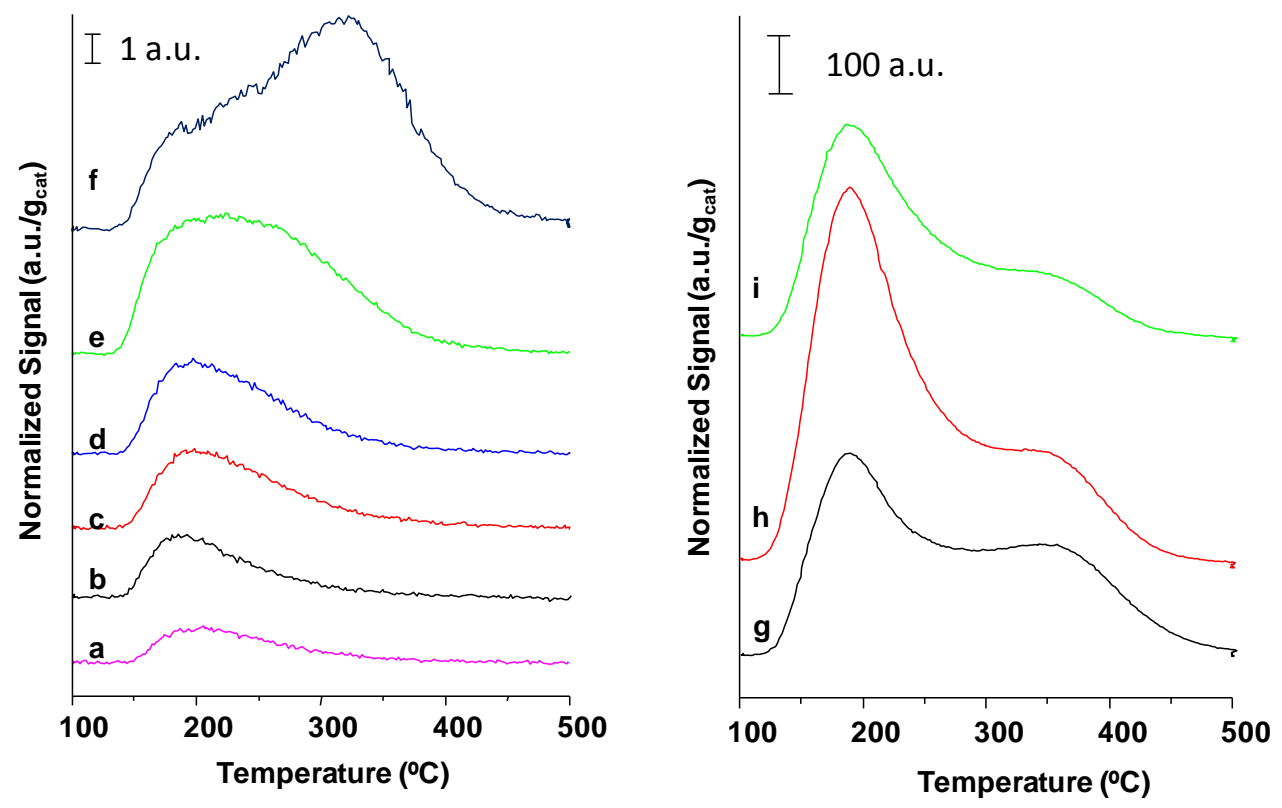

Figure 3.4.3. $\mathrm{NH}_{3}$-TPD profiles of reported catalysts. a) K-syn, b) K-0.5, c) K-0.1, d) K-imp, e) WV-3, f) V/WOx, g) CoAlPO, h) V-CoAIPO, i) V/V-CoAIPO. 
Modified-AIPO catalysts have a much higher total acidity than all the other materials; it is also clear the presence of acid sites with different strength as highlighted by the two desorption maxima at approximately $190^{\circ} \mathrm{C}$ and $270^{\circ} \mathrm{C}$, which can be assigned respectively to the presence of Lewis and Brфnsted acid sites [123].

In order to evaluate the influence of the catalyst composition and preparation method on the redox properties of the catalysts examined, experiments of temperature-programmed-reduction with hydrogen $\left(\mathrm{H}_{2}\right.$-TPR) were carried out (figure 3.4.4). The presence of potassium in the HTB-like catalysts (trace b-e) seems to have a relevant influence not only on acid properties, as previously discussed, but also on the redox ones. The first reduction peak shifted towards higher temperatures as a function of the K-content, from ca. $485^{\circ} \mathrm{C}$ for $\mathrm{WV}-3$ to $570^{\circ} \mathrm{C}$ for $\mathrm{K}-0.5$. Samples with similar amount of potassium (K-0.1, K-imp and K-syn) have an almost identical maximum at around $520^{\circ} \mathrm{C}$, despite the different preparation method used. Analogous behavior was observed for the second reduction maxima but the peaks also broaden considerably. Therefore, the addition of potassium seems to hamper the redox process of vanadium in V-substituted-HTBs since the overall reduction profile is shifted towards higher temperatures.
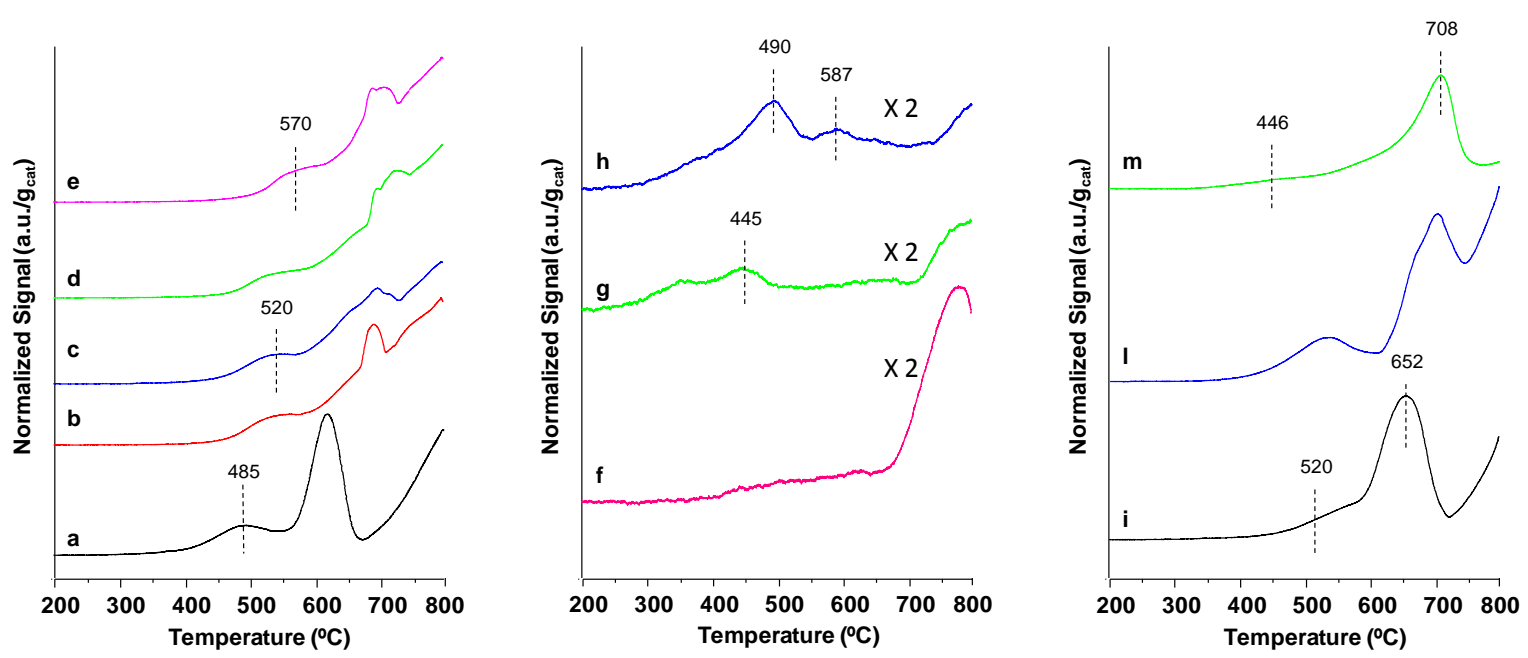

Figure 3.4.4. TPR of selected catalysts. a) WV-3, b) K-0.1, c) K-imp, d) K-syn, e) K-0.5, f) CoAlPO, g) V-CoAIPO, h) V/VCoAIPO, i) WV-2, I) V/WOx, m) VPP. 
The V-free AIPO (sample CoAIPO, trace f) did not show any reduction up to $650^{\circ} \mathrm{C}$. V-CoAIPO (trace g) presents multiple reduction peaks that can be assigned to various species of in-framework Vatoms. The impregnation of vanadium on V-CoAIPO (i.e. sample V/V-CoAIPO, trace h) augments the consumption of hydrogen and shifts the reduction peak towards higher temperatures. A new maxima also appeared at ca. $590^{\circ} \mathrm{C}$, suggesting that extra-framework vanadium-species are more difficult to reduce than the in-framework ones. Compared to $\mathrm{WV}-2, \mathrm{~V} / \mathrm{WO}_{\mathrm{x}}$ presents the first peak of reduction at an almost identical temperature, whereas the second one shifted to higher values and seems to be the sum of two reduction peaks. VPP presents a minor reduction peak at around $446^{\circ} \mathrm{C}$, but a broad peak with a maximum at $708^{\circ} \mathrm{C}$ is present.

\subsubsection{Lab-scale reactor tests}

In figure 3.4.5 are reported the catalytic results obtained on K-V-substituted HTBs and they are compared to WV-3. All the catalysts were tested under the optimal reaction conditions for $\mathrm{W}-\mathrm{V}$ catalysts (see [1] and previous chapters), i.e. $290^{\circ} \mathrm{C}$ and contact time ca. $0.4 \mathrm{~s}$. Moreover, provided the results obtained on the importance of the redox cycle in both $\mathrm{W}-\mathrm{V}-\mathrm{Nb}$ and $\mathrm{W}-\mathrm{Mo}-\mathrm{V}$ catalysts, each mixed-oxide was analyzed both with a feed molar ratio (glycerol/oxygen/water/nitrogen) 2/4/40/54 and 6/12/40/42.

As far as catalytic results obtained with feed molar ratio 2/4/40/54 are concerned, compared to WV-3, the catalysts prepared by exchange method (K-0.5 and K-0.1) formed a significant amount of heavy compounds and the acrylic acid selectivities decreased consistently as well as $\mathrm{CO}_{\mathrm{x}}$. However, the sample containing less potassium, K-0.1, doubled the acrylic acid selectivity compared to $\mathrm{K}-0.5$, whereas the selectivity to $\mathrm{CO}_{\mathrm{x}}$ decreased. $\mathrm{K}$-imp, in spite of its very similar $\mathrm{K}$ content, showed a significantly different behavior compared to the exchanged-catalysts; the heavy compounds selectivity was almost null, as for WV-3, however the acrylic acid selectivity was 
only $14 \%$ vs. $26 \%$ for WV-3 and the acrolein selectivity increased up to $22 \%$. Nonetheless, significant formation of other compounds was registered in this case, with selectivity up to $33 \%$; provided their retention time, these compounds are most likely composed by oligomers and ketals of the same nature discussed in the previous chapters. K-syn presented the higher acrolein selectivity, however very low acrylic acid as well as high heavy compounds formation.
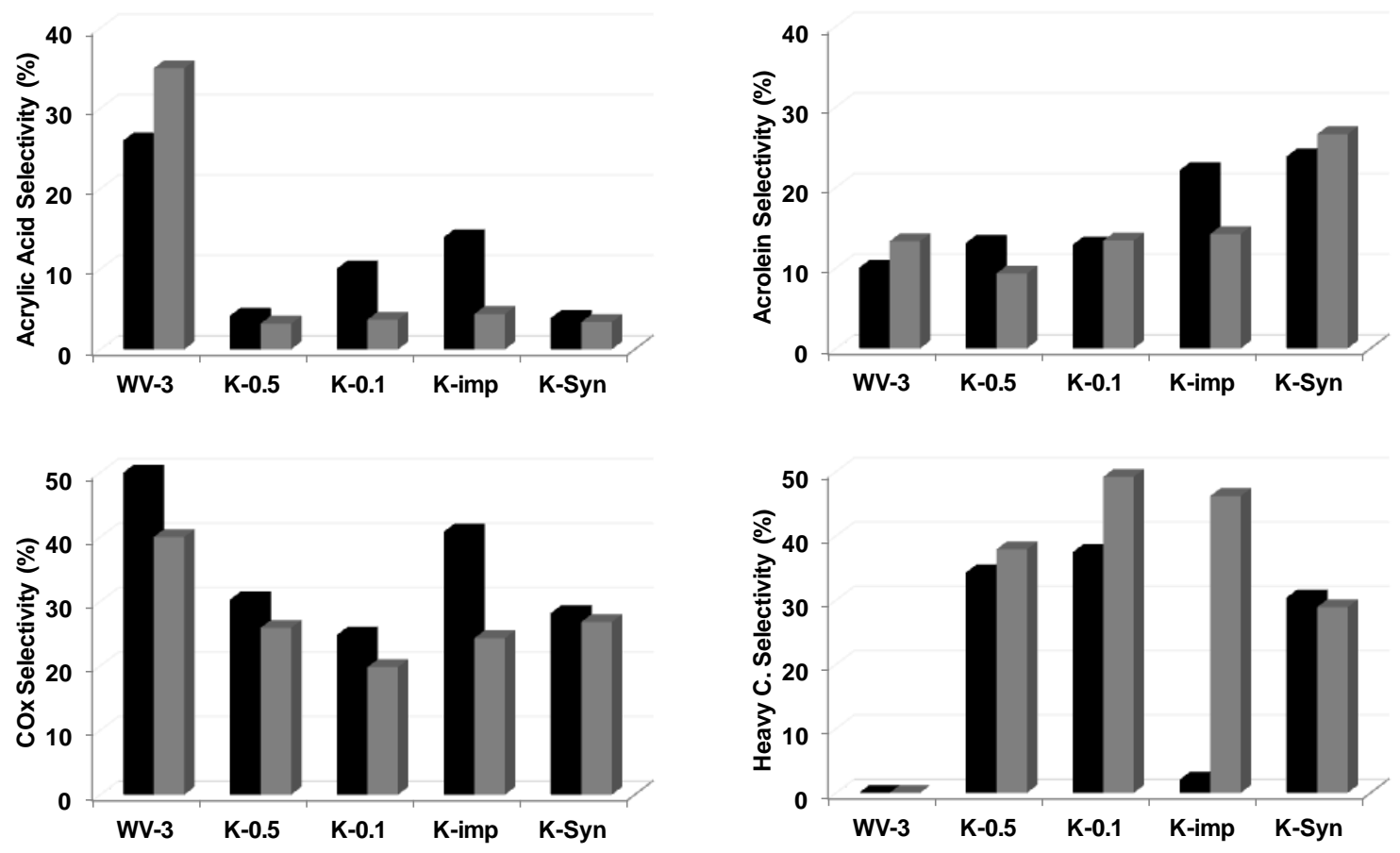

Figure 3.4.5. Glycerol oxidehydration on K-containing catalysts and WV-3. Temperature $290^{\circ} \mathrm{C}$, contact time $0.4 \mathrm{~s}$. Feed molar ratio (glycerol/oxygen/water/nitrogen) 2/4/40/54 (匹) and 6/12/40/42 ( $\square$ ). Glycerol conversion always complete. In all cases, acetaldehyde and acetic acid formed with selectivity values between 10 and $15 \%$. Unknown compounds formed in minor amounts (selectivity 1-2\%), with the only exception for the test with feed molar ratio 2/4/40/54 using $\mathrm{K}$-imp; in this case selectivity to unknown compounds (most likely ketals and oligomers) was close to $33 \%$.

The differences observed show that the preparation method used has remarkable consequences on reactivity, despite the similar amount of alkaline metal. For instance, the exchange method as well as the addition of potassium in the synthesis gel seem to have the greatest influence on acidity and therefore on the dehydration properties. Indeed, with feed molar ratio $2 / 4 / 40 / 54$, the formation of heavy compounds is very high compared to the catalyst prepared by K-impregnation, 
even if in the last case remarkable amounts of oligomers and ketals formed. This might be due to the different influence on $\mathrm{Br} \phi$ nsted and Lewis acid sites of the preparation method used. Indeed, as it was demonstrated and commented in the previous chapters, Br申nsted acid sites are selective for glycerol oxidehydration to acrolein whereas Lewis acid sites lead to monodehydration products and finally to heavy compounds, as reported in scheme 3.4.1.

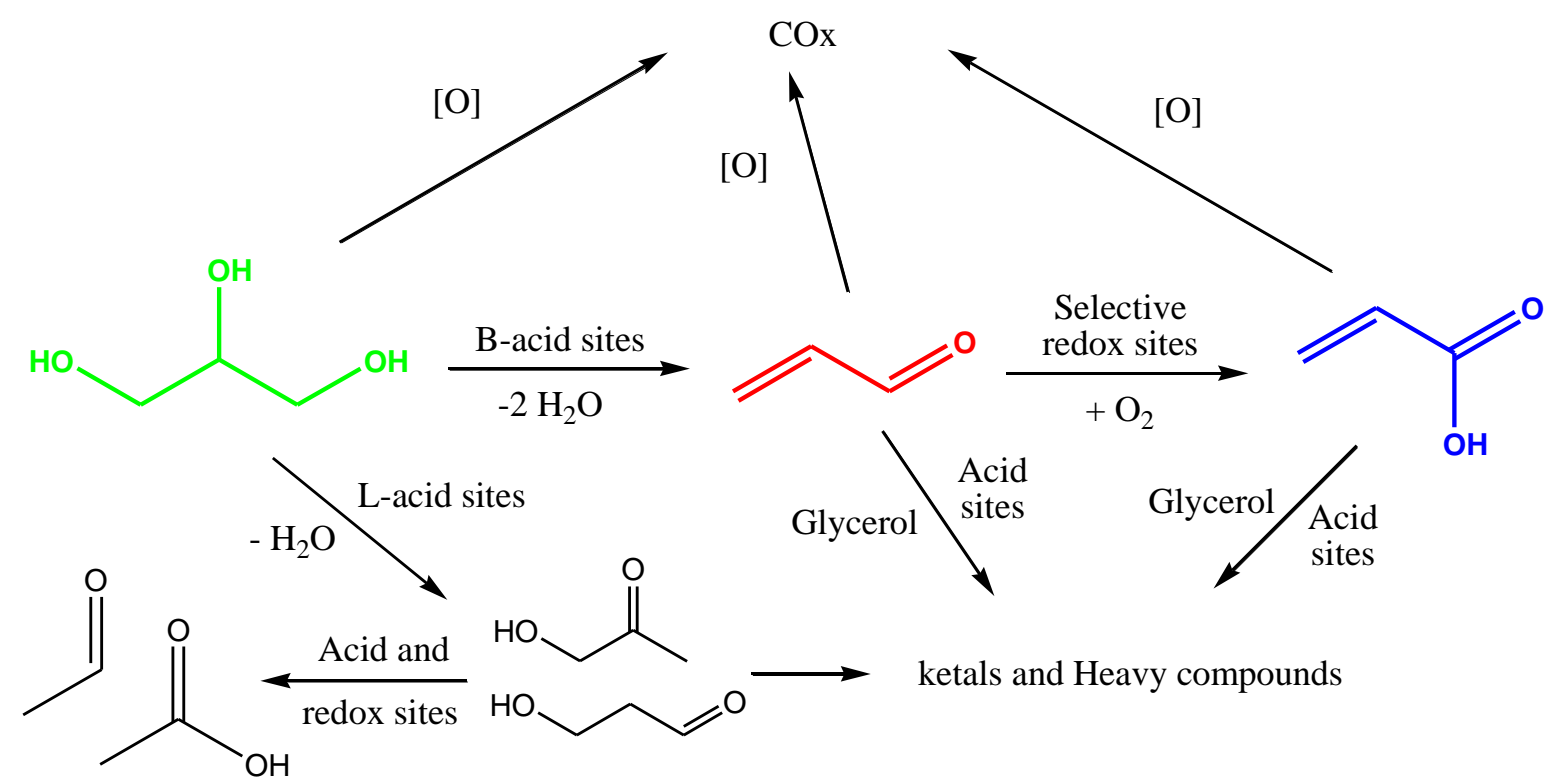

Scheme 3.4.1. Main products obtained from glycerol oxidehydration. It is stressed the role of active sites in each step.

As discussed in chapter 1.8, in HTBs the Brфnsted acid sites important for the glycerol selective dehydration are mainly located within the channels. The exchange method substitutes ammonium ions (which, after heat-treatment, transform into $\mathrm{H}^{+}$) for $\mathrm{K}$-ions in the parent materials of the oxides, therefore affecting consistently the number of Brфnsted acid sites in the final catalysts. Moreover, as evidenced by $\mathrm{NH}_{3}$-TPD analysis, the stronger acid sites are the ones mainly affected by the presence of potassium. In a similar way, the addition of potassium along the synthesis of the catalyst introduces K-ions in the channels, instead of ammonium-ions. Considering the bulk nature of catalyst K-syn, the overall quantity of K-ions present on the surface 
(hence accessible to organic molecules) should be less than the total amount found by EDX analysis, therefore explaining the lower formation of heavy compounds and the higher acrolein formation for K-syn than K-0.1. Instead, with the impregnation method potassium is dispersed randomly on the surface and it affects statistically both Lewis and $\operatorname{Br} \phi$ nsted sites, explaining the much higher acrolein selectivity and the low formation of heavy compounds. So as to further support the results just presented, XP-spectroscopy and FTIR analysis with adsorbed ammonia are currently being carried out for all the catalysts presented in this chapter. These investigations can provide important insights on the relative distribution of potassium in the catalysts as well as semi-quantitative figures on the ratio between Brфnsted and Lewis acid sites. Additionally, from figure 3.4.4 it is evident that the presence of potassium not only affects the acid properties but also the redox ones. Acrylic acid and $\mathrm{CO}_{x}$ selectivities are lower for all the K-containing catalysts compared to WV-3. The impregnation method also affects less the redox properties compared to the exchange preparation. Finally, the low selectivity to acrylic acid of K-syn, can be partially attributed to the lower content of vanadium (0.16 vs. 0.21$)$; however, it cannot be the only explanation since WV-2 that has $\mathrm{V} / \mathrm{W}$ ratio equal to 0.12 , showed acrylic acid yield up to $18 \%$ (vs. $4 \%$ for K-syn) [1]. Overall, comparing these results to $\mathrm{H}_{2}$-TPR analysis, some important differences can be pointed out; catalysts containing significantly different amounts of potassium (i.e. $\mathrm{K} / \mathrm{W}=0$, 0.1 or 0.21 ) presented different reduction profiles. However, when the amount of potassium was similar (catalysts K-0.1, K-Imp and K-Syn), the $\mathrm{H}_{2}$-TPR profiles where quite similar, particularly for the first reduction peak. The differences between TPR and catalytic tests suggest that $\mathrm{H}_{2}$-TPR analysis might not be completely representative of the redox property of vanadium in this systems; the catalytic phenomenon involves only the oxides surface accessible to the organic molecules involved, whereas $\mathrm{H}_{2}$-reduction can affect the whole bulk of the catalyst and/or also the active sites not accessible to larger molecules. However, a univocal rationalization of the 
reasons why the redox properties are so remarkably affected by potassium is not so straightforward. The heavy compounds formation (due to the lower acid properties) in such high amounts is a possible explanation since the deposition of carbonaceous material on the catalysts surface also lowers the availability of the redox sites. Similarly, the decreased surface area due to the presence of potassium (see table 3.4.1) leads to the same phenomenon. Potassium might also directly interact with $\mathrm{V}$-ions because of acid-base affinity, finally poisoning the redox sites.

Remarkable changes in the catalytic performance were observed when the feed molar ratio was varied from 2/4/40/54 to 6/12/40/42 (glycerol/oxygen/water/nitrogen) -see figure 3.4.5-. Indeed, as observed for the other substituted-HTBs previously studied, WV-3 improved its catalytic performance and acrylic acid selectivity up to $35 \%$ where reached (further tests and comments on this mixed-oxide are reported below); however, none of the potassium-containing catalysts showed this behavior, actually displaying a reverse trend for acrylic acid selectivity. Carbon oxides also decreased and heavy compounds augmented, particularly for K-imp. In this case, the oligomers and ketals that formed at lower partial pressures of reactants, might be seen as the "precursors" of the heavy compounds (not eluted in the GC system, but left as residues on both reactor walls and catalyst surface) that form in the latter case. These evidences clearly show that redox sites are poisoned by potassium, making slower their redox cycle and the consecutive oxidation processes, finally enhancing the by-products formation and polymerizations. The remarkable change observed for $\mathrm{K}$-imp also indicates that, although the impregnation process affects less the catalyst, at higher partial pressures of reactants the decreased availability of active sites becomes more evident.

In order to extend the various conclusions drawn in this thesis on HTB-like systems to other multifunctional catalysts, modified-AIPO catalysts and commercial VPP were used as reference 
mixed-oxides. These materials are well known catalysts used in selective oxidation processes, such as cyclohexane oxidation, ethane-ODH and maleic anhydride synthesis $[81,124,125]$.

In figure 3.4.6 are reported the catalytic results obtained on the multifunctional catalysts analyzed. As an explorative test, the contact time optimal for WV-3 (ca. 0.4s) was used also for the other oxides. Preliminary studies were also carried out -not reported in figure- using the CoAIPO catalyst (without vanadium); in spite of the acid properties of this material, glycerol conversion was complete only at temperature $\geq 360^{\circ} \mathrm{C}$ and no acrylic acid was formed. Moreover, significant amounts of heavy compounds were formed (selectivity between $50 \%$ and $40 \%$ ). However, the addition of vanadium consistently improves the activity of the catalyst since in all cases and for all temperatures, glycerol conversion was always complete both for V-CoAIPO and V/V-CoAIPO. VPP showed always a complete conversion of glycerol, too. WV-3, as most of the previously reported substituted-HTBs, displayed the highest acrylic acid yield at low temperature, which decreased steeply rising the temperature, in favor of carbon oxides. Differently, V-CoAIPO showed an acrylic acid maximum at $330^{\circ} \mathrm{C}$; at higher temperatures, heavy compounds selectivity decreased not only in favor of $\mathrm{CO}_{x}$, but also to acrolein in minor extent.

In an attempt to improve the acrylic acid selectivity of V-CoAIPO, catalyst V/V-CoAIPO was prepared by impregnation of the latter with additional vanadium -1wt\%-. Contrary to the vanadium present in V-CoAIPO, which is part of the Al-P-(Co)-O lattice, the vanadium impregnated forms extra-framework species as $\mathrm{V}_{2} \mathrm{O}_{5}$ (see discussion for XRD analysis). Taking into consideration the products distribution obtained on V/V-CoAlPO, the extra-framework vanadium species seem to (i) block the active in-framework-V-sites, (ii) enhance total oxidation to carbon oxides and (iii) be completely inactive towards the selective oxidation of acrolein to acrylic acid. It is of interest to compare our results to the ones obtained by Pestana et al. using vanadium-impregnated zeolitebeta [61]. Indeed, although extra-framework vanadium species were also present in the latter 
materials, acrylic acid selectivity up to $25 \%$ were obtained, although at glycerol conversion lower than $80 \%$. However, these authors used $10 \mathrm{wt} \%$ vanadium loadings and the surface area of the catalyst was quite higher $\left(268 \mathrm{~m}^{2} / \mathrm{g}\right)$ than the one of V/V-CoAlPO discussed in this chapter (192 $\left.\mathrm{m}^{2} / \mathrm{g}\right)$. Unfortunately, the glycerol oxidehydration reaction was performed at only two temperatu-
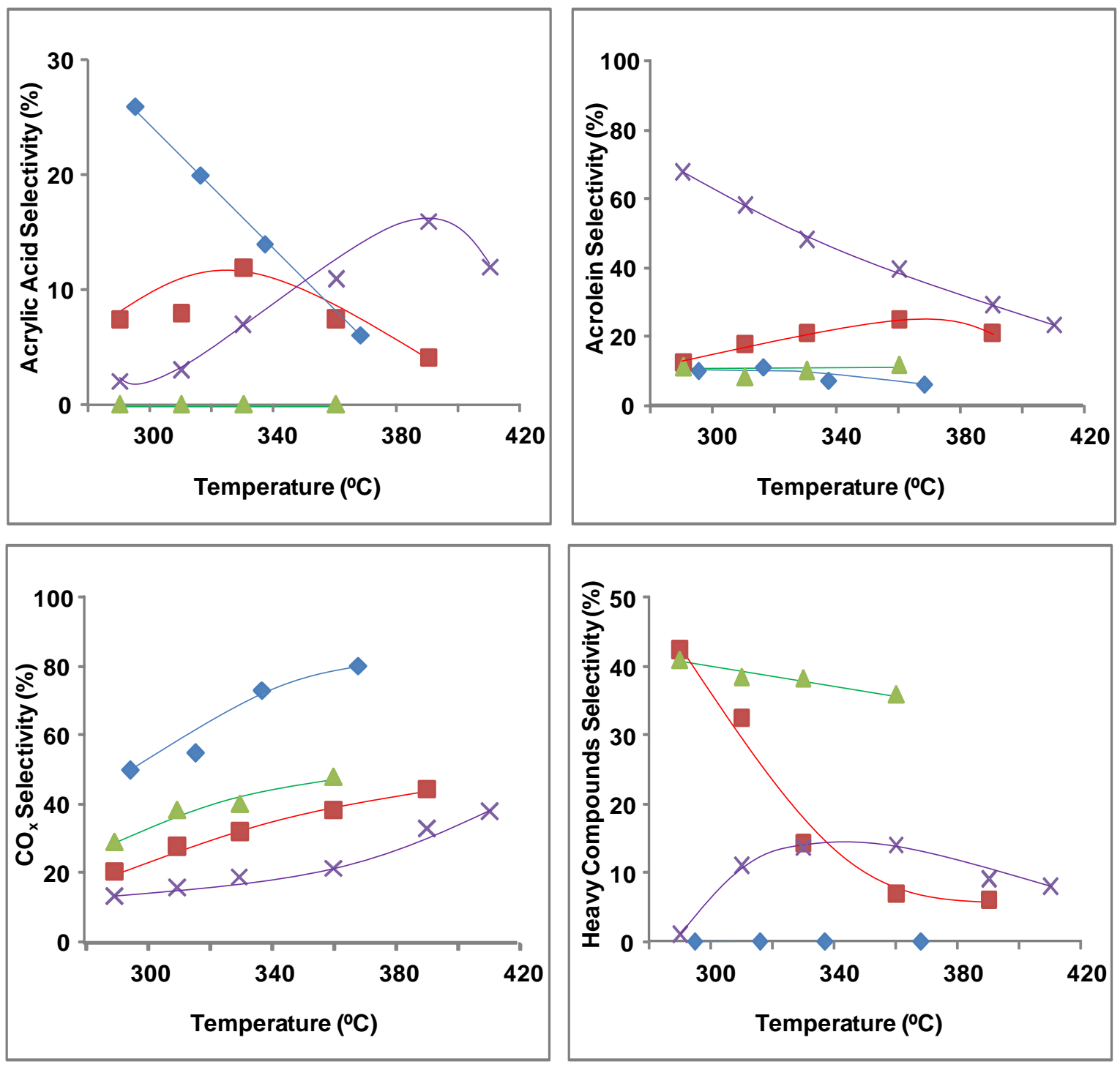

Figure 3.4.6. Catalytic behavior of WV-3 $(\diamond)$, V-CoAIPO $(\square)$, V/V-CoAIPO $(\Delta)$, VPP $(X)$ in glycerol oxidehydration tests as a function of temperature. Feed composition: 2 mol\% glycerol, 4 mol\% oxygen, 40 mol\% water, and 54 mol\% helium. Contact time $0.4 \mathrm{~s}$ (Calculated at room temperature). Glycerol conversion always complete. Acetaldehyde, acetic acid and other compounds formed with the following selectivities on each catalyst: V-CoAIPO 15-25\%, VPP and V/V-CoAIPO $11-18 \%$, WV-3 8-12\%. Among the "other compounds", hydroxyacetone was also present. However, numerous unknown species also formed. 
-res therefore it is not possible to further discuss the catalytic behavior of those materials and compare them with the ones reported herein.

The industrial VPP catalyst displayed a very peculiar catalytic behavior, for some aspects similar to V-CoAIPO but completely opposite to $\mathrm{WV}-3$. The $\mathrm{CO}_{\mathrm{x}}$ selectivities, at all the temperatures investigated, are the lowest among all catalysts; however, what is mainly remarkable is the increase in acrylic acid selectivity at high temperatures (maximum $16 \%$ at $390^{\circ} \mathrm{C}$ ), that is where all the HTB-like catalysts showed their minimum. As a consequence, the acrolein yield decreased since it is partially and totally oxidized to acrylic acid and $\mathrm{CO}_{\mathrm{x}}$.

So as to deepen the knowledge on the catalytic behavior of WV-3, V-CoAlPO and VPP, the same catalytic tests as a function of feed molar ratios previously performed for $\mathrm{W}-\mathrm{V}-\mathrm{Nb}$ and $\mathrm{W}-\mathrm{Mo}-\mathrm{V}$ catalysts, where also carried out for these systems. However, in order to better evaluate the catalytic performance of each oxide, preliminary studies on the influence of contact time were carried out (not shown) using the feed molar ratio gly/oxygen/water/nitrogen 2/4/40/44, which proved that V-CoAIPO has its optimal contact time at ca. $0.4 \mathrm{~s}$ as WV-3, whereas the one of VPP is located at higher values, ca. 1s. In figure 3.4.7 is reported the product distribution for each mixedoxide as a function of feed composition, using for each catalyst the respective optimal temperature and contact time (see details in figure's caption).

WV-3 showed its maximum acrylic acid selectivity (35\%) at oxygen-to-glycerol molar ratio $12: 6$, as all the other HTB-like catalysts. Comparing these results to what observed previously with WMoV3 (see chapter 2.6), it is evident the important role played by molybdenum in the latter system since, under the same reaction conditions, it reached selectivity into the acid monomer as high as $51 \%$, thanks to the more selective oxidation of acrolein (less $\mathrm{CO}_{\mathrm{x}}$ ). V-CoAlPO did not improve its performance varying the feed molar ratio, since the acrylic acid maximum (12\%) was found to be in the previously explored conditions, i.e. oxygen-to-glycerol molar ratio 4:2. 

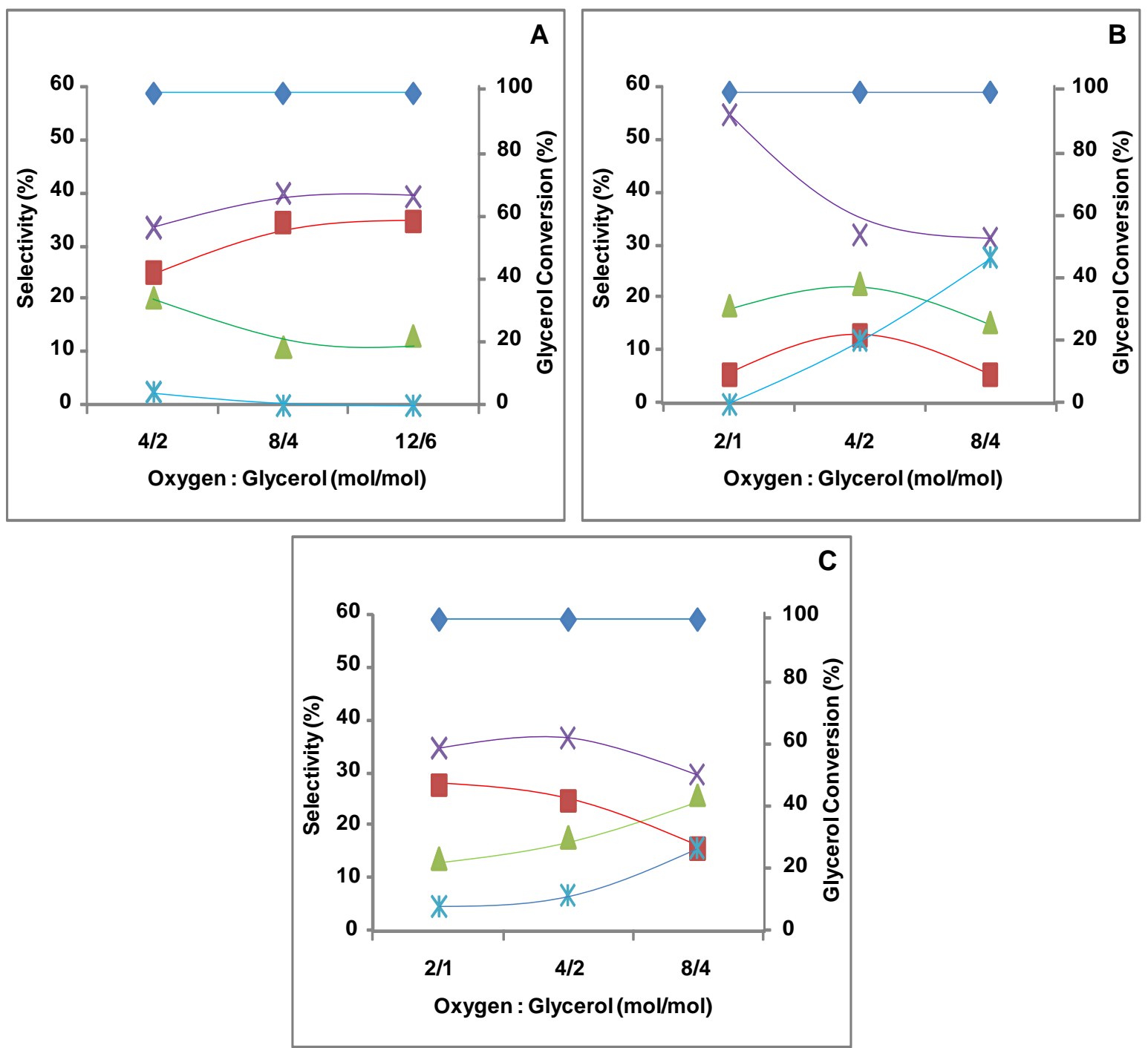

Figure 3.4.7. Glycerol oxidehydration as a function of feed molar ratio on A) WV-3, B) V-CoAIPO, C) VPP. Symbols: Acrylic Acid ( $\square$ ), Acrolein ( $\Delta$ ), $\mathrm{CO}_{x}(\mathrm{X})$, Heavy compounds (*). Glycerol conversion always complete. Further compounds detected but not reported in the plot: (i) WV-3: acetic acid and acetaldehyde 2-3\%, unknown compounds 2-3\%. (ii) VCoAIPO: acetaldehyde + acrylic acid 8-17\%, unknown compounds 3-7\%. (iii) VPP: acetic acid ca. 10\%, unknown compounds $2 \%$. Feed molar ratio Oxygen/Glycerol/Water/Nitrogen=4/2/40/54. Reaction conditions: WV-3: $T$ (temperature) $290^{\circ} \mathrm{C}$, Tau (contact time) $0.4 \mathrm{~s}$; V-CoAlPO: T $330^{\circ} \mathrm{C}$, Tau $0.4 \mathrm{~s}$; VPP: T $390^{\circ} \mathrm{C}$, Tau $1 \mathrm{~s}$.

Also in this case, VPP showed the opposite behavior than HTB-like catalysts, presenting the maximum acrylic acid selectivity (28\%) at oxygen-to-glycerol molar ratio 2:1. At higher pressures of reactants both partial and total oxidation were hampered, provoking the increment of the intermediate product (acrolein) and finally the formation of heavy compounds. 
At this stage, it is worth mentioning that V-P-oxides have already the been subject of publication by Ueda and co-workers as catalysts for glycerol dehydration and oxidehydration [78]. Among the V-P-O materials prepared, these authors found that $\mathrm{VOHPO}_{4} \cdot 0.5 \mathrm{H}_{2} \mathrm{O}$ was the best performing phase, with acrolein yield up to $66 \%$. Their vanadyl pyrophosphate showed acrolein selectivity up to $41 \%$ but only traces of acrylic acid. However, whatever the V-P-O phase used, acrylic acid was always a minor product (maximum selectivity $8 \%$ at $350^{\circ} \mathrm{C}$ ). The different results obtained in this work on the commercial VPP catalyst can be explained as follows: (i) the pyrophosphate catalyst used in [78] has a significantly lower surface area $8 \mathrm{~m}^{2} / \mathrm{g}$ (vs. $41 \mathrm{~m}^{2} / \mathrm{g}$ of the commercial VPP); (ii) the reaction conditions used in [78] are not the optimal ones for VPP, since oxygen-to-glycerol molar ratio of about 9:1 was used, that is the feed molar ratio we have demonstrated, for this catalyst, to depress the selective oxidation of acrolein and favor its total combustion (selectivity up to $22 \%$ in $\mathrm{CO}_{x}$ were obtained associated to the maximum acrylic acid selectivity observed in [78]); (iii) most likely due to the scarce formation of acrylic acid observed on pyrophosphate during the preliminary screening tests [78], its catalytic performance was analyzed at a single temperature, i.e. $300^{\circ} \mathrm{C}$ (differently to what done for the hydrated V-P-O phase), which is too low compared to the optimal value, i.e. $390^{\circ} \mathrm{C}$; (iv) the presence of silica in the commercial-VPP catalyst used might play a role in the catalytic result, although considering the absence of redox properties and the scarce acid features of $\mathrm{SiO}_{2}$, it seems quite unlikely.

All in all, the remarkable difference displayed by HTB-like catalysts and VPP opens important questions on the reasons why their catalytic behavior for glycerol oxidehydration is opposite. Both systems are acid catalysts that can efficiently dehydrate glycerol into acrolein; however, the same active element (vanadium) behaves in an opposite manner in the consecutive oxidation step. Hence, so as to efficiently carry out the glycerol oxidehydration it is not enough to couple acid and redox properties in the same catalyst, but it seems to exist a complex structure-reactivity 
correlation that governs the more or less selective oxidation process. These results could be explained by (i) a faster re-oxidation ability of vanadium in VPP and/or (ii) by a different adsorption of glycerol and acrolein on the surface of the catalyst, which in turn doesn't lead to the fast saturation of the active sites as previously observed in HTB-like catalysts. So as to shed light on these phenomenon, FTIR studies of adsorbed acrolein are currently being carried out on the catalysts involved in this chapter.

In an attempt to further explore the structure-reactivity correlations of multifunctional catalysts for glycerol oxidehydration, the catalytic behavior of HTBs can be compared to an hexagonal tungsten oxide exchanged with $\mathrm{V}$-ions (catalyst $\mathrm{V} / \mathrm{WO}_{\mathrm{x}}$ ). This way, it is possible to compare the catalytic behavior of vanadium when it either belongs to the HTB framework or it is present as extra-framework species -see discussion for XRD (vide supra)-. Due to the lower amount of vanadium that constitute $\mathrm{V} / \mathrm{WO}_{\mathrm{x}}$ compared to $\mathrm{WV}-3$ (V/W 0.15 vs. 0.21 ), it is more convenient to compare its performance to $W V-2$, whose composition is $W_{1} V_{0.12}$-see table 3.4.1-. In figure 3.4.8 are reported the results obtained on the two catalysts under the optimal reaction conditions for

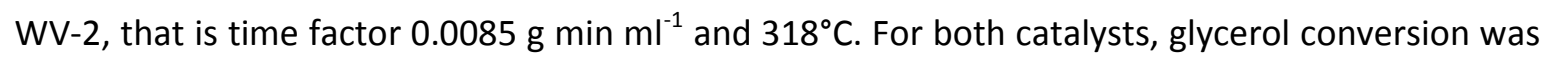
always complete. 


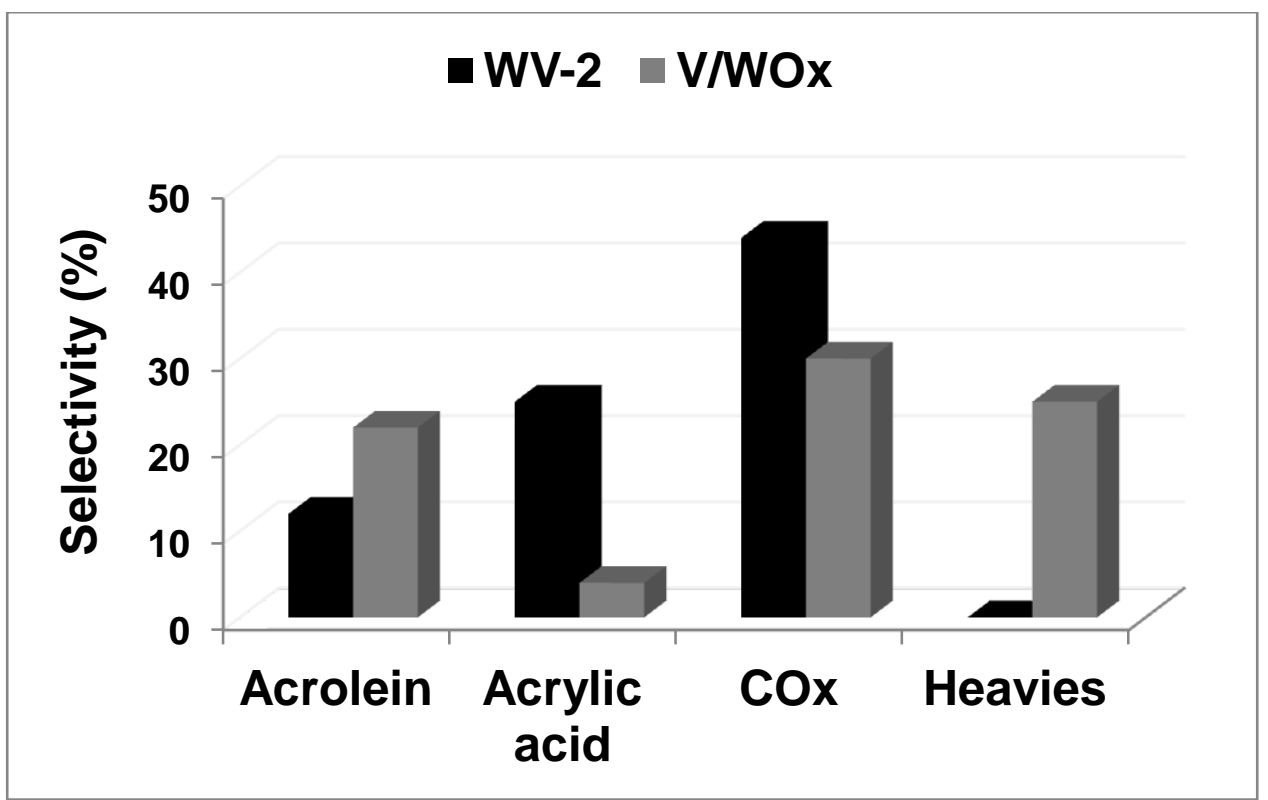

Figure 3.4.8. Glycerol oxidehydration on $\mathrm{WV}-2[1]$ and $\mathrm{V} / \mathrm{WO}_{\mathrm{x}}$. Temperature $290^{\circ} \mathrm{C}$, time factor $0.0085 \mathrm{~g} \mathrm{~min} \mathrm{ml}^{-1}$. Glycerol conversion always complete.

In spite of the formation of acrolein on $\mathrm{V} / \mathrm{WO}_{\mathrm{x}}$, acrylic acid formed just in minor amounts (3\%); however, $\mathrm{CO}_{\mathrm{x}}$ formed in remarkable amounts. Most likely due to the slower oxidation, secondary reactions were favored, finally leading to heavy compounds. This tests make evident that the presence of vanadium either inside or outside the oxide framework has a pivotal influence on the oxidation properties of the transition element.

Finally, some general considerations on the activity of vanadium in the various multifunctional catalysts have to be taken into account. Comparing WV-3 to V-CoAIPO it is clear the superior catalytic performance in glycerol oxidehydration of the former. However, the total amount of vanadium in V-CoAIPO is almost 10 times less than the one in WV-3, respectively ca. $0.4 \mathrm{wt} \%$ and 4 wt\%; if all the vanadium atom were available to the organic molecules, the Turnover Frequency (TOF) of acrylic acid per atom of vanadium would be approximately $1 \mathrm{~h}^{-1}$ for $\mathrm{WV}-3$ and $6 \mathrm{~h}^{-1}$ for $\mathrm{V}$ CoAlPO (compared using the same contact time $-0.4 s^{-}$, the same feed oxygen-to-glycerol molar ratio, $4 / 2$, but respectively at $290^{\circ} \mathrm{C}$ and $330^{\circ} \mathrm{C}$ ). Hence, the overall picture on the catalytic performance at the atomic level would be opposite. Nonetheless, the real accessibility of 
vanadium in the two catalysts is considerably different than the total amount present, particularly for HTBs. Indeed, it has been demonstrated that glycerol and acrolein (as well as the other byproducts) can enter the micropores of zeolites [126] and therefore also the ones of AlPO-5 materials; whereas, only the external surface area of HTBs is available for catalysis since these mixed-oxides have neither micropores nor any other kind of porosity (see the difference between BET and external surface area for the various catalysts reported in table 3.4.1). Concluding, although the quantification of the number of vanadium atoms really accessible by glycerol and acrolein might be impossible, these observations have to be taken into consideration to make a right comparison of the catalytic performances. Analogous reflections are appropriate once considering the mesoporosity of the industrial VPP catalyst used or the availability of vanadium in $\mathrm{V} / \mathrm{WO}_{\mathrm{x}}$.

\subsubsection{Conclusions}

In order to perform the one-pot glycerol oxidehydration on single multifunctional catalysts, the acid and properties of the mixed-oxide used have to be carefully tuned. In spite that strong acid sites have been demonstrated to catalyze not only glycerol dehydration to acrolein but also heavy compounds formation, its presence is mandatory to allow the fast double dehydration of the polyol. If the strong acid sites are poisoned with potassium, the acrolein formation is hampered and glycerol is only partially dehydrated; moreover, potassium also affects the redox properties of vanadium. In the end, both phenomena lead to heavy compounds formation. Therefore, it doesn't seem possible to avoid the by-products formation by lowering the strength of the acid sites, since the same acid sites needed for the efficient glycerol oxidehydration are also responsible for catalyzing polycondensation reactions to ketals and heavy compounds. 
Glycerol oxidehydration was also perform on various multifunctional catalysts with both acid properties and vanadium as the redox element. Specifically were used: (i) V-substituted-HTBs, (ii) V-containing Al-P-(Co)-oxides, (iii) commercial Vanadyl Pyrophosphate -VPP- and (iv) a Vexchanged hexagonal-tungsten oxide. The results obtained on these materials highlight that vanadium doesn't behave in the same way in the consecutive oxidation step. For instance, VPP behaves in an opposite manner than V-substituted-HTBs; the former displays the highest acrylic acid yield (28\%) at high temperature and low feed molar ratios of the reactant, whereas the latter works better ( $35 \%$ acrylic acid selectivity) at low temperatures and high feed molar ratios. Moreover, the vanadium redox sites located either inside or outside the oxide framework of HTBs and modified-AIPOs show very different catalytic behavior. In-framework V-sites seem to be much more selective toward the partial oxidation of acrolein than extra-framework V-species. Further analysis are currently in preparation to better define the phenomena observed. 


\section{$3.5 X$-ray Absorption Spectroscopy (XAS) with synchrotron radiation as a tool to better comprehend the complex structure of substituted-HTBs}

In the previous chapters, substituted-HTBs have been demonstrated to be complex mixed-oxide whose structure is strongly influenced by preparation method, elemental composition and postsynthesis heat-treatments. Their complexity becomes particularly evident in tri-component oxides, i.e. $\mathrm{W}-\mathrm{V}-\mathrm{Nb}$ and $\mathrm{W}-\mathrm{Mo}-\mathrm{V}$, respectively discussed in chapter 2.4-2.5 and 3.3. Indeed, the introduction of vanadium in the HTB structure did not lead to any particular changes in terms of crystallinity, which made it possible to well-characterize the nature of $\mathrm{W}-\mathrm{V}$ catalysts by conventional powder-XRD. However, when either $\mathrm{Nb}$ or Mo were introduced, the crystallinity of these materials significantly decreased, hampering an easy characterization by conventional analysis. For instance, the best performing W-V-Nb catalyst for glycerol oxidehydration (WVNb-1) had almost $60 \%$ of amorphous phase (see chapter 2.5 ). W-Mo-V catalysts were even more complex to characterize since at high contents of molybdenum the only result given by X-ray diffraction was the presence of a stacked material with cell parameters of ca. $3.8 \AA$.

Even though microscopy (particularly TEM) can give important information to characterize these oxides in the so-called long range order, it cannot help in clarifying the very intimate nature of the local-environment around each element in the oxide frame, particularly if the material is poorly crystallized. For instance, this was the case for the TEM investigation carried out on WMoV-3. A more appropriate characterization technique for pursuing this piece of information is $\mathrm{X}$-ray Absorption Spectroscopy (XAS), which however requires highly technological equipments only available at synchrotron facilities -see chapter 2.2 for more details-. Thanks to the co-supervised PhD project that characterizes this thesis, it was possible to access the beamline BM25A "Spanish Line" at the European Synchrotron Radiation Facility (ESFR) in Grenoble (France) (ESFR experiment $\left.n^{\circ} 25-01-901\right)$ 
Part of the results obtained are presented and discussed below in the aim of shedding light on the local geometric structure of the substituted-HTBs presented in this thesis and used as catalysts for the one-pot glycerol oxidehydration.

\subsubsection{From the reagents to HTBs}

Before presenting the results obtained on the heat-treated materials, i.e. the catalysts used for glycerol oxidehydration, some interesting insights have been obtained analyzing vanadium in the catalysts precursors, that is the parent material obtained after the hydrothermal synthesis and that transforms into the final catalysts after heat-treatment at high temperature -see chapter 2.1. In figure 3.5.1 is reported an example of the results obtained for V-substituted hexagonal tungsten bronzes, specifically WV-3. The analysis of both the parent material and the catalyst itself were carried out and $\mathrm{VOSO}_{4}$ and $\mathrm{V}_{2} \mathrm{O}_{5}$ were used as reference materials. The pre-peak position is characteristic of the oxidation state of the investigated element; indeed, generally speaking, the higher the oxidation state, the higher the pre-peak energy. In fact, $\mathrm{V}_{2} \mathrm{O}_{5}$ presents the pre-peak at higher energy than $\mathrm{VOSO}_{4}$ since in the first case vanadium is in oxidation state (V) whereas in the latter (IV). The pre-peak position of WV-3-precursor indicates that the majority of vanadium is present in oxidation state (V), although the presence of vanadium (IV) cannot be discharged. However, once heat-treated in nitrogen at $600^{\circ} \mathrm{C}$, vanadium is reduced to V (IV) and (III) as it was also evidenced by XPS analysis in chapter 3.2. 

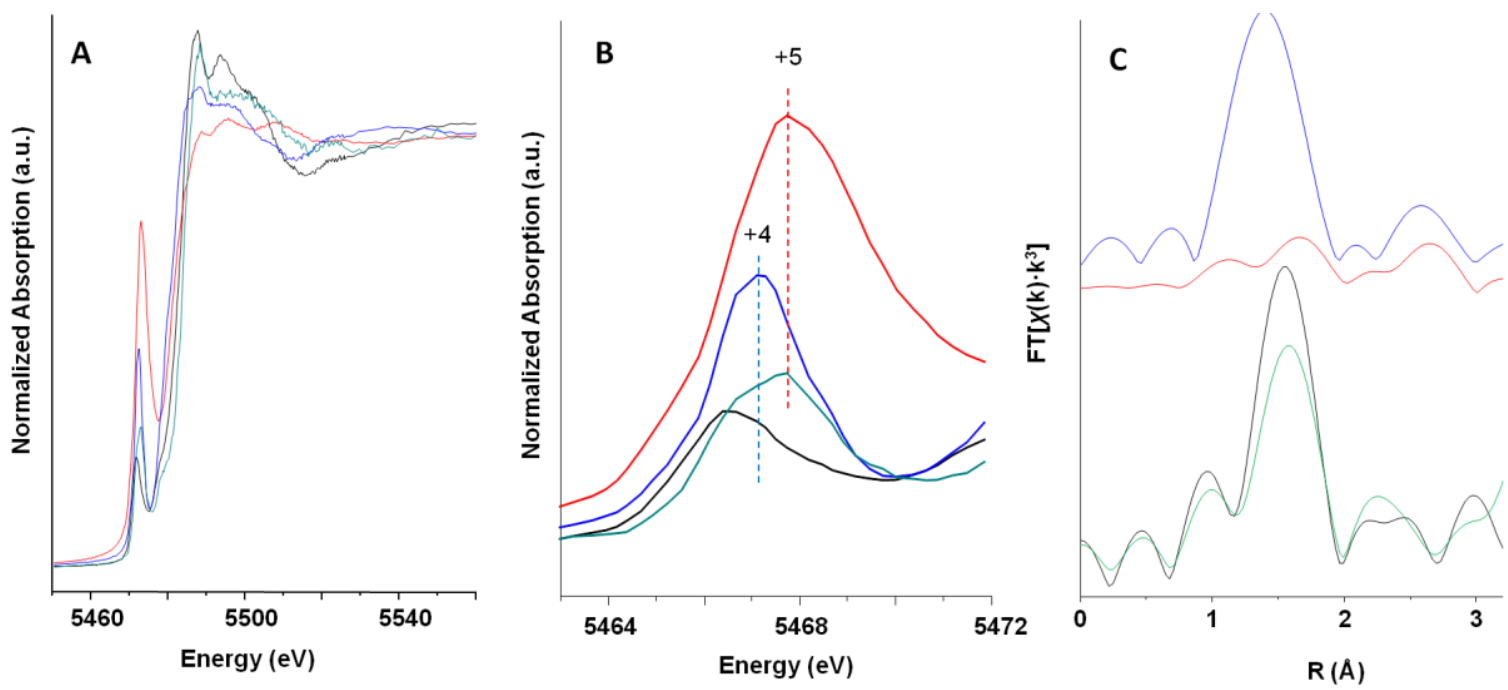

Figure 3.5.1. XAS analysis of WV-3 and related precursor. Vanadium K-edge. A) XANES region; B) Detail of the vanadium pre-peak; C) Fourier-transform of the EXAFS spectra. $\mathrm{V}_{2} \mathrm{O}_{5}$ (red line), $\mathrm{VOSO}_{4}$ (blue line), WV-3-precursor (green line), WV-3 (black line).

The variations observed well explain some aspects of the catalysts synthesis that were not completely understood. Indeed, we noticed that it isn't possible to synthesize the W-V oxide with HTB phase using a vanadium salt with the transition element in oxidation state (V). Moreover, pure $\mathrm{h}-\mathrm{WO}_{\mathrm{x}}$ (without vanadium) cannot be synthesized in the absence of a reductor (e.g. ammonium oxalate), which instead was not needed for the synthesis of W-V-O catalysts using $\mathrm{VOSO}_{4}$ as a source of vanadium. Results obtained by XAS permit to summarize all these observations according to scheme 3.5.1.

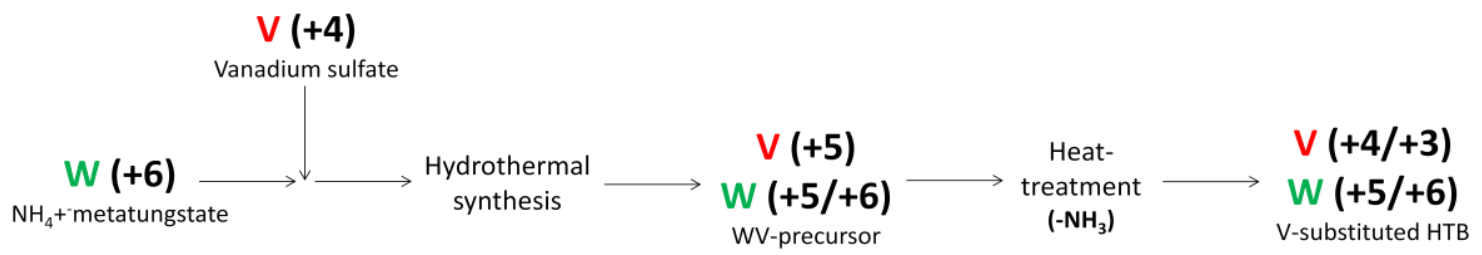

Scheme 3.5.1. Oxidation state of transition metals during the preparation of V-substituted HTBs. 
In short, as a tungsten source is used ammonium meta-tungstate which has tungsten as W (VI); instead, vanadium sulfate, i.e. V (IV), is the source of vanadium. The two reactants are mixed together to form a solution which is used for the hydrothermal synthesis. During the hydrothermal synthesis carried out in inert atmosphere, vanadium partially reduces tungsten to $\mathrm{W}(\mathrm{V})$ therefore it is oxidized to $\mathrm{V}(\mathrm{V})$. This process is fundamental for obtaining the hexagonal phase which is indeed composed by tungsten in a mixed oxidation state (V/VI) -see chapter 1.8-. As it can be observed by powder-XRD (figure 3.5.2), the solid obtained after the synthesis, washed and dried (WV-precursor), is already a W-V-mixed-oxide with hexagonal phase. However, with a slightly lower crystallinity compared to the final catalyst; some minor shifts of diffraction maxima also indicate a minimal rearrangement of atoms and/or of the cell-parameters of the oxide framework during the heat-treatment. This is also confirmed by EXAFS spectra of WV-precursor and WV-3 (figure 3.5.1, c), since the spectra are almost identical, with only minor changes in intensities that can be assigned to the variation in the increment of crystallinity and atom distribution observed by XRD. Comments on the EXAFS spectra of reference oxides are reported below.

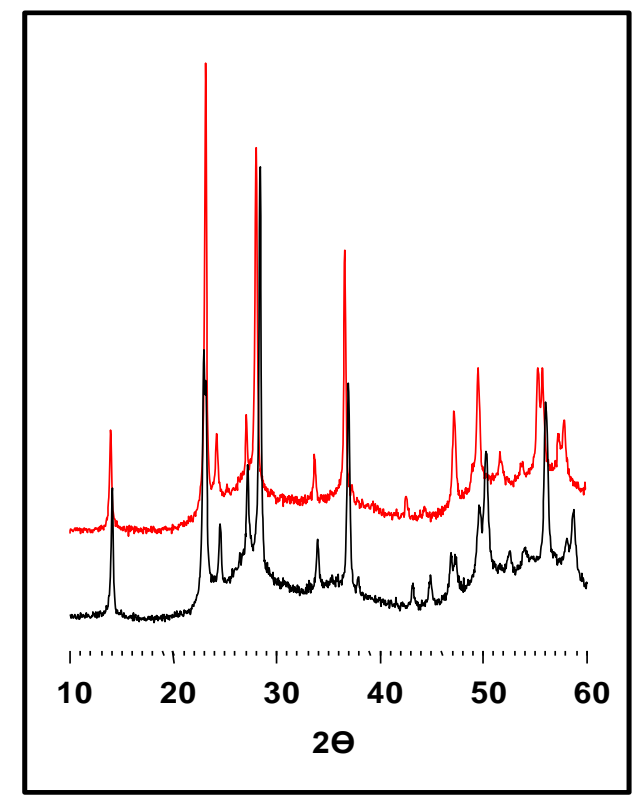

Figure 3.5.2. Powder-XRD of WV-precursor (black pattern below), and WV-3 (red pattern above). 
Finally, when WV-precursor is heat-treated in nitrogen up to $600^{\circ} \mathrm{C}$, ammonium ions decompose in $\mathrm{H}^{+}$and $\mathrm{NH}_{3}$. The protons remains in the channels that characterize the oxide lattice and generate its characteristic acidity; whereas ammonia leaves the solid favoring the reduction of vanadium (V) into vanadium (IV). Therefore, XAS results perfectly explain the reason why the vanadium source must have vanadium in a reduced state (e.g. (IV)) and/or an external source of reductant (e.g. oxalic acid) must be present to form the hexagonal framework. It also explains the mixed-oxidation state of tungsten and vanadium observed on the surface of fresh catalysts by XPS analysis -see chapter 2.5-. Of course, the same conclusions drawn using WV-3 can also be extended to the tri-component catalysts prepared, $\mathrm{W}-\mathrm{V}-\mathrm{Nb}$ and $\mathrm{W}-\mathrm{Mo}-\mathrm{V}$, taking also into consideration the constant oxidation state of $\mathrm{Nb}(\mathrm{V})$ and the easily interchangeable oxidation state of molybdenum (V/VI).

\subsubsection{Vanadium coordination in HTBs}

The studies carried out by studying the K-edge of vanadium in $\mathrm{W}-\mathrm{V}, \mathrm{W}-\mathrm{V}-\mathrm{Nb}$ and $\mathrm{W}-\mathrm{Mo}-\mathrm{V}$, has also allowed us to gain additional knowledge on the local geometry of the transition element in the three series of substituted-HTBs. In figure 3.5.3 are reported the EXAFS spectra of representative samples of each series and compared to reference materials. EXAFS spectra of catalysts prove that vanadium has a very similar oxygen coordination shell in all three samples, despite XRD analysis showed either the presence of a well-crystallized hexagonal phase (WV-3), or consistent presence of amorphous phase (WVNb-1), or simply a structure with orderly stacked crystal planes (WMoV-3) -see previous chapters-. Provided the similarities among them, comparing these catalysts to reference materials $\left(\mathrm{V}_{2} \mathrm{O}_{5}\right.$ and $\left.\mathrm{VOSO}_{4}\right)$ it can be deduced that the local geometry of vanadium in the catalysts is much more similar to $\mathrm{V}_{2} \mathrm{O}_{5}$ than $\mathrm{VOSO}_{4}$. 


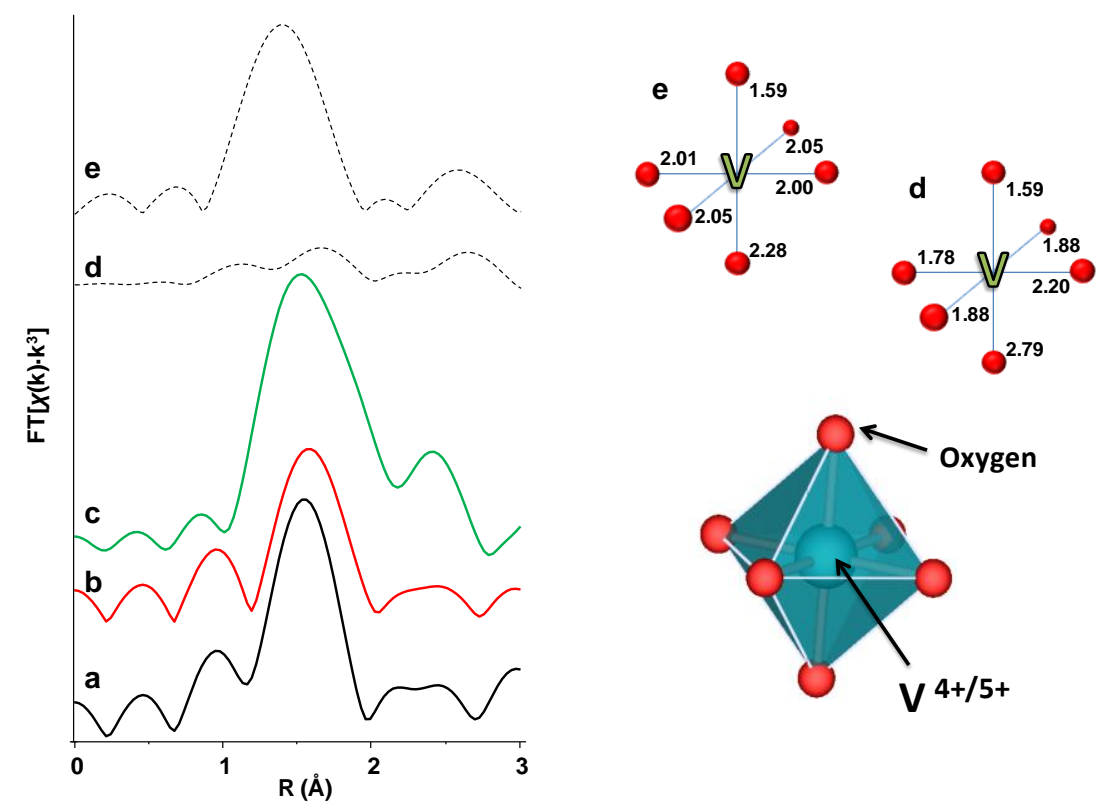

Figure 3.5.3. Left: Fourier-transform of the EXAFS spectra for representative samples of substituted-HTBs and reference materials. a) WV-3, b) WVNb-1, c) WMoV-3, d) $\mathrm{V}_{2} \mathrm{O}_{5}$, e) $\mathrm{VOSO}_{4}$. Right: Exemplification of the V-coordination in HTBs and reference catalysts. Bond length values for references were obtained from the literature (see text).

EXAFS spectra of vanadium pentoxide has a very low intensity due to destructive interference of the various contribution from the multiple V-O lengths that characterize its distorted octahedral coordination [127] (see figure 3.5.3). Instead, vanadyl sulfate has a more regular distribution of VO lengths [128] (see figure 3.5.3) that explains the higher intensity of the EXAFS spectra. Hence, vanadium local geometry in substituted-HTBs is always very similar and it seems to be characterized by octahedral coordination with quite a regular (but not equal) distribution of V-O lengths. These conclusions are supported by XANES (as an example, see spectra of WV-3 and references in figure 3.5.1, $a$ and b) where the pre-peak of vanadyl sulfate is the most similar to the one of the catalysts, and less intense than the one of vanadium pentoxide as an indication of a more centrosymmetric coordination environment for $\mathrm{VOSO}_{4}$. However, the existence of the prepeak also for the catalysts is an unquestionable evidence that, although quite regular, vanadium is in an octahedral environment without inversion center, i.e. not-perfectly regular. 
Concluding, the various catalysts prepared consist of mixed-oxide with hexagonal tungsten bronze structure, which is well or poorly crystallized depending on elemental composition, preparation method and post-synthesis heat treatments. These features characterize the long-range order of crystals, which can be observed by transmission electron microscopy. However, the transition elements that constitute these materials ( W, V, Nb, Mo) are organized in corner-sharing octahedra more or less distorted which form orderly stacked crystal planes with d-spacing of ca. 3.8 $\AA$, typical of any $\mathrm{ReO}_{3}$-like crystal structures, to whom hexagonal tungsten bronzes belong. Computational studies aimed at simulate the EXAFS spectra obtained at the synchrotron are currently in preparation; this way, a quantitative evaluation of the various metal-oxygen distances can be achieved. 


\section{Overall Conclusions}

Hexagonal Tungsten Bronzes (HTBs) and related oxides are a very interesting family of materials with a great potential for innovative application in catalysis. The acid properties related to their peculiar structure make them valuable catalysts for applications where medium-to-strong acidity is needed, particularly if $\operatorname{Br} \phi$ nsted acid sites are required. Moreover, a great number of elements can be incorporated inside or outside the hexagonal framework, giving to these oxides an amazing potential as multifunctional catalysts. However, probably due to the complexity of these materials as well as their difficult characterization, their use in catalysis has been significantly hampered.

Along the PhD promgram, three years of research were dedicated to the synthesis, characterization and utilization as catalysts of multifunctional HTB-like materials, thanks to an international collaboration between ITQ-UPV (Spain) and University of Bologna (Italy). "Soft"chemical methods were used to revise and improve the synthesis of HTBs and a number of physicochemical techniques (among which HR-TEM and XAS) were utilized to fully comprehend their nature. Introduction of niobium in $\mathrm{W}-\mathrm{V}$ HTBs was proved to be possible also through hydrothermal synthesis; moreover, for the first time in literature, new W-Mo-V oxides with HTBlike structure were obtained. These materials were applied as catalysts for the one-pot glycerol oxidehydration, a reaction potentially able to find a viable solution for the glycerol surplus from the biodiesel synthesis. The catalytic results obtained position these multifunctional HTBs as the most effective catalysts so far reported in literature for this reaction. Finally, a comparison of Vcontaining HTBs to other multifunctional (acid and redox) catalysts containing vanadium was performed. The results clearly indicate that a peculiar structure-reactivity correlation exists and the local environment of vanadium seems to govern its redox properties. 
The overall results reported herein might represent a significant contribution for future applications of HTBs in catalysis as well as a general guideline for a multifaceted approach for their physicochemical characterization. 


\section{Publications}

Along the three year of the PhD program various papers were published, both directly related to the topic of this PhD thesis and about other projects not discussed herein.

\subsection{Publications related to the research project presented in this PhD thesis}

- A. Chieregato, F. Basile, P. Concepción, S. Guidetti, G. Liosi, M. Dolores Soriano, C. Trevisanut, F. Cavani, José M. López Nieto, Glycerol oxidehydration into acrolein and acrylic acid over $\mathrm{W}-\mathrm{V}-\mathrm{Nb}-\mathrm{O}$ bronzes with hexagonal structure, Catalysis Today, Volume 197, Issue 1, 2012, Pages 58-65.

- A. Chieregato, M. Dolores Soriano, F. Basile, G. Liosi, S. Zamora, P. Concepción, F. Cavani, José M. López Nieto, One-pot glycerol oxidehydration to acrylic acid on multifunctional catalysts: Focus on the influence of the reaction parameters in respect to the catalytic performance, Applied Catalysis B: Environmental, Volumes 150-151, 2014, Pages 37-46.

- A. Chieregato, M. Dolores Soriano, E. García-González, G. Puglia, F. Basile, P. Concepción, C. Bandinelli, José M. López Nieto, Fabrizio Cavani, Multielement Crystalline and Pseudocrystalline Oxides as Efficient Catalysts for the Direct Transformation of Glycerol into Acrylic Acid, ChemSusChem, DOI: 10.1002/cssc.201402721.

\subsection{Publications related to other projects}

- J. J. Creasey, A. Chieregato, J. C. Manayil, C. M. A. Parlett, K. Wilson, Adam F. Lee, Alkaliand nitrate-free synthesis of highly active $\mathrm{Mg}-\mathrm{Al}$ hydrotalcite-coated alumina for FAME production, Catalysis Science \& Technology, Volume 4, 2014, Pages 861-870.

- D. Cespi, F. Passarini, G. Mastragostino, I. Vassura, S. Larocca, A. laconi, A. Chieregato, J.L. Dubois, F. Cavani, Glycerol as feedstock in the synthesis of chemicals: a life cycle analysis for acrolein production, Green Chemistry, DOI: 10.1039/c4gc01497a.

- A. Chieregato, J. Velasquez Ochoa, C. Bandinelli, G. Fornasari, F. Cavani, M. Mella, On the Chemistry of Ethanol on Basic Oxides: Revising Mechanisms and Intermediates in the Lebedev and Guerbet reactions, ChemSusChem, DOI: 10.1002/cssc.201402632.

- A. Chieregato, José M. López Nieto, F. Cavani, Mixed-oxide catalysts with Vanadium as the key element for gas-phase reactions, Coordination Chemistry Reviews, DOI:10.1016/j.ccr.2014.12.003. 


\section{Bibliography}

1. Soriano, M.D., et al., Tungsten-Vanadium mixed oxides for the oxidehydration of glycerol into acrylic acid. Green Chemistry, 2011. 13(10): p. 2954-2962.

2. Schrödinger, E., What is Life? Cambridge University Press, 1992, 1944.

3. Mackenbach, J.P., Political conditions and life expectancy in Europe, 1900-2008. Social Science \& Medicine, 2013. 82(0): p. 134-146.

4. Taagepera, R., A world population growth model: Interaction with Earth's carrying capacity and technology in limited space. Technological Forecasting and Social Change, 2014. 82(0): p. 34-41.

5. Schneider, F., G. Kallis, and J. Martinez-Alier, Crisis or opportunity? Economic degrowth for social equity and ecological sustainability. Introduction to this special issue. Journal of Cleaner Production, 2010. 18(6): p. 511-518.

6. Kamm, B., P.R. Gruber, and M. Kamm, Biorefineries - Industrial Processes and Products. 2006, Wiley-VCH Verlag GmbH \& Co. KGaA.

7. Cavani, F., et al., Sustainable Industrial Chemistry. Sustainable Industrial Chemistry. 2009. 1-599.

8. Anastas, P. and N. Eghbali, Green Chemistry: Principles and Practice. Chemical Society Reviews, 2010. 39(1): p. 301-312.

9. Exxon Mobil, Energy Outlook to 2040. 2014.

10. BP, Energy Outlook to 2035. 2014.

11. Royal Dutch Shell, Energy Outlook to 2050. 2014.

12. Ragauskas, A.J., et al., The path forward for biofuels and biomaterials. Science, 2006. 311(5760): p. 484-489.

13. Wang, Q., et al., Natural gas from shale formation - The evolution, evidences and challenges of shale gas revolution in United States. Renewable and Sustainable Energy Reviews, 2014. 30(0): p. 1-28.

14. Bruijnincx, P.C.A. and B.M. Weckhuysen, Shale Gas Revolution: An Opportunity for the Production of Biobased Chemicals? Angewandte Chemie International Edition, 2013. 52(46): p. 11980-11987.

15. Sheldon, R.A., Green and sustainable manufacture of chemicals from biomass: state of the art. Green Chemistry, 2014. 16(3): p. 950-963.

16. www.IEA-Bioenergy.Task42-Biorefineries.com.

17. Moncada, J., J.A. Tamayo, and C.A. Cardona, Integrating first, second, and third generation biorefineries: Incorporating microalgae into the sugarcane biorefinery. Chemical Engineering Science, 2014. 118(0): p. 126-140.

18. Scharlemann, J.P.W. and W.F. Laurance, How Green Are Biofuels? Science, 2008. 319(5859): p. 43-44.

19. Brennan, L. and P. Owende, Biofuels from microalgae-A review of technologies for production, processing, and extractions of biofuels and co-products. Renewable and Sustainable Energy Reviews, 2010. 14(2): p. 557-577.

20. Scott, S.A., et al., Biodiesel from algae: challenges and prospects. Current Opinion in Biotechnology, 2010. 21(3): p. 277-286.

21. Wijffels, R.H., M.J. Barbosa, and M.H.M. Eppink, Microalgae for the production of bulk chemicals and biofuels. Biofuels, Bioproducts and Biorefining, 2010. 4(3): p. 287-295.

22. Ragauskas, A.J., et al., Lignin valorization: Improving lignin processing in the biorefinery. Science, 2014. 344(6185). 
23. Huber, G.W., S. Iborra, and A. Corma, Synthesis of Transportation Fuels from Biomass: Chemistry, Catalysts, and Engineering. Chemical Reviews, 2006. 106(9): p. 4044-4098.

24. Kumar, P., et al., Methods for pretreatment of lignocellulosic biomass for efficient hydrolysis and biofuel production. Industrial and Engineering Chemistry Research, 2009. 48(8): p. 3713-3729.

25. Teong, S.P., G. Yi, and Y. Zhang, Hydroxymethylfurfural production from bioresources: past, present and future. Green Chemistry, 2014. 16(4): p. 2015-2026.

26. Hu, L., et al., Catalytic conversion of biomass-derived carbohydrates into fuels and chemicals via furanic aldehydes. RSC Advances, 2012. 2(30): p. 11184-11206.

27. Bond, J.Q., et al., Integrated Catalytic Conversion of $\mathrm{y}$-Valerolactone to Liquid Alkenes for Transportation Fuels. Science, 2010. 327(5969): p. 1110-1114.

28. Ruddy, D.A., et al., Recent advances in heterogeneous catalysts for bio-oil upgrading via "ex situ catalytic fast pyrolysis": catalyst development through the study of model compounds. Green Chemistry, 2014. 16(2): p. 454-490.

29. Digman, B., H.S. Joo, and D.-S. Kim, Recent progress in gasification/pyrolysis technologies for biomass conversion to energy. Environmental Progress \& Sustainable Energy, 2009. 28(1): p. 47-51.

30. Behrendt, F., et al., Direct liquefaction of biomass. Chemical Engineering and Technology, 2008. 31(5): p. 667-677.

31. Van Rossum, G., et al., Liquefaction of lignocellulosic biomass: Solvent, process parameter, and recycle oil screening. ChemSusChem, 2014. 7(1): p. 253-259.

32. Lange, J.-P., Patent WO2014056784A1, assigned to Shell International Research. 2014.

33. Czernik, S. and A.V. Bridgwater, Overview of Applications of Biomass Fast Pyrolysis Oil. Energy \& Fuels, 2004. 18(2): p. 590-598.

34. Vonortas, A. and N. Papayannakos, Comparative analysis of biodiesel versus green diesel. Wiley Interdisciplinary Reviews: Energy and Environment, 2014. 3(1): p. 3-23.

35. Issariyakul, T. and A.K. Dalai, Biodiesel from vegetable oils. Renewable and Sustainable Energy Reviews, 2014. 31(0): p. 446-471.

36. Talebian-Kiakalaieh, A., N.A.S. Amin, and H. Hezaveh, Glycerol for renewable acrolein production by catalytic dehydration. Renewable and Sustainable Energy Reviews, 2014. 40(0): p. 28-59.

37. Creasey, J.J., et al., Alkali- and nitrate-free synthesis of highly active Mg-Al hydrotalcitecoated alumina for FAME production. Catalysis Science \& Technology, 2014. 4(3): p. 861870.

38. Corma, A., S. Iborra, and A. Velty, Chemical Routes for the Transformation of Biomass into Chemicals. Chemical Reviews, 2007. 107(6): p. 2411-2502.

39. Jacobson, K., K.C. Maheria, and A. Kumar Dalai, Bio-oil valorization: A review. Renewable and Sustainable Energy Reviews, 2013. 23(0): p. 91-106.

40. Gielen, F., Solvay will make epichlorohydrin from glycerol. Industrial Bioprocessing, 2006. 28(3): p. 8-9.

41. Martin, A., et al., Glycerol hydrogenolysis into propanediols using in situ generated hydrogen - A critical review. European Journal of Lipid Science and Technology, 2013. 115(1): p. 9-27.

42. Katryniok, B., S. Paul, and F. Dumeignil, Recent Developments in the Field of Catalytic Dehydration of Glycerol to Acrolein. ACS Catalysis, 2013. 3(8): p. 1819-1834.

43. Katryniok, B., et al., Glycerol dehydration to acrolein in the context of new uses of glycerol. Green Chemistry, 2010. 12(12): p. 2079-2098. 
44. Katryniok, B., et al., Towards the Sustainable Production of Acrolein by Glycerol Dehydration. ChemSusChem, 2009. 2(8): p. 719-730.

45. Chementator: High-throughput screening accelerates glycerol-to-chemicals research. Chemical Engineering, 2009. 116(4).

46. Reisch, M.S., Arkema pushes into biobased acrylics: French chemical firm ramps up effort to commercialize acrylic acid based on glycerin. Chemical and Engineering News, 2010. 88(21): p. 20-21.

47. Alperowicz, N., Arkema outlines Indian, Chinese investments. Chemical Week, 2008. 170(9).

48. Zhou, C.-H., et al., Chemoselective catalytic conversion of glycerol as a biorenewable source to valuable commodity chemicals. Chemical Society Reviews, 2008. 37(3): p. 527549.

49. Liu, L., X.P. Ye, and J.J. Bozell, A Comparative Review of Petroleum-Based and Bio-Based Acrolein Production. ChemSusChem, 2012. 5(7): p. 1162-1180.

50. Wang, F., et al., Catalytic oxidative dehydration of glycerol over a catalyst with iron oxide domains embedded in an iron orthovanadate phase. ChemSusChem, 2010. 3(12): p. 13831389.

51. Corma, A., et al., Biomass to chemicals: Catalytic conversion of glycerol/water mixtures into acrolein, reaction network. Journal of Catalysis, 2008. 257(1): p. 163-171.

52. Haider, M.H., et al., Rubidium- and caesium-doped silicotungstic acid catalysts supported on alumina for the catalytic dehydration of glycerol to acrolein. Journal of Catalysis, 2012. 286(0): p. 206-213.

53. ICIS, www.icispricing.com.

54. IHS, www.ihs.com.

55. D. Cespi, F.P., G. Mastragostino, I. Vassura, S. Larocca, A. Iaconi, A. Chieregato, J.-L. Dubois, F. Cavani Glycerol as feedstock in the synthesis of chemicals: a life cycle analysis for acrolein production. Green Chemistry, 2014. Accepted Manuscript, DOI: 10.1039/C4GC01497A.

56. Shen, L., et al., Gas phase oxidehydration of glycerol to acrylic acid over Mo/V and W/V oxide catalysts. Chemical Engineering Journal, 2014. 244: p. 168-177.

57. Chieregato, A., et al., One-pot glycerol oxidehydration to acrylic acid on multifunctional catalysts: Focus on the influence of the reaction parameters in respect to the catalytic performance. Applied Catalysis B: Environmental, 2014. 150-151: p. 37-46.

58. Omata, K., et al., Direct oxidative transformation of glycerol into acrylic acid over phosphoric acid-added WVNb complex metal oxide catalysts. Chemistry Letters, 2014. 43(4): p. 435-437.

59. Chieregato, A., et al., Glycerol oxidehydration into acrolein and acrylic acid over $\mathrm{W}-\mathrm{V}-\mathrm{Nb}-\mathrm{O}$ bronzes with hexagonal structure. Catalysis Today, 2012. 197(1): p. 58-65.

60. Deleplanque, J., et al., Production of acrolein and acrylic acid through dehydration and oxydehydration of glycerol with mixed oxide catalysts. Catalysis Today, 2010. 157(1-4): p. 351-358.

61. Pestana, C.F.M., et al., Oxidative dehydration of glycerol to acrylic acid over vanadiumimpregnated zeolite beta. Journal of the Brazilian Chemical Society, 2013. 24: p. 100-105.

62. C. N. R. Rao, B.R., "Transition Metal Oxides", Second Edition. Wiley-VCH, New York, 1998.

63. Labbe, P., Key Engineering Matererials, 1992. 68: p. 293.

64. Hjelm, A., C.G. Granqvist, and J.M. Wills, Electronic structure and optical properties of $\mathrm{WO}_{3}, \mathrm{LiWO}_{3}, \mathrm{NaWO}_{3}$, and $\mathrm{HWO}_{3}$. Physical Review B, 1996. 54(4): p. 2436-2445. 
65. Tsuyumoto, I. and T. Kudo, Humidity sensor using potassium hexagonal tungsten bronze synthesized from peroxo-pokytungstic acid. Sensors and Actuators B: Chemical, 1996. 30(2): p. 95-99.

66. Dupont, L., et al., Synthesis and characterization of new oxide hydrates $\mathrm{Hx}(\mathrm{VxMo1}-\mathrm{x}) \mathrm{O}$ $0.3 \mathrm{H} 2 \mathrm{O}$ and HO.27(VO.27WO.73)O3 • 1/3H2O. Journal of Solid State Chemistry, 1996. 121(2): p. 339-349.

67. Gopalakrishnan, J., N.S.P. Bhuvanesh, and A.R. Raju, Soft chemical synthesis of new

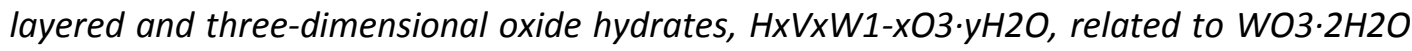
and WO3.1/3H2O. Chemistry of Materials, 1994. 6(4): p. 373-379.

68. Sharma, R., Bronzoid phases in the pseudo-binary system $A x N b x W 1-x O 3$ with $A=K$ and Cs. Materials Research Bulletin, 1985. 20(11): p. 1373-1381.

69. A. Deschanvres, C.M., B. Raveau, Bulletin de la Société Chimique de France, 1968. 12: p. 4805.

70. Gopalakrishnan, J., Chimie douce approaches to the synthesis of metastable oxide materials. Chemistry of Materials, 1995. 7(7): p. 1265-1275.

71. Michailovski, A. and G.R. Patzke, Hydrothermal synthesis of molybdenum oxide based materials: Strategy and structural chemistry. Chemistry - A European Journal, 2006. 12(36): p. 9122-9134.

72. Chemseddine, A. and U. Bloeck, How isopolyanions self-assemble and condense into a $2 D$ tungsten oxide crystal: HRTEM imaging of atomic arrangement in an intermediate new hexagonal phase. Journal of Solid State Chemistry, 2008. 181(10): p. 2731-2736.

73. Tao, Y., M.-S. Hu, and D. Feng, Direct observation of $\alpha-6$ phase transition in KNbW2O9 by transmission electron microscopy. physica status solidi (a), 1988. 109(2): p. 435-444.

74. Dupont, L. and M. Sundberg, The Phase Transitions between H0.27VO.27WO.73O3.13 H2O and V0.27W0.7302.865: An X-Ray, Thermal Analysis, and HREM Study. Journal of Solid State Chemistry, 1998. 136(2): p. 284-292.

75. Mestl, G., et al., Thermally and chemically induced structural transformations of Keggintype heteropoly acid catalysts. Applied Catalysis A: General, 2001. 210(1-2): p. 13-34.

76. Massa, M., et al., Gas-phase dehydration of glycerol to acrolein over Al2O3-, SiO2-, and TiO2-supported Nb-and W-oxide catalysts. Journal of Catalysis, 2013. 307(0): p. 170-184.

77. Liu, R., et al., Highly selective and stable CsPW/Nb2O5 catalysts for dehydration of glycerol to acrolein. Chinese Journal of Catalysis, 2013. 34(12): p. 2174-2182.

78. Wang, F., J.-L. Dubois, and W. Ueda, Catalytic dehydration of glycerol over vanadium phosphate oxides in the presence of molecular oxygen. Journal of Catalysis, 2009. 268(2): p. 260-267.

79. Byrappa, K. and M. Yoshimura, 1 - Hydrothermal Technology-Principles and Applications, in Handbook of Hydrothermal Technology, K.B. Yoshimura, Editor. 2001, William Andrew Publishing: Norwich, NY. p. 1-52.

80. Griffith, C.S. and V. Luca, Ion-Exchange Properties of Microporous Tungstates. Chemistry of Materials, 2004. 16(24): p. 4992-4999.

81. Concepción, P., et al., Preparation, characterization and reactivity of $V$ - and/or Cocontaining AIPO-18 materials (VCOAPO-18) in the oxidative dehydrogenation of ethane. Microporous and Mesoporous Materials, 2004. 67(2-3): p. 215-227.

82. Tichý, J., Oxidation of acrolein to acrylic acid over vanadium-molybdenum oxide catalysts. Applied Catalysis A: General, 1997. 157(1-2): p. 363-385.

83. Niemantsverdriet, J.W., Spectroscopy in Catalysis, 3rd, Completely Revised and Enlarged Edition. Wiley-WCH, 2007. 
84. Brunauer, S., P.H. Emmett, and E. Teller, Adsorption of Gases in Multimolecular Layers. Journal of the American Chemical Society, 1938. 60(2): p. 309-319.

85. Lippens, B.C., B.G. Linsen, and J.H.d. Boer, Studies on pore systems in catalysts I. The adsorption of nitrogen; apparatus and calculation. Journal of Catalysis, 1964. 3(1): p. 3237.

86. Lippens, B.C. and J.H. de Boer, Studies on pore systems in catalysts: V. The $t$ method. Journal of Catalysis, 1965. 4(3): p. 319-323.

87. Harkins, W.D. and G. Jura, Surfaces of Solids. XIII. A Vapor Adsorption Method for the Determination of the Area of a Solid without the Assumption of a Molecular Area, and the Areas Occupied by Nitrogen and Other Molecules on the Surface of a Solid. Journal of the American Chemical Society, 1944. 66(8): p. 1366-1373.

88. Zhu, H.Y., et al., Quantitative Information on Pore Size Distribution from the Tangents of Comparison Plots. Langmuir, 2004. 20(23): p. 10115-10122.

89. Ryczkowski, J., IR spectroscopy in catalysis. Catalysis Today, 2001. 68(4): p. 263-381.

90. Concepción, P., et al., Characterization of Supported Vanadium Oxide Catalysts. Nature of the Vanadium Species in Reduced Catalysts. The Journal of Physical Chemistry B, 2002. 106(10): p. 2574-2582.

91. Sobalik, Z., R. Kozłowski, and J. Haber, Structure of monolayer vanadia $y$-alumina catalysts as revealed by IR spectra of probe molecules. Journal of Catalysis, 1991. 127(2): p. 665674.

92. Jonson, B., et al., Activity measurements and spectroscopic studies of the catalytic oxidation of toluene over silica-supported vanadium oxides. Journal of the Chemical Society, Faraday Transactions 1: Physical Chemistry in Condensed Phases, 1988. 84(6): p. 1897-1910.

93. Hadjiivanov, K.I. and G.N. Vayssilov, Characterization of oxide surfaces and zeolites by carbon monoxide as an IR probe molecule, in Advances in Catalysis. 2002, Academic Press. p. 307-511.

94. National Institute of Standards and Technology XPS Database.

95. Sharma, R. and L. Kihlborg, Structures and defects of new intergrowth tungsten bronze analogues revealed by high resolution electron microscopy. Materials Research Bulletin, 1981. 16(4): p. 377-380.

96. S Rajagopal, D.N., D Mangalaraj, Yahia Djaoued, Jacques Robichaud, O Khyzhun, Controlled Growth of WO3Nanostructures with Three Different Morphologies and Their Structural, Optical, and Photodecomposition Studies. Nanoscale Research Letters, 2009. 4: p. $1335-1342$.

97. Kalpana R. Dey, T.D., Claus H. Rüscher, Margareta Sundberg, Altaf Hussain, Synthesis and characterization of niobium doped hexagonal tungsten bronze in the systems, CsxNbyW1-yO3. Journal of Materials Science, 2011. 46(5): p. 1388-1395.

98. Nishide, T. and F. Mizukami, Crystal structures and optical properties of tungsten oxide films prepared by a complexing-agent-assisted sol-gel process. Thin Solid Films, 1995. 259(2): p. 212-217.

99. M.F. Daniel, B.D., J.C. Lassegues, B. Gerand, M. Figlarz, Infrared and Raman study of WO3 tungsten trioxides and WO3, xH2O tungsten trioxide tydrates. Journal of Solid State Chemistry - A European Journal, 1987. 67(2): p. 235-247.

100. Griffith, C.S., et al., Microcrystalline Hexagonal Tungsten Bronze. 1. Basis of Ion Exchange Selectivity for Cesium and Strontium. Inorganic Chemistry, 2009. 48(13): p. 5648-5662. 
101. Schneider, H., et al., In Situ Diffuse Reflectance FTIR Study of the Selective Catalytic Reduction of NO by NH3 over Vanadia-Titania Aerogels. Journal of Catalysis, 1994. 147(1): p. 5-14.

102. Ivanova, E., et al., FT-IR study of CO and NO adsorption on a VSiBEA zeolite. Microporous and Mesoporous Materials, 2006. 89(1-3): p. 69-77.

103. Okumura, K., et al., Hydrothermal synthesis and catalysis of Nb2O5-WOx nanofiber crystal. Journal of Materials Chemistry, 2011. 21(1): p. 229-235.

104. Badlani, M. and I. Wachs, Methanol: A "Smart" Chemical Probe Molecule. Catalysis Letters, 2001. 75(3-4): p. 137-149.

105. Tatibouët, J.M., Methanol oxidation as a catalytic surface probe. Applied Catalysis A: General, 1997. 148(2): p. 213-252.

106. Blanch-Raga, N., et al., Catalytic abatement of trichloroethylene over Mo and/or W-based bronzes. Applied Catalysis B: Environmental, 2013. 130-131(0): p. 36-43.

107. Botella, P., et al., Mo-W-containing tetragonal tungsten bronzes through isomorphic substitution of molybdenum by tungsten. Catalysis Today, 2010. 158(1-2): p. 162-169.

108. Rodella, C.B., et al., Chemical and structural characterization of V205/TiO2 catalysts. Journal of Vacuum Science \&amp; Technology A, 2001. 19(4): p. 1158-1163.

109. Bhat, B.R., J.S. Choi, and T.H. Kim, Synthesis and characterization of nanocrystalline Mo-V$W$-Fe-O mixed oxide catalyst and its performance in selective methanol oxidation. Catalysis Letters, 2007. 117(3-4): p. 136-139.

110. Cariati, F., J.C.J. Bart, and A. Sgamellotti, Spectroscopic analysis of mixed valence molybdenum oxides. Inorganica Chimica Acta, 1981. 48(0): p. 97-103.

111. Petrini, G. and J.C.J. Bart, Das Phasendiagramm des Systems TeO2-MoO3. Zeitschrift für anorganische und allgemeine Chemie, 1981. 474(3): p. 229-232.

112. Knobl, S., et al., The synthesis and structure of a single-phase, nanocrystalline MoVW mixed-oxide catalyst of the Mo5014 type. Journal of Catalysis, 2003. 215(2): p. 177-187.

113. Mestl, G. and T.K.K. Srinivasan, Raman Spectroscopy of Monolayer-Type Catalysts: Supported Molybdenum Oxides. Catalysis Reviews, 1998. 40(4): p. 451-570.

114. Giebeler, L., et al., Structural changes of vanadium-molybdenum-tungsten mixed oxide catalysts during the selective oxidation of acrolein to acrylic acid. Journal of Molecular Catalysis A: Chemical, 2006. 259(1-2): p. 309-318.

115. Endres, S., et al., The influence of tungsten on structure and activity of Mo-V-W-mixed oxide catalysts for acrolein oxidation. Applied Catalysis A: General, 2007. 325(2): p. 237243.

116. Kampe, P., et al., Heterogeneously catalysed partial oxidation of acrolein to acrylic acidstructure, function and dynamics of the V-Mo-W mixed oxides. Physical Chemistry Chemical Physics, 2007. 9(27): p. 3577-3589.

117. P. Arpentinier, F.C., F. Trifirò, The Technology of Catalytic Oxidations. Editions Technip, Paris, 2001.

118. Mashuga, C.V. and D.A. Crowl, Application of the flammability diagram for evaluation of fire and explosion hazards of flammable vapors. Process Safety Progress, 1998. 17(3): p. 176-183.

119. Dummer, N.F., et al., Structural evolution and catalytic performance of DuPont V-P-O/SiO2 materials designed for fluidized bed applications. Applied Catalysis A: General, 2010. 376(1-2): p. 47-55.

120. Pérez-Moreno, L., et al., Effect of the use in circulating fluidized bed on the performance of a VPO catalyst: Characterization and transient studies. Chemical Engineering Journal, 2009. 147(2-3): p. 330-335. 
121. Pastore, H.O., S. Coluccia, and L. Marchese, POROUS ALUMINOPHOSPHATES :From Molecular Sieves to Designed Acid Catalysts. Annual Review of Materials Research, 2005. 35(1): p. 351-395.

122. Garcia-Gonzalez, E., et al., On the origin of the spontaneous formation of nanocavities in hexagonal bronzes (W, V)O3. Dalton Transactions, 2014. 43(39): p. 14644-14652.

123. Concepción, P. and J.M. López Nieto, Novel synthesis of a vanadium-cobalt aluminophosphate molecular sieve of AEI structure (VCOAPO-18) and its catalytic behaviour for the ethane oxidation. Catalysis Communications, 2001. 2(11-12): p. 363367.

124. Hutchings, G.J., Vanadium phosphate: $A$ new look at the active components of catalysts for the oxidation of butane to maleic anhydride. Journal of Materials Chemistry, 2004. 14(23): p. 3385-3395.

125. López Nieto, J.M., Microporous and mesoporous materials with isolated vanadium species as selective catalysts in the gas phase oxidation reactions. Topics in Catalysis, 2001. 15(24): p. 189-194.

126. Possato, L.G., et al., A comparative study of glycerol dehydration catalyzed by micro/mesoporous MFI zeolites. Journal of Catalysis, 2013. 300(0): p. 102-112.

127. Haa, et al., X-Ray absorption and X-ray diffraction studies on molybdenum doped vanadium pentoxide. Physical Chemistry Chemical Physics, 2003. 5(19): p. 4317-4324.

128. P. Kierkegaard, J.M.L., The crystal structure of vanadium (IV) oxide sulphate, VOSO4. Acta Chemica Scandinavica, 1965. 19: p. 1906-1914. 


\section{Appendix}

\section{(i) Summary in English}

The project of this Ph.D. thesis is based on a co-supervised collaboration between Università di Bologna, ALMA MATER STUDIORUM (Italy) and Instituto de Tecnología Química, Universitat Politècnica de València ITQ-UPV (Spain).

This Ph.D. thesis is about the synthesis, characterization and catalytic testing of complex mixedoxide catalysts mainly related to the family of Hexagonal Tungsten Bronzes (HTBs). The latter have been little explored as catalysts, although they have a great potential as multifunctional materials. Their peculiar acid properties can be coupled to other functionalities (e.g. redox sites) by isomorphous substitution of tungsten atoms with other transition metals such as vanadium, niobium and molybdenum.

In this PhD thesis, it was demonstrated how it is possible to prepare substituted-HTBs by hydrothermal synthesis; these mixed-oxide were fully characterize by a number of physicochemical techniques such as XPS, HR-TEM, XAS etc. They were also used as catalysts for the one-pot glycerol oxidehydration to acrylic acid; this reaction might represent a viable chemical route to solve the important issue related to the co-production of glycerin along the biodiesel production chain. Acrylic acid yields as high as $51 \%$ were obtained and important structurereactivity correlations were proved to govern the catalytic performance; only fine tuning of acid and redox properties as well as the in-framework presence of vanadium are fundamental to achieve noteworthy yields into the acid monomer.

The overall results reported herein might represent an important contribution for future applications of HTBs in catalysis as well as a general guideline for a multifaceted approach for their physicochemical characterization. 


\section{(ii) Summary in Spanish}

Esta tesis doctoral está realizada bajo un convenio de cotutela firmado por la Università di Bologna, ALMA MATER STUDIORUM (Italia) y el Instituto de Tecnología Química, Universitat Politècnica de València ITQ-UPV (España).

La presente tesis doctoral estudia la síntesis, caracterización y ensayos catalíticos de óxidos mixtos relacionados con la familia de los bronces de tungsteno hexagonales. Estos materiales presentan un importante potencial como materiales multifuncionales, aunque han sido utilizados minoritariamente como catalizadores. . Sus peculiares propiedades ácidas pueden ser acopladas con otras características (por ejemplo, sitios redox) a través de la substitución isomórfica de átomos de tungsteno con otros metales de transición como vanadio, niobio y molibdeno.

En esta tesis doctoral se ha demostrado cómo es posible preparar bronces de tungsteno hexagonales substituidos a través de síntesis hidrotermal; estos óxidos mixtos han sido caracterizados empleando numerosas técnicas de caracterización físico-químicas - como XPS, HRTEM, XAS etc. Por otro lado se han utilizado como catalizadores para la síntesis directa de acido acrílico a partir de glicerol.Esta reacción puede representar una solución viable para el problema relacionado con la co-producción de glicerina a lo largo de la cadena productiva del biodiesel. Se han obtenido rendimientos a acido acrílico del $51 \%$. Además, se han observado importantes relaciones entre las estructuras y la actividad catalítica, las cuales han sido determinantes para el proceso catalítico. El ajuste de las propiedades acidas y redox y la presencia en-red de vanadio son esenciales para conseguir rendimientos relevantes en el monómero acido.

En general, los resultados presentados en esta tesis doctoral pueden ser una contribución relevante para futuras aplicaciones de los bronces de tungsteno hexagonales en catálisis y también como una guía general para una completa caracterización físico-química de estos óxidos. 


\section{(iii) Summary in Valencian}

Esta tesi doctoral està basada en un conveni de cotutela signat per la Università di Bologna, ALMA MATER STUDIORUM (Italia) i el Institut de Tecnologia Química , Universitat Politècnica de València ITQ-UPV(Espanya).

La present tesi doctoral estudia la síntesis, caracterització i assajos catalítics de òxids mixtes relacionats amb la família dels bronzes de tungstèn hexagonals. Aquestos materials presenten un gran potencial com materials multi funcionals, encara que no han sigut molt emprats com catalitzadors. Les propietats àcides particulars de aquestos materials poden ser potenciades amb altres característiques (per exemple, llocs redox) mitjançant la substitució isomòrfica d’àtoms de tungstèn amb altres metalls de transició com vanadi, niobi i molibdè.

En aquesta tesi doctoral es demostra com es possible sintetitzar bronzes de tungstèn hexagonals substituïts a partir de síntesis hidrotermal. Aquestos òxids mixtes han segut caracteritzats emprant diverses tècniques de caracterització físico-químiques com XPS, HR-TEM, XAS, etc...Per altra part, s'han utilitzat com catalitzadors per a la síntesis directa de àcid acrílic a partir de glicerol, aquesta reacció pot representar una solució viable per al problema relacionat amb la coproducció de glicerina al llarg de la cadena productiva de biodiesel. S'han obtingut rendiments a àcid acrílic del 51\%. A més, s'han observat importants relacions entre les estructures i la activitat catalítica, les quals han sigut determinants per al procés catalític. El ajust de les propietats àcides i redox i la presència en red de vanadi són essencials per a obtindre rendiments rellevants en el monòmer àcid.

En general, el resultats presentats en aquesta tesi doctoral poden ser una contribució rellevant per a futures aplicacions del bronzes de tungstèn hexagonal en catàlisis i també com una guia general per a una completa caracterització físico-química d'aquestos òxids. 


\section{Acknowledgements}

The work presented in this Ph.D. thesis is not just my work, but also the work of other people that have given a lot of their time and passion to develop this project. First of all, and with great pleasure, I want to thank my supervisors Prof. Fabrizio Cavani and José Manuel López Nieto, not only for passing me some of their invaluable scientific knowledge and enthusiasm for science but also for their kindness and help all along these years. No further words can express the gratitude I have towards them.

I also want to thank Dr. Ma Dolores Soriano Rodriguez (Dolo) for teaching me so much about the synthesis and characterization of HTBs as well as her patience and kindness; and, very important, for teaching me how to cook paella! I would also like to thank Claudia Bandinelli for sharing with me all the lab work in Bologna and carry on with the reaction tests... and, also, for her patience!

Both in Italy and in Spain many people gave me advice and help or shared with me beautiful moments. Amada, Daniel, Lidia, Federico, Davide, Thomas... and all the people from the labs at ITQ and $\mathrm{DCl}$. All of you gave me something invaluable for my professional and personal development.

Thank you very much!!! 